\title{
Personalización de Aplicaciones Web
}

\section{UN ENFOQUE DE REINGENIERÍA}

\author{
Analista U. de Sistemas Adriana Elba MARTín
}

\section{DIRECTOR: DOCTOR GUSTAVO ROSSI}

TeSis PRESENTADA A LA FACUlTAD DE INFORMÁticA DE LA UNIVERSIDAD de LA Plata COMO PARTE DE LOS REQUISITOS PARA LA OBTENCIÓN DEL TÍTULO

MAGÍSTER EN INGENIERÍA DE SOFTWARE.

La Plata, Febrero de 2003

FACULTAD DE INFORMÁTICA

UNIVERSIDAD NACIONAL DE LA PLATA

REPÚBLICA ARGENTINA 
A Erika y Reinaldo, que con muchísima paciencia y amor acompañaron incondicionalmente el progreso de esta tesis.

A Mamá y Papá, que con todo el cariño alientan permanentemente mi marcha. 


\section{AgRADECIMIENTOS}

Un agradecimiento especial al Dr. Gustavo Rossi, por haber aceptado ser mi director de tesis y por haber brindado su ayuda y ánimo durante todo el desarrollo de este trabajo.

Un cariñoso agradecimiento a Luz Sede, por haber contribuido con sus eximios conocimientos de Inglés.

Un enorme gracias y mi amor incondicional a Mi Hermosa Familia, ya que ha estado siempre a mi lado acompañando con fuerza y cariño mis estudios; sin su apoyo la concreción de esta tesis no hubiera sido posible. 


\section{RESUMEN}

Trabajar en el campo de las aplicaciones Web no es una tarea sencilla, sino de hecho, todo un arte. La inherente complejidad de estas aplicaciones, enfrenta a las más diversas problemáticas, sobre todo a la hora de realizar proyectos serios de diseño.

En tal sentido, los esfuerzos permanentemente invertidos por las comunidades de investigación han dado y siguen dando sus frutos. La aparición de valiosos enfoques y métodos auxilian al manejo del intrincado mundo de la aplicaciones Web. Sin embargo, la fuente de desafíos está lejos de agotarse. El desarrollo de nuevas aplicaciones, utilizando buenas prácticas de ingeniería de software (y de Web), es solo "la punta del iceberg".

Para respaldar esta afirmación basta con remitirse a la Internet (y la WWW) donde miles de aplicaciones, desarrolladas con prácticas 'ad hoc', requieren evolución substancial. Esta demanda se intensifica, cuando se trata de aplicaciones para las cuales la personalización se ha convertido en una cuestión clave. Áreas tales como el comercio electrónico, están implícitamente ligadas a aplicaciones Web completamente personalizadas que responden acabadamente a las necesidades individuales de cada usuario o grupo de usuarios - roles o perfiles -.

La situación retratada, vuelve inútil la búsqueda de motivos sustentables que permitan negar la necesidad creciente, de una reingeniería de software (y de Web) que aporte soluciones a la problemática del rediseño.

Con la elocuencia que brinda una argumentación tan fuerte, en esta tesis se presenta un enfoque para llevar a cabo un proyecto de reingeniería para personalizar aplicaciones Web existentes. A tal fin, se describe paso a paso un proceso de reingeniería compuesto por dos actividades principales: Ingeniería en Reversa e Ingeniería 'Forward' de Personalización. La propuesta resultante, se basa sobre conceptos, métodos y herramientas con una robustez totalmente probada por la (re)ingeniería de software y de aplicaciones Web. Es importante aclarar, que para lograr una redacción más concisa, en esta tesis se utiliza la expresión "Reingeniería de Personalización de Aplicaciones Web" o directamente "Reingeniería de Personalización" en vez de la forma correcta de la expresión "Enfoque de Reingeniería para la Personalización de Aplicaciones Web".

Finalmente, se aplica el enfoque a un caso real, una aplicación Web no personalizada correspondiente a una corporación petrolera internacional, para mostrar sobre el terreno los resultados de nuestra propuesta. 


\begin{abstract}
Working on Web applications arena isn't a simple task, in fact, it's an art. The inherent complexity of these applications, deals with the most several problems, specially when well done design's projects, are realized.

That's why, the continuous efforts made by the research groups have been, and still are, successful. New methods and tendencies help to handle the intricate world of web applications. However, the source of challenges won't run out for a long time. The development of new applications, using good software (and web) engineering's practices, is only "the tip of the iceberg".

To support this statement, it's enough to refer to Internet (and WWW) where thousand of applications, developed with "ad hoc" practices, require substantial evolution. This demand becomes more important, in those applications in which the personalization is a key concern. Areas like ecommerce, are implicitly bound to web applications fully customizable that completely answer to individual needs of each user or group of users - roles or profiles -.

The described situation, turns useless the search of sustained reasons that allow to deny the growing need of software (and web) engineer that provide solutions to the redesign problematic.

With the eloquence that brings such a strong argument, an approach is presented to carry out with a reengineering project for existing web applications. For such purpose, a process of reengineering is described step by step made up of two main activities: Reverse Engineering and Personalization Forward Engineering. The resultant propose, is based on concepts, methods and tools with a forcefullness totally proved by software and web applications (re)engineering. It's important to make clearer, that to achieve a more concise essay, it is used in this thesis, the expression: "Personalization Reengineering of web applications" o directly "Personalization Reengineering" instead of the correct expression "Reengineering approach for web applications Personalization".
\end{abstract}

Finally, the approach is applied to a real case, to a non personalize web application corresponding to an international oil corporation, to show on the field the results of our proposal. 


\section{INDICE}

Capitulo 1: Introducción ...................................................................... 1

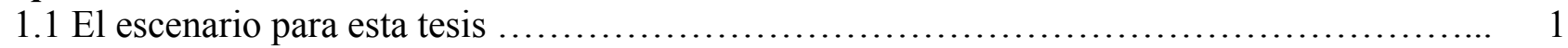

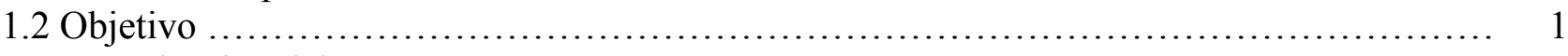

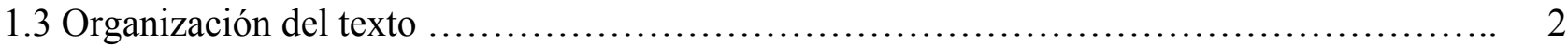

Capítulo 2: Aplicaciones Web .............................................................. 3

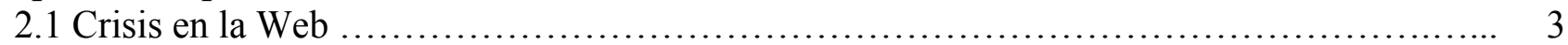

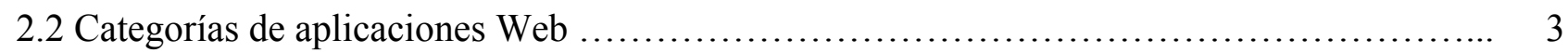

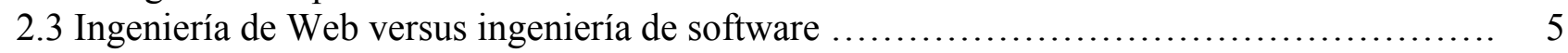

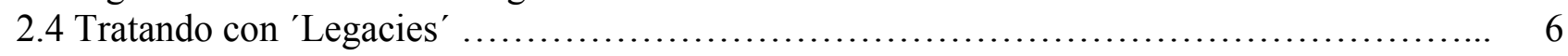

2.5 ¿Por qué reingeniería de personalización? ....................................... 7

Capítulo 3: Herramientas de diseño ...................................................... 8

$3.1 \mathrm{Un}$ vistazo al OOHDM ........................................................... 8

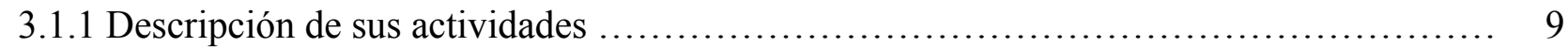

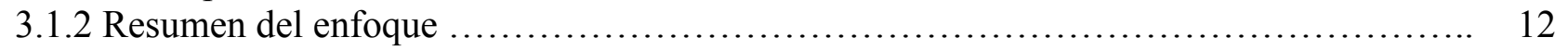

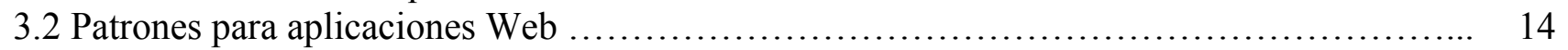

3.2.1 Patrones de navegación ......................................................... 15

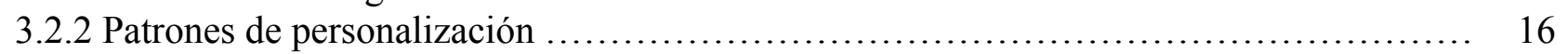

3.3 ¿Qué es un UID? ............................................................ 19

3.3.1 Aportes al modelado de aplicaciones Web ..................................... 19

3.3.2 Notación ..................................................................... 19

3.4 Herramientas de diseño y reingeniería ......................................... 22

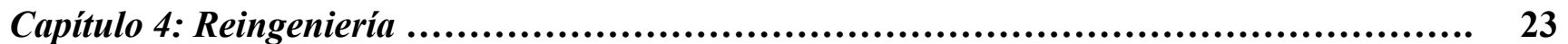

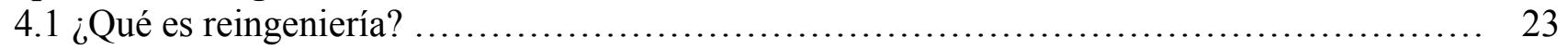

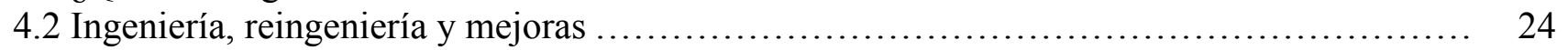

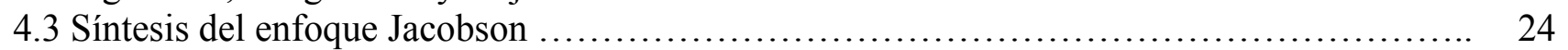

4.3.1 Búsqueda del modelo actual: Ingeniería en reversa ............................. 26

4.3.2 Diseño del nuevo modelo: Ingeniería 'forward' ................................ 27

4.4 ¿Por qué reingeniería de Jacobson? .......................................... 28

Capítulo 5: Nuestro enfoque ............................................................ 29

5.1 Un proyecto de reingeniería para la personalización de una aplicación Web ................ 29

5.2 Características deseadas en la nueva aplicación: Directiva de reingeniería ................. 30

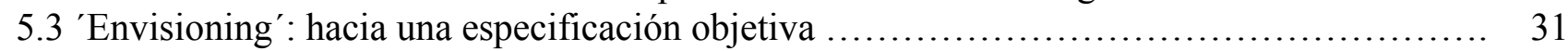

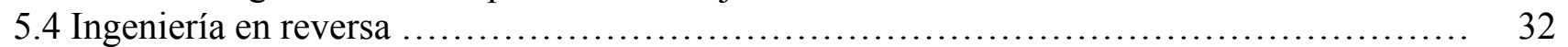

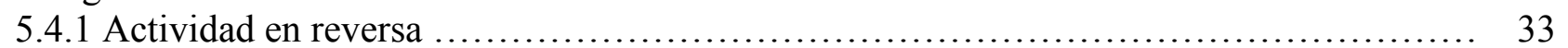

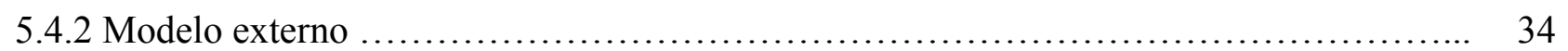

5.4.2.1 Modelo caso de uso general .................................................. 34

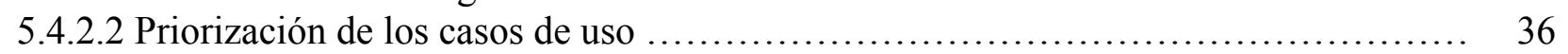

5.4.2.3 Descripción de los casos de uso ........................................... 36

5.4.3 Especificación objetiva incorporando patrones de personalización .................... 37

5.4.4 UIDs: un puente entre los modelos externo e interno personalizados .................. 38

5.4.5 Modelo interno .............................................................. 40

5.4.5.1 Obtención del modelo conceptual .......................................... 40

5.4.5.2 Obtención del modelo de navegación incorporando patrones de hipermedia:

Diagrama de clases de navegación y Diagrama de contextos de navegación .......... 42 


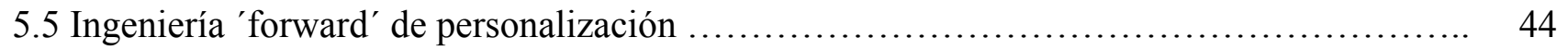

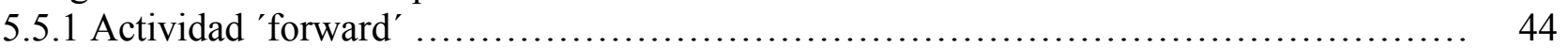

5.5.2 Nuevo modelo externo ..................................................... 47

5.5.2.1 Desde la especificación objetiva al modelo caso de uso personalizado .............. 47

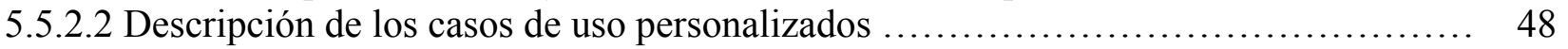

5.5.3 UIDs para aplicaciones Web personalizadas ................................. 49

5.5.4 Nuevo modelo interno ...................................................... 51

5.5.4.1 Obtención de un modelo conceptual que responde a los requerimientos de personalización

5.5.4.2 Obtención del modelo de navegación incorporando patrones de personalización: Diagrama de clases de navegación y Diagrama de contextos de navegación

Capítulo 6: Aplicando el enfoque

6.1 Acerca de la Corporación Weatherford ........................................... 58

6.2 Un sitio en la Web: http://www.weatherford.com .................................. 58

6.3 ¿Cuál es nuestra directiva de reingeniería? ....................................... 58

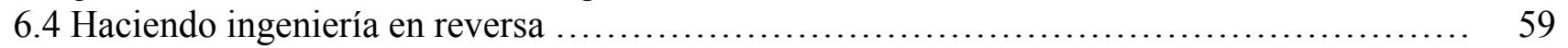

6.4.1 Comprendiendo el sitio actual: modelo caso de uso general ........................ 59

6.4.2 Delineando la especificación objetiva del nuevo sitio con patrones de personalización ... 78

6.4.3 Construyendo el puente UID entre modelos ..................................... 85

6.4.4 Obteniendo el modelo interno: modelos conceptual y modelo de navegación con

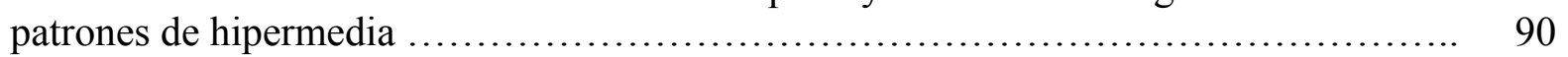

6.5 Haciendo ingeniería 'forward' de personalización .................................. 105

6.5.1 Bosquejando Portales para los perfiles de usuario .............................. 105

6.5.2 Reflejando la especificación objetiva en un nuevo modelo caso de uso ................ 110

6.5.3 Describiendo los casos de uso personalizados ................................... 111

6.5.4 Construyendo el puente UID entre modelos personalizados ....................... 116

6.5.5 Obteniendo el modelo interno personalizado: modelo conceptual y modelo de navegación incorporando patrones de hipermedia y de personalización ................ 121

Capítulo 7: Trabajos Relacionados ....................................................... 139

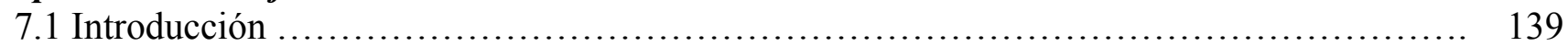

7.2 Sobre reingeniería de aplicaciones Web ......................................... 139

7.2.1 'WARE: a Tool for Reverse Engineering of Web Applications' ....................... . 140

7.2.2 'Reverse Engineering to Achieve Maintainable WWW Sites' ......................... 141

7.2.3 Nuestro enfoque versus WARE y RI System ................................... 142

7.3 Sobre personalización de aplicaciones Web ....................................... 143

7.3.1 'Modelling Customizable Web Applications - A Requirement's Perspective' ............ 144

7.3.2 'Improving the Usability of an E-commerce Web Site through Personalization' .......... 146

7.3.3 Aportes de Nuestro enfoque, 'Framework' de Requerimientos y 'Profile Extractor' ...... 147

Capítulo 8: Conclusiones y Trabajos Futuros ......................................... 150

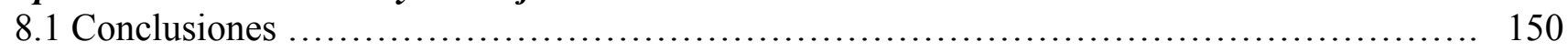

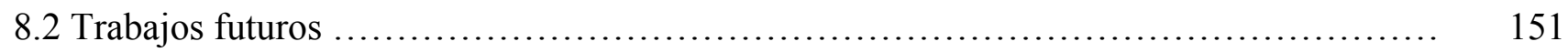

Bibliografia y Referencias ............................................................. 153 


\section{Capítulo 1}

\section{INTRODUCCIÓN}

\subsection{El escenario para esta tesis}

Tiempo transcurrido y mucho camino recorrido separan el presente, del momento en el cual la comunidad informática, instala la importancia de establecer una disciplina de ingeniería para el desarrollo de software. Pero el desafío de la ingeniería de software no termina con el establecimiento y uso de principios para tratar con el desarrollo de nuevas aplicaciones, sino que continúa con la necesidad de definir estrategias para tratar con aplicaciones existentes, de las cuales en su gran mayoría, no se conocen sus diseños ni modelos que los registren. La reingeniería de software cobra protagonismo.

El desarrollo de aplicaciones Web, no escapa a la realidad antes planteada. En un período muy corto la Internet y la World Wide Web han impuesto su presencia sobrepasando cualquier otro progreso tecnológico en la historia. Los sistemas basados en la Web han incrementado y extendido sus ámbitos $\mathrm{y}$ usos generando fuertes dependencias al mundo cotidiano, y capturando al usuario con la incorporación de técnicas de personalización.

Considerando a estas aplicaciones desde el punto de vista de la ingeniería de software, a medida que su complejidad aumenta, también aumenta la importancia de las técnicas de modelado. Modelos de las aplicaciones Web anteriores a su construcción son esenciales para la compresión en su totalidad, para la comunicación entre los grupos de proyecto, y para asegurar una arquitectura sólida y posible de mantener [Kappe100]. Existen algunos métodos especialmente dedicados al modelado de aplicaciones Web, pero la historia se repite, la mayoría de los desarrolladores de aplicaciones Web ponen muy poca atención a los aspectos que conciernen al diseño, llevando directamente a la implementación sus experiencias prácticas. En este contexto, cualquier intento de rediseño se torna sumamente complejo, titánico, si el objetivo del rediseño es la personalización.

Mientras la personalización se ha convertido en un requerimiento con presencia casi prioritaria en las aplicaciones Web de hoy, la realidad nos enfrenta a la existencia de aplicaciones Web no personalizadas y en su gran mayoría sin modelos que respalden su diseño.

Con esta realidad de escenario, surgió la idea de llevar a cabo esta tesis, en la cual se estudia el dominio de las aplicaciones Web considerando la creciente oferta / demanda de personalización y se propone un enfoque de reingeniería de personalización para estas aplicaciones, empleando principios y herramientas de: la reingeniería con tecnología de objetos [Jacobson94], el método OOHDM [Schwabe98a] y [OOHDM00] y el diseño de aplicaciones Web personalizadas [Rossi01b, 01c], [Schwabe02] y [Bäumer00].

\subsection{Objetivo}

El propósito de esta tesis es analizar el dominio de las aplicaciones Web desde la óptica de la personalización, a los efectos de proponer un enfoque de reingeniería que aporte a la tarea de personalizar aplicaciones Web existentes. 


\subsection{Organización del texto}

Los capítulos que suceden, organizan el resto del texto de esta tesis de la siguiente manera:

\section{Capítulo2: Aplicaciones Web}

Introduce conceptos referidos a la Internet y la WWW, haciendo hincapié en aquellos aspectos que resultan relevantes a este trabajo.

\section{Capítulo3: Herramientas de diseño}

Sintetiza las siguientes herramientas de modelado para el diseño de aplicaciones Web: el enfoque OOHDM 'Object-Oriented Hypermedia Design Method', los patrones de diseño (específicamente de navegación y de personalización) y los UIDs 'User Interaction Diagrams'.

\section{Capítulo4: Reingeniería}

Puntualiza conceptos de reingeniería, refiriendo al BPR de Jacobson 'Business Process Reengineering with Object Technology'.

\section{Capítulo5: Nuestro enfoque}

Presenta Nuestro Enfoque para la reingeniería de personalización de aplicaciones Web. Utilizando tópicos discutidos en los capítulos 2 a 4, se construye y explica paso a paso una propuesta de personalización de aplicaciones Web existentes, compuesta básicamente por dos procesos: Ingeniería en reversa e Ingeniería 'forward' de personalización.

\section{Capítulo6: Aplicando el enfoque}

Aplica completamente Nuestro Enfoque sobre un caso real no personalizado: la aplicación Web correspondiente a la corporación Weatherford Internacional Inc. Oil Field Services.

\section{Capítulo7: Trabajos relacionados}

Menciona algunos trabajos relacionados fundamentalmente a la reingeniería y a la personalización, temas centrales en esta tesis.

\section{Capítulo8: Conclusiones y trabajos futuros}

Expone las conclusiones finales y cita futuros trabajos. 


\section{Capítulo 2}

\section{Aplicaciones WeB}

\subsection{Crisis en la Web}

La Web es cada vez más utilizada como plataforma para aplicaciones con creciente complejidad, donde una enorme cantidad de datos altamente variables, es manejada por sistemas de bases de datos subyacentes. Desde el punto de vista de la ingeniería de software, el desarrollo de estas aplicaciones requiere métodos de modelado apropiados para asegurar solidez y mantenimiento [Kappel00].

Sin embargo, la gran mayoría de los numerosos sistemas basados en la Web que están en uso actualmente, causan graves problemas por la manera en que de ellos han sido desarrollados, implementados y gestionados. Los desarrolladores Web normalmente usan enfoques 'ad hoc', los cuales son carentes de rigor, técnicas sistemáticas, metodologías sólidas, y garantía de calidad.

Los problemas relacionados con los sistemas basados en la Web, en parte resultan, de los avances continuos en Internet y tecnologías Web, el incremento en aplicaciones Web de comercio electrónico con altas exigencias de personalización, la precipitación frenética por estar en la Web, y la necesidad de migrar rápidamente sistemas 'legacy' a entornos Web. Por otra parte, la tendencia a implementar desarrollos pobres de aplicaciones Web condena a bajo rendimiento y/o alta probabilidad de fracaso [Ginige01]. En el campo de las aplicaciones Web, como ya se ha mencionado, el costo de realizar malos diseños, desarrollos e implementaciones mezquinos, y/o gestiones no satisfactorias, crea serias consecuencias.

Como resultado, los desarrolladores, usuarios, y otros 'stakeholders', se están comenzando a preocupar por la manera en que los sistemas basados en la Web de complejidad son creados, como así también en el nivel de rendimiento, calidad, e integridad de dichos sistemas. Si bien esta nueva tendencia es una señal que nos alienta a pensar en aplicaciones Web de mayor calidad, no soluciona el problema de las aplicaciones Web existentes, que coexisten con las anteriores y requieren soluciones en lo inmediato.

\subsection{Categorías de aplicaciones Web}

Actualmente el uso que se le da a la Web es bastante diferente del propósito para el cual fue originalmente creada: un medio para compartir información científica entre algunos científicos. El alcance y la complejidad de las aplicaciones Web actuales varían notablemente: desde servicios efímeros a pequeña escala hasta aplicaciones de empresa a gran escala distribuidas a través de la Internet y de las Intranets / Extranets corporativas.

La figura 2.1 indica las siete categorías dentro de las cuales pueden ser agrupadas las aplicaciones Web (aunque una aplicación puede pertenecer a más de una categoría); la figura2.2 contrapone las características de las aplicaciones Web simples (más tempranas) de las aplicaciones Web avanzadas (más recientes) [Ginige01]. 


\begin{tabular}{|c|c|}
\hline CATEGORÍA & EJEMPLOS \\
\hline DE INFORMACIÓN & 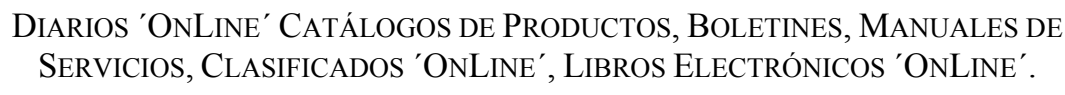 \\
\hline $\begin{array}{c}\text { INTERACTIVO } \\
\text { ( USA INFORMACIÓN } \\
\text { PROVISTA POR EL } \\
\text { USUARIO O } \\
\text { PERSONALIZADA AL } \\
\text { ACCESO ) }\end{array}$ & $\begin{array}{c}\text { FoRMULARIOS DE REGISTRO, PRESENTACIÓN DE INFORMACIÓN } \\
\text { PERSONALIZADA, JUEGOS 'ONLINE'. }\end{array}$ \\
\hline DE TRANSACCIÓN & $\begin{array}{c}\text { COMERCiO Electrónico, Pedido de SERVICIOS y BIENES, } \\
\text { BANCA 'OnLINE'. }\end{array}$ \\
\hline $\begin{array}{c}\text { FLUJO } \\
\text { DE TRABAJO }\end{array}$ & $\begin{array}{l}\text { Sistemas de ProgramaCiÓN y PLANIFICACIÓN 'ONLINE', GESTIÓN DE } \\
\text { INVENTARIOS, MONITOREO DE ESTADO. }\end{array}$ \\
\hline $\begin{array}{l}\text { ENTORNOS DE } \\
\text { TRABAJO DE } \\
\text { COLABORACIÓN }\end{array}$ & $\begin{array}{l}\text { SisTEMAS DE AUTORIDAD DISTRIBUIDOS, HERRAMIENTAS DE DISEÑO DE } \\
\text { COLABORACIÓN. }\end{array}$ \\
\hline $\begin{array}{l}\text { MERCADOS, } \\
\text { COMUNIDADES } \\
\text { 'ONLINE' }\end{array}$ & $\begin{array}{l}\text { GRUPOS DE 'CHAT', SiSTEMAS DE RECOMENDACIONES QUE ACONSEJAN } \\
\text { PRODUCTOS Y SERVICIOS, MERCADOS 'ONLINE', SUBASTAS 'ONLINE'. }\end{array}$ \\
\hline Portales Web & CENTROS DE COMPRAS ELECTRÓNICOS, INTERMEDIARIOS 'ONLINE'. \\
\hline
\end{tabular}

Figura 2.1: Categorías de aplicaciones Web

\begin{tabular}{|c|c|}
\hline $\begin{array}{l}\text { SISTEMAS BASADOS EN LA WEB } \\
\text { SIMPLES }\end{array}$ & $\begin{array}{c}\text { SiSTEMAS BASADOS EN LA WEB } \\
\text { AVANZADOS }\end{array}$ \\
\hline $\begin{array}{l}\text { PÁGINAS WEB SIMPLES PRESENTANDO } \\
\text { PRINCIPALMENTE INFORMACIÓN TEXTUAL. }\end{array}$ & PÁGINAS WEB COMPLEJAS. \\
\hline $\begin{array}{l}\text { EL CONTENIDO DE LA INFORMACIÓN NO } \\
\text { CAMBIA - BASTANTE ESTÁTICO. }\end{array}$ & $\begin{array}{c}\text { LA INFORMACIÓN ES DINÁMICA - CAMBIA } \\
\text { CON EL TIEMPO Y LAS NECESIDADES DE LOS } \\
\text { USUARIOS. }\end{array}$ \\
\hline
\end{tabular}




\begin{tabular}{|c|c|}
\hline NAVEGACIÓN SIMPLE. & $\begin{array}{c}\text { DIFICULTAD PARA NAVEGAR Y ENCONTRAR } \\
\text { LA INFORMACIÓN. }\end{array}$ \\
\hline SISTEMAS AUTOMÁTICOS. & $\begin{array}{c}\text { SISTEMAS INTEGRADOS CON BASES DE } \\
\text { DATOS Y OTROS SISTEMAS DE } \\
\text { PLANIFICACIÓN, PROGRAMACIÓN Y } \\
\text { LOCALIZACIÓN / RASTREO. }\end{array}$ \\
\hline $\begin{array}{l}\text { NO ES UN REQUERIMIENTO MAYOR EL ALTO } \\
\text { RENDIMIENTO. }\end{array}$ & $\begin{array}{l}\text { REQUIEREN ALTO RENDIMIENTO Y } \\
\text { DISPONIBILIDAD. }\end{array}$ \\
\hline $\begin{array}{l}\text { DESARROLLADOS POR UN INDIVIDUO O UN } \\
\text { PEQUEÑO EQUIPO. }\end{array}$ & $\begin{array}{c}\text { REQUIEREN UN GRAN EQUIPO DE } \\
\text { DESARROLLO CON EXPERIENCIA EN } \\
\text { DIVERSAS ÁREAS. }\end{array}$ \\
\hline $\begin{array}{l}\text { USADOS PARA LA DISEMINACIÓN DE } \\
\text { INFORMACIÓN EN APLICACIONES NO VITALES. }\end{array}$ & $\begin{array}{l}\text { DESPLIEGUE EN MISIÓN - APLICACIONES } \\
\text { CRÍTICAS. }\end{array}$ \\
\hline
\end{tabular}

Figura 2.2: Características de los sistemas basados en la Web - simples / avanzados -

\subsection{Ingeniería de Web versus ingeniería de software}

Contrario a la percepción que tienen algunos desarrolladores de software y profesionales de la ingeniería de software, la ingeniería de Web no es un clon de la ingeniería de software, si bien ambas requieren programación y desarrollo de software.

Mientras la ingeniería de Web adopta y abarca muchos principios de la ingeniería de software, incorpora a la vez muchos nuevos enfoques, metodologías, herramientas, técnicas y guías para lograr unificar los requerimientos de los sistemas basados en la Web. El desarrollo de sistemas basados en la Web es significativamente diferente del desarrollo de software tradicional y posee muchos y diversos desafíos adicionales. Existen sutiles diferencias en la naturaleza y el ciclo de vida de los sistemas de software y los basados en la Web y en la forma en la cual ellos se desarrollan y mantienen. El desarrollo Web es una mezcla entre publicidad escrita y desarrollo de software, entre marketing y computación, entre comunicaciones internas y relaciones externas y entre arte y tecnología. [Ginige01].

Si bien se puede asegurar que los métodos de modelado para aplicaciones Web han evolucionado notablemente, todavía resultan pobres a la hora de considerar el requerimiento primordial de las aplicaciones Web de hoy: la personalización. Las aplicaciones Web deben ser personalizadas con respecto a varios factores del contexto, por ejemplo, diferentes preferencias de usuarios, capacidades de los dispositivos y localizaciones en escenarios móviles, por mencionar solo algunos de ellos [Kappel00].

Sin lugar a dudas, los conceptos vertidos arriba apuntalan lo que se ha venido reiterando (y se reiterará en el transcurso de este trabajo): la necesidad de que el desarrollo de aplicaciones Web se lleve a cabo aplicando métodos de modelado apropiados para asegurar solidez, pero sobretodo, el mantenimiento de las mismas a los que las hereden. 


\subsection{Tratando con 'Legacies'}

El término 'legacy' no es nuevo y se viene usando en varios contextos tales como 'legacy LANs' (por ejemplo las LANs de Ethernet), 'legacy operating systems' (por ejemplo el PC DOS), 'legacy management styles' (por ejemplo el Taylorismo, Movimiento de Gestión Científico de Frederick Taylor), etc. [Umar97]. Algunos usan el término 'legacy' para indicar algo que no es de moda, por ejemplo métodos de diseño tradicionales, lenguajes de programación viejos, tecnologías de bases de datos desusadas, entornos de implementación anticuados, etc.

Si nos remitimos a las definiciones que proveen los diccionarios, 'legacy' es:

\section{Legacy: \{noun\} "something of value received from an ancestor or predecessor or from the past"}

Webster's Third New International Dictionary -1986

Ed. Merriam Webster

Legacy: noun "a thing passed to somebody by people who lived before them or from earlier events, etc.”

Oxford Advanced Learner's Dictionary -1995

Ed. Oxford University Press

\section{Legacy: sustantivo “legado, herencia.”}

The University of Chicago Dictionary - 1974

Ed. Pocket \& Books New York

Entonces, cuando hablamos de aplicaciones 'legacy' nos estamos refiriendo a una aplicación heredada, legada de un ancestro o predecesor. Utilizando la definición dada en [Umar97]:

\section{"A legacy application is an application of value inherited from the past"}

Los elementos claves de esta definición son 'value' (crítica a los negocios) e 'inherited from the past' (normalmente de 5 años a más). Específicamente las aplicaciones legadas son una clase de aplicaciones que tienen las siguientes características [Umar97]:

- Cruciales para la operación día a día de las corporaciones.

- Fuertemente asistidas con inversiones a través de los años y no pueden ser desechadas.

- Enormes (por ejemplo, miles de líneas de código, cientos de programas).

- Viejas (por ejemplo, de 5 a 20 de antigüedad, algunas más).

- De uso intensivo (por ejemplo, de miles de transacciones por día).

- Mal documentadas y difíciles de entender (los cambios en el código no se reflejan en la documentación).

- Inflexibles, costosas, consumidoras de tiempo, y riesgosas de mantener y cambiar.

- Basadas en viejas tecnologías de bases de datos (por ejemplo, Base de Datos IMS) o sin tecnología de base de datos (por ejemplo, archivos VSAM/ISAM).

- Escritas en viejos lenguajes de programación (por ejemplo, COBOL, PL1, y Assembler). 
- Basadas en interfaces de usuario de texto (por ejemplo, pantallas 3270) en vez de GUI (por ejemplo, Windows).

- Integradas verticalmente y monolíticas (por ejemplo, fuertemente ligadas al usuario, procesos, y gestión de datos).

- Depósitos de años de prácticas y experiencia corporativa (por ejemplo, muchas reglas del negocio están arraigadas en el código legado).

Muchos de los sistemas de negocios que fueron desarrolladas durante los años $70 \mathrm{y}$ el inicio de los 80 son buenos ejemplos de sistemas legados. Pero los sistemas legados no necesariamente son tan viejos. Expresiones tales como: aplicaciones no Java son aplicaciones legadas; cualquier artefacto que no sea $O O$ es un artefacto legado; cualquier cosa que no use Web es una cosa legada, reflejan claramente que los sistemas legados siempre estarán con nosotros, ya que lo que hoy resulta ser una aplicación de última generación, será 'legacy' en unos pocos años, si subsiste.

Si nos remitimos específicamente al campo de la Internet (y de la WWW), hoy se puede decir, y quizás sin temor a equivocarnos, que toda aplicación Web que no incorpore personalización es 'legacy'.

\section{5 ¿Por qué reingeniería de personalización?}

La personalización representa un desafío mayor desde que el usuario final está en el centro de la discusión cuando se desarrollan aplicaciones basadas en la Web. La personalización comprende todo un sinnúmero de aspectos y agrega una nueva dimensión a los diseños de las aplicaciones Web.

La comunidad investigadora es coincidente al asignar un rol protagónico al diseño de la aplicación Web, como el eje central sobre el cual (de manera más o menos "suave") se construye el proceso de personalización.

Por ejemplo [Rossi01c], observa que la gran mayoría de los tipos de personalización (si no todos) finalmente involucran algún tipo de adaptación al modelo conceptual. Al respecto, [Kappel00], plantea que la personalización especializa una aplicación Web (llamada corazón de la aplicación Web) adaptándola a las circunstancias particulares de consumo (llamadas contexto).

Nuevamente a escena, la necesidad imperativa de utilizar métodos y herramientas de diseño adecuados para el modelado de esta nueva generación de aplicaciones Web. Pero también, es tan o más imperativa la necesidad de poder contar con un buen bagaje de métodos y herramientas para tratar con las aplicaciones Web existentes, debido a que, como ya mencionamos, en la WWW coexisten sistemas con 'backgrounds' muy diferentes. Por ejemplo, la aplicación Web para la corporación Weatherford (caso real que se incluye en esta tesis, capítulo6), muestra un sistema básicamente informativo, que nace sin el estigma de la personalización y que hoy requiere inmediata evolución, a los efectos de mantener su vigencia en la Web.

Lo dicho hasta aquí, da razones más que elocuentes para entrar en el desafío de la reingeniería de personalización de aplicaciones Web. 


\section{Capítulo 3}

\section{HeRramientas de Diseño}

\subsection{Un vistazo al OOHDM}

El 'Object-Oriented Hypermedia Design Method' [Schwabe98a] y [OOHDM00], es un enfoque basado en modelos para construir grandes aplicaciones de hipermedia. Este enfoque ha sido utilizado para el diseño de diferentes tipos de aplicaciones tales como: sitios Web y sistemas de información, kioscos interactivos, presentaciones de multimedia, etc.

OOHDM comprende cuatro actividades diferentes denominadas: Diseño Conceptual $\rightarrow$ 'Conceptual Design'; Diseño de Navegación $\rightarrow$ 'Navegational Design'; Diseño de Interfaz Abstracta $\rightarrow$ 'Abstract Interface Design' e Implementación $\rightarrow$ 'Implementation'. Durante cada actividad un conjunto de modelos orientados a objetos que describen aspectos de diseño en particular es construido o enriquecido por la iteración previa. Considerar a los diseños conceptual, de navegación y de interfaz como actividades separadas no solamente nos permite concentrarnos en diferentes aspectos, de uno en uno, sino principalmente obtener un 'framework' para razonar sobre el proceso de diseño, encapsulando experiencia de diseño específica a cada actividad. [Rossi99c].

La figura3.1 ofrece un bosquejo de las actividades y los modelos que resultan de las mismas en OOHDM [Schwabe98b].

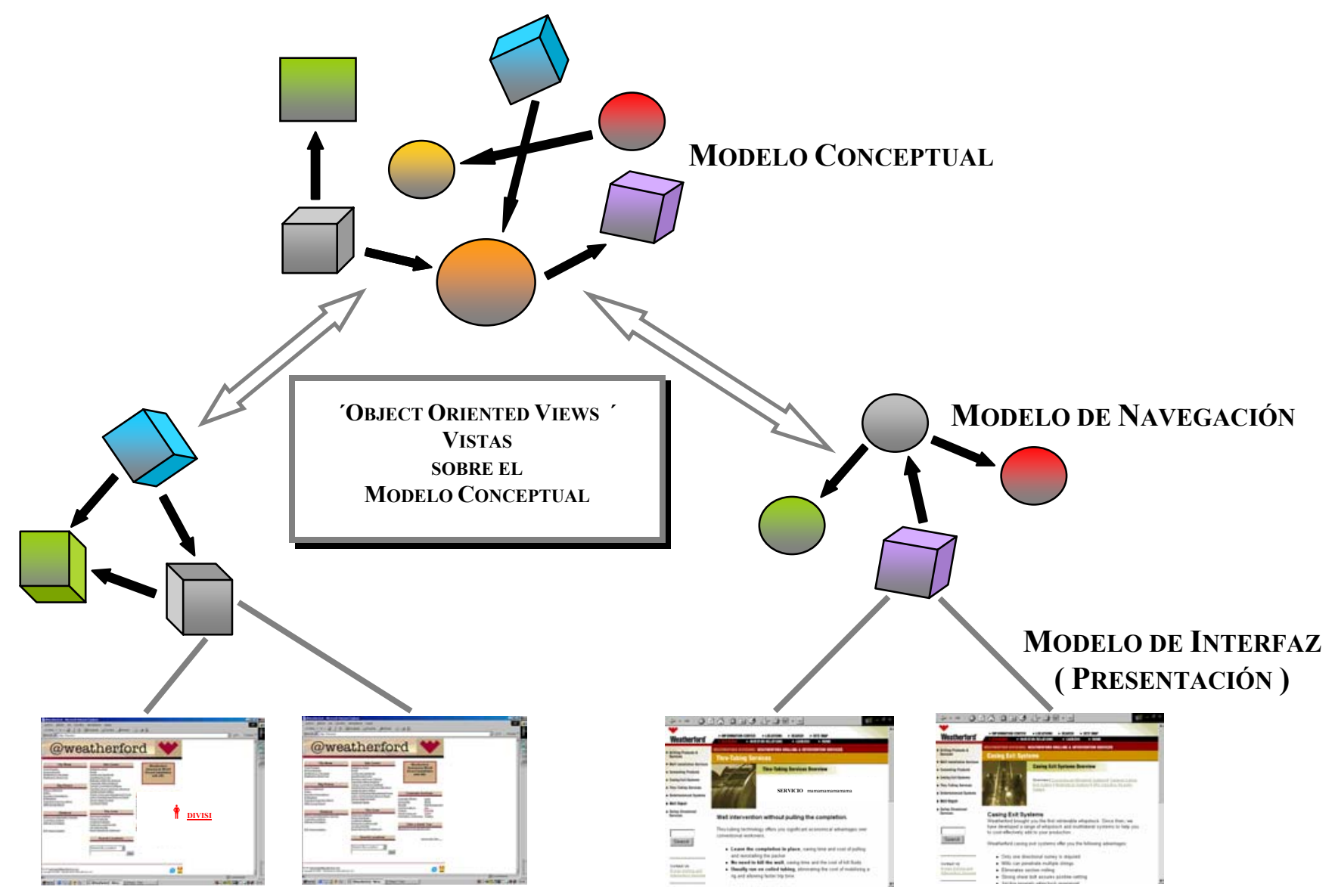

Figura 3.1: Actividades y modelos en OOHDM 
Las primitivas de diseño se pueden reflejar fácilmente sobre lenguajes o entornos de implementación no orientados a objetos (tales como HTML o Toolbook). Consecuentemente, OOHDM puede ser usado sin tener en cuenta si el sistema objetivo es un entorno orientado a objetos puro o un híbrido (tales como los que usualmente se encuentran en Internet) [Schwabe99].

\subsubsection{Descripción de sus actividades}

\section{Modelado CONCEPTUAL}

El objetivo de la actividad de diseño conceptual es construir un modelo del dominio de la aplicación, empleando los principios de modelado orientado a objetos y usando una notación similar a UML [UML97]. El producto de esta etapa es un esquema de clases construido por subsistemas, clases y relaciones. La diferencia más notable con UML es el uso de atributos multivaluados y la indicación explícita del sentido de dirección en las relaciones. Las jerarquías agregación y generalización/especialización se usan como mecanismos de abstracción [Rossi99c].

El modelado conceptual tiene el propósito de capturar las semánticas del dominio lo más "neutralmente" posible, con poco o nada sobre aspectos referidos a los tipos de usuarios y tareas. Cuando la aplicación involucra algún comportamiento sofisticado dentro de los objetos conceptuales, esta puede evolucionar a un modelo objeto dentro del entorno de implementación. No obstante, puede ser implementado fácilmente en las plataformas Web actuales combinando, por ejemplo, una base de datos relacional con ciertos procedimientos almacenados. Destacable es, que el modelo conceptual puede no reflejar el hecho de que la aplicación será implementada en un entorno WWW, ya que el modelo clave de aplicación se construirá durante la actividad de diseño de navegación. Esta visión permite usar la misma estrategia para implementar aplicaciones 'legacy' en la Web (capítulo2, ítem2.4), considerando sus modelos conceptuales como el producto de esta actividad OOHDM [Rossi99c].

Las clases en el modelo conceptual se reflejarán en nodos en el modelo de navegación usando un mecanismo de vistas y las relaciones se usarán para definir 'links' entre los nodos. Pero además, podrán existir otros 'links' que no se corresponden directamente con relaciones en el modelo conceptual, sino que pueden surgir en respuesta a requerimientos de navegación.

La figura3.2 ofrece parte de un Esquema Conceptual de un sitio Web para el estudio de abogados 'Winners'. Las perspectivas (atributos multivaluados) se indican enumerando los posibles tipos, con un ' + ' próximo al tipo por defecto. Por ejemplo en la clase Abogado, antecedentes: [Text+, Photo: Image] significa que el atributo antecedentes tiene una perspectiva de texto (siempre presente) y puede tener además, una perspectiva de imagen conteniendo una foto. Lo mismo vale para el atributo descripción de la clase Juicio.

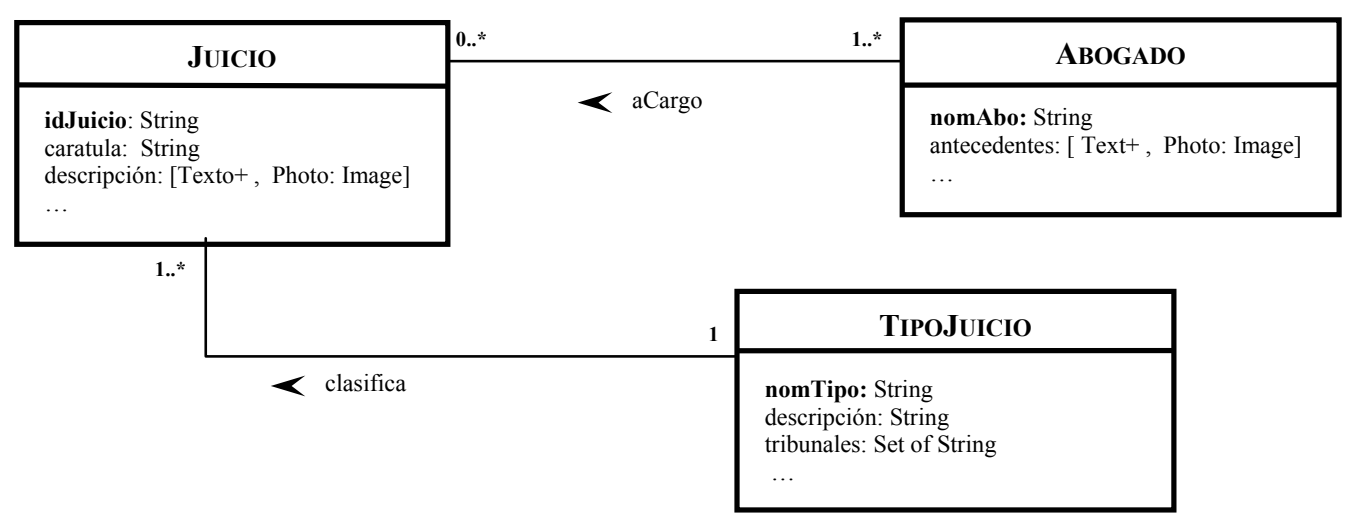

Figura 3.2: Esquema conceptual correspondiente al sitio Web del estudio de abogados 'Winners' 


\section{Diseño DE NAVEGaCión}

En OOHDM, una aplicación se visualiza como una vista de navegación sobre el modelo conceptual. Esta característica refleja una de las mayores innovaciones del enfoque OOHDM, el cual reconoce que los objetos que el usuario navega no son los objetos conceptuales, sino otro tipo de objetos que son "construidos" de uno o más objetos conceptuales [Schwabe99].

El modelo de navegación se expresa en dos esquemas:

\section{- Esquema de Clases de Navegación $\rightarrow$ 'Navigational Class Schema'}

Este esquema es el encargado de definir los objetos navegables de una aplicación de hipermedia y sus clases reflejan la vista seleccionada sobre el dominio de aplicación. En OOHDM existe un conjunto de tipos predefinidos de clases de navegación: nodos, 'links', 'anchors' y estructuras de acceso. La semántica de los nodos, 'links' y 'anchors' es la usual de las aplicaciones de hipermedia, y las estructuras de acceso, tales como índices, representan posibles formas de comenzar la navegación y acceder los nodos [Rossi99c] y [Schwabe98a].

La figura3.3 ofrece el Esquema de Clases de Navegación del sitio Web para el estudio de abogados 'Winners', cuyo Modelo Conceptual ilustra la figura3.2. Las clases de navegación (llamadas nodos) se indican como clases con una caja cuadrada en la esquina superior derecha. Observar en este diseño que:

- los atributos multivaluados en el esquema conceptual han sido representados sobre diferentes atributos de las clases de navegación (nodos) Juicio y Abogado;

- el nodo Juicio es actualmente un vista sobre las clases conceptuales Juicio y TipoJuicio;

- el nodo Juicio incluye un atributo nomTipoJuicio cuyo valor es tomado del atributo nomTipo de la clase conceptual TipoJuicio, más todos los otros atributos propios de la clase conceptual Juicio;

- el nodo Juicio ofrece una lista de 'anchors' a el/los nodo/s de su/s abogado/s;

- el nodo Abogado ofrece un índice a el/los nodo/s de su/s juicio/s;

- el 'link' entre los nodos Abogado y Juicio está definido sobre la relación Abogado aCargo Juicio.

\begin{tabular}{|l|l|l|}
\hline \multicolumn{1}{|c|}{ JUICIO } & 0..** & ABOGADO \\
\hline $\begin{array}{l}\text { idJuicio: String } \\
\text { caratula: String } \\
\text { descripción: Text+ } \\
\text { photo: Image* } \\
\text { nomTipoJuicio: t.nomTipo where t: TipoJuicio and } \\
\text { t clasifica Juicio(self) }\end{array}$ \\
$\begin{array}{r}\text { abogado/sDelJuicio: list of anchor ( a: Abogado } \\
\text { where a aCargo Juicio(self) })\end{array}$ \\
$\ldots$
\end{tabular}

Figura 3.3: Esquema de Clase de Navegación correspondiente al sitio Web del estudio de abogados 'Winners'

Es importante destacar que el enfoque OOHDM permite definir una estructura de navegación diferente para cada perfil de usuario, que reflejará los objetos y relaciones en el esquema conceptual, de acuerdo con las tareas que este tipo de usuario deba ejecutar. Es decir, que diferentes aplicaciones (sobre el mismo dominio) pueden contener diferentes topologías de enlace 'links', de acuerdo al perfil del usuario [Rossi99c]. Por ejemplo, el sitio Web para el estudio de abogados, puede incluir la información del tipo de juicio para los expertos (abogados), y no incluir esta información para el resto de los usuarios casuales.

La diferencia más notable entre el enfoque OOHDM y los demás que usan mecanismos de visualización de objetos, es que mientras los últimos consideran las páginas Web principalmente como interfaces de usuario, que son construidas de la observación de objetos conceptuales, en 
OOHDM se propicia claramente un representación explícita de los objetos de navegación (nodos y 'links') durante el diseño [Rossi99c].

\section{- Esquema de Contexto de Navegación $\rightarrow$ ' Navigational Context Schema'}

En OOHDM, la principal primitiva de estructuración del espacio de navegación es la noción de contexto de navegación. Un contexto de navegación es un conjunto de: nodos, 'links', clases de contexto, otros contextos de navegación anidados y estructuras de acceso asociadas. Puede ser definido por comprensión o por extensión, es decir, ya sea definiendo una propiedad común a todos los nodos y 'links' que el contexto posee, o mediante la enumeración de todos sus miembros. En resumen, un contexto se compone de: los elementos que contiene; la especificación de su estructura interna de navegación; un punto de entrada; restricciones de acceso en términos de clases de usuarios y operaciones; y estructuras de acceso asociadas. Existen seis diferentes formas de definir contextos a las cuales es posible asociar estructuras de acceso (índices).

Debido a que este ítem, aspira a ser solamente una presentación que sintetice las principales ideas subyacentes al enfoque OOHDM, para más detalles sobre tipos de contextos y estructuras de acceso, cartas CRC, etc., remitirse a [Rossi99c] [Scwabe98a, 99].

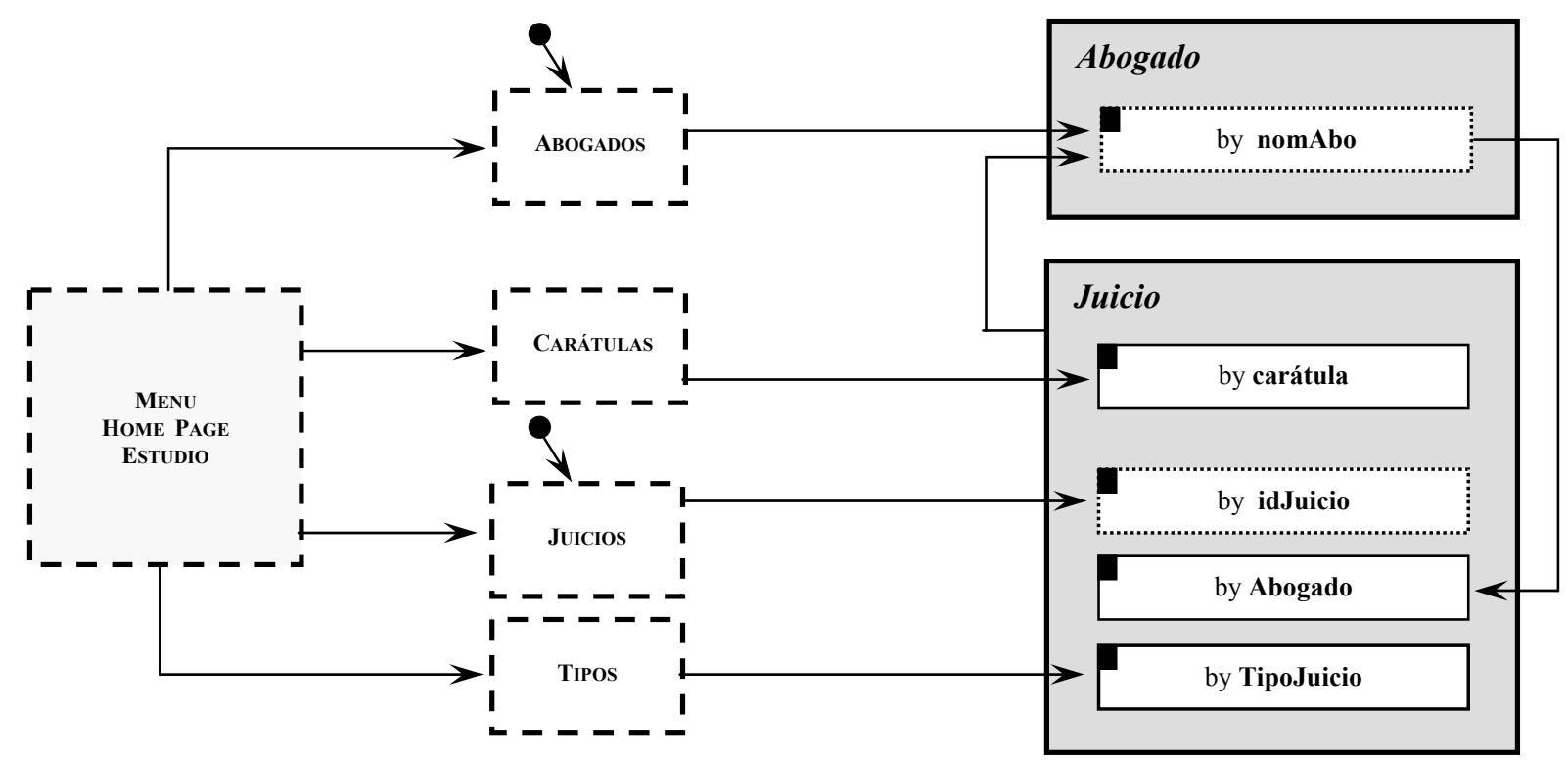

Figura 3.4 : Esquema de Contexto de Navegación correspondiente al sitio Web del estudio de abogados 'Winners'

La figura3.4 ofrece el Esquema de Contexto de Navegación del sitio Web para el estudio de abogados 'Winners', cuyos esquemas Conceptual y de Clase de Navegación ilustran las figuras3.2. y 3.3 respectivamente.

Observar en este diseño que el menú principal ('home page' del estudio 'Winners') tiene los cuatro diferentes índices siguientes:

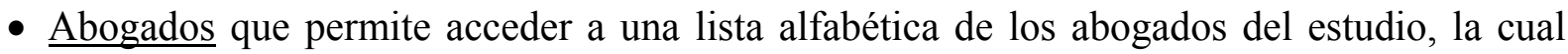
puede ser atravesada en algún orden; este menú puede ser accedido desde cualquier punto de la aplicación;

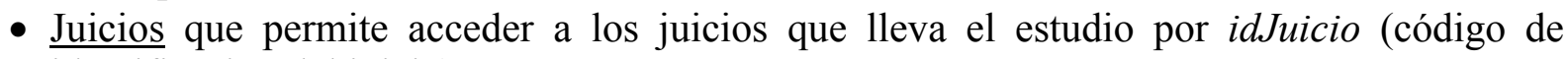
identificación del juicio);

- Carátulas que permite acceder a los juicios del estudio agrupados por carátula;

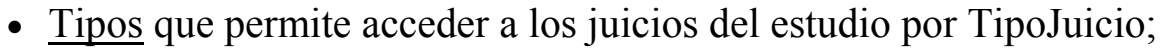


Observar además que:

- los juicios pueden también agruparse de acuerdo con el abogado que este a cargo de ellos; este contexto solamente puede ser accedido desde otro contexto, tal como Abogados;

- el símbolo “q” indica que los índices Abogados y Juicios pueden ser accedidos desde cualquier nodo de la aplicación [Rossi99a], (capítulo3 ítem3.2, Patrón de Diseño de Hipermedia 'Landmark').

\section{Diseño de INTERFAZ ABSTRACTA}

En la actividad de Diseño de la Interfaz Abstracta se especifica cuáles objetos de interfaz el usuario percibirá y cómo la interfaz se comportará. Para cada atributo de nodo (ya sean contenidos o 'anchors') se debe definir su apariencia. Por medio de la distinción entre diseño de navegación e interfaz se pueden construir interfaces distintas para la misma aplicación y paralelamente alcanzar independencia de implementación [Rossi99c].

La especificación de la Interfaz Abstracta incluye la forma en la cual los diferentes objetos de navegación lucirán, cuales objetos de interfaz activarán la navegación, la forma en la cual los objetos de interfaz de multimedia estarán sincronizados y qué transformaciones de interfaz tendrán lugar [Schwabe99].

Es importante enfatizar que la construcción de un modelo formal de la interfaz de las aplicaciones Web es una actividad que gratifica, ya que las interfaces de usuario tienden a cambiar más rápidamente que las topologías de navegación. Por lo tanto, claramente se necesita una especificación de diseño precisa que permita afrontar los cambios "suavemente" [Rossi99c].

\section{IMPLEMENTACIÓN}

Durante la actividad de Implementación, reflejamos los objetos conceptuales, de navegación y de interfaz, sobre el entorno de ejecución destinatario. Cuando el entorno de implementación no es totalmente orientado a objeto, tenemos que reflejar los objetos conceptuales, de navegación y de interfaz abstracta sobre objetos concretos, es decir, aquellos disponibles en el entorno de implementación seleccionado. Esto puede requerir definir páginas HTML (o, por ejemplo, objetos Toolbook en entornos no basados en la Web), código en cierto lenguaje, preguntas a bases de datos relacionales, etc. Observar que aún en entornos orientados a objeto, puede no existir diferencias significativas entre objetos conceptuales y de navegación, los cuales actuarán como modelos de interfaces Smalltalk. Mientras tanto, en un entorno más híbrido, los objetos conceptuales se reflejarán en un almacenamiento persistente (archivos y bases de datos relacionales) y los objetos de navegación y de interfaz se implementarán como páginas Web convencionales [Rossi99c].

\subsubsection{Resumen del enfoque}

La figura3.5 ofrece una tabla que sintetiza los aspectos más relevantes del enfoque OOHDM [Schwabe98b], también disponible en http://www.telemidia.puc-rio.br/oohdm/oohdm.html : 


\begin{tabular}{|c|c|c|c|c|}
\hline ACTIVIDADES & Productos & FORMALISMOS & MECANISMOS & $\begin{array}{l}\text { ASPECTOS } \\
\text { DE DISEÑO }\end{array}$ \\
\hline $\begin{array}{c}\text { CAPTURA } \\
\text { DE } \\
\text { REQUERIMIENTOS }\end{array}$ & $\begin{array}{l}\text { CASOS DE UsO, } \\
\text { ANOTACIONES. }\end{array}$ & $\begin{array}{c}\text { ESCENARIOS, } \\
\text { DIAGRAMAS DE } \\
\text { INTERACCIÓN DE } \\
\text { USUARIO 'USER } \\
\text { INTERACTION } \\
\text { DIAGRAMS' - UIDS -, } \\
\text { PATRONES DE DISEÑO. }\end{array}$ & $\begin{array}{c}\text { ANÁLISIS DE } \\
\text { ESCENARIOS Y CASOS } \\
\text { DE USO, ENTREVISTAS, } \\
\text { UIDS } \\
\text { CORRESPONDIENTES } \\
\text { AL MODELO } \\
\text { CONCEPTUAL. }\end{array}$ & $\begin{array}{c}\text { CAPTURA LOS } \\
\text { REQUERIMIENTOS DE } \\
\text { LOS 'STAKEHOLDERS' } \\
\text { PARA LA APLICACIÓN. }\end{array}$ \\
\hline $\begin{array}{l}\text { MODELADO } \\
\text { CONCEPTUAL }\end{array}$ & $\begin{array}{l}\text { Clases, } \\
\text { SubSISTEMAS, } \\
\text { RELACIONES, } \\
\text { PERSPECTIVAS DE } \\
\text { ATRIBUTOS. }\end{array}$ & $\begin{array}{l}\text { CONSTRUCTORES DE } \\
\text { MODELADO } \\
\text { ORIENTADOS A } \\
\text { OBJETO (CLASES, } \\
\text { RELACIONES, CASOS } \\
\text { DE USO), PATRONES } \\
\text { DE DISEÑO. }\end{array}$ & $\begin{array}{l}\text { CLASIFICACIÓN, } \\
\text { AGREGACIÓN, } \\
\text { GENERALIZACIÓN Y } \\
\text { ESPECIALIZACIÓN. }\end{array}$ & $\begin{array}{l}\text { MODELA LA } \\
\text { SEMÁNTICA DEL } \\
\text { DOMINIO DE } \\
\text { APLICACIÓN. }\end{array}$ \\
\hline $\begin{array}{c}\text { DISEÑo } \\
\text { DE } \\
\text { NAVEGACIÓN }\end{array}$ & $\begin{array}{l}\text { NODOS, 'LINKS', } \\
\text { ESTRUCTURAS DE } \\
\text { ACCESO, CONTEXTOS } \\
\text { DE NAVEGACIÓN, } \\
\text { TRANSFORMACIONES } \\
\text { DE NAVEGACIÓN. }\end{array}$ & $\begin{array}{c}\text { VISTAS ORIENTADAS A } \\
\text { OBJETO; DIAGRAMAS } \\
\text { DE ESTADO } \\
\text { ORIENTADOS A } \\
\text { OBJETO; CLASES DE } \\
\text { CONTEXTO; } \\
\text { ESCENARIOS } \\
\text { CENTRADOS EN EL } \\
\text { USUARIO; PATRONES } \\
\text { DE DISEÑO. }\end{array}$ & $\begin{array}{l}\text { CLASIFICACIÓN, } \\
\text { AGREGACIÓN, } \\
\text { GENERALIZACIÓN / } \\
\text { ESPECIALIZACIÓN. }\end{array}$ & $\begin{array}{c}\text { TIENE EN CUENTA } \\
\text { PERFIL DEL USUARIO Y } \\
\text { TAREA. ENFASIS } \\
\text { SOBRE LOS ASPECTOS } \\
\text { COGNITIVOS. } \\
\text { CONSTRUYE LA } \\
\text { ESTRUCTURA DE } \\
\text { NAVEGACIÓN DE LA } \\
\text { APLICACIÓN. }\end{array}$ \\
\hline $\begin{array}{c}\text { DISEÑO } \\
\text { DE } \\
\text { INTERFAZ } \\
\text { ABSTRACTA }\end{array}$ & $\begin{array}{l}\text { OBJETOS DE INTERFAZ } \\
\text { ABSTRACTA, } \\
\text { RESPUESTAS A } \\
\text { EVENTOS EXTERNOS, } \\
\text { TRANSFORMACIONES } \\
\text { DE INTERFAZ. }\end{array}$ & $\begin{array}{c}\text { VISTAS DE DATOS } \\
\text { ABSTRACTA } \\
\text { 'ABSTRACT DATA } \\
\text { VIEWS' - ADVS - ; } \\
\text { DIAGRAMAS DE } \\
\text { CONFIGURACIÓN; } \\
\text { DIAGRAMAS ADV; } \\
\text { PATRONES DE DISEÑO. }\end{array}$ & $\begin{array}{c}\text { CORRESPONDENCIA } \\
\text { ENTRE OBJETOS DE } \\
\text { NAVEGACIÓN Y } \\
\text { OBJETOS } \\
\text { PERCEPTIBLES. } \\
\text { COMPOSICIÓN Y } \\
\text { GENERALIZACIÓN / } \\
\text { ESPECIALIZACIÓN. }\end{array}$ & $\begin{array}{l}\text { MODELA LOS OBJETOS } \\
\text { PERCEPTIBLES, } \\
\text { IMPLEMENTANDO LAS } \\
\text { 'METAPHORS' } \\
\text { SELECCIONADAS. } \\
\text { DESCRIBE INTERFAZ } \\
\text { PARA OBJETOS DE } \\
\text { NAVEGACIÓN. DEFINE } \\
\text { LA PRESENTACIÓN, } \\
\text { 'LAY-OUT', DE LOS } \\
\text { OBJETOS DE INTERFAZ. }\end{array}$ \\
\hline IMPLEMENTACIÓN & $\begin{array}{l}\text { APLICACIÓN } \\
\text { EJECUTABLE } \\
\text { 'CORRIENDO' }\end{array}$ & $\begin{array}{c}\text { AQUELLOS } \\
\text { SOPORTADOS POR EL } \\
\text { ENTORNO OBJETIVO, } \\
\text { DESTINATARIO DE LA } \\
\text { APLICACIÓN. }\end{array}$ & $\begin{array}{l}\text { AQUELLOS PROVISTOS } \\
\text { POR EL ENTORNO } \\
\text { OBJETIVO, } \\
\text { DESTINATARIO DE LA } \\
\text { APLICACIÓN. }\end{array}$ & $\begin{array}{l}\text { PERFORMANCE, } \\
\text { COMPLETITUD. }\end{array}$ \\
\hline
\end{tabular}

Figura 3.5: Resumen de la metodología OOHDM 


\subsection{Patrones para Aplicaciones Web}

La idea de patrones fue originalmente desarrollada por Christopher Alexander en el campo de la arquitectura urbanística [Alexander77] y fue adaptada al software orientado a objeto algunos años después [Gamma95]. Un patrón muestra un problema de diseño recurrente conjuntamente con una buena solución para dicho problema. Es un instrumento eficaz, que permite registrar experiencia de diseño y razonar sobre el proceso de diseño. Se describe exponiendo su intención, el problema al que apunta y la solución abstracta a dicho problema. Los patrones complementan los métodos de diseño mostrando soluciones que van más allá del uso 'naive' de las primitivas de los métodos. Mejoran la comunicación entre los diseñadores al enriquecer el vocabulario de diseño, con términos que expresan estructuras no triviales. Los patrones formalizan soluciones bien conocidas, de tal manera que los diseñadores novatos pueden sacar provecho del conocimiento de los expertos [Rossi00a]. En síntesis, los patrones registran experiencia de diseño enunciando en forma abstracta, problemas recurrentes y soluciones probadas a dichos problemas recurrentes de diseño. Son herramientas extraordinarias para capturar, transmitir y reutilizar experiencia de diseño. Cuando un grupo de patrones cubre todos los problemas de diseño de un dominio en particular y existe un conjunto de reglas que nos permite aplicar dichos patrones siguiendo cierto orden parcial, este grupo se denomina lenguaje de patrones, 'pattern language'.

En los últimos años, la comunidad de hipermedia ha recabado y documentado patrones que cubren diferentes aspectos en el campo de las aplicaciones Web: para diseño de topologías de navegación [Rossi99a, 99b] y [Garrido97], (capítulo3 ítem3.2.1); para diseño de interfaz [Rossi97, 00b]; para uso específico en el campo de las aplicaciones 'e-commerce' [Rossi00c]; para incorporar capacidad de búsqueda [Lyardet99]; etc. En todos estos casos, los patrones han sido documentados usando una plantilla, 'template', similar a la utilizada por Alexander. De hecho, los patrones para aplicaciones Web son similares a los patrones urbanísticos originales, ya que expresan estructuras recurrentes para construir espacios de navegación aprovechables y muestran soluciones de diseño que auxilian al usuario a encontrar el camino a través del hiperespacio [Rossi00a].

Por otra parte y como una consecuencia de la creciente sofisticación de los sitios Web, impulsada por la competencia despiadada entre sitios por atraer visitantes, la personalización se convierte en una cuestión muy importante en la Internet. El diseño de aplicaciones Web personalizadas puede implicar tratar con asuntos diferentes y se puede convertir en un problema abrumador debido a su complejidad. Esta actividad puede significar construir distintas interfaces (personalizadas a un artefacto en particular), suministrar topologías diferentes de navegación para personas diferentes, recomendar productos específicos de acuerdo a las preferencias de los usuarios, implementar políticas de precios diferenciadas, etc. Todas estas facetas de la personalización comparten la necesidad de modelar al usuario y sus preferencias, construir perfiles, encontrar algoritmos para opciones de 'linking' mejores. etc., y además integrar estas en un diseño cohesivo [Schwabe02].

Sin embargo, es importante destacar que de la exploración y construcción de aplicaciones Web personalizadas, la comunidad de hipermedia ha identificado estructuras de diseño recurrentes que le permitieron registrar un nuevo grupo de patrones: patrones para el diseño de aplicaciones Web personalizadas [Rossi01a, 01b], [Schwabe02], [Bäumer00], (capítulo3 ítem3.2.2).

A continuación, ítem3.2.1 e ítem3.2.2, se presenta una síntesis sobre los patrones de navegación y de personalización que resultan de interés para esta tesis, los cuales forman parte de un extenso catálogo de patrones de hipermedia. 


\subsubsection{Patrones de navegación}

El diseño de la estructura de navegación de una aplicación Web requiere, no solamente definir nodos significativos y conectarlos juiciosamente reflejando las relaciones semánticas en el dominio de aplicación, sino también ayudar al usuario a encontrar la información deseada haciéndolo sentir confortable mientras navega [Rossi99a].

El hecho de contar con herramientas de orientación (mapas) o de atajos (índices) es importante, sin embargo, a la hora de diseñar la topología de navegación para una aplicación Web, existen problemas más delicados que requieren especial atención y apropiada respuesta. En este sentido, los patrones de navegación proveen soluciones que permiten mejorar notablemente las estrategias de navegación.

La figura3.6 presenta una síntesis sobre los patrones de navegación, señalando su nombre, su intención e indicando referencias bibliográficas a las que es posible remitirse para profundizar sobre el tema.

\begin{tabular}{|c|c|c|}
\hline PATRÓN & INTENCIÓN & $\begin{array}{c}\text { OTRAS } \\
\text { REFERENCIAS }\end{array}$ \\
\hline $\begin{array}{c}\text { 'SET-BASED } \\
\text { NAVIGATION' }\end{array}$ & $\begin{array}{l}\text { ORGANIZA LA INFORMACIÓN EN CONJUNTOS 'SETS' DE ÍTEM } \\
\text { DE INFORMACIÓN RELACIONADOS. } \\
\text { PROVEE CAPACIDAD DE NAVEGACIÓN INTER / INTRA } \\
\text { CONJUNTOS. } \\
\text { BRINDA AL USUARIO SUB-ESPACIOS DE NAVEGACIÓN MÁS } \\
\text { CERRADOS QUE PUEDEN SER FÁCILMENTE NAVEGADOS. }\end{array}$ & $\begin{array}{l}\text { [Rossi99B] } \\
\text { [Rossi99A] }\end{array}$ \\
\hline 'NEWS' & $\begin{array}{l}\text { PROVEE FÁCIL ACCESO A NUEVOS ÍTEM DE INFORMACIÓN A } \\
\text { MEDIDA QUE EL WIS CRECE. } \\
\text { PERMITE DESTACAR LAS NOVEDADES DEL SITIO. }\end{array}$ & $\begin{array}{l}{[\text { Rossi99B] }} \\
{[\text { Rossi99A] }} \\
\text { [RossI99D] }\end{array}$ \\
\hline 'LANDMARK' & $\begin{array}{l}\text { PROVEE ACCESO DIRECTO A SUB-SISTEMAS CRÍTICOS } \\
\text { (DIFERENTES E INCLUSIVE NO RELACIONADOS) EN EL WIS. } \\
\text { POSIBILITA EL DISEÑO DE ACCESOS DIRECTOS (CONJUNTOS DE } \\
\text { 'LANDMARKS') QUE SEAN VISIBLES DESDE TODOS LOS NODOS } \\
\text { DE LA RED. } \\
\text { PERMITE DEFINIR DIFERENTES NIVELES DE ACCESOS DIRECTOS } \\
\text { (CONJUNTOS DE 'LANDMARKS' ORGANIZADOS } \\
\text { JERÁRQUICAMENTE) DE ACUERDO CON EL ÁREA DEL SITIO QUE } \\
\text { SE ESTÉ VISITANDO. }\end{array}$ & $\begin{array}{l}{[\operatorname{RosSI} 99 \mathrm{~B}]} \\
{[\mathrm{RoSSI} 9 \mathrm{~A}]} \\
{[\mathrm{ROSSI00A}]}\end{array}$ \\
\hline 'PORTAL' & $\begin{array}{c}\text { PERMITE EL DISEÑO DE 'HOMES' COMO AGREGADOS DE } \\
\text { DIFERENTES ÍTEM DE INFORMACIÓN (QUE PUEDEN O NO ESTAR } \\
\text { 'SEMÁNTICAMENTE' CONECTADOS), 'ANCHORS' Y } \\
\text { ESTRUCTURAS DE ACCESO. } \\
\text { BRINDA UNA SOLUCIÓN DE DISEÑO OPORTUNISTA PARA } \\
\text { INCREMENTAR EL NÚMERO DE VISITANTES DEL SITIO. }\end{array}$ & $\begin{array}{l}{[\text { Rossi99B] }} \\
{[\text { Rossi00A] }}\end{array}$ \\
\hline $\begin{array}{l}\text { 'SHOPPING } \\
\text { BASKET' }\end{array}$ & $\begin{array}{c}\text { MANTIENE REGISTRO DE LAS SELECCIONES QUE EFECTÚA EL } \\
\text { USUARIO DURANTE LA NAVEGACIÓN, HACIENDO ESTAS } \\
\text { SELECCIONES PERSISTENTES PARA PROCESARLAS DESPUÉS } \\
\text { CUANDO EL USUARIO LO DECIDE. }\end{array}$ & $\begin{array}{l}\text { [Rossi99B] } \\
{[\text { Rossi00A] }}\end{array}$ \\
\hline
\end{tabular}




\begin{tabular}{|c|c|c|}
\hline $\begin{array}{c}\text { 'ACTIVE } \\
\text { REFERENCE' }\end{array}$ & $\begin{array}{c}\text { DEFINE ÍNDICES COMO HERRAMIENTAS DE ORIENTACIÓN } \\
\text { ACTIVAS EN SUB-ÁREAS DE TODO EL HIPERESPACIO. } \\
\text { HACE QUE ESTOS ÍNDICES CO-EXISTAN CON LOS OBJETOS } \\
\text { OBJETIVO. }\end{array}$ & $\begin{array}{l}\text { [Rossi99B] } \\
\text { [Rossi00A] }\end{array}$ \\
\hline $\begin{array}{l}\text { 'NODE IN } \\
\text { CONTEXT' }\end{array}$ & $\begin{array}{l}\text { PERSONALIZA LA REPRESENTACIÓN DE LOS OBJETOS DE } \\
\text { ACUERDO AL CONJUNTO DENTRO DEL CUAL ESTÉN SIENDO } \\
\text { ACCEDIDOS. } \\
\text { PERMITE QUE EL MISMO OBJETO APAREZCA EN DIFERENTES } \\
\text { CONJUNTOS, MODIFICANDO SU APARIENCIA Y CONEXIONES CON } \\
\text { OTROS OBJETOS DE ACUERDO AL CONJUNTO EN CURSO. }\end{array}$ & $\begin{array}{l}\text { [Rossi99B] } \\
\text { [Rossi00A] }\end{array}$ \\
\hline
\end{tabular}

Figura 3.6: Patrones de Navegación

\subsubsection{Patrones de personalización}

La construcción de aplicaciones Web personalizadas, es decir aquellas aplicaciones que son sensibles a las necesidades individuales de cada usuario o grupo de usuarios, es una tarea desafiante. Involucra toda una miríada de tecnologías diferentes que van desde simples vistas de bases de datos hasta agentes de software y algoritmos de filtro y colaboración. La personalización se ha vuelto sumamente popular e indispensable en áreas tales como el comercio electrónico, y podemos encontrar cientos de aplicaciones que reclaman ser totalmente personalizadas a diferentes perfiles de usuarios o individuos [Rossi01a].

Como sucede con otras características Web, existe una gran variedad de tecnologías y sistemas disponibles, pero poca o ninguna atención se le ha prestado al proceso de diseño y modelado de aplicaciones Web personalizadas. Sin embargo, ya señalamos, que la comunidad de hipermedia ha recabado y documentado patrones de personalización que caracterizan las diferentes situaciones usualmente presentes en las aplicaciones Web actuales [Rossi01a, 01b], [Schwabe02], [Bäumer00]. Además, se ha demostrado que es posible representar estos patrones dentro de estructuras de diseño concretas, por ejemplo, el 'framework' que provee el enfoque OOHDM [Schwabe02].

La figura3.7 presenta una síntesis sobre algunos de los patrones de personalización, señalando su nombre, su intención, el mecanismo con el cual se puede modelar la solución de diseño que propone y un ejemplo práctico, e indicando además referencias bibliográficas a las que es posible remitirse para profundizar sobre el tema. Debido a que el diseño de interfaz esta fuera del alcance de este trabajo, no se incluye la personalización de interfaz. 


\begin{tabular}{|c|c|c|c|c|}
\hline $\begin{array}{c}\text { PATRÓN } \\
\text { Y } \\
\text { TIPO DE } \\
\text { PERSONALIZACIÓN }\end{array}$ & INTENCIÓN & MECANismos & EJEMPLO & $\begin{array}{c}\text { OTRAS } \\
\text { REFERENCIAS }\end{array}$ \\
\hline 'ROLE-BASED' & $\begin{array}{l}\text { ADAPTA LA } \\
\text { TOPOLOGÍA DE } \\
\text { NAVEGACIÓN AL } \\
\text { PERFIL / ROL DEL } \\
\text { USUARIO. }\end{array}$ & $\begin{array}{c}\text { ViSTAS ENTRE LOS } \\
\text { ModELOS CONCEPTUAL Y } \\
\text { DE ClASES DE } \\
\text { NAVEGACIÓN; } \\
\text { CONTEXTOS; } \\
\text { ClASES EN CONTEXTO } \\
\text { 'INCONTEXT ClASSES'; } \\
\text { FILTROS. }\end{array}$ & $\begin{array}{c}\text { DIFERENTES TIPOS DE } \\
\text { USUARIOS ACCEDIENDO } \\
\text { LA MISMA INFORMACIÓN } \\
\text { BASE. } \\
\text { POR EJEMPLO, PERFIL } \\
\text { PROFESOR Y PERFIL } \\
\text { OTROS EN LA APLICACIÓN } \\
\text { WEB PARA EL INSTITUO } \\
\text { DE INGLÉS 'FIRST' } \\
\text { (CAPÍTULO5). }\end{array}$ & $\begin{array}{c}\text { [SCHWABE02] } \\
\text { [RosSI01B] }\end{array}$ \\
\hline 'LINK' & $\begin{array}{c}\text { ADAPTA LA } \\
\text { TOPOLOGÍA DE } \\
\text { NAVEGACIÓN A LAS } \\
\text { NECESIDADES O } \\
\text { PREFERENCIAS DEL } \\
\text { USUARIO. }\end{array}$ & $\begin{array}{c}\text { CLASES DE NAVEGACIÓN; } \\
\text { CONTEXTOS; } \\
\text { CLASES EN CONTEXTO } \\
\text { 'INCONTEXT CLASES'; } \\
\text { FILTROS; } \\
\text { DESACOPLAMIENTO DEL } \\
\text { 'LINK ENDPOINT } \\
\text { COMPUTATION'. } \\
\\
\text { COMPORTAMIENTOS } \\
\text { ASOCIADOS CON LOS } \\
\text { OBJETOS USUARIO. }\end{array}$ & $\begin{array}{c}\text { RECOMENDACIONES EN } \\
\text { LOS ALMACENES } \\
\text { VIRTUALES. } \\
\\
\text { DIFERENTES INDIVIDUOS } \\
\text { CON DIFERENTES } \\
\text { DERECHOS DE ACCESO. } \\
\\
\text { POR EJEMPLO, } \\
\text { EL PROFESOR ACCEDE A } \\
\text { INFORMACIÓN DE LOS } \\
\text { CURSOS QUE ÉL DICTA, } \\
\text { EN LA APLICACIÓN WEB } \\
\text { PARA EL INSTITUO DE } \\
\text { INGLÉS 'FIRST' } \\
\text { (CAPÍTULO5). }\end{array}$ & $\begin{array}{c}\text { [SCHWABE02] } \\
\text { [Rossi01A] } \\
\text { [Rossi01B] }\end{array}$ \\
\hline 'CONTENT' & $\begin{array}{l}\text { PROVEE AL USUARIO } \\
\text { DE CONTENIDOS } \\
\text { PERSONALIZADOS EN } \\
\text { LOS NODOS. }\end{array}$ & $\begin{array}{c}\text { CLASES DE NAVEGACIÓN; } \\
\text { CONTEXTOS; } \\
\text { CLASES EN CONTEXTO } \\
\text { 'INCONTEXT CLASES'; } \\
\text { FILTROS; } \\
\text { MODELO DE USUARIO } \\
\text { EXPLÍ́CITO. } \\
\\
\text { ACOPLAMIENTO DE } \\
\text { INFORMACIÓN } \\
\text { SIGNIFICATIVA CON LOS } \\
\text { OBJETOS USUARIO. }\end{array}$ & $\begin{array}{l}\text { DIFERENTES PRECIOS } \\
\text { PARA EL MISMO } \\
\text { PRODUCTO DE ACUERDO } \\
\text { CON LA CATEGORÍA DE } \\
\text { CADA USUARIO } \\
\text { INDIVIDUAL. } \\
\text { POR EJEMPLO, EL } \\
\text { PROFESOR ACCEDE } \\
\text { SOLAMENTE A LOS } \\
\text { CURSOS QUE ÉL DICTA, } \\
\text { EN LA APLICACIÓN WEB } \\
\text { PARA EL INSTITUO DE } \\
\text { INGLÉS 'FIRST' } \\
\text { (CAPÍTULO5). }\end{array}$ & $\begin{array}{c}\text { [SCHWABE02] } \\
{[\text { Rossi01A] }} \\
{[\text { Rossi01B] }}\end{array}$ \\
\hline
\end{tabular}




\begin{tabular}{|c|c|c|c|c|}
\hline 'STRUCTURE' & $\begin{array}{l}\text { LIGA EL ESPACIO DE } \\
\text { NAVEGACIÓN A LOS } \\
\text { ASPECTOS EN LOS QUE } \\
\text { EL USUARIO ESTÉ } \\
\text { INTERESADO. }\end{array}$ & $\begin{array}{l}\text { AGREGACIÓN RECURSIVA } \\
\text { DE LAS CLASES DE } \\
\text { NAVEGACIÓN. } \\
\text { AGREGACIÓN SIMILAR EN } \\
\text { EL MODELO } \\
\text { CONCEPTUAL. } \\
\text { RELACIONES ENTRE ESAS } \\
\text { CLASES Y LOS OBJETOS } \\
\text { USUARIO. }\end{array}$ & $\begin{array}{c}\text { PORTALES DE } \\
\text { INFORMACIÓN (TALES } \\
\text { COMO NETSCAPE, YAHOO, } \\
\text { CNN, ETC.) } \\
\text { QUE PROVEEN } \\
\text { CARACTERÍSTICAS } \\
\text { 'MYPORTAL'. }\end{array}$ & $\begin{array}{c}\text { [SCHWABE02] } \\
{[\text { Rossi01A] }} \\
\text { [Rossi01B] }\end{array}$ \\
\hline 'BEHAVIOR' & $\begin{array}{c}\text { ADAPTA EL } \\
\text { COMPORTAMIENTO DE } \\
\text { LA APLICACIÓN AL } \\
\text { USUARIO QUE LA } \\
\text { DISPARA. }\end{array}$ & $\begin{array}{c}\text { CLASES DE NAVEGACIÓN; } \\
\text { CONTEXTOS; } \\
\text { CLASES EN CONTEXTO } \\
\text { 'INCONTEXT CLASSES'; } \\
\text { FILTROS; } \\
\text { MODELO DE USUARIO } \\
\text { EXPLÍCITO. } \\
\text { DESACOPLAMIENTO DE } \\
\text { ALGORITMOS DEL } \\
\text { MODELO DE APLICACIÓN. }\end{array}$ & $\begin{array}{c}\text { DIFERENTES } \\
\text { PROCEDIMIENTOS DE } \\
\text { COBRO EN LOS } \\
\text { ALMACENES VIRTUALES, } \\
\text { DE ACUERDO A LA } \\
\text { HISTORIA PREVIA. } \\
\\
\text { DIFERENTES ALGORITMOS } \\
\text { DE RECOMENDACIONES DE } \\
\text { ACUERDO A CADA } \\
\text { USUARIO. }\end{array}$ & [SCHWABE02] \\
\hline 'CLIENT-SIDE' & $\begin{array}{c}\text { PERMITE A UNA } \\
\text { APLICACIÓN WEB } \\
\text { PROVEER } \\
\text { INFORMACIÓN } \\
\text { PERSONALIZADA } \\
\text { DIFERENTE CUANDO ES } \\
\text { ACCEDIDA DESDE } \\
\text { SITIOS DE CLIENTE } \\
\text { DIFERENTES. }\end{array}$ & $\begin{array}{c}\text { VISTO DESDE LOS SITIOS } \\
\text { DE CLIENTE ESTE PATRÓN } \\
\text { ES SIMILAR A } \\
\text { 'STRUCTURE' Y 'LINK'; } \\
\\
\text { SIN EMBARGO DESDE EL } \\
\text { LADO DEL PROVEEDOR } \\
\text { DEL SERVICIO REFLEJA EL } \\
\text { MISMO } \\
\text { DESACOPLAMIENTO QUE } \\
\text { EL PATRÓN DE DISEÑO } \\
\text { 'OBSERVER'[GAMMA95]. }\end{array}$ & $\begin{array}{c}\text { APLICACIONES QUE } \\
\text { PROVEEN } \\
\text { PERSONALIZACIÓN } \\
\text { REMOTA, PERMITIÉNDOLE } \\
\text { A SUS CLIENTES } \\
\text { PERSONALIZAR SERVICIOS } \\
\text { (TALES COMO CNN, } \\
\text { BLOOMBERG, AMAZON, } \\
\text { ETC.) }\end{array}$ & [Rossi01A] \\
\hline 'ROLE OBJECT' & $\begin{array}{l}\text { ADAPTA UN OBJETO A } \\
\text { LAS DIFERENTES } \\
\text { NECESIDADES DEL } \\
\text { USUARIO MEDIANTE } \\
\text { LA INCORPORACIÓN DE } \\
\text { OBJETOS ROL, CADA } \\
\text { UNO REPRESENTANDO } \\
\text { UN ROL QUE EL OBJETO } \\
\text { DEBE JUGAR EN EL } \\
\text { CONTEXTO DEL } \\
\text { USUARIO. }\end{array}$ & $\begin{array}{l}\text { MODELO DE USUARIO } \\
\text { EXPLÍ́CITO CON } \\
\text { ROLES / PERFILES. } \\
\\
\text { INCORPORANDO LA } \\
\text { ESTRUCTURA DE CLASES } \\
\text { DEL 'ROLE OBJECT' EN EL } \\
\text { MODELO CONCEPTUAL. }\end{array}$ & $\begin{array}{l}\text { APLICACIONES EN LAS } \\
\text { CUALES CADA USUARIO } \\
\text { PUEDE JUGAR DIFERENTES } \\
\text { ROLES / PERFILES. }\end{array}$ & [BÄUMER00] \\
\hline
\end{tabular}

Figura 3.7: Patrones de Personalización 


\section{3 ¿Qué es un UID?}

Un 'User Interaction Diagram' (UID) [Vilain00], es una herramienta gráfica para representar la interacción entre el usuario y el sistema.

Recordar que, se denomina interacción a la actividad de comunicación que tiene lugar entre el usuario y el sistema, mediante la cual es posible identificar la información manipulada por el sistema y la funcionalidad que el sistema debe ofrecer.

Los UIDs han probado ser un instrumento sumamente efectivo para recopilar requerimientos, ya que ellos describen el intercambio de información usuario/sistema. Además, permiten trabajar en un alto grado de abstracción, ya que no toman en consideración los aspectos específicos de interfaz de usuario y los detalles de diseño. Esta técnica gráfica, retrata con claridad la información de interacción que textualmente describe el caso de uso.

\subsubsection{Aportes al modelado de aplicaciones Web}

Un diseño exitoso comienza con una recopilación de requerimientos adecuada de los usuarios y otros 'stakeholders'. Para identificar los roles/perfiles y tareas del usuario, el diseñador interactúa con el dominio para identificar los roles/perfiles que juega el usuario y las tareas que la aplicación soporta. Un usuario puede jugar varios roles/perfiles, debajo del cual intercambia información con la aplicación; para cada rol/perfil se deben identificar las tareas que la aplicación Web debe soportar [Güello0a].

La mayoría de los métodos de diseño de hipermedia (y Web) actuales, inclusive las últimas versiones del enfoque OOHDM [OOHDM00], proveen al diseñador con modelos y una notación correspondiente para especificar el diseño y la implementación de las aplicaciones. Pero en general todos estos métodos ofrecen al diseñador muy poca ayuda de cómo deberá interactuar con todos los 'stakeholders' involucrados, capturando sus requerimientos y eventualmente desarrollando el diseño actual.

Por su parte, el 'Unified Modeling Language' (UML) [UML97], visualiza la interacción como el intercambio de mensajes entre los objetos del sistema y el 'Use Case' [Jacobson94], si bien describe textualmente la interacción entre el usuario y el sistema, resulta poco eficiente en el proceso de validación con los usuarios, principalmente porque carece de precisión y síntesis.

Una notación gráfica como el 'User Interaction Diagram' (UID), no sufre las desventajas de una descripción textual, permitiendo retratar en forma concisa y altamente explícita la recopilación de requerimientos y facilitando la realimentación con los 'stakeholders' de la aplicación.

\subsubsection{Notación}

La figura3.8 incluye la notación para los diferentes tipos de información en la representación de la interacción usuario/sistema con UIDs. 


\begin{tabular}{|c|c|c|}
\hline TIPO DE INFORMACIÓN & DESCRIPCIÓN & REPRESENTACIÓN GRÁFICA \\
\hline $\begin{array}{l}\text { INTERACCIÓN } \\
\text { INICIAL }\end{array}$ & $\begin{array}{l}\text { REPRESENTA EL INICIO DE LA } \\
\text { INTERACCIÓN ENTRE EL USUARIO Y } \\
\text { EL SISTEMA. }\end{array}$ & \\
\hline INTERACCIÓN & $\begin{array}{l}\text { REPRESENTA UNA INTERACCIÓN } \\
\text { ENTRE EL USUARIO Y EL SISTEMA. } \\
\text { LA INFORMACIÓN DADA POR EL } \\
\text { USUARIO Y RETORNADA POR EL } \\
\text { SISTEMA SE MUESTRA ADENTRO DE } \\
\text { LA ELIPSIS. }\end{array}$ & \\
\hline $\begin{array}{l}\text { INTERACCIÓN } \\
\text { OPCIONAL }\end{array}$ & $\begin{array}{l}\text { REPRESENTA UNA INTERACCIÓN QUE } \\
\text { DEPENDE DE LA INTERACCIÓN } \\
\text { PREVIA. } \\
\text { DE ACUERDO CON EL RESULTADO DE } \\
\text { LA INTERACCIÓN PREVIA, ESTA } \\
\text { INTERACCIÓN PUEDE O NO OCURRIR. } \\
\text { SI NO OCURRE, LA SALIDA DE LA } \\
\text { INTERACCIÓN PREVIA SERÁ } \\
\text { DIRECTAMENTE LA ENTRADA DE LA } \\
\text { SIGUIENTE INTERACCIÓN. }\end{array}$ & 1 \\
\hline $\begin{array}{l}\text { INTERACCIONES } \\
\text { ALTERNATIVAS }\end{array}$ & $\begin{array}{c}\text { ESTA REPRESENTACIÓN ES USADA } \\
\text { CUANDO EXISTEN DOS SALIDAS } \\
\text { ALTERNATIVAS DESDE UNA } \\
\text { INTERACCIÓN. } \\
\text { LA INTERACCIÓN SUBSECUENTE } \\
\text { DEPENDE DE LOS ELEMENTOS U } \\
\text { OPERACIÓN SELECCIONADOS POR EL } \\
\text { USUARIO. }\end{array}$ & \\
\hline $\begin{array}{l}\text { ENTRADA } \\
\text { DE } \\
\text { DATOS }\end{array}$ & $\begin{array}{l}\text { REPRESENTA DATOS OBLIGATORIOS } \\
\text { INGRESADOS POR EL USUARIO. }\end{array}$ & \\
\hline $\begin{array}{c}\text { ENTRADA } \\
\text { OPCIONAL } \\
\text { DE } \\
\text { DATOS }\end{array}$ & $\begin{array}{l}\text { REPRESENTA DATOS OPCIONALES } \\
\text { INGRESADOS POR EL USUARIO. }\end{array}$ & $\begin{array}{l}1--------\frac{1}{1} \\
1---------1\end{array}$ \\
\hline $\begin{array}{c}\text { ELEMENTO } \\
\text { Y SUS } \\
\text { ITEMS DE DATOS }\end{array}$ & $\begin{array}{l}\text { REPRESENTA UN ELEMENTO Y SUS } \\
\text { ÍTEM DE DATOS. } \\
\text { LOS ÍTEM DE DATOS SON } \\
\text { OPCIONALES. }\end{array}$ & ELEMENTO( ÍTEM DE DATOS ) \\
\hline
\end{tabular}




\begin{tabular}{|c|c|c|}
\hline $\begin{array}{l}\text { CONJUNTO } \\
\text { DE } \\
\text { ELEMENTO }\end{array}$ & $\begin{array}{c}\text { REPRESENTA UN CONJUNTO DE } \\
\text { ELEMENTO. } \\
\text { LOS ÍTEM DE DATOS ASOCIADOS AL } \\
\text { ELEMENTO SON TAMBIÉN } \\
\text { PRESENTADOS. }\end{array}$ & ... ElEMENTO( ÍTEM dE DATOS ) \\
\hline $\begin{array}{l}\text { ELEMENTO } \\
\text { ESPECÍFICO }\end{array}$ & $\begin{array}{l}\text { REPRESENTA EL ELEMENTO } \\
\text { ESPECÍFICO SELECCIONADO O } \\
\text { INGRESADO POR EL USUARIO EN LA } \\
\text { INTERACCIÓN PREVIA. }\end{array}$ & ELEMENTO $\mathrm{X}$ \\
\hline TеXто & $\begin{array}{c}\text { REPRESENTA ALGUNOS DATOS } \\
\text { ADICIONALES QUE PARTICIPAN DE LA } \\
\text { INTERACCIÓN. }\end{array}$ & XXXX \\
\hline $\begin{array}{c}\text { TEXTO } \\
\text { OPCIONAL }\end{array}$ & $\begin{array}{l}\text { REPRESENTA ALGUNOS DATOS } \\
\text { OPCIONALES QUE PARTICIPAN DE LA } \\
\text { INTERACCIÓN. }\end{array}$ & $\mathbf{X X X X} *$ \\
\hline $\begin{array}{c}\text { NUEVA } \\
\text { INTERACCIÓN }\end{array}$ & $\begin{array}{l}\text { REPRESENTA UNA NUEVA } \\
\text { INTERACCIÓN QUE OCURRE DESPUÉS } \\
\text { DE QUE EL USUARIO HA INGRESADO } \\
\text { LOS DATOS Y EL SISTEMA HA } \\
\text { RETORNADO OTRA INFORMACIÓN EN } \\
\text { LA INTERACCIÓN PREVIA. }\end{array}$ & \\
\hline $\begin{array}{c}\text { SELECCIÓN DE } \\
\text { N ELEMENTOS } \\
\text { Y } \\
\text { NUEVA } \\
\text { INTERACCIÓN }\end{array}$ & $\begin{array}{l}\text { REPRESENTA QUE PREVIO A LA } \\
\text { NUEVA INTERACCIÓN, } \\
\text { N ELEMENTOS } \\
\text { DEBEN SER SELECCIONADOS. }\end{array}$ & $\mathbf{N}$ \\
\hline $\begin{array}{l}\text { INVOCACIÓN DE LA } \\
\text { OPERACIÓN Z } \\
\text { Y } \\
\text { NUEVA } \\
\text { INTERACCIÓN }\end{array}$ & $\begin{array}{l}\text { REPRESENTA QUE PREVIO A LA } \\
\text { NUEVA INTERACCIÓN, } \\
\text { LA OPERACIÓN Z } \\
\text { DEBE SER INVOCADA. }\end{array}$ & $(\mathrm{Z})$ \\
\hline $\begin{array}{c}\text { SELECCIÓN DE } \\
\text { N ELEMENTOS } \\
\text { E } \\
\text { INVOCACIÓN DE LA } \\
\text { OPERACIÓN Z } \\
\text { Y } \\
\text { NUEVA } \\
\text { INTERACCIÓN }\end{array}$ & $\begin{array}{c}\text { REPRESENTA QUE PREVIO A LA } \\
\text { NUEVA INTERACCIÓN, } \\
\text { N ELEMENTOS } \\
\text { DEBEN SER SELECCIONADOS } \\
\text { Y LA OPERACIÓN Z } \\
\text { DEBE SER INVOCADA }\end{array}$ & $\mathbf{N}(\mathbf{Z})$ \\
\hline
\end{tabular}




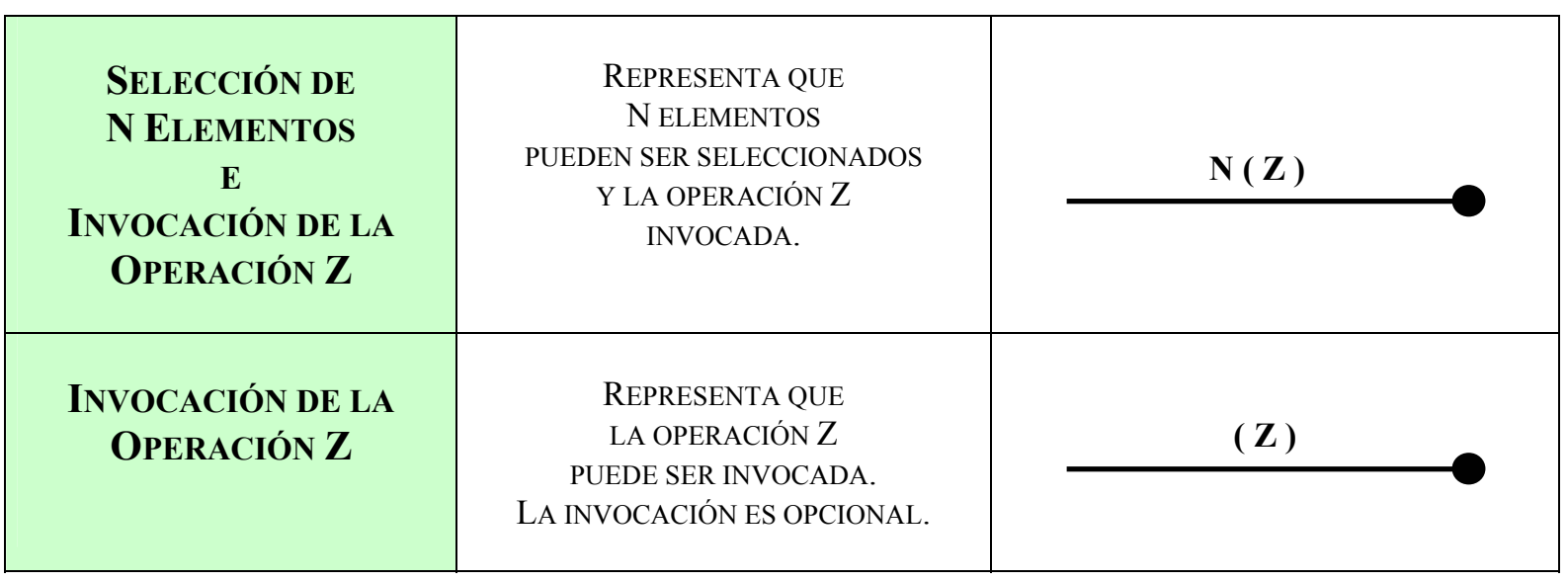

Figura 3.8: 'User Interaction Diagram' - Notación -

Es importante destacar, que con posterioridad a la utilización de los UIDs en esta tesis, la notación de esta herramienta gráfica evolucionó, incrementando su expresividad y por lo tanto facilitando la representación de la interacción usuario/sistema [Vilain02].

\subsection{Herramientas de diseño y reingeniería}

Las herramientas de diseño citadas en este capítulo, facilitan la manipulación de la complejidad inherente a las aplicaciones Web. Cada una en su terreno, ha demostrado exitosamente su eficacia, dando respuesta a las exigencias que demanda la nueva generación de aplicaciones Web.

Hoy nadie puede dudar de la necesidad de diseñar aplicando sistemáticamente los principios de la ingeniería de software y de la ingeniería de Web (capítulo2, ítem2.3), en pos de que las aplicaciones resultantes tengan chance de ser fácilmente mantenidas y modificadas. Pero la herencia existe y de un tiempo a esta parte, la realidad nos ha estado enfrentando a toda una generación de aplicaciones 'legacies' (capítulo2 ítem2.4), coexistiendo con la nueva generación de aplicaciones Web.

Afrontar esta problemática, ha forzado y sigue forzando al desarrollo de nuevos enfoques sistemáticos que provean herramientas de rediseño. Dentro de este contexto, la reingeniería es protagónica y cobra día a día renovada vigencia. 


\section{Capítulo 4}

\section{REINGENIERÍA}

\section{1 ¿Qué es reingeniería?}

El término reingeniería fue acuñado en 1993 por Michael Hammer y James Champy cuando presentan el 'Bussiness Process Reengineering' (BPR) en su libro 'Reengineering the Corporation'. Rápidamente, se volvió el tema más popular en las conferencias sobre gestión de negocios y diseño de sistemas de información, convirtiéndose con el pasar del tiempo, en un concepto clave y cada vez más vigente. En este libro, Hammer y Champy definieron a la reingeniería como [Umar94]:

"the fundamental rethinking and radical redesign of business processes to achieve dramatic improvements in critical, contemporary measures of performance, such as cost, quality, service and speed"

Claramente, la definición articula un mensaje que le permite al lector entender no solamente el significado y la importancia de la reingeniería, sino que también, la razón por la cual la reingeniería sigue siendo hoy, tema de extraordinaria actualidad. Esta definición tiene como protagonistas las siguientes palabras, claves en la comprensión de la naturaleza de la reingeniería:

- 'fundamental': la reingeniería es fundamental en la medida que sea necesario preguntar sobre las cuestiones más básicas de la compañía y cómo opera. Antes de pensar en lo que se está haciendo (o lo que se está haciendo mal), se debe advertir porque se está haciendo. Muy a menudo, el esfuerzo se agota en arreglar procesos sin pensar en primer lugar porqué el proceso está allí, y lo que es más importante, si después de todo, necesita estar allí.

- 'radical': contrario al sentido habitual, radical no significa que la reingeniería deba ser revolucionaria o violenta, sino que hace alusión a enfocar la atención en la raíz de los problemas, como fuente de reconstrucción de los procesos.

- 'dramatic': la reingeniería se trata de mejoras dramáticas, es decir la reingeniería es requerida cuando se necesitan mejoras sustanciales. Las mejoras marginales o de alcance modesto, no requieren reingeniería (capítulo4, ítem 4.2).

- 'process': la reingeniería es acerca de procesos, ya que el rediseño de procesos dirige los esfuerzos de reingeniería.

- 'redesign': normalmente esta palabra se asocia directamente a un proceso de reingeniería, y significa la posibilidad de centrar los esfuerzos en volver a diseñar los procesos claves para el rendimiento de la compañía.

La definición tradicional de reingeniería, se puede extender agregando [BA00]:

“... by leveraging proven models of process, organization, and technology to dramatically improve the pace of change and to compress the time to achieve measurable business results"

En esta extensión de la definición tradicional, destacamos las siguientes palabras claves:

- 'leverage': es esencial promover las mejores prácticas (modelos de proceso, organización y tecnología) y usarlas como punto de lanzamiento para avanzar y obtener ventaja estratégica de la organización.

- 'pace': el esfuerzo de reingeniería debe mantener un paso rápido y producir continuamente resultados para tener éxito. Los esfuerzos que llevan un ritmo demasiado lento fracasan, ya que 
a medida que el entusiasmo decrece la resistencia crece, y la iniciativa inicial de urgencia es reemplaza por indecisión y segundas intenciones.

- 'results': el objetivo de todo esfuerzo de reingeniería es entregar resultados mensurables. Es preciso alcanzar un balance entre entender los procesos existentes y avanzar con nuevos diseños, ya que sin este balance la organización pierde de vista su objetivo: los resultados.

Cuando nos referimos a la reingeniería, surge un vínculo inevitable al enfoque de Ivar Jacobson [Jacobson94], que anexa al BPR las ventajas de la tecnología OO (capítulo4, ítem4.3). En esta tesis utilizaremos los principios de este enfoque.

\subsection{Ingeniería, reingeniería y mejoras}

La ingeniería se puede considerar como un concepto que engloba a los otros dos conceptos: reingeniería y mejoras. Para ponerlo de una manera simple y clara, se puede decir que [Jacobson94]:

\section{"Business Engineering" = Business Reengineering + Business Improvement"}

Como ya señalamos, la reingeniería implica lograr un panorama comprensivo de la totalidad del negocio existente y pensar en porqué, qué y cómo se hacen en él las cosas, para tratar de encontrar mejores formas de reconstruirlo.

Por su parte, las mejoras tienen un efecto de mantenimiento con objetivos de alcance más modesto, y el trabajo requerido para concretarlos, no tiene una influencia dramática sobre el rendimiento de la compañía.

La figura4.1 muestra como se relacionan y complementan ambos procesos dentro de un proceso continuo para el desarrollo del negocio [Jacobson94].

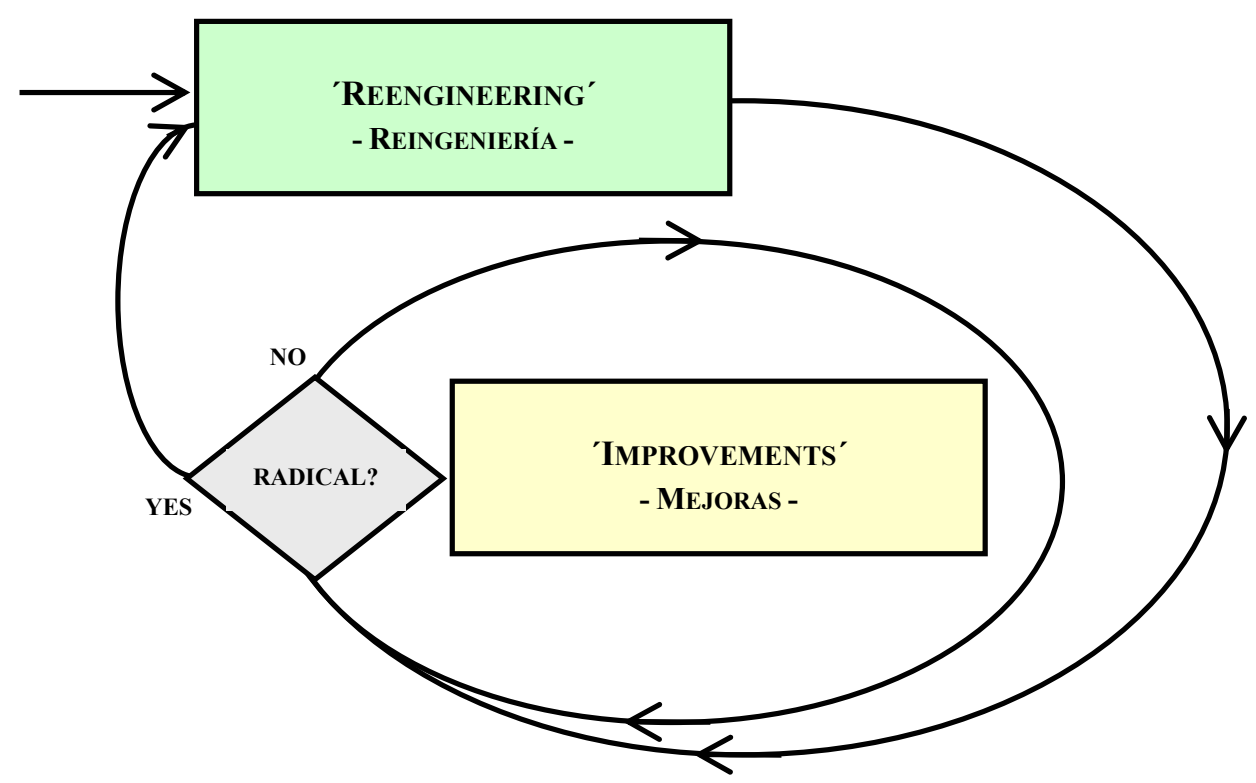

Figura 4.1: Reingeniería y Mejoras

\subsection{Síntesis del enfoque Jacobson}

Un proyecto de reingeniería usualmente se describe como compuesto por cuatro actividades primarias, denominadas: Desarrollo de la imagen (o visión) del negocio; Comprensión del negocio existente; Diseño del negocio nuevo e Instalación del negocio nuevo. 
La figura42. presenta de una manera muy simplificada estas cuatro actividades básicas [Jacobson94].

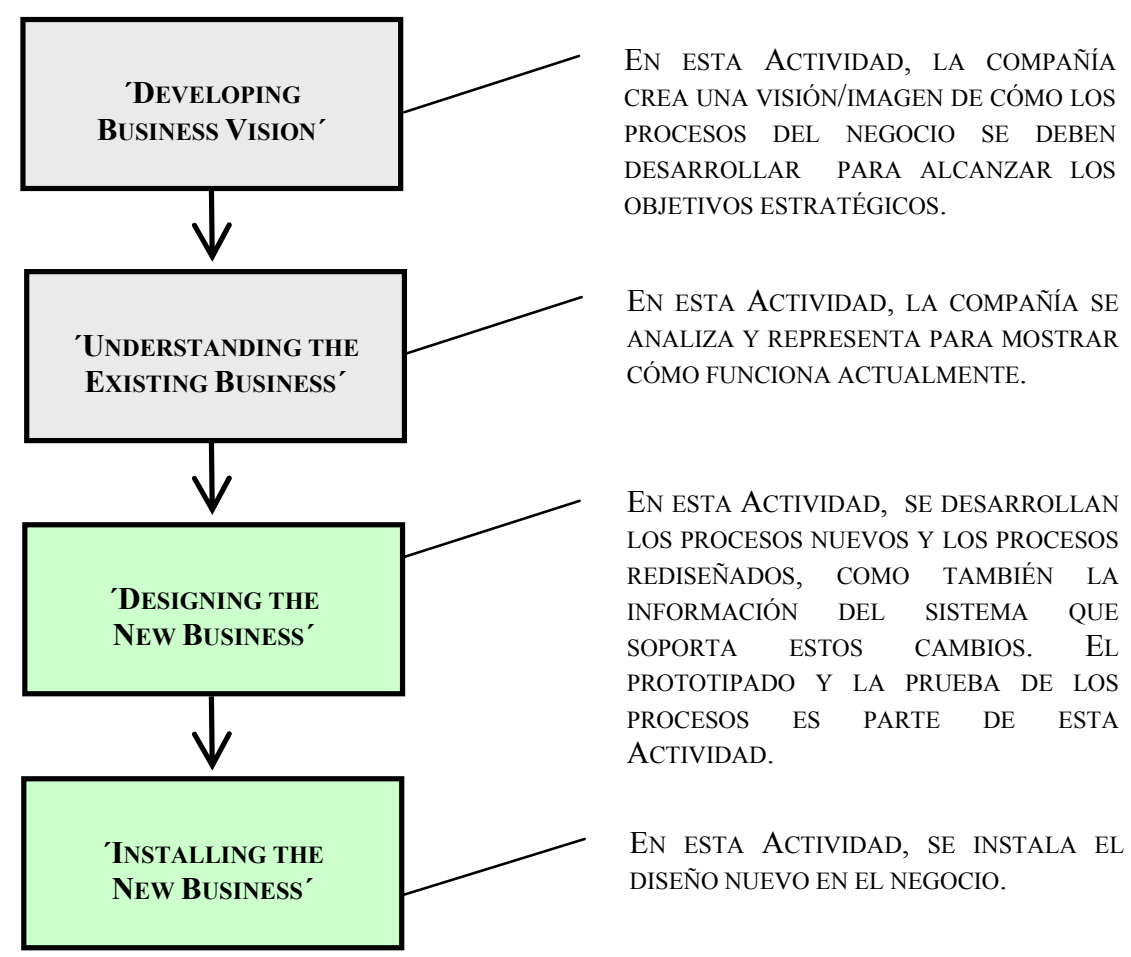

Figura 4.2: Un proyecto de reingeniería - bosquejo simplificado -

Pero este modelo es demasiado simple, ya que en realidad el orden de estas actividades no es secuencial: en parte son paralelas y en parte son iterativas. La reingeniería consiste de dos procesos principales: Ingeniería en Reversa de la compañía existente e Ingeniería 'Forward' de la nueva compañía. De una manera intuitiva, se puede expresar de la siguiente manera [Jacobson94]:

\section{"Business Reengineering = Reverse Business Engineering + Forward Business Engineering"}

\section{( 1 )}

( 1 ) Actividad que permite entender la compañía existente; esto implica hacer un modelo abstracto del negocio y los procesos a rediseñar.

( 2 ) Actividad que permite diseñar la nueva compañía.

La figura4.3 muestra estas actividades [Jacobson94].

Un proyecto de reingeniería puede iniciar de maneras distintas y en situaciones diferentes. En este enfoque, se considera que un proyecto de reingeniería comienza en repuesta a una Directiva de Reingeniería, la cual explica porqué se lleva a cabo y qué debe alcanzar el proyecto. Esta directiva dispara a su vez una actividad denominada 'Envisioning' que produce y entrega una visión del nuevo negocio o de los nuevos procesos en el negocio en un documento denominado 'Objective Specification' [Jacobson94]. 


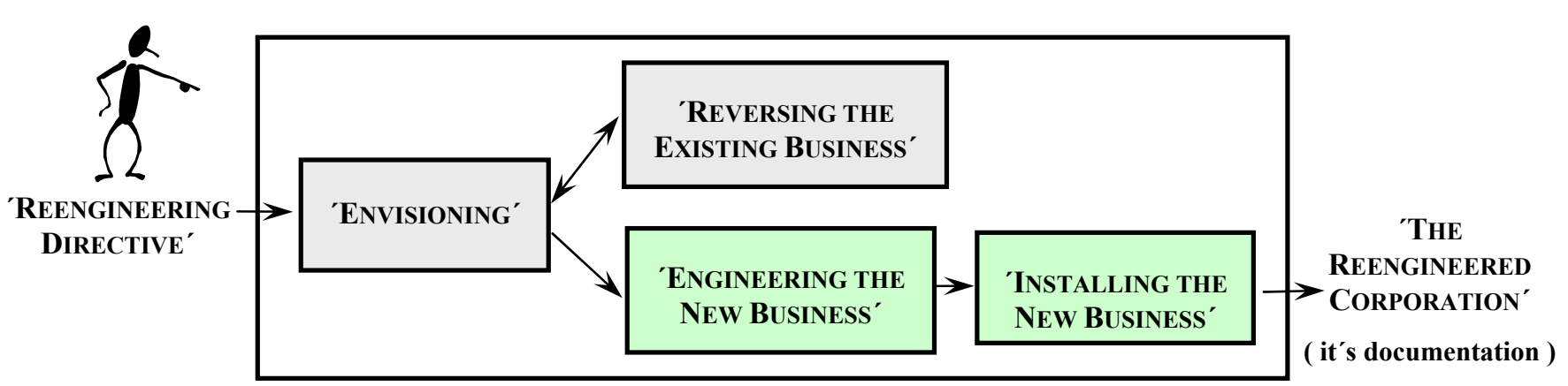

Figura 4.3: Proyecto de reingeniería: Vista de sus actividades

En ambas actividades - ingeniería en reversa e ingeniería 'forward' - se construyen dos tipos de modelos: Externo e Interno. El modelo externo, como su nombre lo indica, describe el negocio y el mundo externo a él, es decir describe los procesos de la compañía que satisfacen los intereses de los clientes y los intereses de otros externos al negocio. La interacción entre cada proceso y su entorno es vital en este modelo. Debido a que el constructor de procesos es el 'use case', el modelo externo describirá los casos de uso del negocio. Este enfoque denomina al modelo externo 'Use-Case Model'. Por su parte, el modelo interno describe cada proceso del negocio: cómo están construidos para las diferentes tareas de trabajo (procesos internos) y los distintos tipos de recursos que ellos explotan o producen. El negocio puede estar estructurado en sub-negocios (funciones). Este enfoque denomina al modelo interno 'Object Model' [Jacobson94].

Es importante destacar que al desarrollar un modelo objeto para el negocio, se pueden incluir o excluir todas aquellas consideraciones referidas al modelo llevado a la práctica. Cada una de estas ópticas definen dos tipos de modelos internos: Ideal y Real [Jacobson94]. El modelo ideal de la aplicación enfoca sus esfuerzos en atender los requerimientos funcionales derivados de la directiva de reingeniería. El modelo real de la aplicación, no solo considera dichos requerimientos funcionales sino que se esfuerza por conciliarlos con los requerimientos no funcionales, es decir adaptar el modelo a todos aquellos factores técnicos, económicos, legales, etc., que hacen a la viabilidad del mismo, denominados restricciones de implementación del modelo.

Dado que la actividad de implementación esta fuera del alcance de esta tesis, utilizaremos el modelo objeto de la aplicación para representar el modelo interno ideal de la misma.

\subsubsection{Búsqueda de modelo actual: Ingeniería en reversa}

Para poder cambiar algo, es necesario conocer la situación actual. Este trabajo de adquirir una comprensión de cómo opera hoy el negocio recibe el nombre de 'Reverse Business Engineering'. La ingeniería en reversa implica obtener un modelo de la compañía existente (cuando no se dispone de él), el cual se usará como base para el trabajo de rediseño en la actividad de ingeniería 'forward' de la compañía.

La figura4.4 grafica la ingeniería en reversa y sus dos principales actividades de modelado, denominadas [Jacobson94]: 
- 'Use-Case Modelling': para producir y describir un modelo de proceso del negocio existente en términos de actores y casos de uso. Llamamos a este modelo una imagen (o visión) externa de la compañía.

- 'Object Modelling': para producir un modelo objeto del negocio existente. Este modelo tiene el propósito de proveer una imagen interna de cómo el negocio existente opera.

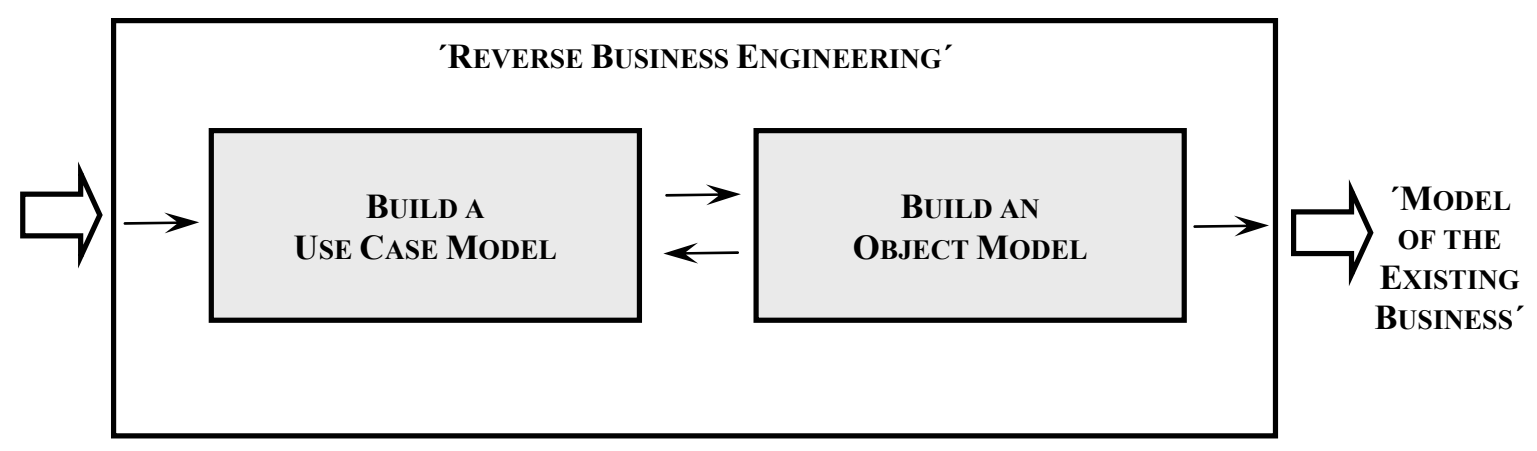

Figura 4.4: Ingeniería en reversa del negocio existente

\subsubsection{Diseño del nuevo modelo: Ingeniería 'forward'}

Durante la actividad de 'Envisioning', se identifican los procesos existentes que necesitan reingeniería. Los objetivos para el nuevo negocio se expresan en términos de estos procesos en la 'Objective Specification'. Este es el momento de descubrir cómo los nuevos objetivos afectarán al negocio existente y determinar la forma más apropiada de mejorar y optimizar los procesos seleccionados. Aquí comienza el verdadero trabajo de desarrollo que recibe el nombre de 'Forward Business Engineering'.

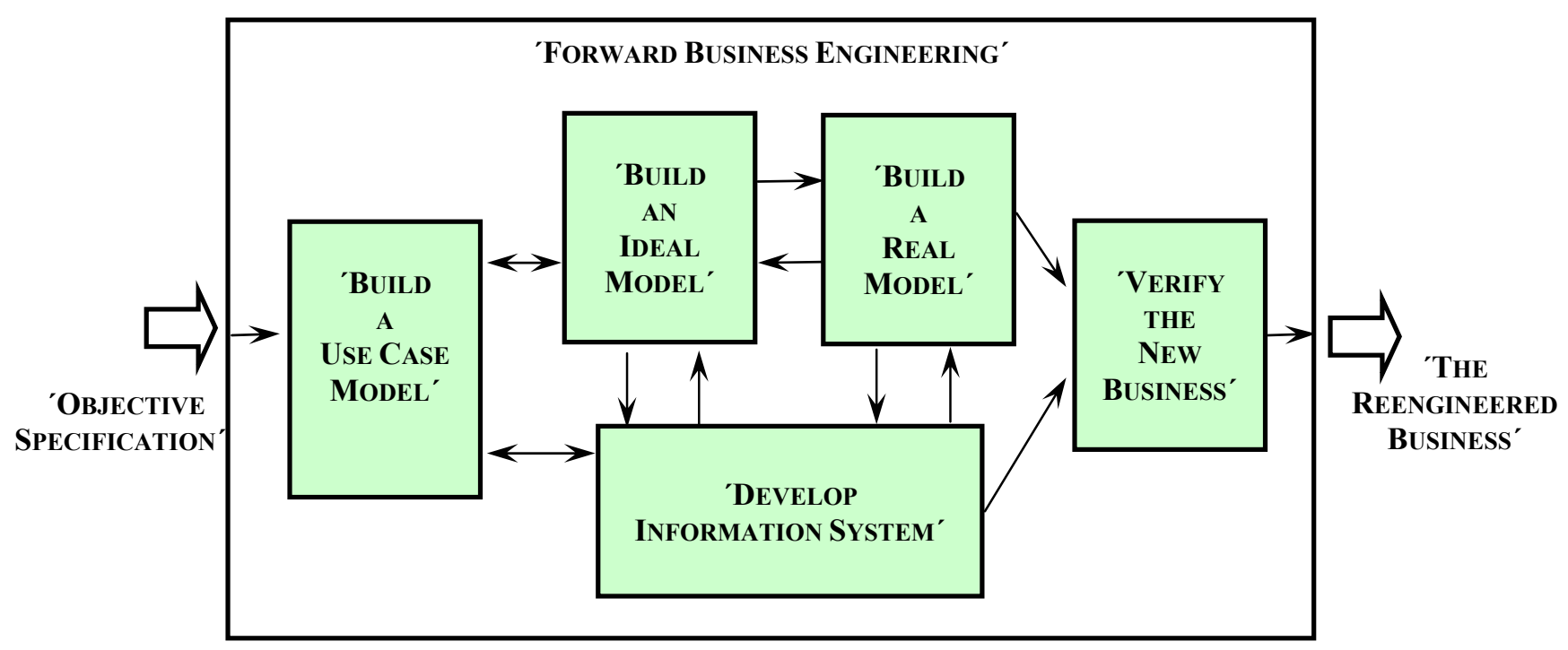

Figura 4.5: Ingeniería 'forward' del nuevo negocio

La figura4.5 grafica la ingeniería 'forward' y sus cinco actividades de modelado, denominadas [Jacobson94]: 
- 'Build a Use-Case Model': este modelo es una imagen (o visión) externa de la nueva compañía. Los casos de uso capturan los procesos en el nuevo negocio.

- 'Build an Ideal Model': este modelo es una imagen (o visión) interna de la nueva compañía. Describe la compañía en términos de objetos que se comunican y captura cómo esos objetos interactúan para realizar casos de uso.

- 'Buid a Real Model': este modelo implica adaptar el modelo ideal a las restricciones halladas en el negocio, y construir un modelo objeto real del negocio.

- 'Develop an Information System': esta actividad significa crear el soporte IT para los procesos en el nuevo negocio.

- 'Verify the New Business': antes de que los modelos a gran escala se instalen en el negocio, estos se deben probar a menor escala.

\section{4 ¿Por qué reingeniería de Jacobson?}

Ivar Jacobson es bien conocido por ser pionero en combinar el 'Business Process Reengineering' (BPR) con técnicas de diseño 'Object-Oriented'. Su libro 'The Object Advantage: Business Process Reengineering with Object Technology' [Jacobson94], describe como se puede, en la práctica, rediseñar un negocio de acuerdo con las ideas del BPR incorporando las ventajas de la tecnología OO. Esta técnica de reingeniería se basa en 'use cases' y se sostiene en las siguientes ideas fundamentales [Jacobson94]:

- Los casos de uso son simples, una forma natural de identificar los procesos en el negocio. Un cliente es un usuario de una compañía, y él o ella usan la compañía a través de un proceso del negocio.

- La orientación a objetos es una forma excelente de clarificar el trabajo interno de la compañía - sus procesos, productos, servicios, recursos - y cómo todos estos componentes dependen unos de otros.

- El modelo del negocio de la compañía rediseñada y el modelo de requerimientos para el sistema de información deben estar en armonía. Esto se obtiene apareando ingeniería de negocios $\mathrm{OO}$ con ingeniería de software OO.

Debido a que este enfoque ha resultado muy adecuado para el desarrollo de esta tesis, lo hemos seleccionado como el referente de reingeniería. Los motivos son varios, desde los más obvios - tales como la presencia en dicho enfoque de la OO - hasta la visión desde la cual encausa el desafío del rediseño - considerando a los clientes como usuarios del negocio y por lo tanto evaluando el éxito de dicho rediseño en función de la utilidad que brinda la compañía a estos usuarios -.

Por su parte, con la tecnología OO como base y los usuarios como protagonistas, esta tesis propone un enfoque para la reingeniería de personalización de aplicaciones Web. 


\section{Capítulo 5}

\section{NUESTRO ENFOQUE}

\subsection{Un proyecto de reingeniería para la personalización de una aplicación Web}

Nuestro enfoque consiste en asociar los fundamentos de reingeniería [Jacobson94] a los de diseño de aplicaciones Web personalizadas [Rossi01b, 01c], [Schwabe02] y [Bäumer00] en un enfoque que se pueda aplicar a la problemática de rediseño de aplicaciones Web para su personalización. Es importante destacar que para construir este enfoque, también se utilizan los aportes al diseño de aplicaciones Web de: el método OOHDM [Schwabe98a] y [OOHDM00]; los patrones de hipermedia, [Garrido97], [Rossi99a, 99b, 99d, 00]; los patrones de personalización [Rossi01a, 01b], [Schwabe02] y [Bäumer00]; y la herramienta UID [Vilain00].

Con el propósito de contribuir a la claridad de esta tesis, separamos el enfoque (capítulo5) de la aplicación del enfoque (capítulo6). En este capítulo5, solamente se incluyen ejemplos simples, cuando se considera que pueden ilustrar aportando a la comprensión del enfoque.

Nuestro proceso de reingeniería para personalizar una aplicación Web, considera las siguientes actividades:

Actividad 1: extraer el diseño actual de la aplicación Web no personalizada

Ingeniería en reversa $\rightarrow$ Modelo de la aplicación Web existente

Actividad 2: rediseñar la aplicación Web para personalizarla

Ingeniería 'forward' de Personalización $\rightarrow$ Modelo de la aplicación Web personalizada

Aplicando los conceptos tal cual son, se puede decir que (ver Reingeniería, capítulo4):

Reingeniería de Personalización Figura $5.1=$

(3)

Ingeniería en reversa + Ingeniería 'forward' de Personalización

(1)

(2)

(1) Actividad que consiste en aplicar ingeniería en reversa a la aplicación Web existente para obtener su modelo actual.

(2) Actividad que consiste en aplicar ingeniería 'forward' de personalización a la aplicación Web existente para obtener la nueva aplicación Web personalizada.

(3) Actividad que aplica reingeniería de personalización para convertir una aplicación Web existente no personalizada en una aplicación Web personalizada, dada una Directiva de Reingeniería de Personalización. 


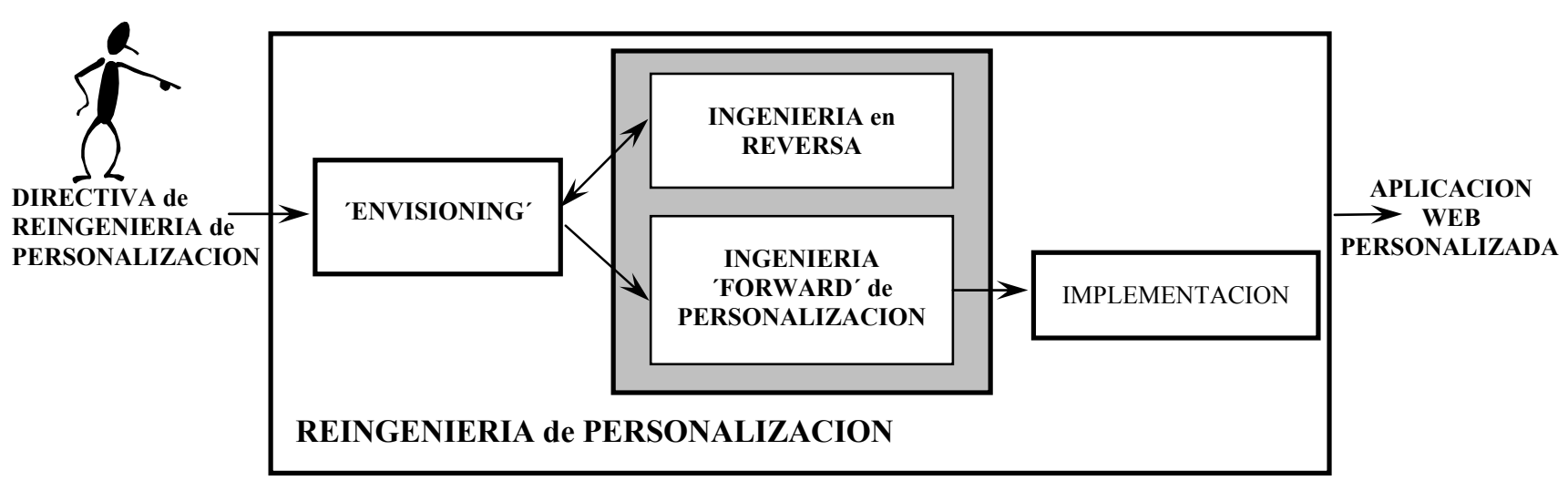

Figura 5.1: Reingeniería de Personalización: Vista de sus actividades

Nota: En el gráfico, el área sombreada en gris representa las actividades sobre las cuales se enfocará el esfuerzo de este trabajo. La actividad de implementación está fuera del alcance de este trabajo.

Ahora bien, un proceso de ingeniería, ya sea en reversa o 'forward', necesita producir dos tipos de modelos: externo e interno [Jacobson94], (capítulo4). Es posible extender estos conceptos a la reingeniería de aplicaciones Web:

Modelo de la aplicación Web $\rightarrow$

Modelo externo de la aplicación Web + Modelo interno de la aplicación Web

El modelo externo de la aplicación Web se encarga de identificar y describir, tal cual son, las tareas que la aplicación soporta para satisfacer los intereses de los usuarios. La función que cumple la interfaz de ligar dichas tareas con su entorno, es vital en este modelo. Para la construcción del modelo externo de la aplicación usaremos un Modelo Caso de Uso, recreado a partir del 'Use-case model' [Jacobson94].

El modelo interno de la aplicación Web se encarga de especificar cada una de las tareas, identificadas y descriptas por el modelo caso de uso de dicha aplicación, detallando sus respectivas operaciones internas con los recursos que explotan o producen. Para la construcción del modelo interno de la aplicación usaremos un Modelo Objeto, aplicando el enfoque OOHDM [Schwabe98a] y [OOHDM00].

Obviamente, ambos modelos de la aplicación Web deben ser consistentes, cada 'QUE' presente en el modelo externo debe tener su correspondiente 'COMO' en el modelo interno.

\subsection{Características deseadas en la nueva aplicación Web personalizada: directiva de reingeniería}

La directiva de reingeniería es el disparador del proceso de reingeniería [Jacobson94] y resulta vital en la definición de las características deseadas para la nueva aplicación Web personalizada. Las propiedades que debe exhibir la directiva de reingeniería para la personalización de una aplicación Web son: expresar en un lenguaje concreto y conciso el objetivo de aplicar reingeniería de personalización a dicha aplicación Web.

Apuntando a obtener una directiva con estas propiedades, resulta indispensable considerar en la elaboración de la misma, cuestiones tales como:

- El entorno de la aplicación Web: ¿cuáles son los tipos de usuarios y las aplicaciones Web competidoras?

- Las expectativas de los usuarios de la aplicación Web: ¿qué necesidades hay que satisfacer?

- La presencia de las aplicaciones Web competidoras: ¿cómo responden a las necesidades de sus usuarios? 
En la formulación de esta directiva deben trabajar conjuntamente un representante del ente o negocio propietario de la aplicación Web y el responsable de la ejecución del proyecto (o un representante, si se trata de un equipo de trabajo).

La convicción de que un cambio es necesario y una directiva de reingeniería como entrada, dan inicio al proceso de reingeniería con la actividad de 'envisioning'.

\section{3 'Envisioning': hacia una especificación objetiva}

Esta actividad tiene como misión producir una visión de la nueva aplicación Web personalizada y formularla en términos de una especificación objetiva.

Si bien no es factible formalizar esta tarea, si lo es, adaptar las pautas propuestas en [Jacobson94], al entorno de las aplicaciones Web, para que permitan guiar el desarrollo de la actividad de 'envisioning' y chequear la coherencia de la visión resultante para la nueva aplicación Web personalizada.

Proponemos adaptar las pautas señaladas al entorno de las aplicaciones Web de la siguiente manera Figura 5.2.

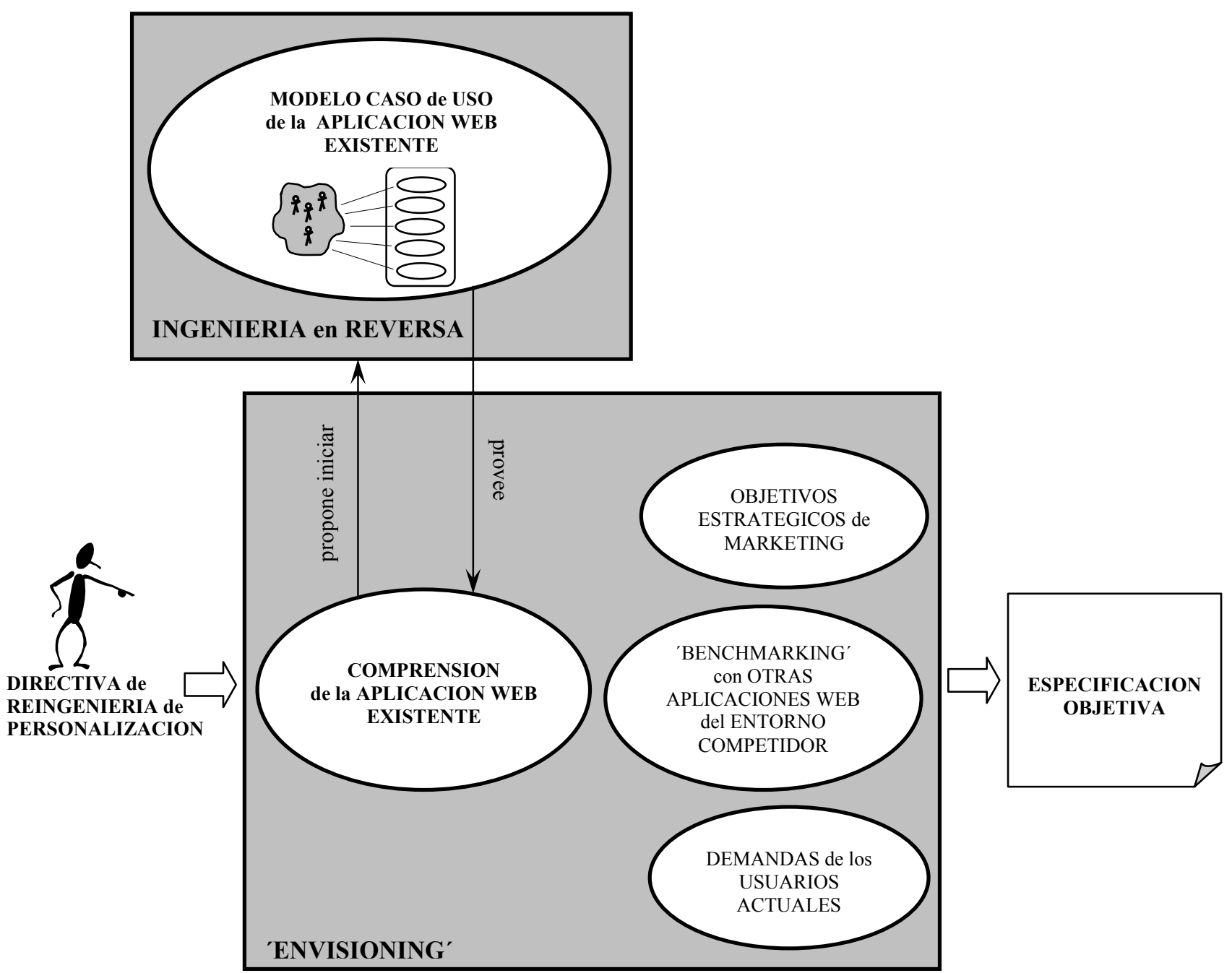

Figura 5.2: 'Envisioning': Detalle de la actividad en su contexto

- Comprender la aplicación Web existente. El conocimiento de la aplicación Web existente es fundamental para especificar la nueva aplicación Web personalizada. En este punto, si no se dispone de este conocimiento, proponemos iniciar el proceso de ingeniería en reversa hasta alcanzar el Modelo Caso de Uso de la aplicación. Este modelo provee una 
buena descripción general de la aplicación y su entorno, muy adecuada al propósito de adquirir la comprensión requerida por la actividad de 'envisioning'.

- Verificar que los objetivos estratégicos de marketing establecidos para la aplicación Web existente por el ente o negocio, sean concordantes con los precisados para la nueva aplicación Web personalizada. Un proceso de reingeniería implica cambios que van más allá de una simple mejora. Obviamente la coherencia entre objetivos se torna indispensable, los objetivos planteados para la nueva aplicación, deben reforzar y complementar los objetivos iniciales, nunca contraponerse.

- Entrevistar los usuarios actuales de la aplicación Web existente para que la nueva aplicación Web personalizada mejore la satisfacción de los mismos. Los usuarios son los destinatarios del esfuerzo del proceso de reingeniería de aplicaciones Web. Es fundamental identificar los tipos de usuarios que hacen uso de la aplicación e indagar sus expectativas presentes y de ser posible futuras, a los efectos de descubrir demandas actualmente insatisfechas.

- Comparar la aplicación Web existente con otras aplicaciones del entorno competidor en términos de 'benchmarking'. Esta técnica permite el análisis e intercambio de conocimiento con lo mejor de otras aplicaciones Web pertenecientes al entorno competidor. El objetivo es descubrir virtudes y falencias de nuestra aplicación que contribuyan a definir los cambios que debe implementar el proceso de reingeniería de personalización de la aplicación Web existente.

\subsection{Ingeniería en reversa}

Para que sea posible modificar o cambiar algo en una entidad, es requisito indispensable tener conocimiento del estado actual de esa entidad, es decir, cuál es su situación y cómo opera hoy. Este principio es aplicable al proceso de reingeniería de personalización de aplicaciones Web: comprender la aplicación Web existente, especificar la nueva aplicación Web personalizada y conjuntamente con el modelo de la aplicación Web existente iniciar el proceso de rediseño.

Aplicando ingeniería en reversa es posible lograr esta comprensión y plasmar el conocimiento obtenido en el modelo de la aplicación Web existente. Así, el modelo actual junto a la especificación objetiva, resultante de la actividad de 'envisioning' Figura 5.2, formarán la base para el trabajo posterior de ingeniería 'forward' de personalización de la aplicación Web.

Ahora bien, las características propias de una aplicación Web, determinan la necesidad de definir un proceso de ingeniería en reversa que se ajuste a estas peculiaridades. En tal sentido, el enfoque OOHDM [Schwabe98a] y [OOHDM00], (ver OOHDM, capítulo3), es un método desarrollado para construir aplicaciones Web (sitios, sistemas de información, kioscos interactivos, presentaciones de multimedia, etc.). Esta especialmente pensado para tratar con las complejas particularidades que caracterizan a estas aplicaciones. El método se compone de cuatro pasos, cada uno de los cuales lleva a cabo una actividad que enfoca su atención en un asunto de diseño particular, produciendo como resultado un modelo orientado a objetos:

Aplicación Web deseada

$\Rightarrow$ Modelo Conceptual $\Leftrightarrow$ Modelo de Navegación $\Leftrightarrow$ Modelo de Interfaz $\Leftrightarrow$ Implementación $\Rightarrow$ Aplicación Web corriendo

Nota: El Modelo de Interfaz y la Implementación están fuera del alcance de este trabajo. Los esfuerzos se enfocan en los modelos Conceptual y de Navegación, ya que son claves en el proceso de personalización de una aplicación Web.-

Volviendo al objetivo inicial de obtener el modelo de una aplicación existente, proponemos utilizar OOHDM para especializar los conceptos básicos de la ingeniería en reversa: 
Aplicación Web existente

\section{$\Rightarrow$ Ingeniería en reversa + Enfoque OOHDM}

$\Rightarrow$ Modelo de la aplicación Web existente

\subsubsection{Actividad en reversa}

La propuesta de aunar los conceptos de ingeniería en reversa y el enfoque OOHDM, se plasma en el siguiente procedimiento, cuya descripción indica paso a paso la actividad a desarrollar para obtener el modelo de la aplicación Web existente Figura 5.3.

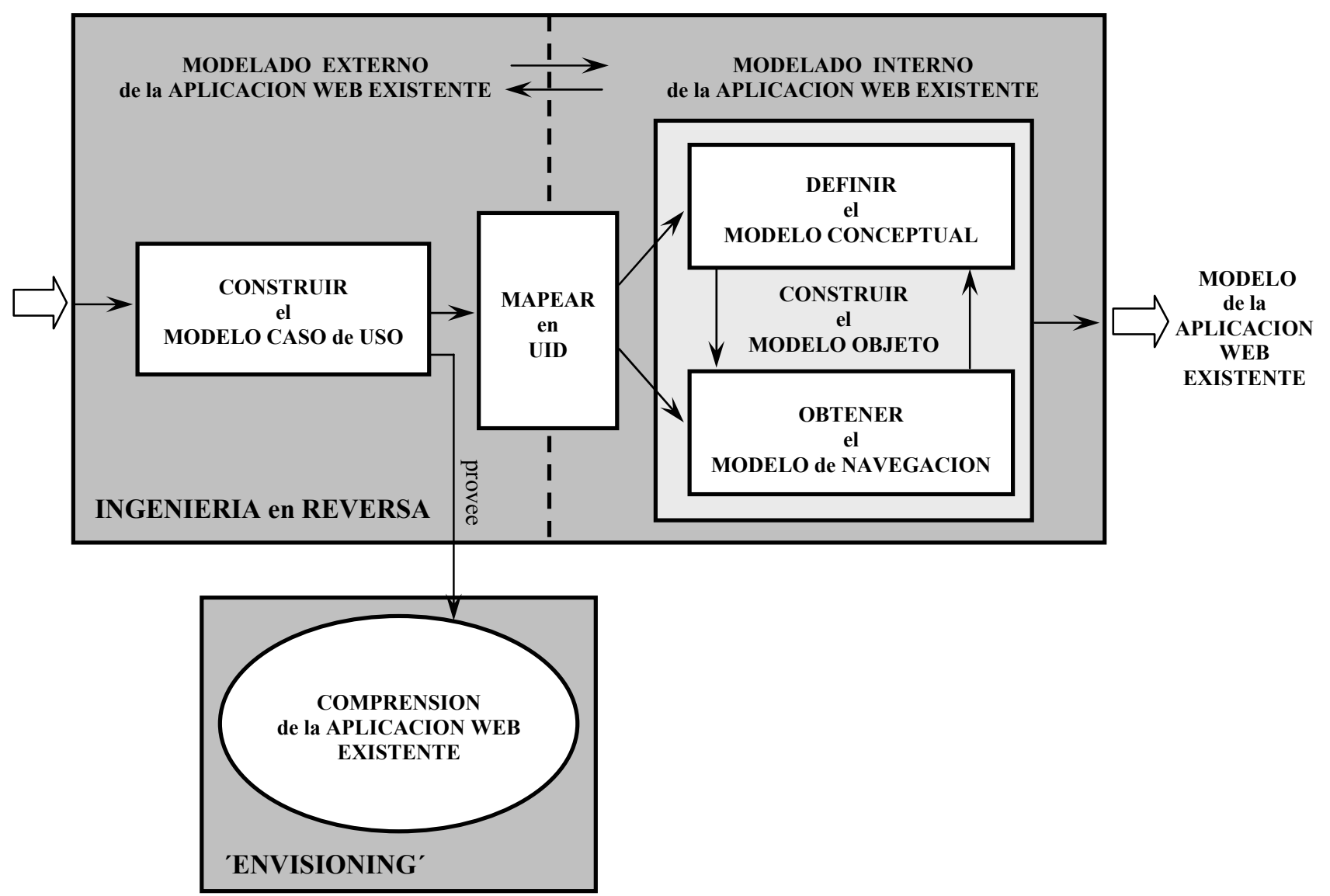

Figura 5.3: Ingeniería en reversa de una aplicación Web existente: Vista de sus actividades y contexto

Paso 1. Trabajar con las opciones de la 'home page' de la aplicación Web y los perfiles de usuarios, a los efectos de reconocer casos de uso que permitan representar y describir la aplicación Web existente.

Paso 2. Construir un modelo caso de uso general; un retrato de la aplicación Web existente factible de ser comunicado a todos los interesados para su discusión.

Paso 3. Seleccionar los casos de uso más prometedores (utilizar para tal fin la directiva de reingeniería de personalización de la aplicación Web).

Paso 4. Describir los casos de uso seleccionados en un lenguaje natural y simple: curso básico de eventos, cursos alternativos de eventos y cursos de eventos de retroceso. Este último curso de eventos no existen en el enfoque original de Jacobson [Jacobson94], y lo proponemos a los efectos de extender la aplicabilidad del enfoque a las características propias de un sistema que tiene el comportamiento de una aplicación Web.

En este punto, se concretó la construcción del modelo externo de la aplicación Web existente, que como su nombre lo indica, ofrece una visión externa de la aplicación 'tal como se 
presenta a sus usuarios'. Ya indicamos en 5.3, que este Modelo Caso de Uso aporta adecuadamente al propósito de adquirir la comprensión de la aplicación requerida por la actividad de 'envisioning'. Es un buen momento para obtener la especificación objetiva.

Paso 5. Obtener el mapeo de los casos de uso en UIDs [Vilain00]. El UID, (ver UIDs, capítulo3), es una herramienta gráfica que juega un rol fundamental en este procedimiento, ya que además de representar la interacción usuario/sistema, se observará en los puntos sucesivos que se convierte en el pivote que habilita el nexo entre el modelado externo y el modelado interno de la aplicación Web existente.

Paso 6. Definir el Modelo Conceptual OOHDM de la aplicación Web existente. Proponemos diseñar el esquema conceptual aplicando a los UIDs el conjunto de reglas que se detallan en [Vilain00] y en [Güell00a].

Paso 7. Obtener el Modelo de Navegación OOHDM, para completar el modelo objeto de la aplicación Web existente. Proponemos utilizar los UIDs y el método que se describe en [Güell00a].

En este punto, se concretó el modelo interno de la aplicación Web existente, que como su nombre lo indica, ofrece una visión interna de cómo opera actualmente la aplicación. Este Modelo Objeto es el producto resultante del proceso de ingeniería en reversa y marca el punto de partida para lanzar el proceso de ingeniería 'forward' de personalización de la aplicación Web.

\subsubsection{Modelo externo}

La construcción del modelo externo de la aplicación Web existente es la primera meta del proceso de ingeniería en reversa. Con el modelo externo representaremos la aplicación Web y entorno. Así, nuestro modelo externo caso de uso describe cómo los usuarios actuales interactúan con la aplicación Web existente Figura 5.4.

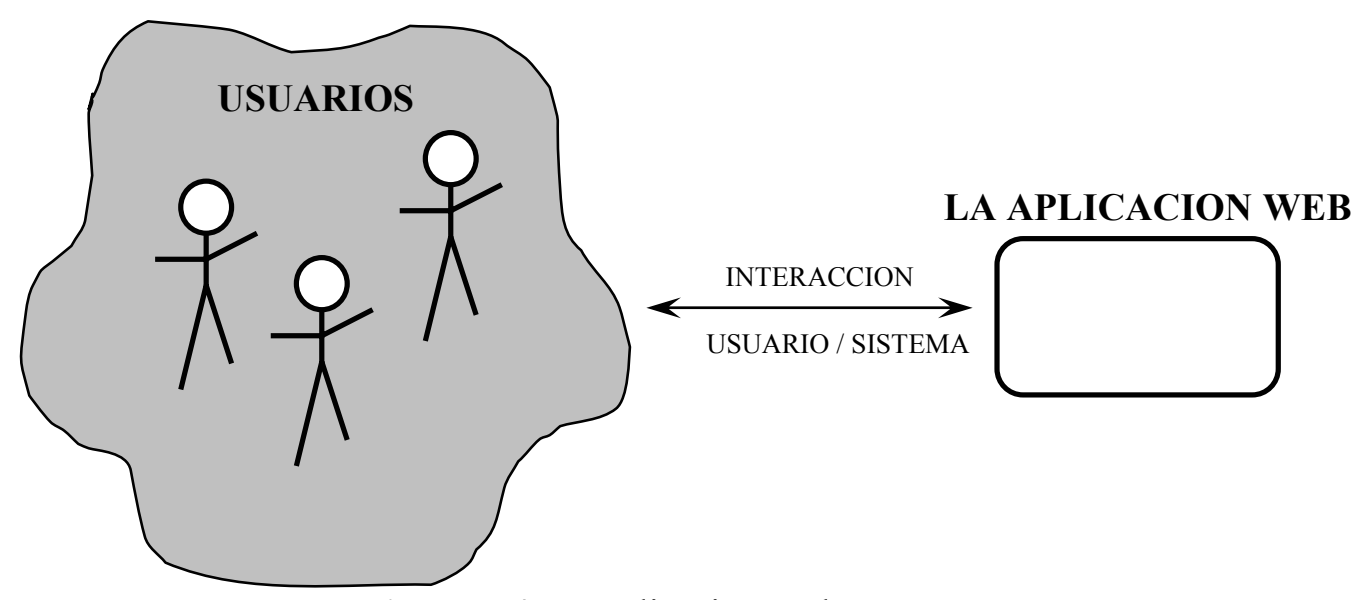

Figura 5.4: La aplicación Web y su entorno

\subsubsection{Modelo caso de uso general}

El modelo caso de uso general permite visualizar la aplicación Web existente como un sistema, sus usuarios como usuarios actuales del sistema y sus operaciones como las diferentes formas (casos de uso) en que los usuarios actuales utilizan el sistema. Fundamentalmente, este modelo refleja cómo los usuarios actuales se comunican con los casos de uso dentro de la aplicación Web existente Figura $\mathbf{5 . 5}$. 


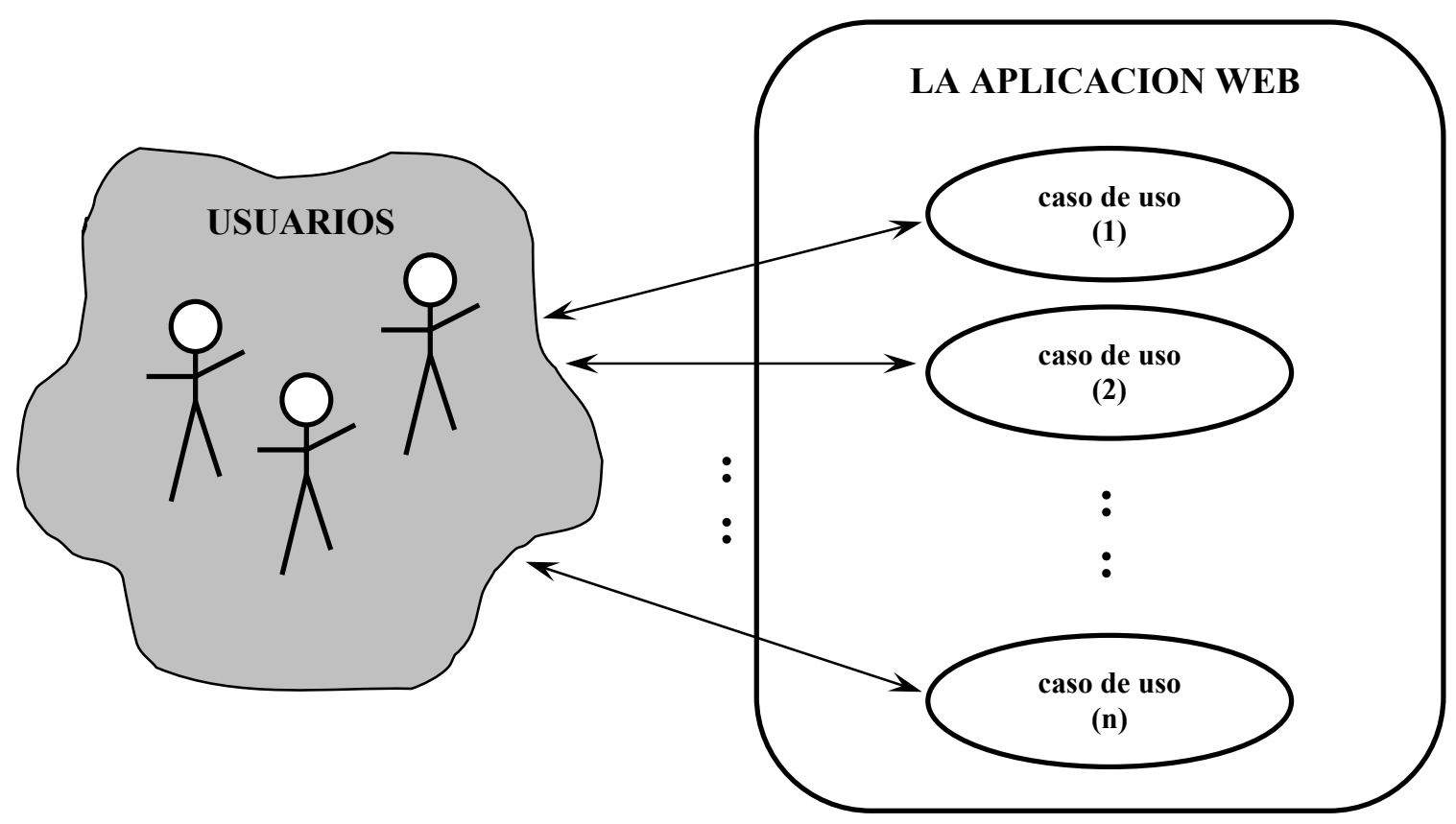

Figura 5.5: Modelo caso de uso general de una aplicación Web

\section{Ejemplo $\mathrm{N}^{\mathrm{o}} 1$ Figura 5.6:}

Supongamos una aplicación Web para el Instituto 'First' que dicta cursos de inglés y un caso de uso que brinda esta aplicación, el cual permite a sus usuarios consultar toda la información referida a los cursos que ofrece el instituto: Caso de uso (1) "Informando sobre los cursos ofrecidos".

Parte del modelo caso de uso para esta aplicación Web es:

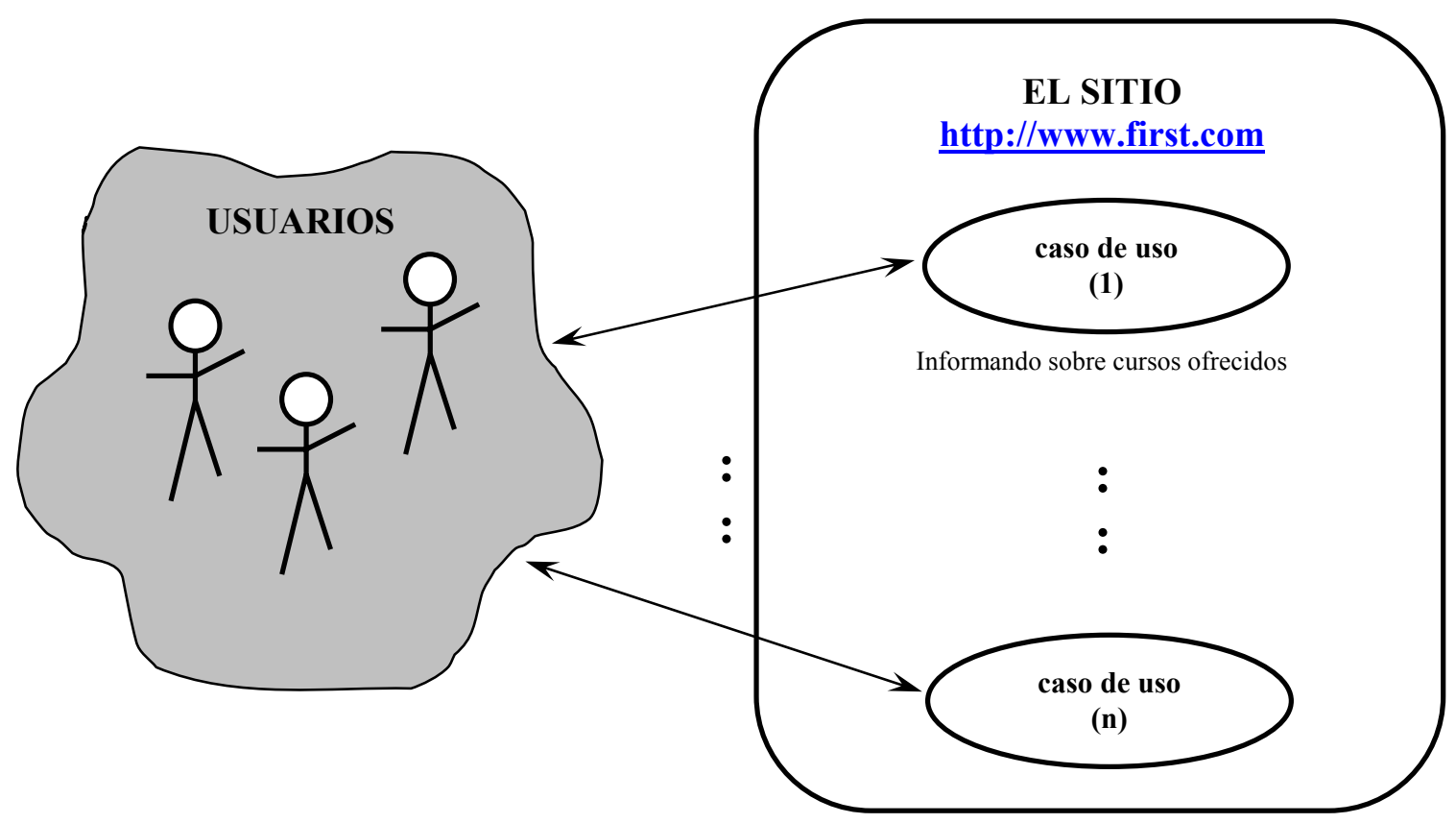

Figura 5.6: Modelo caso de uso general de la aplicación Web del Instituto de Inglés 'First' 


\subsubsection{Priorización de los casos de uso}

De acuerdo con lo señalado, el objetivo de este paso es seleccionar aquellos casos de uso que luzcan más prometedores a los efectos de dar respuesta a la directiva de reingeniería de personalización. Un caso de uso perteneciente a una aplicación Web se califica como prometedor, cuando puede contribuir al propósito de aplicar reingeniería de personalización a dicha aplicación, es decir, es un caso de uso que tiene potencial de renovación con impacto positivo en la aplicación y sus usuarios.

Manteniendo siempre presente la directiva de reingeniería de personalización, esta tarea de priorizar casos de uso, requiere utilizar algún principio o criterio de selección, por ejemplo [Cockburn01], que explica cuales son las características de un buen caso de uso, efectivo a su propósito.

\subsubsection{Descripción de los casos de uso}

El formato que se propone para describir los casos de uso seleccionados es una adaptación del enfoque original de Jacobson [Jacobson94] y permite una descripción que identifica: curso básico de eventos, cursos alternativos de eventos y cursos de eventos de retroceso. Como ya señalamos en el Paso 4, el curso de eventos de retroceso no existen en el enfoque original de Jacobson, y lo proponemos a los efectos de extender la aplicabilidad del enfoque a las características propias de un sistema que tiene el comportamiento de una aplicación Web.

A continuación incorporamos un bosquejo del formato sugerido para la descripción de casos de uso de una aplicación Web:

\section{Caso de uso (n) “nombre”}

\section{Descripción Caso de uso (n): Perfil de Usuario (*)}

\section{Curso básico de Eventos}
A. El caso de uso comienza cuando el usuario selecciona ...
B. El sistema retorna ... El usuario selecciona ...

:

n. El sistema retorna ... El caso de uso se completa ...

Cursos alternativos de Eventos

Alternativa (etapa): Si el usuario lo desea ... El caso de uso finaliza / continuará en la etapa ...

Alternativa (desde etapa .. hasta etapa): Si el usuario lo desea ... El caso de uso finaliza / continuará en la etapa ...

Alternativa (etapa, .. , etapa): Si el usuario lo desea ... El caso de uso finaliza / continuará en la etapa ...

Cursos de Eventos de retroceso

Retroceso (etapa): Si el usuario lo desea ... retrocediendo el caso de uso con la opción ... El caso de uso continuará en la etapa ...

Retroceso (desde etapa .. hasta etapa): Si el usuario lo desea ... retrocediendo el caso de uso con la opción ... El caso de uso continuará en la etapa ...

Retroceso (etapa, .. , etapa): Si el usuario lo desea ... retrocediendo el caso de uso con la opción ... El caso de uso continuará en la etapa ...

Nota: El color gris indica componentes opcionales en la descripción.

(*) Se individualiza el perfil del usuario solamente cuando se trata de una descripción del caso de uso específica para ese perfil. 
Ejemplo $\mathrm{N}^{\circ} 2$ :

Utilizaremos la aplicación Web del Instituto 'First' incorporada en 5.4.2.1, parte de cuyo modelo caso de uso describe la figura5.6. La descripción del Caso de uso (1) "Informando sobre los cursos ofrecidos" es:

Caso de uso (1) "Informando sobre los cursos ofrecidos"

\section{Descripción Caso de uso (1)}

\section{Curso básico de Eventos}

A. El caso de uso comienza cuando el usuario selecciona la opción Cursos Ofrecidos del menú que ofrece el sistema en la 'home page' del Instituto 'First'.

B. El sistema retorna la página asociada a ésta opción, mostrando en un menú los nombres y niveles de todos los cursos de inglés que ofrece el Instituto. El usuario selecciona un curso por su nombre.

C. El sistema retorna la página asociada al curso requerido mostrando nombre, nivel, orientación, programa, carga horaria, ... , etc. , de dicho curso. En este caso, el usuario recibe toda la información de la que dispone la aplicación y el caso de uso se completa.

Cursos de Eventos de retroceso

Retroceso C: Si el usuario lo desea, puede seleccionar otro curso, retrocediendo el caso de uso con la opción atrás de la aplicación de Internet. En este caso, el caso de uso continuará en la etapa B.

Tal como lo indica nuestro procedimiento propuesto para el proceso de ingeniería en reversa, en este punto, se concretó la construcción del modelo externo de la aplicación Web existente en un Modelo Caso de Uso, el cual aporta adecuadamente al propósito de adquirir la comprensión de la aplicación requerida por la actividad de 'envisioning'.

\subsubsection{Especificación objetiva incorporando patrones de personalización}

La especificación objetiva fija objetivos a la reingeniería de personalización y se constituye en la referencia válida para el proceso de ingeniería 'forward'. Tomando como guía las pautas descriptas en 5.3, la actividad de 'envisioning' nos permite delinear una visión para la nueva aplicación Web personalizada utilizando los siguientes instrumentos:

- Comprender la aplicación Web existente $\rightarrow$ Modelo Caso de Uso de la aplicación existente.

- Verificar que los objetivos estratégicos establecidos para la aplicación Web existente por el ente o negocio, sean concordantes con los precisados para la nueva aplicación Web personalizada $\rightarrow$ Directiva de reingeniería de personalización originada en la compañía.

- Entrevistar los usuarios actuales de la aplicación Web existente para que la nueva aplicación Web personalizada mejore la satisfacción de los mismos $\rightarrow$ Demandas de los usuarios actuales de la aplicación Web pertenecientes a los perfiles de interés.

- Comparar la aplicación Web existente con otras aplicaciones del entorno competidor en términos de 'benchmarking' $\rightarrow$ Trabajo comparativo entre aplicaciones utilizando en la caracterización de las mismas patrones de hipermedia [Rossi99a, 99b, 99d, 00].

Luego de recorrer esta guía, es posible redactar la especificación objetiva, integrando el conocimiento obtenido para plasmar las características de la futura aplicación Web personalizada. La especificación objetiva debe identificar los puntos sobre los cuales se enfocará el esfuerzo de reingeniería, indicando la personalización requerida: características (describir con patrones de 
personalización [Swchabe01] [Rossi01a]), perfil de usuario destinatario (señalar grupo de pertenencia) y grado (categorizar como 'coarse grained' o 'fine grained').

Ejemplo No3:

Para la aplicación Web del Instituto 'First' incorporada en 5.4.2.1, parte de cuyo modelo caso de uso describe la figura5.6, la actividad de 'envisioning' puede derivar en la siguiente especificación objetiva delineada incorporando patrones de personalización.

La nueva aplicación Web personalizada debe:

- Proveer una 'home page' del sitio por cada uno de los siguientes perfiles de usuario: usuarios no profesores del instituto (Perfil Otros) y usuarios profesores del instituto (Perfil Profesor).

Patrón Portal [Rossi00a] + Patrón Role-Based Personalization [Schwabe02]

Este será un primer nivel de personalización 'coarse grained' destinada a tratar con grupos de usuarios del sitio, que pertenecen a los perfiles identificados). Recordar que al Perfil Otros se le asignará la visión actual existente.

- Especializar la visión ligada al Perfil Profesor, de tal manera que el usuario Profesor puede acceder a:

i los cursos que él dicta en el instituto 'First' (desde el Portal a través de un índice que le permite seleccionar el curso a navegar).

Patrón Content Personalization [Rossi01a]

+ Patrón Individual-Based Personalization [Schwabe02]

i los documentos 'Listado de alumnos' y 'Registro de calificaciones' (desde el Curso actual a través de dos vínculos que respectivamente le permiten seleccionar el documento a navegar). El profesor podrá navegar, imprimir y 'download' estos documentos.

Patrón Link Personalization [Rossi01a]

Este será un segundo nivel de personalización 'finer grained' destinada a individualizar los usuarios pertenecientes al Perfil Profesor.

Para aplicar esta personalización a la aplicación Web existente reutilizaremos el caso de uso (1) "Informando sobre cursos ofrecidos" que se describe en el proceso de ingeniería en reversa.

\subsubsection{UID: un puente entre los modelos externo e interno}

El UID [Vilain00], (capítulo3), es la herramienta gráfica que nos va a permitir construir un nexo entre el modelado externo y el modelado interno de la aplicación Web existente. De acuerdo con lo prescripto por el método propuesto en [Vilain00], para reflejar los casos de uso en UIDs es crucial reconocer la información de intercambio usuario/sistema y la secuencia de dicho intercambio. Posteriormente, se debe organizar esta secuencia en interacciones.

A continuación se exhibe el método citado (a aplicar a cada uno de los casos de uso seleccionados de la aplicación Web existente): 


\section{... DESDE CASOS DE USO HACIA UIDS}

1. IDENTIFICAR QUE INFORMACION SE INTERCAMBIA ENTRE EL USUARIO Y EL SISTEMA. Generalmente estos ítem de datos se representan por sustantivos. Es importante también identificar que ítem de datos son provistos por el usuario y cuáles son retornados por el sistema.

\section{REPARTIR LOS ITEM DE DATOS DENTRO DE INTERACCIONES.}

Los ítem de datos se sitúan en la misma interacción, a no ser que requieran procesamiento del sistema antes de que se presenten; en este caso se sitúan en otra interacción. Luego, se sitúan los ítem de datos restantes en estas interacciones y así. Para llevar registro de la secuencia entre interacciones, cada nueva interacción obtenida que se obtiene por este proceso se le asigna temporalmente un número de orden.

3. DISTINGUIR ENTRE LOS ITEM DE DATOS OTORGADOS POR EL USUARIOS Y LOS RETORNADOS POR EL SISTEMA.

Los ítem de datos obligatorios otorgados por el usuario se sitúan dentro de rectángulos con bordes continuos y los ítem de datos opcionales se sitúan dentro de rectángulos con bordes punteados. Los ítem de datos retornados por el sistema se sitúan directamente dentro de la interacción, sin rectángulos alrededor de ellos. Los ítem de datos asociados con un elemento se sitúan dentro de paréntesis y el conjunto de elementos se representa por elipsis antes del nombre del conjunto.

\section{CONECTAR LAS INTERACCIONES POR FLECHAS.}

Cuando las interacciones se conectan, la interacción objetivo debe tener un número de secuencia mayor que la interacción origen. Es posible conectar una interacción a dos o más interacciones, representando así varias alternativas sucediendo las interacciones. En este caso, la información ingresada por el usuario determina cuáles de las interacciones alternativas ocurrirá luego. Si el cambio de interacción es el resultado de la selección de un elemento, el número de elementos seleccionados se adjunta a la flecha, y el origen de esta flecha es el conjunto del cual los elementos son seleccionados. La interacción inicial siempre tiene una flecha sin origen. Si la una interacción ocurre luego de que todos los ítem de datos de la interacción anterior se ingresan, el origen de la flecha que conecta estas interacciones se adjunta a todo la interacción. En cambio, si una interacción ocurre luego de que el usuario selecciona un elemento de la interacción anterior, a la flecha que conecta estas interacciones se la adjunta el número 1 y su origen es el conjunto de elementos del cual el usuario efectuó la selección y no la interacción completa.

5. IDENTIFICAR LAS OPERACIONES QUE SE EJECUTAN SOBRE LOS ITEM DE DATOS.

Generalmente se representan en los casos de uso por medio de verbos. Una operación se representa en el diagrama por una línea con un círculo relleno en el extremo. Si después de la ejecución de una operación otra interacción ocurre, entonces la operación se representa adjuntada a la flecha en vez de la línea con el punto relleno. El número de elementos y la operación se sitúan próximos a la línea y el nombre de la operación se sitúa dentro de paréntesis.

6. NO ESPECIFICAR REQUERIMIENTOS NO-FUNCIONALES EN LOS UIDS.

Si bien los casos de uso no especifican este tipo de requerimientos, algunas veces se puede presentar un requerimiento no-funcional. En este caso debe aparecer adjunto al UID como texto. 
Ejemplo No4 ${ }^{\text {Figura }}$ 5.7:

Utilizaremos el Caso de uso (1) "Informando sobre los cursos ofrecidos" cuya descripción fue incorporada en 5.4.2.3. Aplicando el método citado en 5.4.4, el UID correspondiente es:

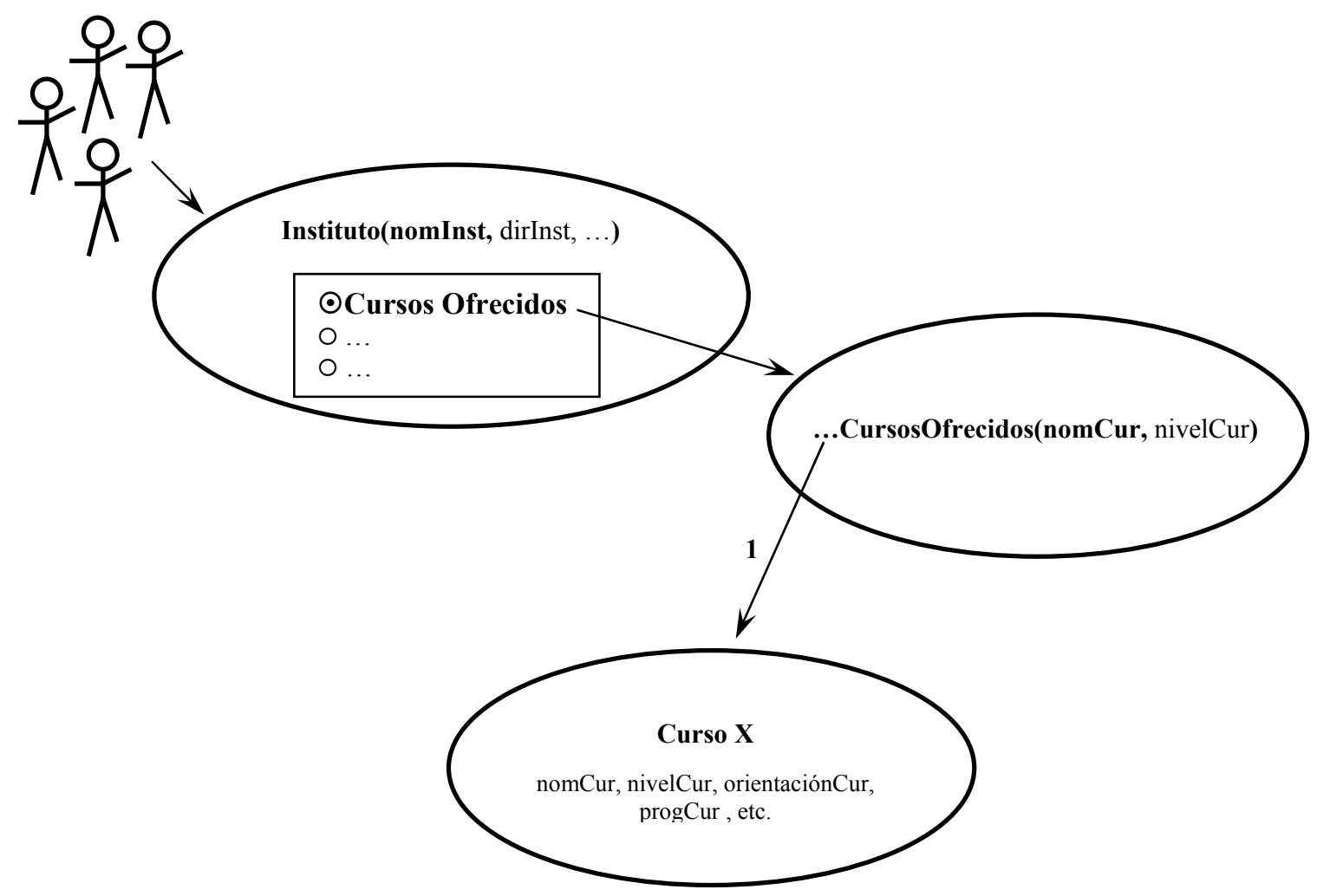

Figura 5.7: UID para el Caso de Uso (1) "Informando sobre los cursos ofrecidos"

\subsubsection{Modelo interno}

Obtener el modelo objeto de la aplicación Web existente, aplicando el enfoque OOHDM [Schwabe98a] y [OOHDM00] (capítulo3), es el objetivo de los Pasos 6 y 7 del procedimiento propuesto para el proceso de ingeniería en reversa. Ya hemos señalado, que nuestro modelo de una aplicación Web se compone de dos visiones: una externa y una interna. Mientras el modelo caso de uso representa la visión externa de la aplicación descripta desde la perspectiva del entorno, el modelo objeto representa la visión de la aplicación que describe su estructura interna. A continuación explicamos cómo obtener este modelo objeto utilizando el enfoque OOHDM, que desdobla este modelo en dos: conceptual y de navegación. Si bien aquí se optó por comenzar definiendo el modelo conceptual y luego el modelo de navegación, esto de ninguna manera indica un orden (recordar que el enfoque OOHDM no propicia un desarrollo secuencial, sino iterativo y creciente que permite que los modelos se enriquezcan entre sí).

\subsubsection{Obtención del modelo conceptual}

Tal como señalamos en el capítulo3 de este trabajo, el modelo conceptual provee un modelo del dominio de la aplicación Web, determinando el universo del discurso [Schwabe98a, 98b]. Dos tipos de objetos coexisten en el modelo conceptual: aquellos que serán percibidos como nodos en el modelo de navegación (que son los denominados 'entity objects' en [Jacobson94]) y aquellos que proveerán soporte computacional a la aplicación encapsulando comportamiento. Este modelo no incluye cuestiones referidas a la navegación y es la base sobre la cual es posible construir varias aplicaciones. 
Obtener la especificación del esquema conceptual es la única fase de la que se compone el diseño del modelo conceptual. De acuerdo con lo prescripto por [Vilain00] y [Güell00a], es posible obtener el modelo conceptual aplicando ciertas directivas a los UIDs correspondientes a los casos de uso seleccionados de la aplicación Web existente; algunas de estas directivas son simplemente una adaptación de las técnicas de normalización del esquema estándar.

A continuación se enumeran las reglas mencionadas (la presentación que se cita no es textual, se ha ensamblado a partir de los aspectos más relevantes y didácticos de los procedimientos descritos en [Vilain00] y [Güell00a]):

\section{... DESDE UIDS HACIA MODELO CONCEPTUAL}

\section{REGLA 1:}

PARA CADA UID, DEFINIR UNA CLASE POR CADA ELEMENTO, ELEMENTO DE CONJUNTO Y ELEMENTO ESPECÍFICO. PARA CADA CLASE DEFINIDA, ASUMA LA EXISTENCIA DE UN ATRIBUTO IDENTIFICADOR OID.

\# Recordar que la representación de un elemento, un elemento de conjunto y un elemento específico en UID responden a los siguientes formatos respectivamente:

ELEMENTO( ítem-de-dato1, ítem-de-dato2, . ., ítem-de-daton ) Representa un elemento con sus ítems de datos. Los ítems de datos son opcionales.

... ELEMENTO( ítem-de-dato1, ítem-de-dato2, .. , ítem-de-daton ) Representa un elemento de conjunto. Los ítems de datos asociados al elemento también se presentan.

ELEMENTO X Representa el elemento específico seleccionado o ingresado por el usuario en la interacción previa.

\section{REGLA 2:}

PARA CADA ÍTEM DE DATO DE LOS ELEMENTOS DE CONJUNTO QUE APARECEN EN CADA UID, O ÍTEM DE DATO INGRESADO POR EL USUARIO, DEFINIR UN ATRIBUTO DE ACUERDO CON LO SIGUIENTE:

\# Verificar que el ítem de dato es funcionalmente dependiente pero no transitivamente dependiente sobre el atributo OID en cada clase, es decir, que OID $\rightarrow$ ítem de dato. Verificar que el ítem de dato no es transitivamente dependiente sobre el OID. Si estas condiciones son satisfechas, entonces el ítem de dato debe convertirse en un atributo de la clase.

\# Verificar que el ítem de dato es funcionalmente dependiente pero no transitivamente dependiente, sobre el atributo OID de dos o más clases diferentes, y que el ítem de dato no es transitivamente dependiente sobre los OIDs. Si estas condiciones se cumplen, entonces el ítem de dato debe convertirse en un atributo de la relación entre estás clases.

\section{REGLA 3:}

PARA CADA ATRIBUTO QUE APARECE EN UN CONJUNTO DISTINTO AL DE SU CLASE, TENTATIVAMENTE DEFINIR UNA RELACIÓN ENTRE SU CLASE Y LA CLASE DE LOS ELEMENTOS DEL CONJUNTO. SI LA CLASE DEL ATRIBUTO NO ESTÁ RELACIONADA CON LA CLASE QUE REPRESENTA EL CONJUNTO, ENTONCES VERIFICAR QUE LA CLASE DEL ATRIBUTO ESTE RELACIONADA A LA CLASE DE OTRO ATRIBUTO PRESENTE EN EL CONJUNTO.

(Verificar que la relación resultante sea semánticamente correcta, es decir tenga sentido dentro del dominio que se esta modelando).

REGLA 4:

PARA CADA FLUJO DE INTERACCIÓN ( REPRESENTADOS POR FLECHAS EN LOS UIDS), SI HAY DISTINTAS CLASES EN LA INTERACCIÓN ORIGEN Y LA INTERACCIÓN OBJETIVO, DEFINIR UNA RELACIÓN ENTRE ESTAS CLASES.

(Verificar que la relación resultante sea semánticamente correcta, es decir tenga sentido dentro 
del dominio que se esta modelando).

REGLA 5:

PARA CADA OPERACIÓN QUE APARECE CONECTADA A UN ELEMENTO O CONJUNTO, SI ES UNA OPERACIÓN DE LA CLASE CORRESPONDIENTE A DICHO ELEMENTO O CONJUNTO, AGREGARLA A ESA CLASE.

\section{REGLA 6:}

AL FINALIZAR El PROCESO, REALIZAR LOS AJUSTES NECESARIOS EN EL DIAGRAMA DE CLASE, POR EJEMPLO, IDENTIFICANDO GENERALIZACIONES Y CARDINALIDADES DE ASOCIACIONES FALTANTES.

\section{Ejemplo $\mathrm{N}^{0} 5$ Figura 5.8:}

Utilizaremos el UID de la figura5.7 correspondiente al Caso de uso (1) "Informando sobre los cursos ofrecidos". Aplicando las reglas citadas en 5.4.5.1 a este único caso de uso, el modelo conceptual resultante es:

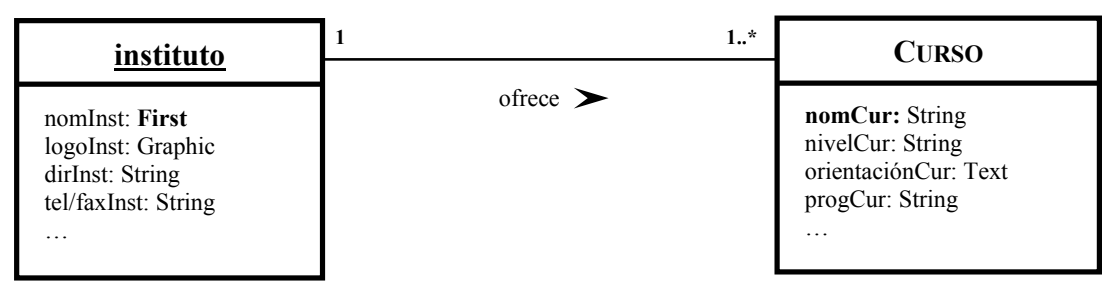

Figura 5.8: Modelo conceptual resultante de aplicar las reglas citadas al UID "Informando sobre cursos ofrecidos"

\subsubsection{Obtención del modelo de navegación incorporando patrones de hipermedia: Diagrama de clases de navegación y Diagrama de contexto de navegación.}

Tal como señalamos en el capítulo3 de este trabajo, el concepto de navegación es una de las características esenciales distintivas de las aplicaciones Web. El usuario de una aplicación Web navega en un espacio construido por objetos, que no son iguales a los objetos conceptuales sino más bien objetos personalizados al perfil y tareas de dicho usuario [Schwabe98a].

Obtener la especificación del esquema de clases de navegación y del esquema de contexto de navegación son las fases de las que se compone el diseño del modelo de navegación. De acuerdo con lo prescripto por el método que se describe en [Güell00a], es posible estructurar el espacio de navegación aplicando un conjunto de reglas a los UIDs seleccionados para la aplicación Web.

A continuación se enumeran las reglas del método mencionado (la presentación que se cita no es completa, rescata solamente los aspectos más relevantes del procedimiento descrito en [Güell00a]):

\section{... DESDE UIDS HACIA MODELO DE NAVEGACION OOHDM}

\section{REGLA 1:}

UNA INTERACCION QUE PRESENTA UN OBJETO SE MAPEA DENTRO DE UN CONTEXTO DE SU CLASE.

Los objetos son navegados dentro de contextos; por lo tanto cada interacción que presenta un objeto se debe reflejar dentro de un contexto.

El siguiente paso es determinar los elementos de cada contexto. Los elementos de un contexto generalmente tienen cierta característica en común: pertenecen a la misma clase, o tienen atributos con el mismo valor, o están ligados a un objeto a través de la misma relación. De otra manera, el conjunto es arbitrario, con elementos enumerados. Existen muchas guías que se pueden usar para identificar elementos de contexto, que no se muestran aquí por razones de espacio. 


\section{REGLA 2:}

UN CONJUNTO QUE ES PARTE DE LA INFORMACIÓN DENTRO DE UN OBJETO SE MAPEA DENTRO DE UNA ESTRUCTURA DE ACCESO, DENTRO DE UN CONTEXTO, O DENTRO DE UN ATRIBUTO DE LISTA DE TIPO.

Para decidir el mapeo de cada uno de estos conjuntos se analiza la importancia de su información para la ejecución de la tarea, basándose en el caso de uso y escenarios:

\# La información muy importante debe aparecer íntegramente en un atributo de objeto de lista de tipo que contiene los elementos del conjunto.

\# La información importante debe aparecer como una estructura de acceso dentro del objeto. En este caso el diseñador debe decidir los atributos que se mostrarán en la estructura; cada elemento de estructura de acceso apuntará a un elemento del conjunto.

\# La información complementaria debe aparecer como un anchor apuntando a una estructura de acceso o a un elemento dentro de un contexto.

Para cada contexto, se incluye una tarjeta con sus visiones de objetos y sus permisos de acceso. Puede ocurrir que el mismo objeto se pueda acceder en diferentes contextos y sea necesario que en cada contexto el objeto presente la información de diferentes maneras, como también permitir navegaciones diferentes. Estas variaciones se resolverán a través de 'InContext classes'.

REGLA 3:

UNA INTERACCION DE ENTRADA DE DATOS SEGUIDA POR UNA INTERACCIÓN QUE PRESENTA UN CONJUNTO DE OBJETOS SE MAPEA DENTRO DE UNA ESTRUCTURA DE ACCESO APUNTANDO LOS OBJETOS DENTRO DEL CONJUNTO.

La elección de la estructura de acceso depende de si los posibles valores de los datos ingresados por el usuario pueden ser computados por la aplicación por adelantado, o si estos datos pertenecen a objetos del conjunto destino o a otros objetos ligados a él.

Para diseñar el modelo de navegación, proponemos además incorporar patrones de hipermedia [Rossi99a, 99b, 99d, 00], (ver Patrones de navegación, capítulo3).

Ejemplo $\mathrm{N}^{\mathrm{o}} 6$ Figura 5.9 - Figura 5.10:

Utilizaremos el Caso de uso (1) "Informando sobre los cursos ofrecidos" para ejemplificar la obtención del modelo de navegación..

Considerando su modelo conceptual ilustrado por la figura5.8 e incorporando patrones de hipermedia, el diagrama de clases de navegación para este caso de uso es:

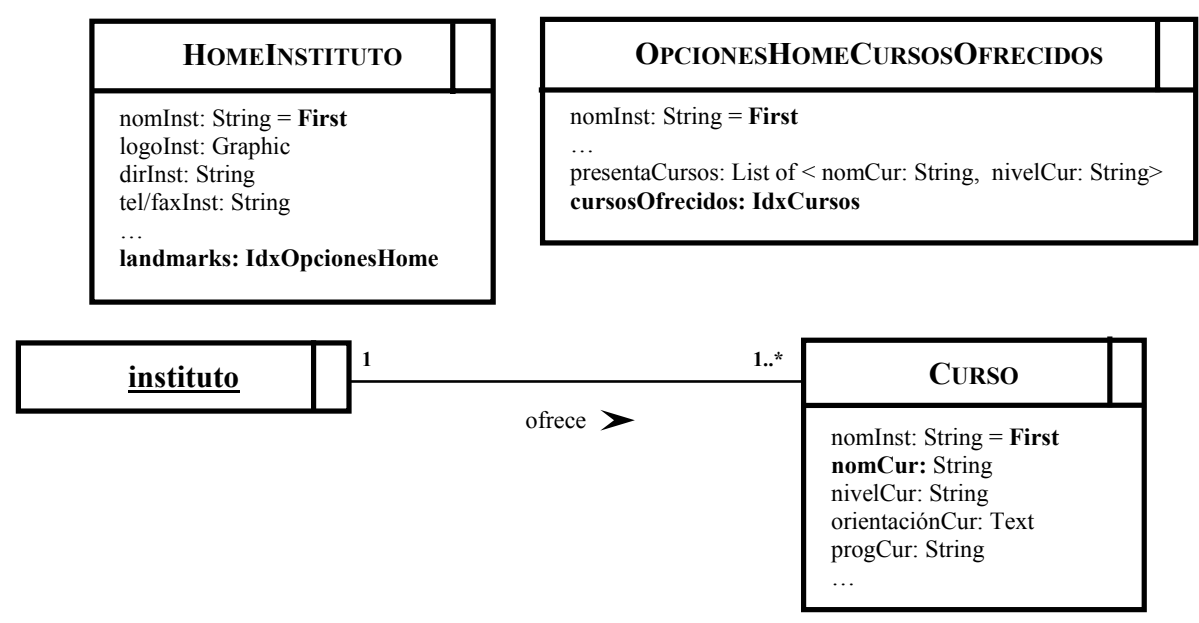

Figura 5.9: Esquema de clases de navegación correspondiente al UID

"Informando sobre cursos ofrecidos" 
Aplicando las reglas descriptas en 5.4.5.2 al correspondiente UID del caso de uso ilustrado por la figura5.7, el diagrama de contexto de navegación para este caso de uso es:

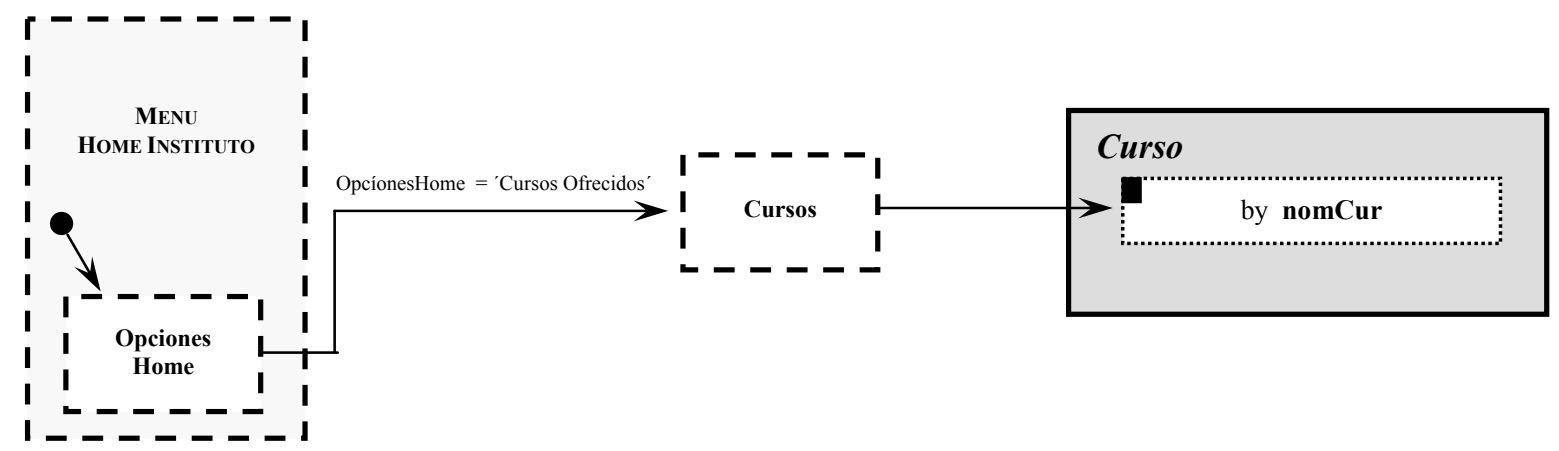

Figura 5.10: Diagrama de contexto de navegación correspondiente al caso de uso "Informando sobre cursos ofrecidos"

\subsection{Ingeniería 'forward' de personalización}

Teniendo conocimiento del estado actual de la aplicación Web existente y disponiendo de una especificación objetiva que individualiza los casos de uso de dicha aplicación que necesitan reingeniería de personalización, iniciamos el esfuerzo de reingeniería propiamente dicho.

Aplicando ingeniería 'forward', es posible plasmar los objetivos del proceso de reingeniería de personalización en el modelo de la nueva aplicación Web personalizada.

Como ya señalamos en 5.4, las características propias de una aplicación Web, determinan la necesidad de definir un proceso de ingeniería 'forward' que se ajuste a estas peculiaridades. Para llevar adelante este proceso, nuevamente proponemos utilizar OOHDM, pero esta vez para especializar los conceptos básicos de la ingeniería 'forward':

Modelo de la aplicación Web existente

Especificación objetiva

\section{$\Rightarrow$ Ingeniería 'forward' + Enfoque OOHDM}

$\Rightarrow$ Modelo de la aplicación Web personalizada

\subsubsection{Actividad 'forward'}

La propuesta de aunar los conceptos de ingeniería 'forward' y el enfoque OOHDM, se plasma en el siguiente procedimiento, cuya descripción indica paso a paso la actividad a desarrollar para obtener el modelo interno de la aplicación Web personalizada Figura 5.11:

Paso 1. Producir bosquejos de la/s página/s que refleja/n los cambios deseados en la aplicación Web personalizada. Utilizando una herramienta gráfica a elección, la representación resultante, perseguirá moldear y complementar la especificación objetiva, reforzando no solo el acuerdo entre las partes interesadas en la aplicación 'stakeholders de la aplicación', sino también el punto de partida para la tarea de personalización.

Paso 2. Confeccionar una vista externa para la nueva aplicación Web en un Modelo Caso de Uso Personalizado. Para lograr este propósito, utilizar como material inicial los productos resultantes de la actividad de 'envisioning' (la especificación objetiva) y del proceso de ingeniería en reversa (el modelo de la aplicación Web existente, especialmente los casos de uso seleccionados en dicho proceso de ingeniería en reversa). 
Paso 3. Describir los casos de uso personalizados (utilizar para tal fin: las descripciones de los casos de uso seleccionados en el proceso de ingeniería en reversa, el modelo caso de uso general personalizado, la especificación objetiva y los bosquejos producidos en el Paso 1).

En este punto, se concretó la construcción del modelo externo de la nueva aplicación Web personalizada, que como su nombre lo indica, ofrece una visión externa de la aplicación 'tal como se presenta a los distintos tipos de usuarios identificados para dicha aplicación'.

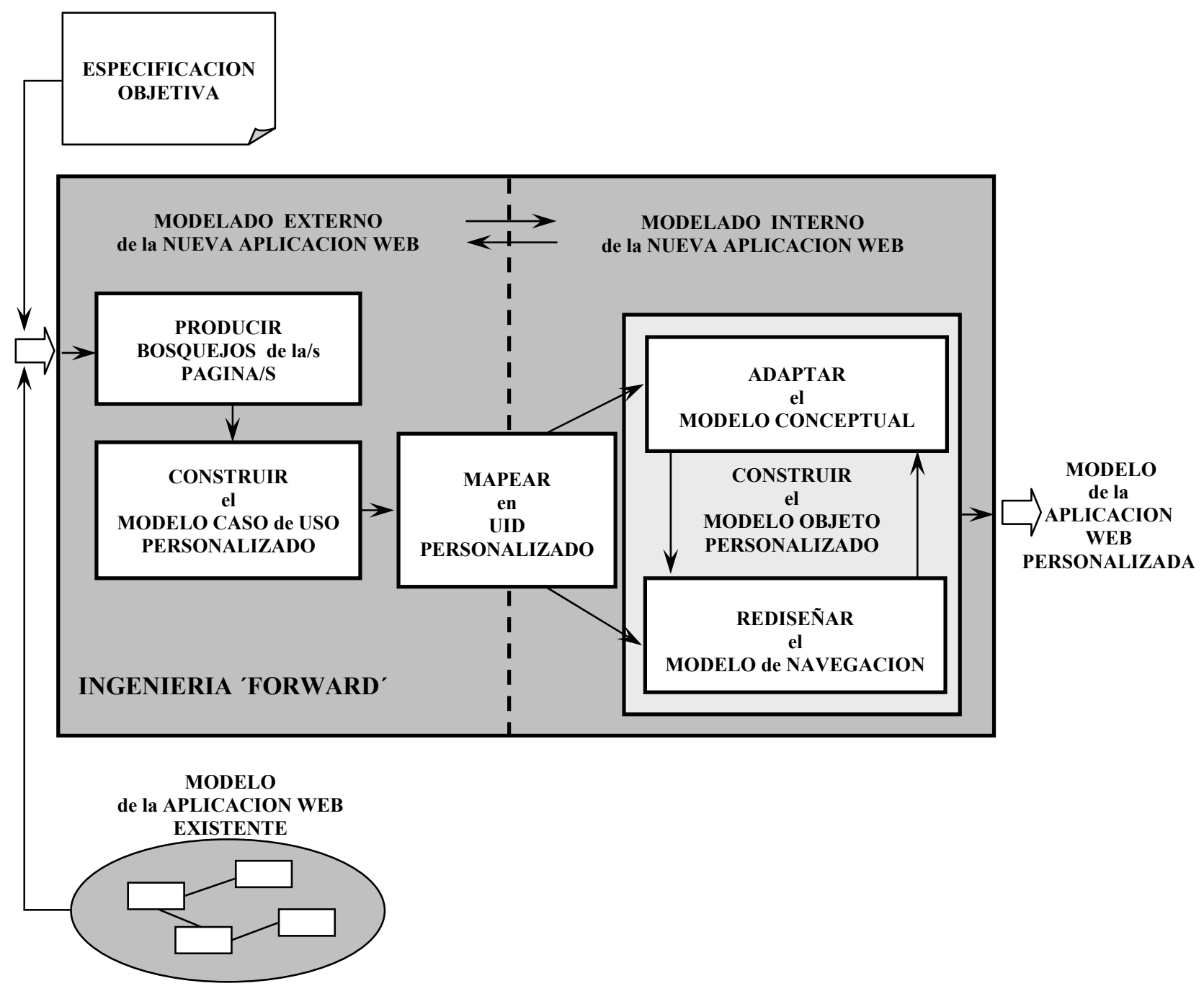

Figura 5.11: Ingeniería 'forward' de personalización de una aplicación Web:

Vista de sus actividades y contexto

Paso 4. Mapear los casos de uso personalizados en UIDs[Vilain00] que reflejen las formas en que los distintos usuarios (generales, pertenecientes a un perfil o individuales) interactúan con la aplicación Web.

Paso 5. Adaptar el Modelo Conceptual OOHDM existente para que responda a los requerimientos de personalización. Para lograr este ajuste se propone:

- aplicar a los UIDs personalizados el conjunto de reglas que se detallan en 5.4.5.1, sugerido en el Paso 6 del proceso de ingeniería en reversa, [Vilain00] y [Güell00a]. Este ejercicio permite descubrir la necesidad de incluir nuevos objetos o de agregar atributos o comportamiento a objetos existentes.

- considerar e incorporar los conceptos de diseño de aplicaciones Web personalizadas con patrones de personalización, [Rossi01c], [Schwabe02] y [Bäumer00].

Paso 6. Rediseñar el Modelo de Navegación OOHDM, para completar el modelo objeto de la aplicación Web personalizada. Para lograr este rediseño se propone: 
- aplicar a los UIDs personalizados el método que se detalla en 5.4.5.2, sugerido en el Paso 7 del proceso de ingeniería en reversa, [Güell00a] y en [Güell00b]. Este ejercicio permite descubrir la necesidad de incluir nuevos nodos o de agregar atributos a nodos existentes y de incorporar contextos y estructuras de acceso a objetos existentes.

- considerar e incorporar patrones de personalización [Rossi01b] y [Schwabe02].

En este punto, se concretó el modelo interno de la aplicación Web personalizada, que como su nombre lo indica, ofrece una visión interna de cómo opera la nueva aplicación. Este Modelo Objeto es el producto resultante del proceso de ingeniería 'forward' y el objetivo del proceso de reingeniería de personalización. Es además, el punto de partida para lanzar la actividad de Diseño de Interfaz Abstracta y la etapa de Implementación de la aplicación Web personalizada. Recordemos que OOHDM, propicia la independencia entre los diseños de navegación y de interfaz abstracta. Esta propiedad permite la construcción de diferentes interfaces sobre el mismo modelo de navegación y asegura que los cambios producidos en la interfaz del usuario puedan ser llevados a cabo "suavemente" (capítulo3). Tanto el Diseño de Interfaz Abstracta como la etapa de Implementación quedan fuera del alcance de esta tesis.

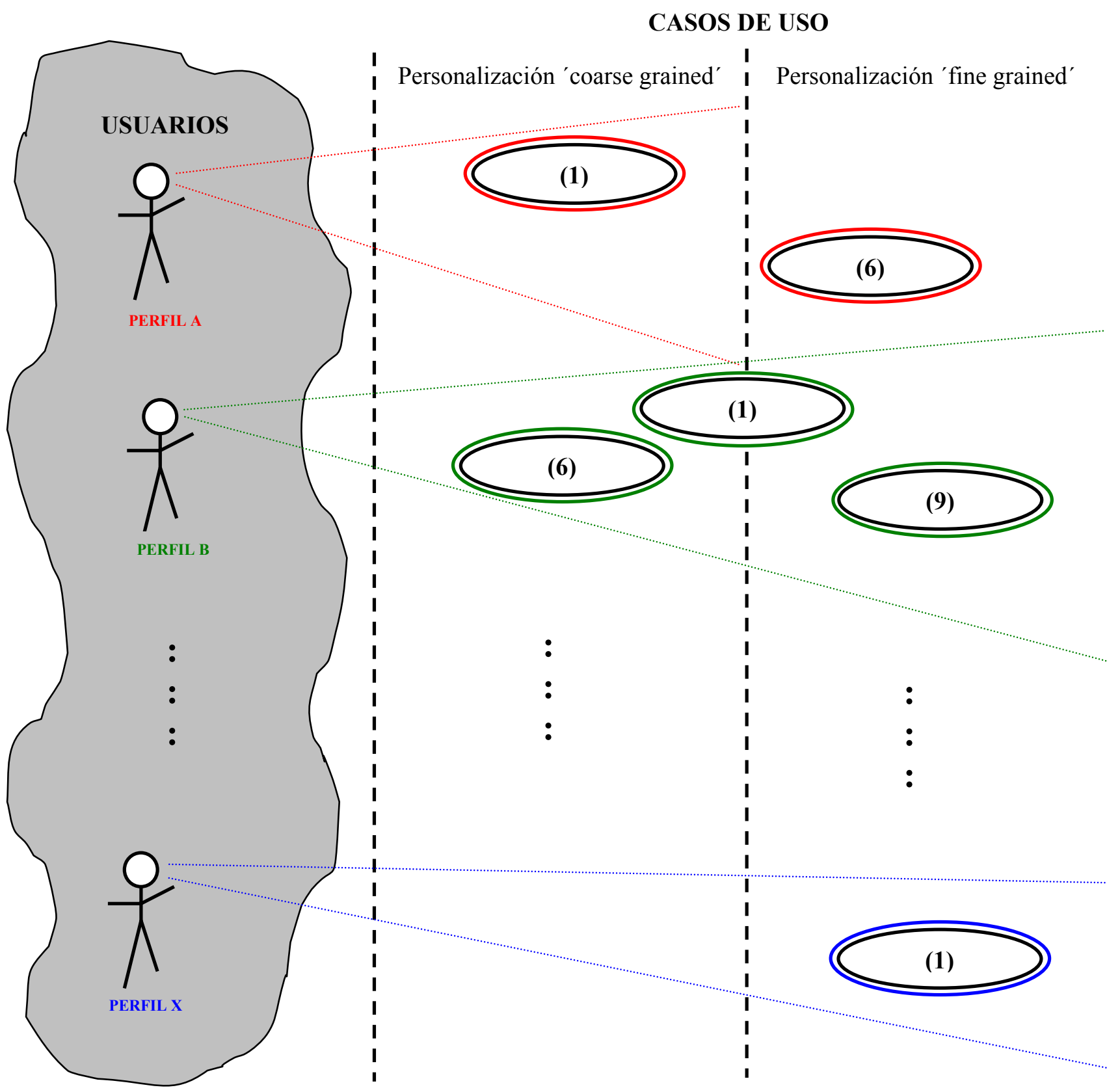

Figura 5.12: Ejemplo de Modelo caso de uso personalizado de una hipotética aplicación Web 


\subsubsection{Nuevo modelo externo}

Tal como señalamos en los Pasos 2 y 3 del proceso de ingeniería 'forward', la construcción del modelo externo de la aplicación Web personalizada requiere como materia prima básica la especificación objetiva y los casos de uso seleccionados en el proceso de ingeniería en reversa.

A continuación, en el ítem 5.5.2.1, explicamos cómo diseñar un modelo externo para una aplicación Web personalizada tomando como punto de partida la especificación objetiva.

\subsubsection{Desde la especificación objetiva hacia el modelo caso de uso personalizado}

Ya señalamos en 5.4.2.1, que fundamentalmente el modelo caso de uso refleja cómo los usuarios actuales se comunican con los casos de uso dentro de la aplicación Web. El propósito del modelo caso de uso personalizado es más ambicioso, ya que refleja además el/los grado/s de personalización requerida para cada uno de los casos de uso dentro de la aplicación Web y el/los perfil/es de usuarios destinatario/s de dichos casos de uso personalizados.

Para confeccionar esta vista externa de la nueva aplicación Web personalizada proponemos ${ }^{\text {Figura 5.12. }}$

- asignar a cada perfil de usuarios un color que lo identifique de aquí en adelante.

- definir las visiones de cada perfil de usuario utilizando el color que le fue asignado; estas visiones están compuestas por casos de uso personalizados.

- indicar el/los grado/s de personalización a aplicar ('coarse' o 'fine' grained) a cada caso de uso asignado a un perfil de usuario.

Ejemplo No7 Figura 5.13:

Consideramos nuevamente la aplicación Web del Instituto 'First' y el Caso de uso (1) "Informando sobre los cursos ofrecidos".

La especificación objetiva, ítem 5.4.3, prescribe individualizar a los usuarios profesores (Perfil Profesor) del conjunto de usuarios, para que puedan acceder al/los curso/s que tienen a su cargo. Los demás usuarios (Perfil Otros) seguirán accediendo a todos los cursos que dicta el instituto.

\section{CASOS DE USO}

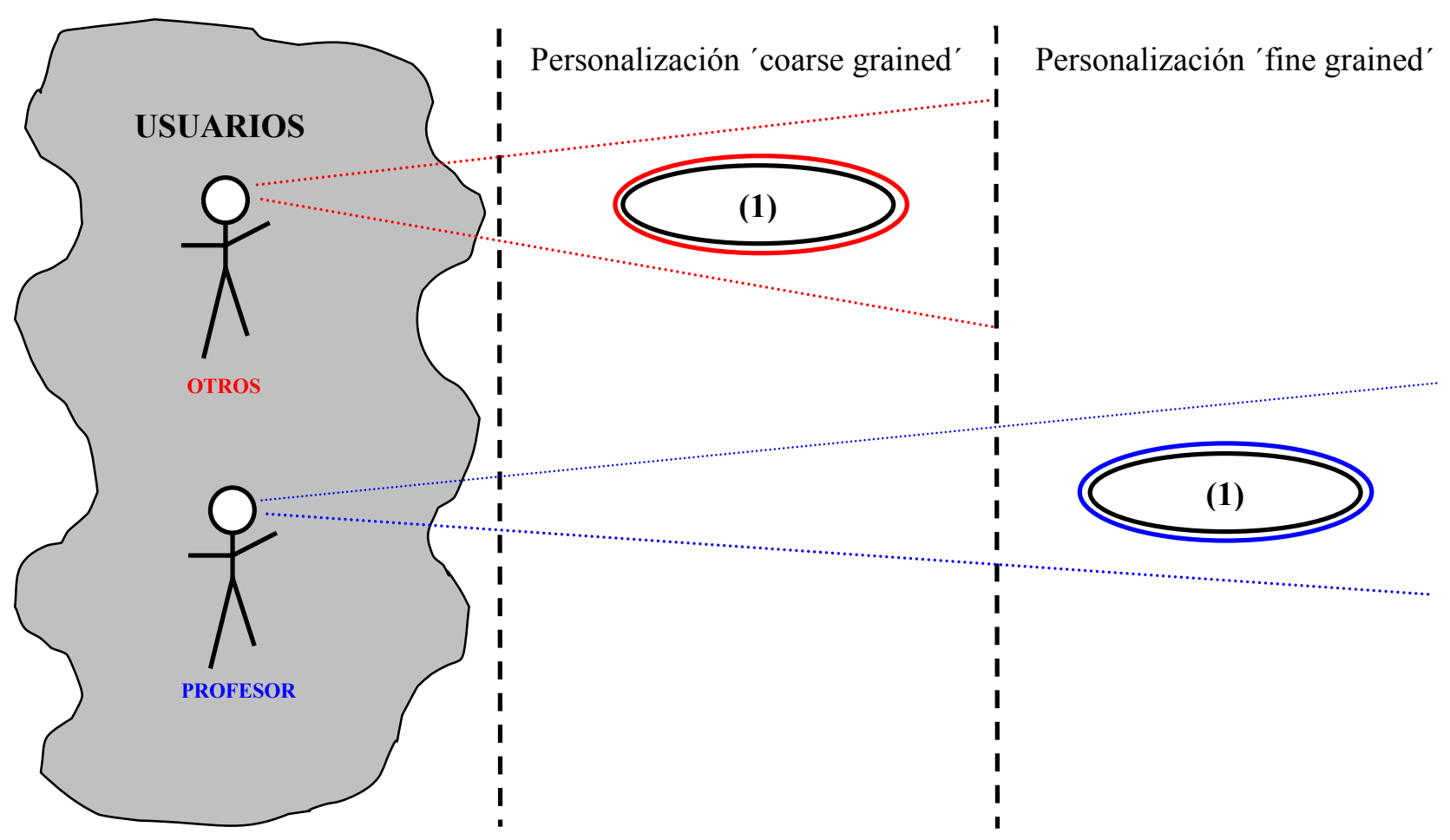

Figura 5.13: Modelo caso de uso personalizado de la aplicación Web del Instituto 'First' 
Considerando solamente el caso de uso (1), surge este Modelo caso de uso personalizado para la aplicación Web del instituto 'First'.

\subsubsection{Descripción de los casos de uso personalizados}

Para describir los casos de uso personalizados, también proponemos utilizar el formato detallado en 5.4.2.3. La diferencia radica, en que para responder a las exigencias de personalización, cada caso de uso puede dar respuesta a las demandas de más de un perfil de usuario variando su descripción. Lo que proponemos es definir para cada caso de uso tantas descripciones alternativas como perfiles de usuarios sean destinatarios de dicho caso de uso.

Así, si un caso de uso (n) atiende demandas de usuarios pertenecientes a $\mathrm{N}$ perfiles, esto implica que se le asociarán $\mathrm{N}$ descripciones personalizadas, una por cada perfil.

A continuación incorporamos un bosquejo para un hipotético caso de uso (n) cuyo modelo caso de uso personalizado podría ser el de la figura5.12, que atiende demandas de usuarios pertenecientes a los perfiles A, B y X utilizando el formato sugerido en 5.4.2.3, a los efectos de ilustrar, sin detallar los eventos que componen las respectivas descripciones:

\section{Caso de uso (n) “nombre”}

\section{Descripción Caso de uso (n): Perfil A}

\section{Curso básico de Eventos}

A. El caso de uso comienza cuando el usuario Perfil A selecciona...

B. El sistema retorna... El usuario Perfil A selecciona...

n. El sistema retorna... El caso de uso se completa...

\section{Cursos alternativos de Eventos}

Alternativa (etapa): Si el usuario Perfil A lo desea... El caso de uso finaliza / continuará en la etapa...

$$
\text { : }
$$

\section{Descripción Caso de uso (n): Perfil B}

\section{Curso básico de eventos}

A. El caso de uso comienza cuando el usuario Perfil B selecciona ...

B. El sistema retorna... El usuario Perfil B selecciona...

(a partir de acá, idem descripción Caso de uso(n) no personalizado)

\section{Cursos alternativos de Eventos}

(idem descripción Caso de uso(n) no personalizado)

\section{Descripción Caso de uso (n): Perfil X}

Ejemplo $\mathrm{N}^{\mathrm{0}} 8$ :

Utilizaremos el modelo caso de uso personalizado de la figura5.13.

El Caso de uso (1): "Informando sobre los cursos ofrecidos" personalizado tiene dos descripciones alternativas asociadas: la original (confeccionada en el proceso de ingeniería en reversa) asignada al usuario que no sea profesor (Perfil Otros) y una nueva asignada al usuario profesor (Perfil Profesor). 
Caso de uso (1) "Informando sobre los cursos ofrecidos"

\section{Descripción Caso de uso (1) ): Perfil Otros}

\section{Curso básico de Eventos}

A. El caso de uso comienza cuando el usuario Otros selecciona la opción Cursos Ofrecidos del menú que ofrece el sistema en su 'home page'.

B. El sistema retorna la página asociada a ésta opción, mostrando en un menú los nombres y niveles de todos los cursos de inglés que ofrece el Instituto. El usuario Otros selecciona un curso por su nombre.

C. El sistema retorna la página asociada al curso requerido mostrando nombre, nivel, orientación, programa, carga horaria, ..., etc. , de dicho curso. En este caso, el usuario Otros recibe toda la información de la que dispone la aplicación y el caso de uso se completa.

\section{Cursos de Eventos de retroceso}

Retroceso C: Si el usuario Otros lo desea, puede seleccionar otro curso, retrocediendo el caso de uso con la opción atrás de la aplicación de Internet. En este caso, el caso de uso continuará en la etapa $\mathbf{B}$.

\section{Descripción Caso de uso (1): Perfil Profesor}

\section{Curso básico de Eventos}

A. El caso de uso comienza cuando el usuario Profesor selecciona un curso por su nombre del menú que ofrece el sistema en su 'home page', compuesto por el/los cursos que están a su cargo.

B. El sistema retorna la página asociada al curso requerido mostrando no solo los datos básicos del curso (nombre, nivel, orientación, programa, carga horaria, ..., etc.) sino también el número de alumnos inscriptos, el estado de avance de acuerdo al cronograma y ofrece además otros vínculo relacionados con dicho curso y su profesor. En este caso, el usuario Profesor recibe toda la información de la que dispone la aplicación y el caso de uso se completa.

\section{Cursos alternativos de Eventos}

Alternativa B: Si el usuario Profesor lo desea puede seleccionar el vínculo MisAlumnos que ofrece el sistema en esta página. En este caso, el caso de uso retornará una página que ofrece al usuario Profesor el listado de los alumnos de su curso. De cada alumno provee además el dni y la edad. El usuario Profesor recibe la información y dispone de la misma para su navegación, impresión y 'download'. El usuario Profesor puede seleccionar una de estas operaciones, la operación se llevará a cabo y el caso de uso se completará.

Alternativa B: Si el usuario Profesor lo desea puede seleccionar el vínculo MisCalificaciones que ofrece el sistema en esta página. En este caso, el caso de uso retornará una página que ofrece al usuario Profesor un reporte del registro de calificaciones de los alumnos de su curso. El usuario Profesor recibe la información y dispone de la misma para su navegación, impresión y 'download'. El usuario Profesor puede seleccionar una de estas operaciones, la operación se llevará a cabo y el caso de uso se completará.

\subsubsection{UIDs para aplicaciones Web personalizadas}

Tal como lo señalamos en 5.4.4, nuevamente el UID [Vilain00], (capítulo3), es la herramienta gráfica que nos va a permitir construir un nexo entre el modelado externo y el modelado interno, en este caso, de la aplicación Web personalizada. La tarea consiste en representar cada caso de uso personalizado (con todas sus descripciones alternativas) en un UID que refleje los perfiles de usuarios destinatarios de dicho caso de uso. El método prescripto en [Vilain00], citado en 5.4.4, nos auxilia en esta tarea, pero no resulta suficiente ya que debemos introducir algunos cambios a la representación gráfica de los UIDs para que se ajusten a los requerimientos de personalización. 
Para confeccionar el UID personalizado proponemos Figura 5.14:

- crear una interacción de entrada para cada perfil de usuario que sea destinatario de una descripción alternativa del caso de uso a representar. Si el caso de uso tiene una alternativa para todos, usuarios en general, crear la interacción de entrada necesaria que lo refleje. Para facilitar el reconocimiento visual de cada perfil involucrado, mantener el color asignado a dicho perfil en el modelo caso de uso personalizado, reflejando el grado de personalización de la siguiente manera: interacción en color $=$ personalización a nivel de grupo o perfil 'coarse grained' y elementos de la interacción en color = personalización a nivel de individuo 'fine grained'; el color negro representa reuso de la descripción original del caso de uso en la interacción.

- por cada entrada creada aplicar el método citado en 5.4.4, prescripto en [Vilain00], para determinar las interacciones sucesivas, conectores y operaciones.

- integrar la representación unificando aquellas interacciones que sean comunes a más de un perfil.

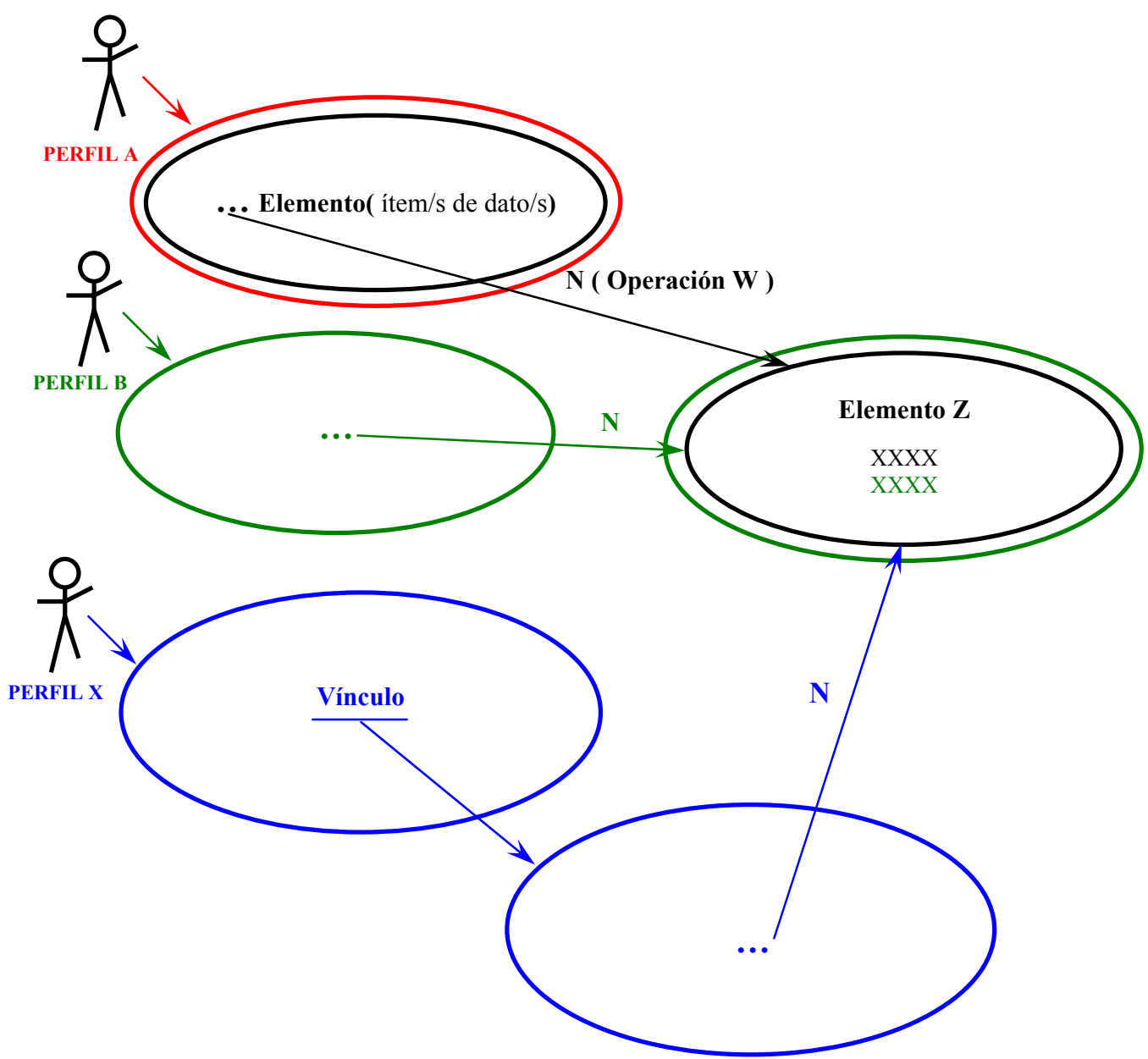

Figura 5.14: Ejemplo de UID personalizado para un hipotético

Caso de Uso (n) “nombre” Perfil A, Perfil B y Perfil X

Ejemplo N9 Figura 5.15.

Utilizaremos la aplicación Web para el instituto de inglés incorporada en 5.5.2.1, cuyo modelo caso de uso personalizado es el correspondiente a la figura5.8.

Aplicando lo prescripto, el Caso de uso (1): "Informando sobre los cursos ofrecidos" personalizado deriva en el siguiente UID personalizado: 


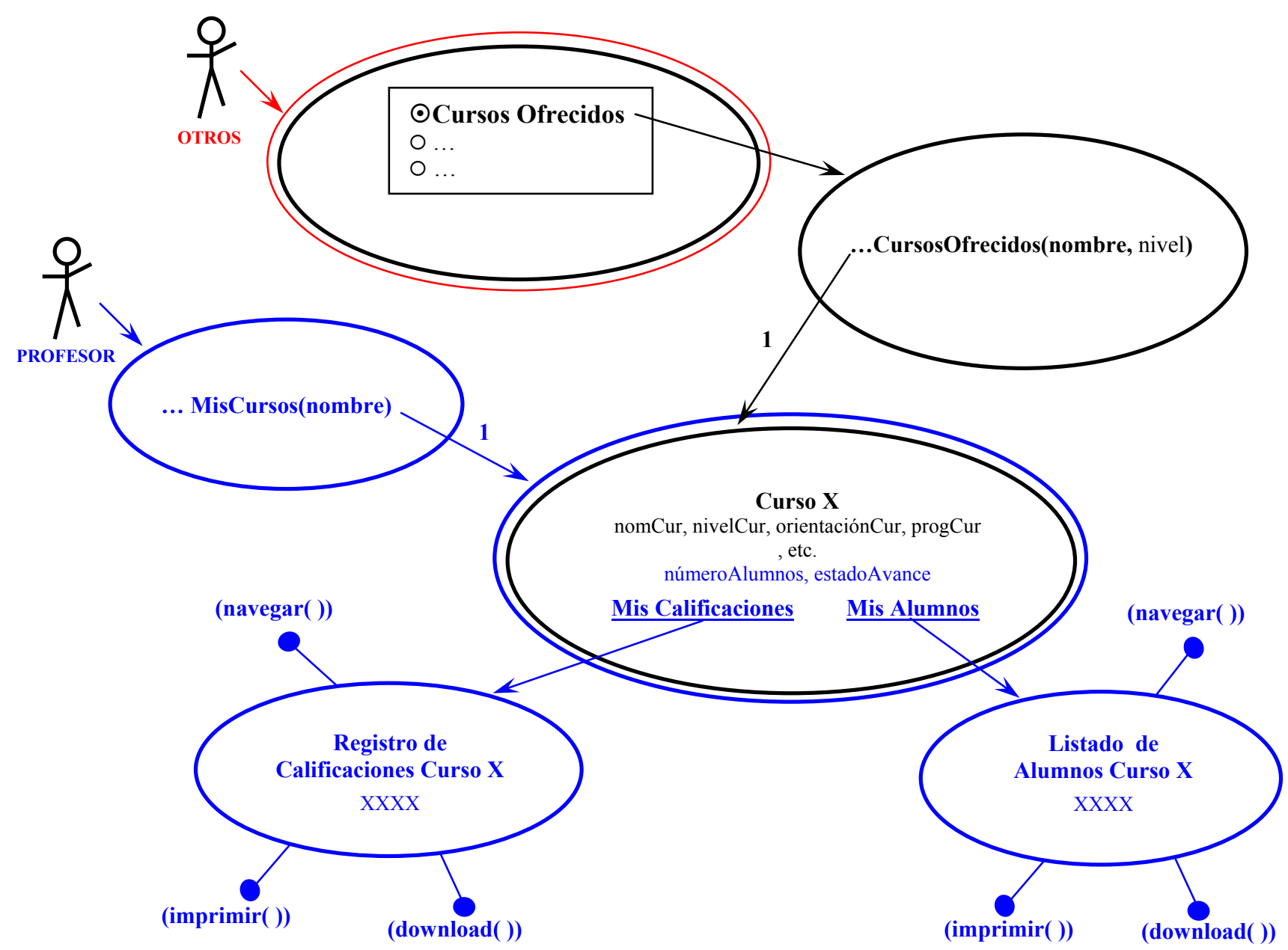

Figura 5.15: UID para el Caso de Uso (1) "Informando sobre los cursos ofrecidos" Perfil Otros y Perfil Profesor

\subsubsection{Nuevo modelo interno}

El concepto clave del enfoque OOHDM [Schwabe98a] y [OOHDM00], (capítulo3), es que el modelado de una aplicación Web conlleva a un Modelo Conceptual (que captura la semántica del dominio de la aplicación) y un Modelo de Navegación (que define la estructura de navegación para dicha aplicación). Este contexto que ofrece el enfoque OOHDM, donde los modelos conceptual y de navegación pueden ser tratados por separado, resulta propicio para la ejecución de los Pasos 5 y 6 del proceso de ingeniería 'forward' para obtener el modelo objeto de la aplicación Web personalizada.

El enfoque OOHDM provee algunos 'hot-spots' dentro de los cuales podemos especificar estructuras y comportamiento personalizado [Rossi01b]:

- en el modelo conceptual: explícitamente representando usuarios, roles o perfiles y grupos definiendo algoritmos que implementen diferentes reglas para diferentes usuarios.

- en el modelo de navegación: definiendo aplicaciones diferentes para cada rol o perfil, personalizando el contenido y la estructura del nodo y los índices y 'links'.

Estos aspectos de personalización pueden ser dirigidos a nivel de grupo de usuarios 'coarse grained personalization' o a nivel de individuo 'fine grained personalization'. Es por ello que en los modelos personalizados propuestos para el proceso de ingeniería 'forward' se ha hecho hincapié en incorporar componentes que reflejen el grado de personalización requerido para la nueva aplicación Web personalizada. 


\subsubsection{Obtención de un modelo conceptual que responde a los requerimientos de personalización}

La utilización de la palabra adaptar en el Paso 5 de nuestro proceso de ingeniería 'forward', no es casual. Justamente, el principio de un proceso de reingeniería es trabajar sobre el modelo del dominio existente para producir cambios que van allá de meras mejoras sin que esto implique de ninguna manera desechar dicho modelo. La experiencia indica, que la mayoría de los tipos de personalización (si no todos) finalmente involucran algún tipo de adaptación al modelo conceptual. Nuestro enfoque para la reingeniería de personalización de aplicaciones Web, respalda el principio de reingeniería propiciando técnicas y enfoques que permiten incorporar la personalización requerida minimizando y suavizando los cambios en el modelo del dominio [Rossi01c].

Tal como señalamos en el Paso 5 del proceso de ingeniería 'forward', el ejercicio de aplicar a los UIDs personalizados el conjunto de reglas que se detallan en 5.4.5.1, [Vilain00] y [Güell00a], permite descubrir la necesidad de incluir en el modelo conceptual nuevos objetos o de agregar atributos o comportamiento a objetos existentes. Para realizar esta adaptación, sugerimos considerar e incorporar los conceptos de diseño de aplicaciones Web personalizadas con patrones de personalización, [Rossi01c], [Schwabe02] y [Bäumer00], que resulten más apropiados a los requerimientos de personalización de la aplicación Web en cuestión.

Ejemplo $\mathrm{N}^{\mathrm{o}} 10$ Figura 5.16:

Trabajaremos con el UID personalizado de la aplicación Web para el instituto de inglés correspondiente a la figura5.15 y el Modelo conceptual original correspondiente a la figura5.8.

Aplicando lo prescripto, surge el siguiente Modelo conceptual que incorpora una propuesta de adaptación:

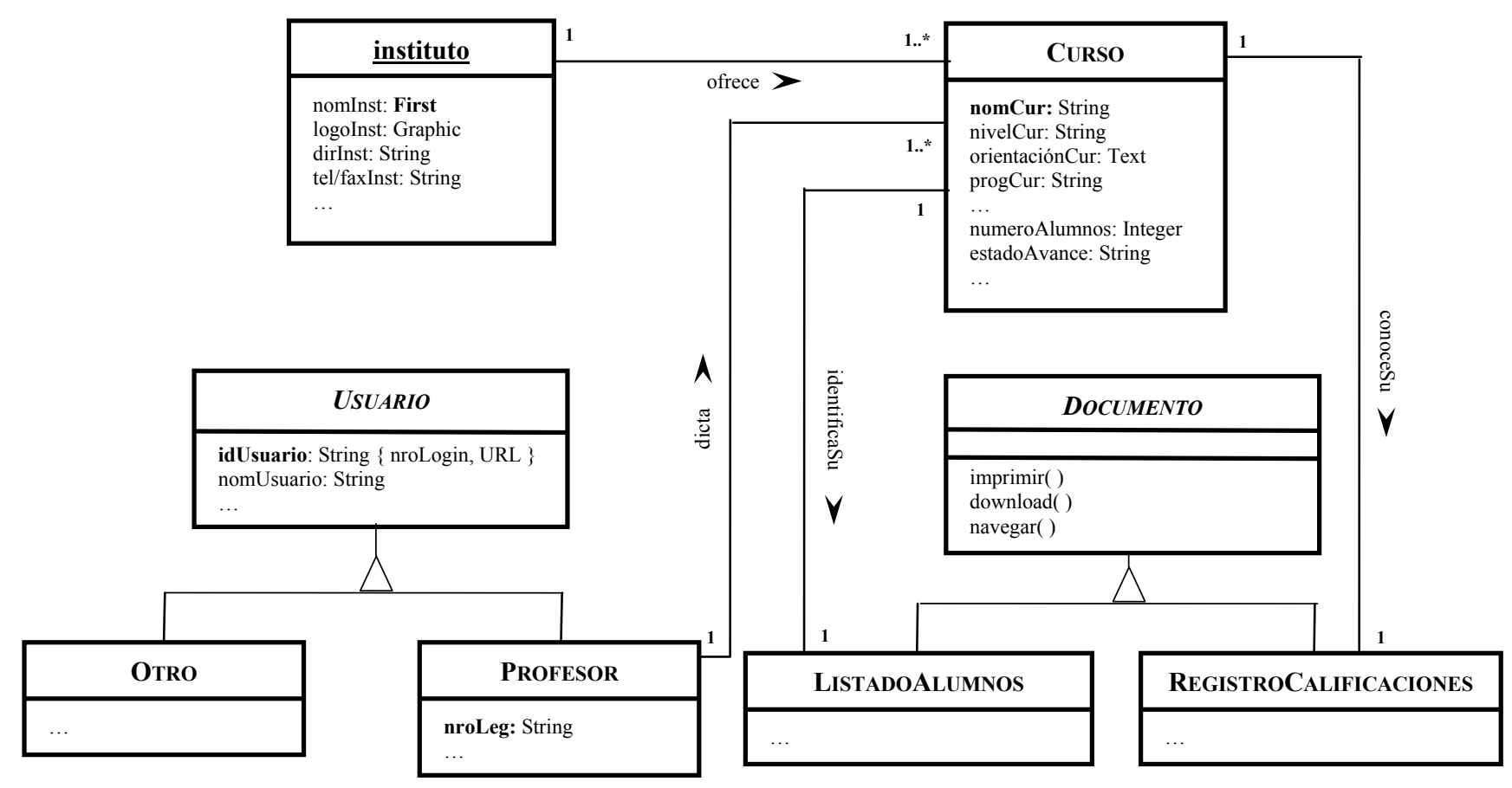

Figura 5.16: Modelo conceptual resultante de aplicar las directivas del paso 5 del proceso de ingeniería 'forward' 


\subsubsection{Obtención de un modelo de navegación incorporando patrones de personalización: Diagrama de clases de navegación y Diagrama de contexto de navegación}

Tal como señalamos en el Paso 6 del proceso de ingeniería 'forward', el ejercicio de aplicar a los UIDs personalizados el método que se detalla en 5.4.5.2, [Güell00a] y en [Güell00b], permite descubrir la necesidad de incluir nuevos nodos o de agregar atributos a nodos existentes y de incorporar contextos y estructuras de acceso a objetos existentes. Para realizar esta adaptación, sugerimos considerar e incorporar los conceptos de diseño de aplicaciones Web personalizadas con patrones de personalización, [Rossi01b] y [Schwabe02], que resulten más apropiados a los requerimientos de personalización de la aplicación Web en cuestión.

Quizás, es en este punto dónde el conflicto mayor se presenta, ya que reflejar la personalización y sus grados en los respectivos diagramas de navegación no es una tarea para la cual siempre existen todas las herramientas necesarias. Como ya mencionamos, el punto fuerte de partida consiste en explotar el concepto clave que ofrece el enfoque OOHDM [Schwabe98a] y [OOHDM00], (capítulo3), que permite tratar por separado los modelos conceptual y de navegación. De hecho, una aplicación Web es considerada por OOHDM como una 'vista' construida sobre el modelo conceptual. Más aún, es posible definir tantas aplicaciones (vistas) sobre el mismo modelo conceptual como perfiles de usuarios sean requeridos.

Ligando concepto (vistas 'views' + patrones de personalización), las vistas, son una de las primitivas que brinda el enfoque OOHDM para diseñar Link Personalization y Content Personalization para Role-Based Personalization [Schwabe02].

Ejemplo $\mathrm{N}^{\mathrm{o}} 11^{\text {Figura }}$ 5.17:

Trabajaremos con el UID personalizado de la aplicación Web para el instituto de inglés correspondiente a la figura5.15 y el Modelo conceptual correspondiente a la figura5.16.

Aplicando lo prescripto e identificando patrones de personalización, surgen los siguientes dos Esquemas de clases de navegación, uno por cada perfil de usuario:

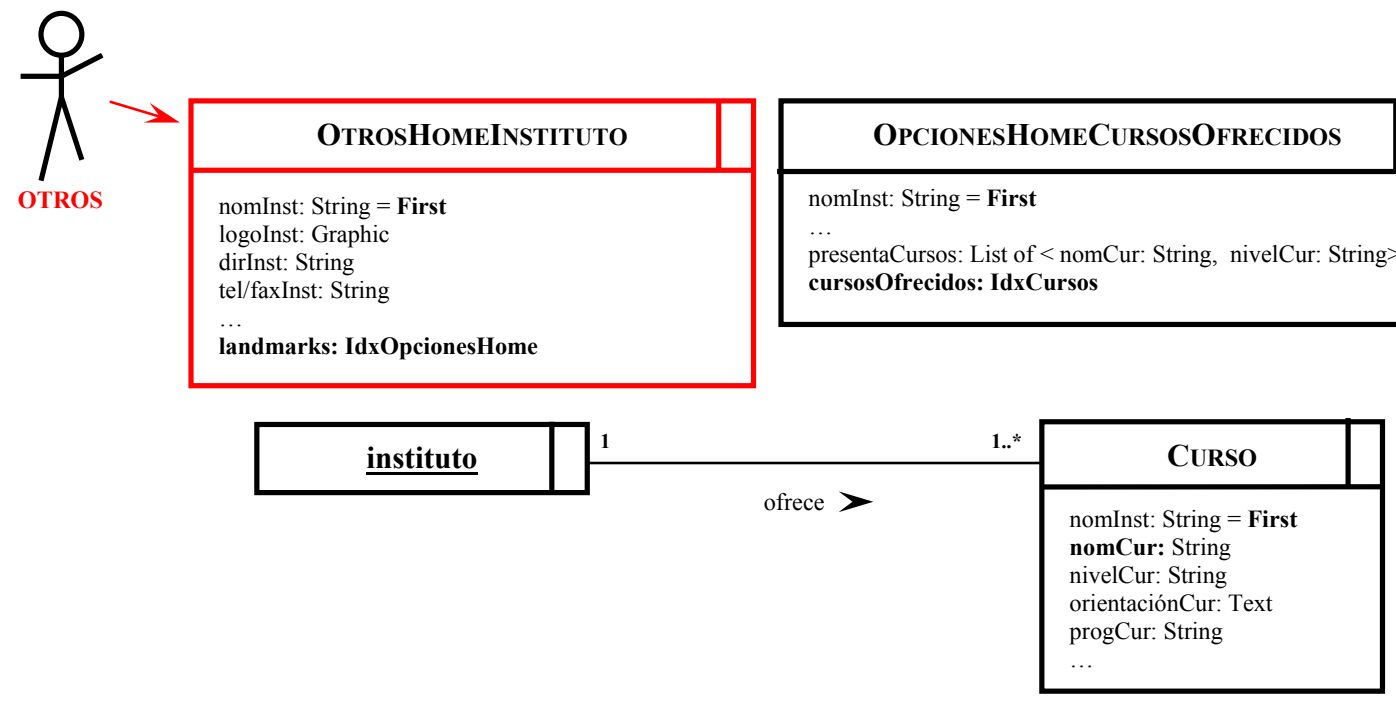

Figura 5.17a: Vista del Perfil Otros 


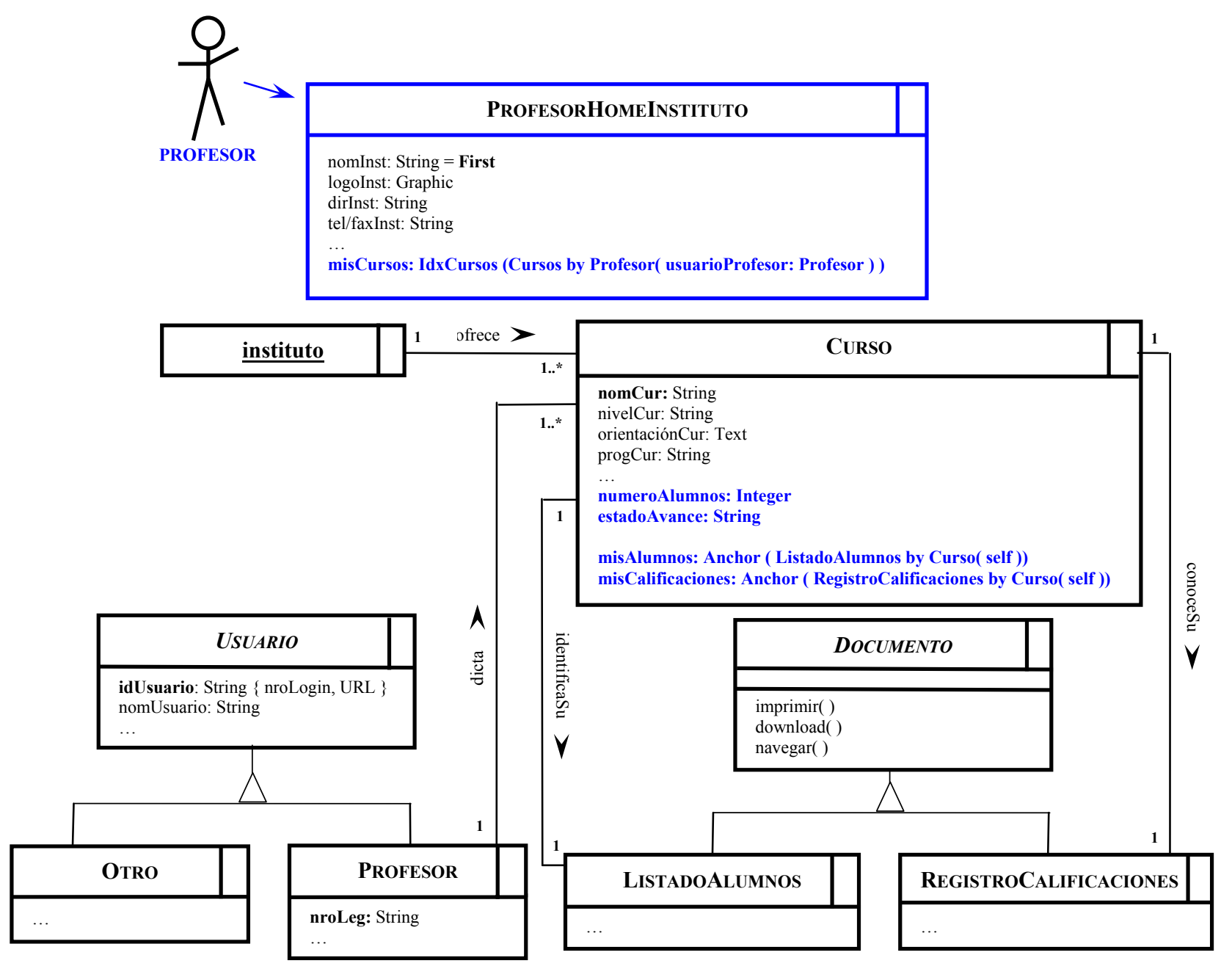

Figura 5.17b: Vista del Perfil Profesor

Figura 5.17: Diferentes Esquemas de clases de navegación correspondiente al UID "Informando sobre cursos ofrecidos" para Perfil Otros y Perfil Profesor

En nuestro ejemplo, el Esquema de clases de navegación original se convierte en la vista asignada a los usuarios pertenecientes al Perfil Otros, es decir, todos aquellos usuarios que no son profesores del instituto 'First'. La vista asignada a los usuarios pertenecientes al Perfil Profesor, incorpora además Individual-Based Personalization, ya que el atributo misCursos es un índice cuyos componentes permiten acceder a los nodos de los cursos dictados por el usuarios-profesor actual y los atributos misAlumnos y misCalificaciones son 'anchors' a los nodos ListadoAlumnos y RegistroCalificaciones respectivamente que se correspondan con el curso dictado y seleccionado para su navegación por el usuario-profesor actual.

El próximo paso es definir el Esquema de contextos de navegación para completar el modelo de navegación de la aplicación Web personalizada.

La personalización de los contextos de navegación es una actividad crítica cuando la misma información (nodo) puede ser alcanzado en diferentes situaciones. En el enfoque OOHDM usamos una especificación declarativa simple para indicar: 
- qué nodos están contenidos en un contexto y

- qué usuarios o perfiles de usuarios están autorizados a ver un nodo dentro de un contexto en particular [Rossi01b].

El conjunto de nodos se especifica usando expresiones que determinen que nodos formarán parte de dicho conjuntos y las restricciones de acceso (si existen) se especifican en las cartas de contexto 'Context cards' señalando ya sea un perfil de usuario o una expresión indicando una condición sobre el objeto del usuario [Schwabe98a].

Surge aquí la conveniencia de contar además con una herramienta gráfica que permita reflejar la personalización y sus grados en el esquema de contexto de navegación. El enfoque OOHDM no provee aún una herramienta de este tipo.

A los efectos de atenuar esta necesidad, proponemos anexar las siguientes consignas al graficar el Esquema de contextos de navegación personalizado Figura 5.17:

- crear una entrada por cada vista destinada a un perfil de usuario. Para facilitar el reconocimiento visual de cada perfil involucrado, mantener los colores que se les asignaron.

- definir para los objetos involucrados las estructuras de accesos y los contextos que sean requeridos por cada perfil de usuario.

- indicar la personalización a nivel de individuo, 'fine grained', graficando los 'links', las estructuras de acceso y los contextos en el color asignado al perfil al que pertenece el individuo y especificando a dicho individuo (usuario actual) sobre el 'link' correspondiente (filtro que determina que los elementos del contexto son solo aquellos con los que se relaciona el usuario actual).

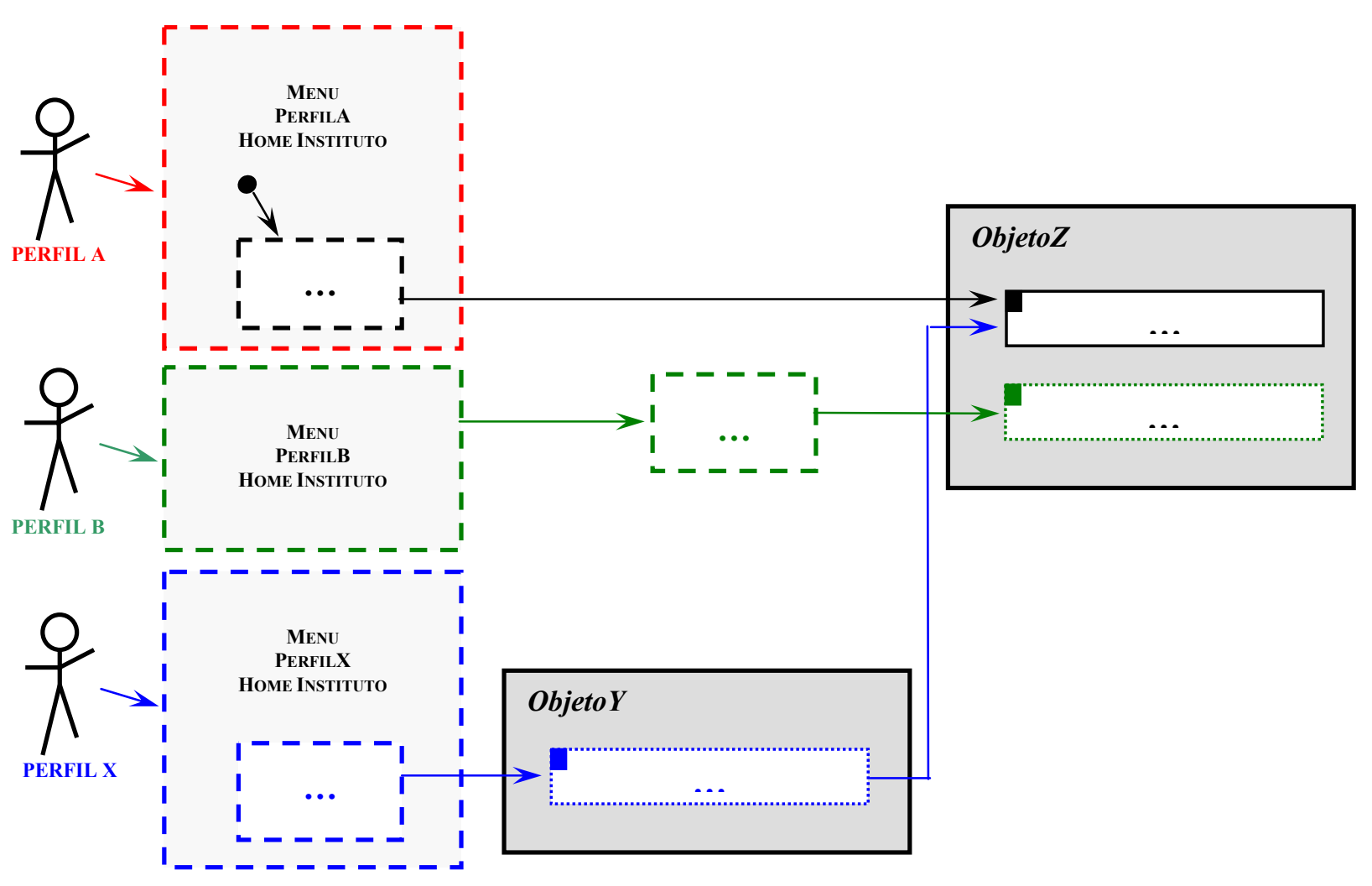

Figura 5.18: Ejemplo de Esquema de contextos de navegación para un hipotético Caso de Uso (n) “nombre”" Perfil A, Perfil B y Perfil X 
Ejemplo No12 Figura 5.19:

Trabajaremos con el UID personalizado de la aplicación Web para el instituto de inglés correspondiente a la figura5.15, el Modelo conceptual correspondiente a la figura5.16 y el Modelo de clases de navegación correspondiente a la figura5.17.

Aplicando todo lo prescripto surge el siguiente Esquema de contextos de navegación:

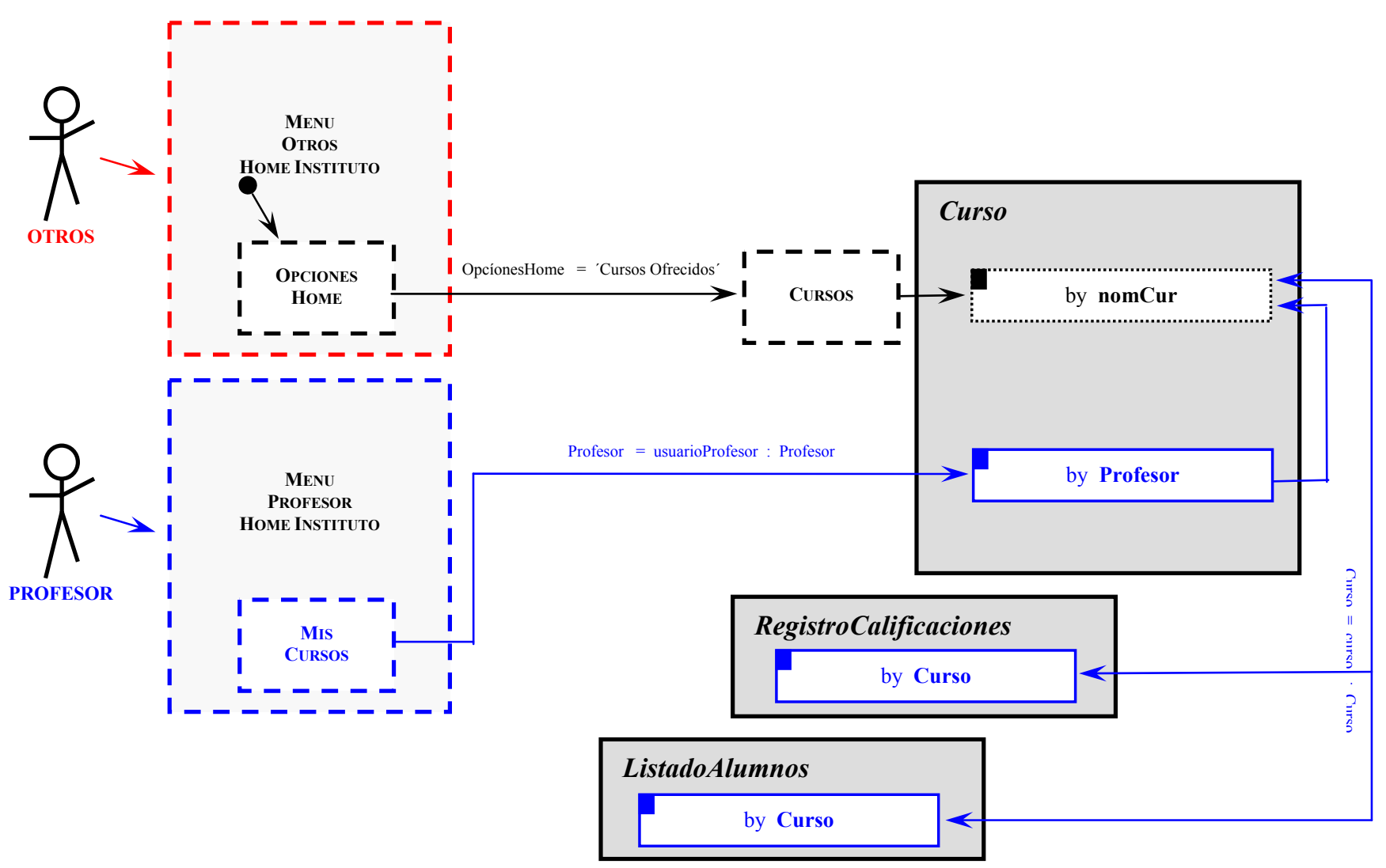

Figura 5.19: Diagrama de contexto de navegación correspondiente al UID "Informando sobre cursos ofrecidos" para Perfil Otros y Perfil Profesor

Ya mencionamos en este ítem, que el enfoque OOHDM provee cartas de contexto 'Context cards', que permiten aplicar filtros a nivel de perfil de usuario 'Role-Based Personalization' o nivel de individuo 'Individual-Based Pesonalization' para reflejar la personalización y sus grados [Rossi01b] y [Schwabe02].

El Diagrama de contexto de navegación de la figura5.19 puede respaldar las siguientes especificaciones de cartas de contextos:

Context: Curso By Profesor

PARAMETERS: usuarioProfesor : Profesor

Elements: c : Curso Where c esDictado By usuarioProfesor

INCONTEXT Class: ---

NAVEGATION: by index

ACCESS Restriction: Profesor Permission: navegar 
ConteXt: ListadoAlumnos By Curso

PARAMETERS: curso : Curso

Elements: I : ListadoAlumnos WhERE I esIdentificado By curso

INCONTEXT CLASS: ---

NAVEGation: by index

ACCess Restriction: Profesor Permission: navegar, imprimir, download

ConteXt: RegistroCalificaciones By Curso

PARAMETERS: curso : Curso

ELEMENTS: $\mathbf{r}$ : RegistroCalificaciones WHERE $\mathbf{r}$ esConocido By curso

INCONTEXT ClASS:

NAVEGATION: by index

ACCess Restriction: Profesor Permission: navegar, imprimir, download

En este punto, se concretó el Modelo Objeto que es el producto resultante del proceso de ingeniería 'forward' y el objetivo del proceso de reingeniería de personalización. Además, están dadas las condiciones y existen todos los elementos para que este sea también el punto de partida para lanzar las actividades de Diseño de Interfaz Abstracta y de Implementación de la aplicación Web personalizada (que como ya indicamos esta fuera del alcance de este tesis).

En el capítulo siguiente, aplicamos completamente nuestro enfoque a un caso real, la aplicación Web correspondiente a la Corporación Weatherford, cuyo sitio es: http://www.weatherford.com . 


\section{Capítulo 6}

\section{APLiCANDO EL ENFOQUE}

\subsection{Acerca de la Corporación Weatherford}

Weatherford International Inc. se estableció en mayo de 1988 después de la fusión entre EVI Inc. y Weatherford Enterra Inc. Esta fusión creó una de las compañías más grandes de servicios al yacimiento petrolífero en el mundo, situándola entre las cuatro primeras en su especie con ingresos anuales por encima de los 2 billones de dólares.

EVI Inc., que adopta el nombre y el logotipo de Weatherford después de la fusión, por el fuerte reconocimiento mundial del que goza está última en el mercado petrolero, fue creada en 1987 y en menos de 12 años la compañía completó más de 40 adquisiciones, desde tecnología de 'artificial lift' hasta sofisticados productos de 'completion and drilling'.

Por su parte, el nombre 'Weatherford' data de 1940, cuando el Sr. Jess Hall funda Weatherford Spring Company en Weaherford, un pequeño pueblo petrolero del estado de Texas. Desde entonces, Weatherford se ha convertido rápidamente en una de las fuerzas mayores en los sectores de producción y terminación de la industria petrolera, afianzando su posición de liderazgo en el mercado mundial al concretar la fusión con EVI Inc.

A través de sus tres divisiones: Completion Systems, Drilling \& Intervention Services y Artificial Lift Systems, Weatherford International Inc. opera en 50 países y con más de 300 locaciones en el mundo desde las cuales ofrece sus productos, servicios y sistemas.

En Argentina, su presencia data de 1994, con bases operativas y administrativas en lo principales puntos de producción petrolera del país: Neuquén, Chubut, Río Gallegos, Salta y Mendoza, plantas de producción y reparación en Córdoba y San Luis y oficina central en la Capital Federal.

\subsection{Un sitio en la Web: http://www.weatherford.com}

El objetivo principal de este sitio es ser una fuente de contacto válida y genuina con la corporación Weatherford International Inc. Oil Field Services. La consigna básica en este sentido, es mantener una aplicación capaz de ofrecer al usuario un acceso conveniente al sitio, capturando su atención y proporcionando respuesta a sus inquietudes.

En un contexto tan complejo como el de las aplicaciones de hipermedia, signado por la evolución constante de los requerimientos para la concepción de sitios Web y los consecuentes cambios en las preferencias y gustos de los usuarios de estos sitios, sostener la consigna señalada, no resulta una tarea sencilla. Como si esto fuera poco, el advenimiento de la personalización agrega un ingrediente más al escenario en el cual la reingeniería debe dar respuestas a aplicaciones legales existentes.

Frente a esta realidad, el caso real seleccionado sufre las consecuencias propias de la falta de actualización sostenida, mostrando a sus usuarios un sitio con una apariencia excesivamente conservadora y sin personalización. Existe una excepción para el conjunto de usuarios empleados de la compañía, a los cuales se les ofrece un sitio que anexa cierta funcionalidad distintiva a la del resto de los usuarios (personalización 'coarse grainned' para los usuarios pertenecientes al perfil empleado). Estos usuarios son identificados por la aplicación a través de su $\mathrm{N}^{\mathrm{o}}$ de Login.

\section{3 ¿Cuáles es nuestra directiva de reingeniería?}

Ya se señaló, que el esfuerzo de reingeniería de personalización da inicio con la directiva de reingeniería de personalización, la cual expresa en un lenguaje concreto y sencillo las características deseadas en el nuevo sitio. 
Para el caso real, nuestra directiva de reingeniería es:

- Mejorar la aplicación para que el usuario se sienta considerado por el sitio.

- Modificar la aplicación para que exhiba visiones diferentes, acordes a los perfiles de usuarios que hoy comparten una misma visión del sitio: inversor, cliente actual y cliente potencial.

- Permitir que la aplicación sea lo suficientemente sensible para percibir y responder muy bien a las necesidades individuales de los usuarios del sitio, pertenecientes a los perfiles empleado, inversor y cliente actual.

\subsection{Haciendo ingeniería en reversa}

Para concretar la actividad de ingeniería en reversa, aplicaremos paso a paso el procedimiento propuesto en 5.4.1 al caso real. En primera instancia, definiremos el modelo caso de uso y delinearemos nuestra especificación objetiva. Luego, describiremos los casos de uso más prometedores y posteriormente, confeccionaremos los UIDs correspondientes a los casos de uso seleccionados. Finalmente, utilizando como puente a los UIDs obtendremos el modelo objeto. En este punto, la actividad de ingeniería en reversa se habrá concretado en un modelo del sitio existente, es decir un modelo que refleja cómo es y opera la aplicación actual.

\subsubsection{Comprendiendo el sitio actual: modelo caso de uso general}

Paso 1. Trabajar con las opciones de la 'home page' del sitio Figura 6.1 - Figura 6.2 y los perfiles de usuarios, a los efectos de reconocer casos de uso que permitan representar y describir al sitio existente.

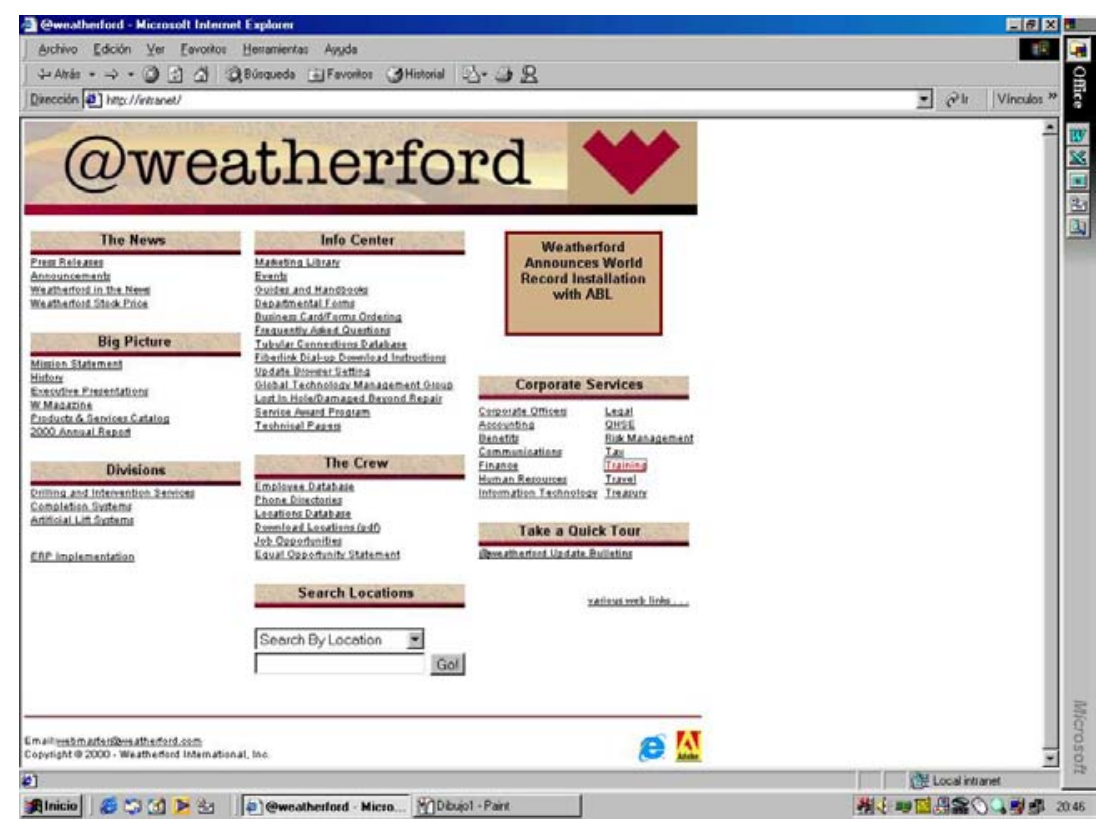

Figura 6.2: 'Home page' del sitio para los usuarios Empleados 


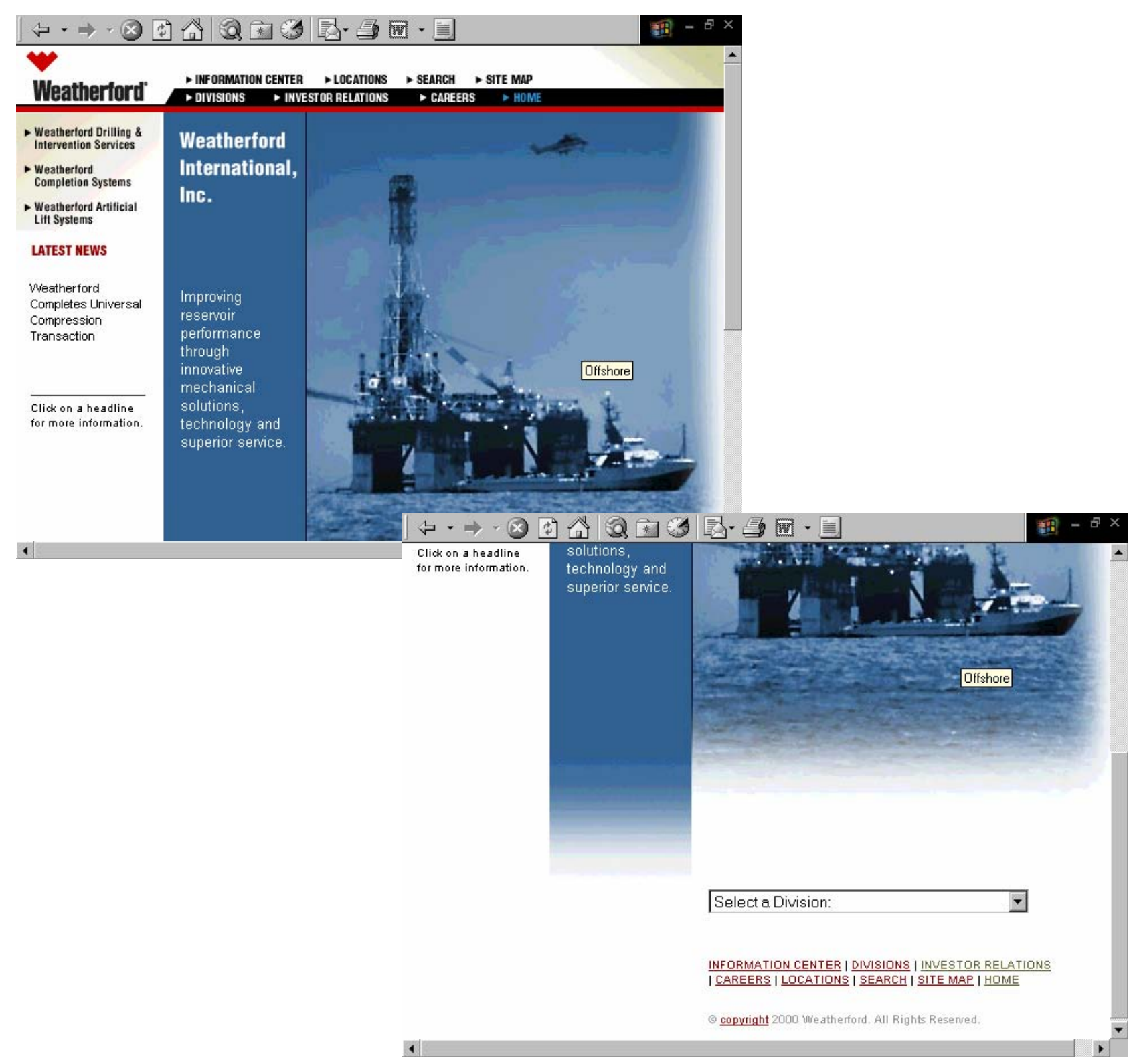

Figura 6.2: 'Home page' del sitio

Los perfiles de usuarios identificados para el caso real son:

i Usuarios como Empleados de la Compañía

insuarios como Inversores de la Compañía

i. Usuarios como Clientes Actuales de la Compañía

î Usuarios como Clientes Potenciales de la Compañía 
La figura ${ }^{\text {Figura } 6.3}$ es un primer bosquejo del sitio existente (caso real) y sus usuarios.

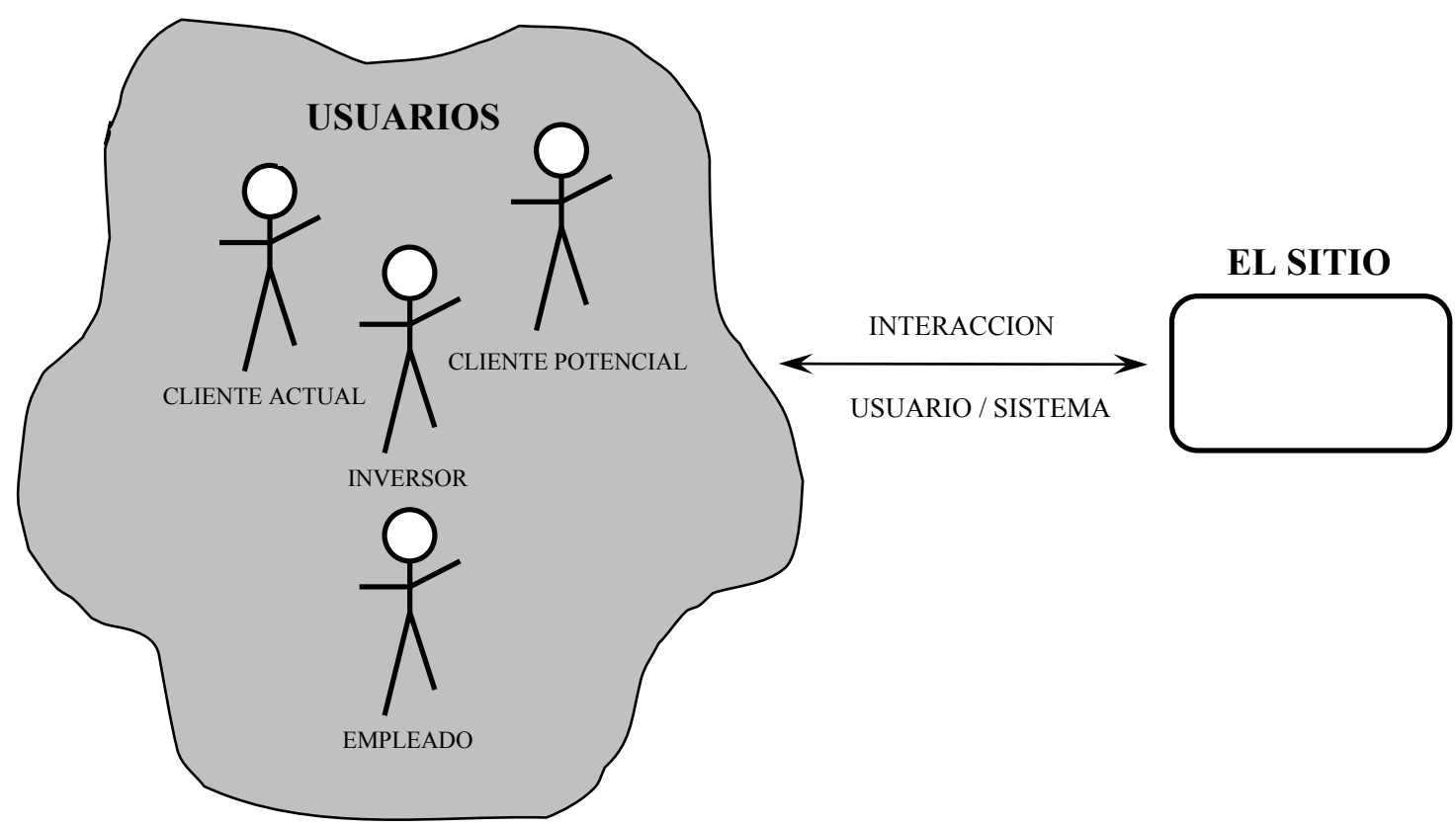

Figura 6.3: El sitio y sus usuarios

Se reconocen los siguientes Casos de uso:

(1) Suministrando mapa del sitio

(2) Comunicando noticias de la compañia

(3) Ubicando locaciones en el mundo

(4) Navegando líneas de prestaciones dada una división

(5) Brindando información financiera

(6) Realizando búsqueda de productos, servicios y sistemas

(7) Ofreciendo oportunidades laborales

(8) Informando prestaciones al yacimiento petrolífero

(9) Posibilitando llamadas en conferencia

(10)Posibilitando envío de inscripción en cursos de capacitación

Paso 2. Construir un modelo caso de uso general Figura 6.4; un retrato del sitio factible de ser comunicado a los interesados para su discusión. 


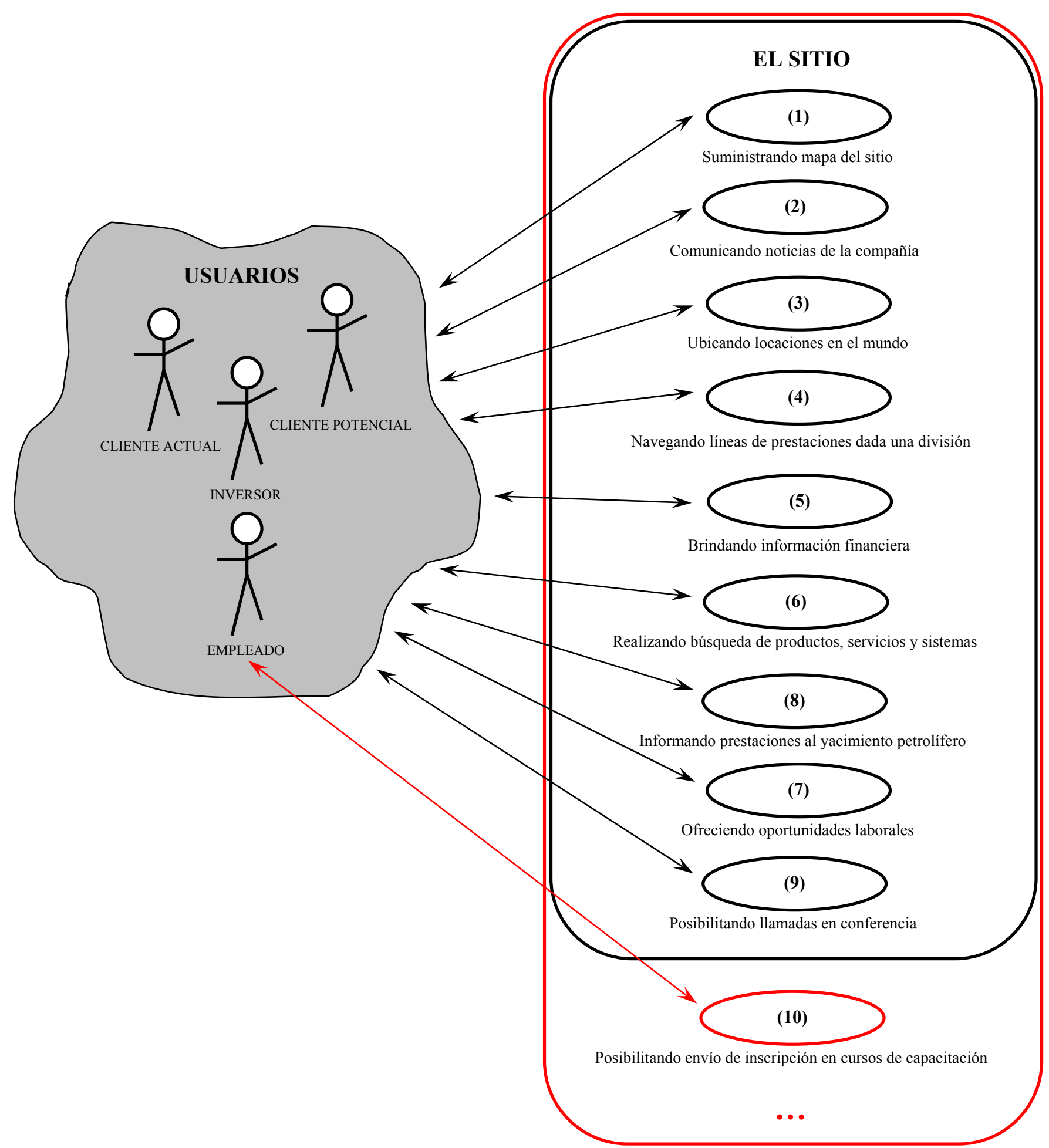

Figura 6.4: Modelo Caso de Uso General del sitio

Paso 3. Seleccionar los casos de uso más prometedores (utilizar para tal fin la directiva de reingeniería de personalización del sitio).

El modelo caso de uso del sitio existente evidencia un sitio prácticamente sin personalización, ya que su visión es única para los perfiles de usuarios inversor, cliente actual y cliente potencial. La tarea de priorizar los casos de uso se llevará a cabo según lo señalado en 5.4.2.2 a los efectos de dar 
respuesta a la directiva de reingeniería. Recordemos que un caso de uso prometedor es aquel para el cual resulte interesante aplicar el proceso de reingeniería, es decir, es un caso de uso que tiene potencial de renovación con impacto positivo en sus usuarios.

Teniendo en cuenta lo señalado, se seleccionan los siguientes casos de uso:

(2) Comunicando noticias de la compañía

(4) Navegando líneas de prestaciones dada una división

(5) Brindando información financiera

(8) Informando prestaciones al pozo petrolifero

(10) Posibilitando envío de inscripción en cursos de capacitación

Paso 4. Describir los casos de uso seleccionados en un lenguaje natural y simple: curso básico de eventos, cursos alternativos de eventos y cursos de eventos de retroceso. Este último curso de eventos no existe en el enfoque original de Jacobson [Jacobson94], y lo proponemos a los efectos de extender la aplicabilidad del enfoque a las características propias de un sistema que tiene el comportamiento de un sitio.

\section{Caso de uso (2) “Comunicando noticias de la compañía”}

\section{Descripción Caso de uso (2)}

\section{Curso básico de eventos}

A. El caso de uso comienza cuando el usuario selecciona una noticia por su título del menú que ofrece el sistema en su 'home page', compuesto por las noticias más recientes de la Compañía. Figura $\mathbf{6 . 5}$

B. El sistema retorna la página, asociada a la noticia requerida, mostrando al usuario título, lugar, fecha, texto y fuente de la misma y el nombre y logotipo de la Compañía, para su lectura Figura 6.6 y el caso de uso se completa.

C. El sistema retornará una página con nombre del Dpto., nombre, logotipo y nombre corporativo de la Compañía y un menú compuesto por las noticias archivadas, mostrando título y fecha de las mismas. El usuario seleccionará una noticia archivada por su título y el caso de uso continuará en la etapa $\mathbf{B}$.

\section{Cursos alternativos de eventos}

Alternativa A: Este caso de uso también puede comenzar cuando el usuario selecciona el tópico Comunicados de Prensa, incluido en el menú de tópicos que componen las opciones Relaciones de

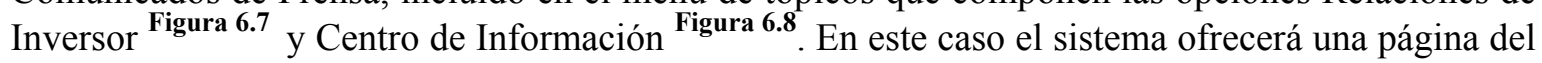
Dpto. Relaciones de Inversor, con un menú compuesto por las noticias actuales (donde están incluidas las noticias más recientes que se exhiben en la ventana activa de la 'home page') y un vínculo a noticias archivadas, mostrando además nombre y logotipo de la Compañía y nombre del Dpto. De cada noticia el sistema mostrará título y fecha. Figura 6.9 Si el usuario selecciona una noticia actual por su título, el caso de uso continuará en la etapa B. Caso contrario, si el usuario selecciona el vínculo a noticias archivadas el caso de uso continuará en la etapa $\mathbf{C}$. 


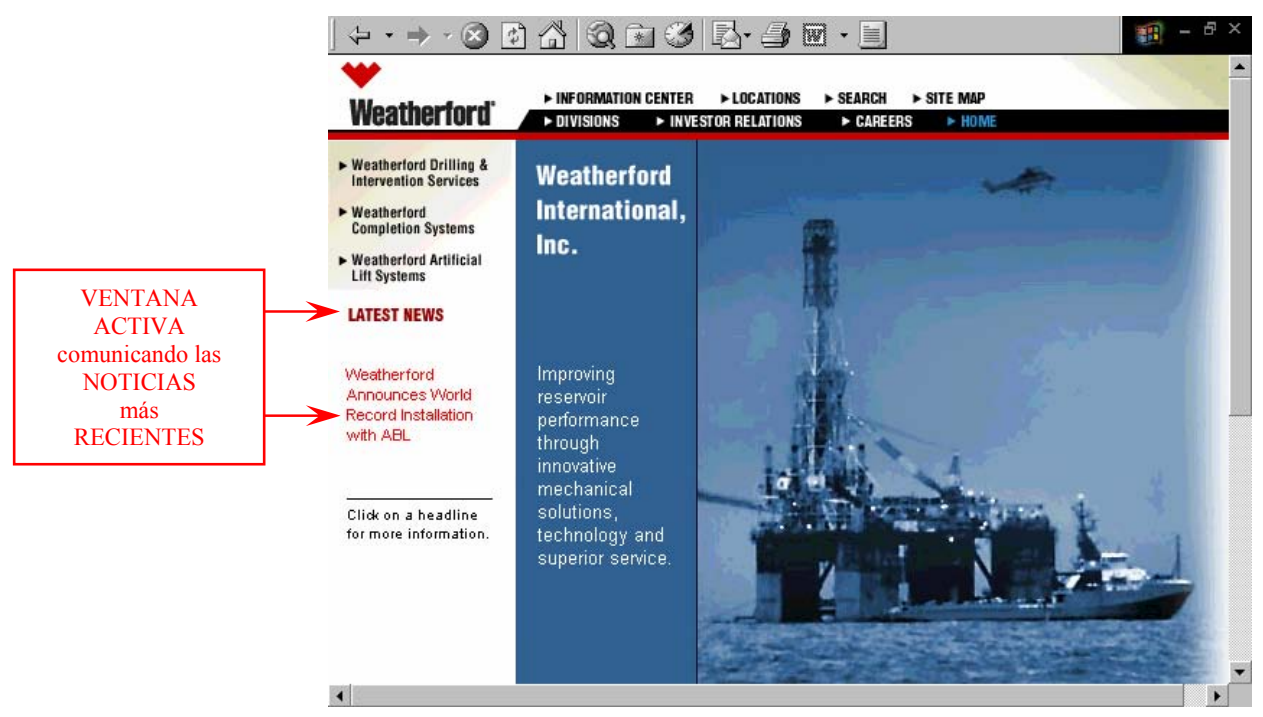

Figura 6.5: Seleccionando una noticia reciente desde la 'home page' del sitio

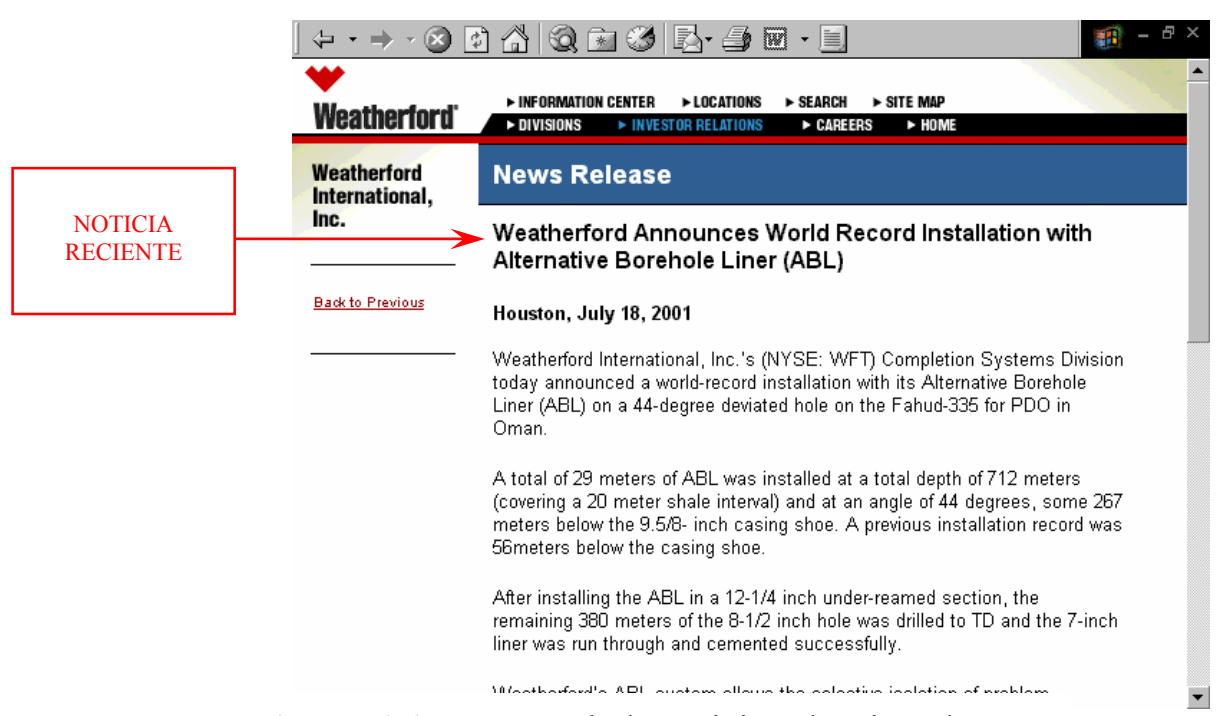

Figura 6.6: Navegando la noticia seleccionada

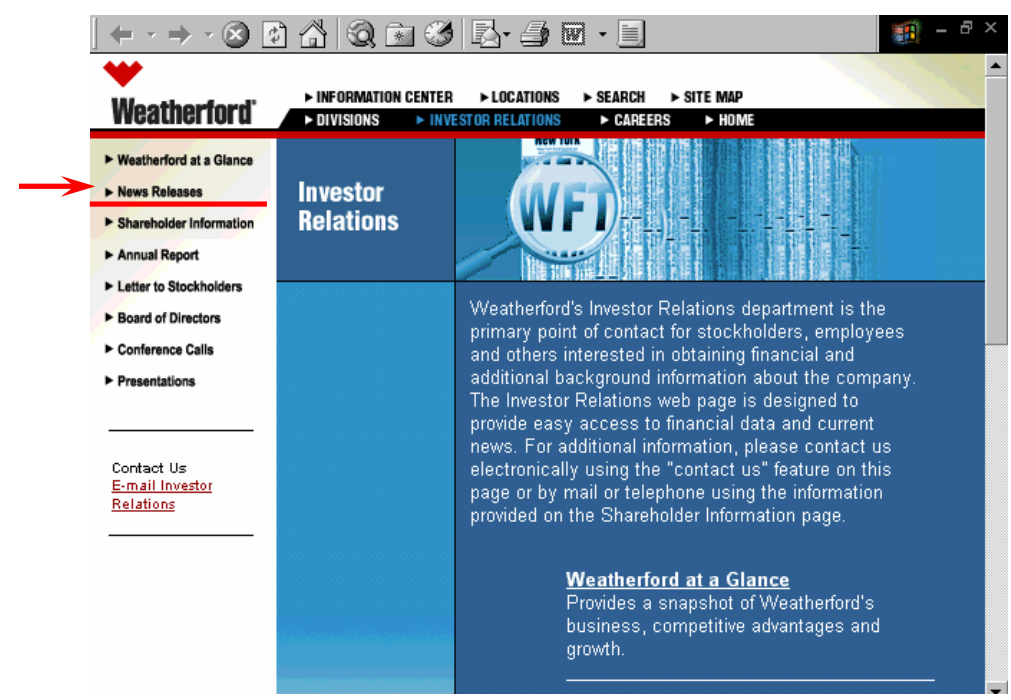

Figura 6.7: Seleccionando el tópico Comunicados de prensa desde la opción Relaciones de Inversor 


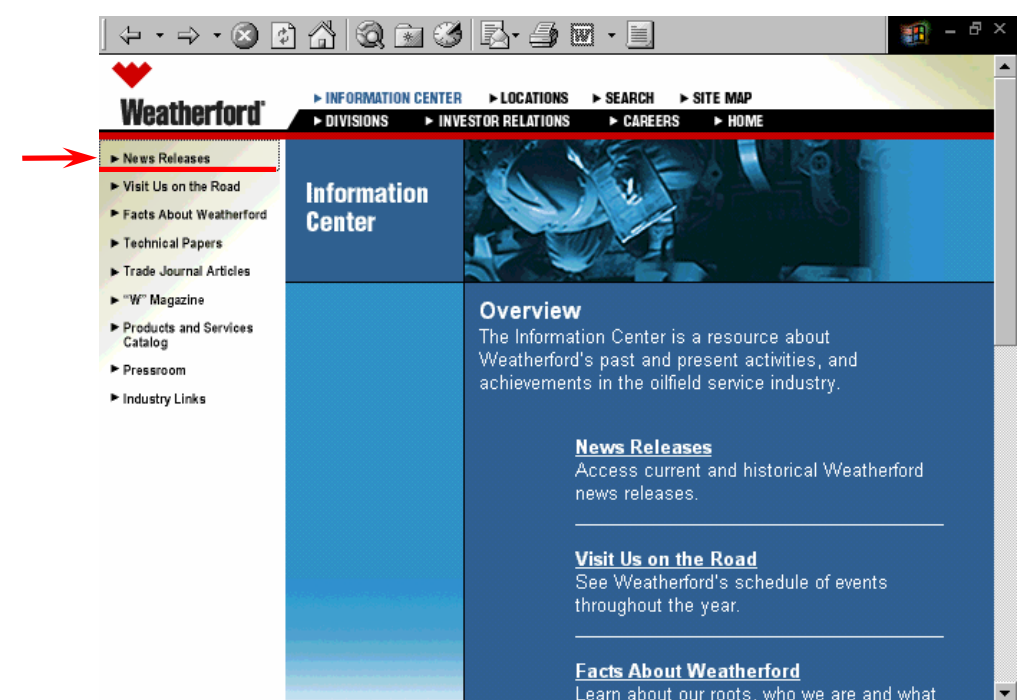

Figura 6.8: Seleccionando el tópico Comunicados de prensa desde la opción Centro de Información

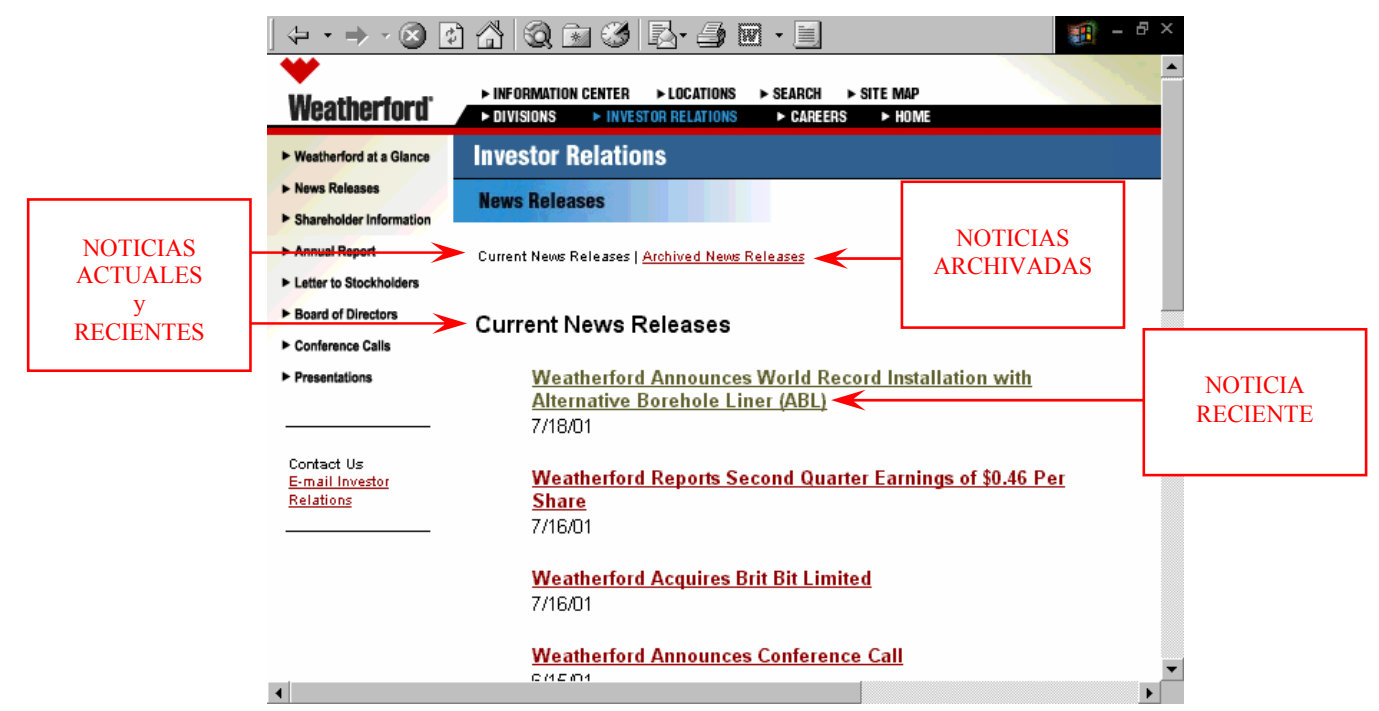

Figura 6.9: Navegando las noticias del tópico Comunicados de prensa 
Caso de uso (4): "Navegando líneas de productos, servicios y sistemas dada una división"

\section{Descripción Caso de uso (4)}

\section{Curso básico de eventos}

A. El caso de uso comienza cuando el usuario selecciona una división por su nombre del menú que ofrece el sistema en su 'home page', formado por las divisiones en que se estructura la compañía. Figura 6.10

B. El sistema retorna la página asociada a la división requerida mostrando nombre-división, imagen, texto-informativo, e-mail-división y un menú formado por las líneas de prestaciones que componen la división. El usuario selecciona una línea por su nombre. Figura 6.11

C. El sistema retorna la página asociada a la línea de prestaciones requerida mostrando nombre-línea, imagen, texto-informativo, nombre-división, e-mail-división, un menú formado por conjuntos de prestaciones que brinda la línea y manteniendo el menú formado por las líneas de prestaciones que componen la división. El usuario selecciona una prestación por su nombre. Figura 6.12

D. El sistema retorna la página asociada a la prestación requerida mostrando nombre-prestación, imagen, texto-descriptivo citando los productos/ servicios/ sistemas pertenecientes a la prestación seleccionada, nombre-línea, nombre-división, e-mail-división y manteniendo el menú formado por las líneas de prestaciones que componen la división y el menú formado por las prestaciones de productos/servicios/ sistemas. En este caso, el usuario recibe toda la información de la que dispone la aplicación y el caso de uso se completa. Figura 6.13

E. El sistema retorna la página asociada al producto/ servicio/ sistema específico correspondiente a la prestación de productos/ servicios/ sistemas seleccionada en D. mostrando nombre-producto/ servicio/ sistema, descripción, nombre-división, nombre-línea y otra información relevante acorde al producto/ servicio/ sistema consultado. En este caso, el usuario recibe toda la información de la que dispone la aplicación y el caso de uso se completa. Figura 6.14

\section{Cursos alternativos de eventos}

Alternativa A: Si el usuario no tiene conocimientos previos de la compañía y sus divisiones, el sistema ofrece la opción Divisiones, situada tanto en las solapas superiores como en la barra inferior de la 'home page'. En este caso, el sistema retornará una página con información preliminar y un menú formado por las divisiones en las que se estructura la compañía. Por cada división el sistema ofrece datos de las mismas tales como nombre, imagen y texto-previo. El usuario seleccionará una división y el caso de uso continuará en la etapa B. Figura 6.15

Alternativa B..D: Si el usuario lo desea puede enviar un e-mail de la división. En este caso, el caso de uso invocará la aplicación de correo electrónico que tenga instalada el usuario en su computador, retornando un e-mail con la dirección de correo electrónico de la división y permitiendo el ingreso del texto del e-mail y su envío. Figura 6.16 $\mathrm{Si}$ el usuario desea continuar con el caso de uso, cerrará la aplicación de correo y el caso de uso retomará la etapa B, C o D desde la cual se disparó este evento. Figura 6.11 - Figura 6.12 - Figura 6.13

Alternativa D: Algunas prestaciones de productos/ servicios/ sistemas en su texto-descriptivo no solamente citan los productos/ servicios/ sistemas, sino que además los presentan en un menú que permiten acceder a nuevas páginas informativas. En este caso, el usuario selecciona un producto/ servicio/ sistema por su nombre y el caso de uso continúa en la etapa E. Figura 6.13

Alternativa B..D: Si el usuario lo desea puede disparar una búsqueda. En este caso, el caso de uso (6) “Realizando búsqueda de productos, servicios y sistemas" comenzará, y el caso de uso en curso finalizará. Figura 6.11 - Figura 6.12 - Figura 6.13

Alternativa C: Si el usuario lo desea puede acceder a otra línea desde la línea actual. En este caso, el caso de uso continuará en la etapa $\mathbf{C}$. Figura 6.12

Alternativa D: Si el usuario lo desea puede acceder a otra línea desde la prestación actual. En este caso, el caso de uso continuará en la etapa $\mathbf{C}$.

Alternativa D: Si el usuario lo desea puede acceder a otra prestación desde la prestación actual. En este caso, el caso de uso continuará en la etapa $\mathbf{D}$. 


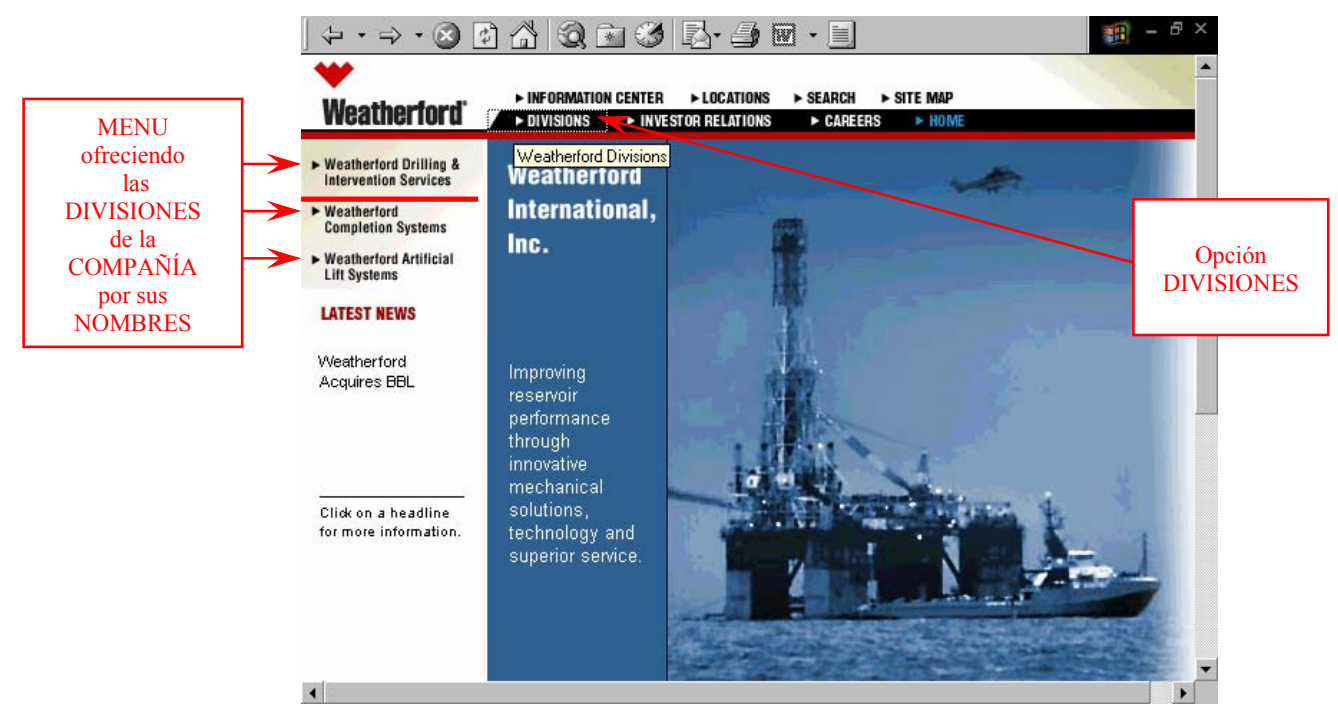

Figura 6.10: Seleccionando una división desde la 'home page'

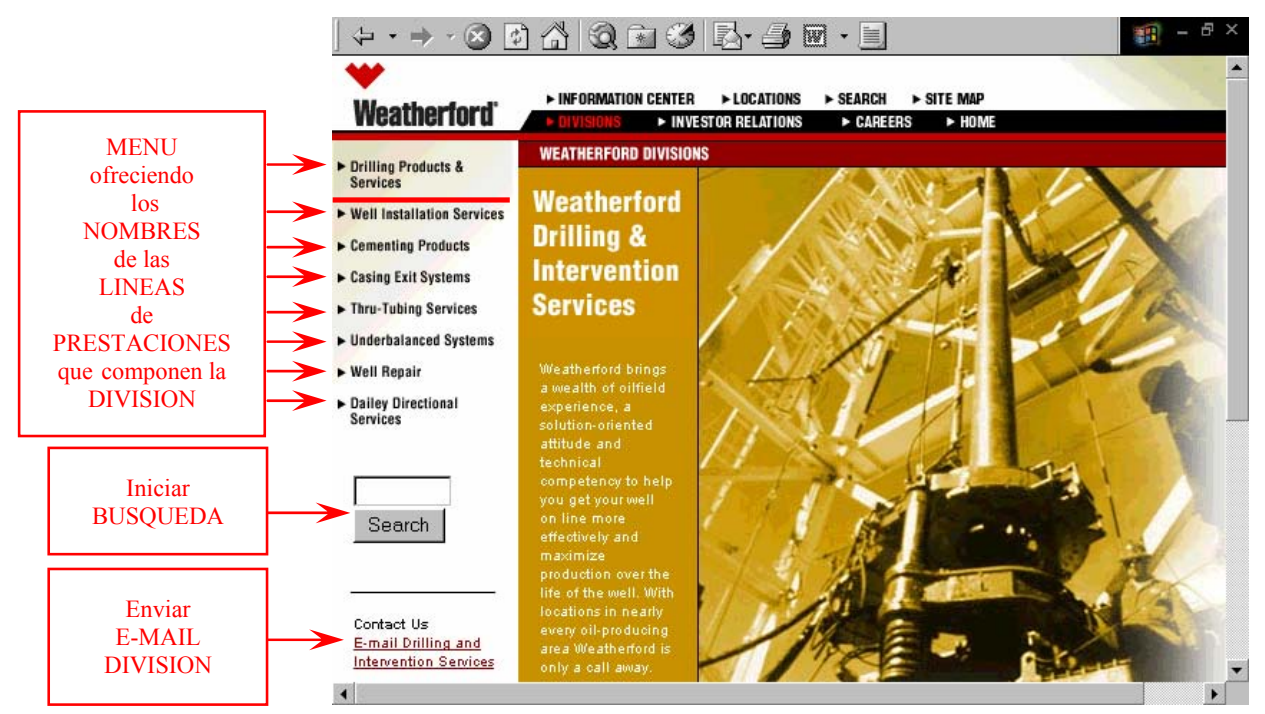

Figura 6.11: Navegando la división y seleccionando una línea

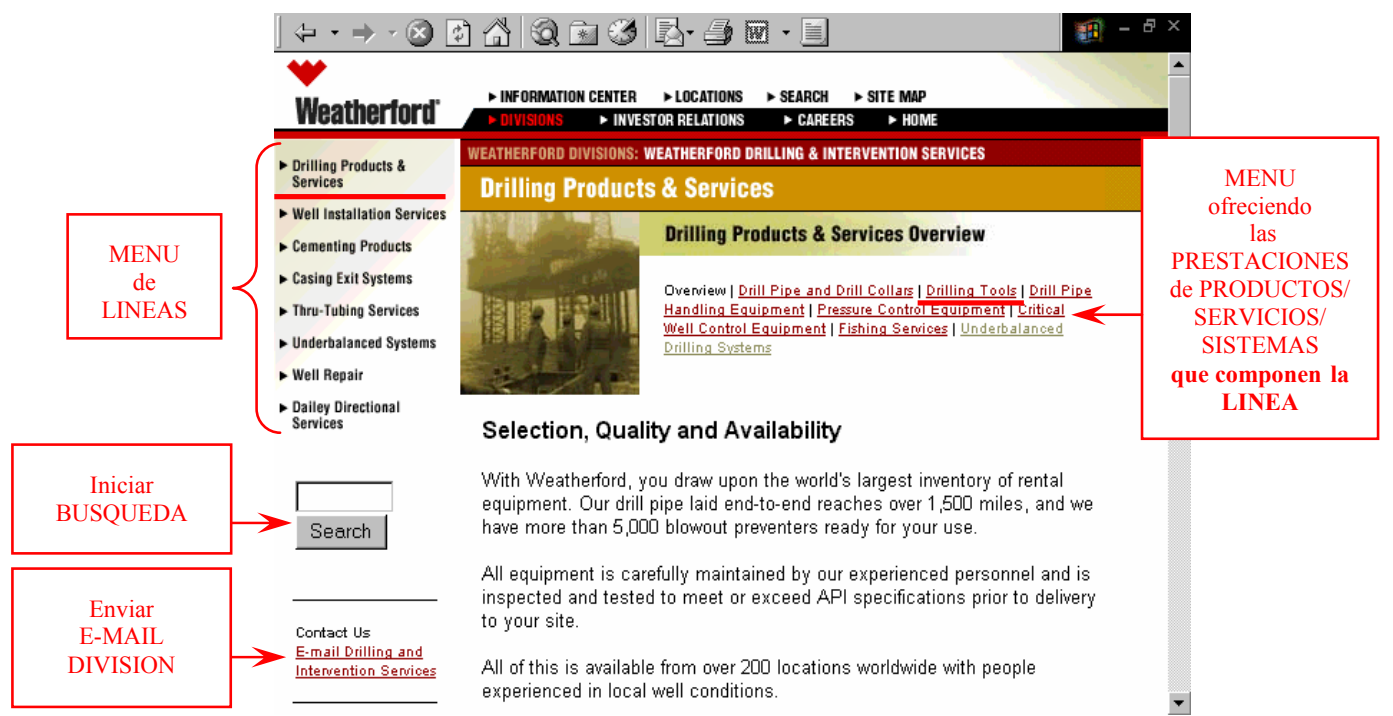

Figura 6.12 (a): Navegando la línea y seleccionando una prestación 


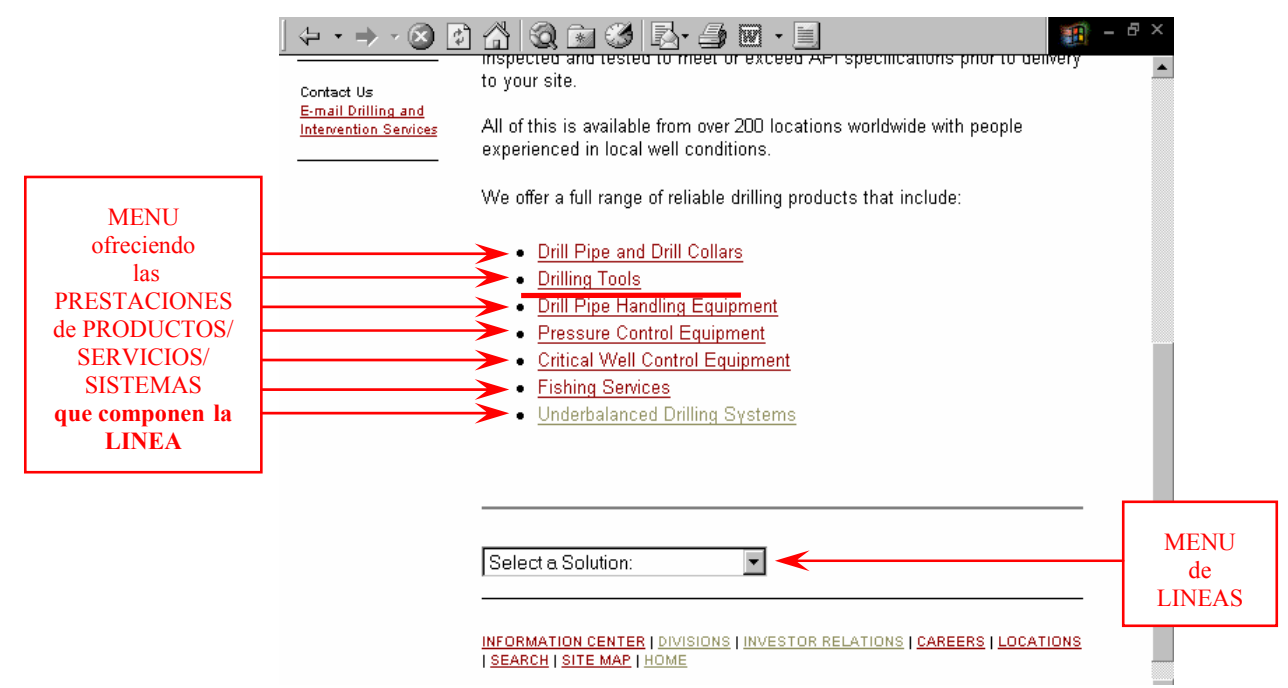

Figura 6.12 (b): Navegando la línea y seleccionando una prestación

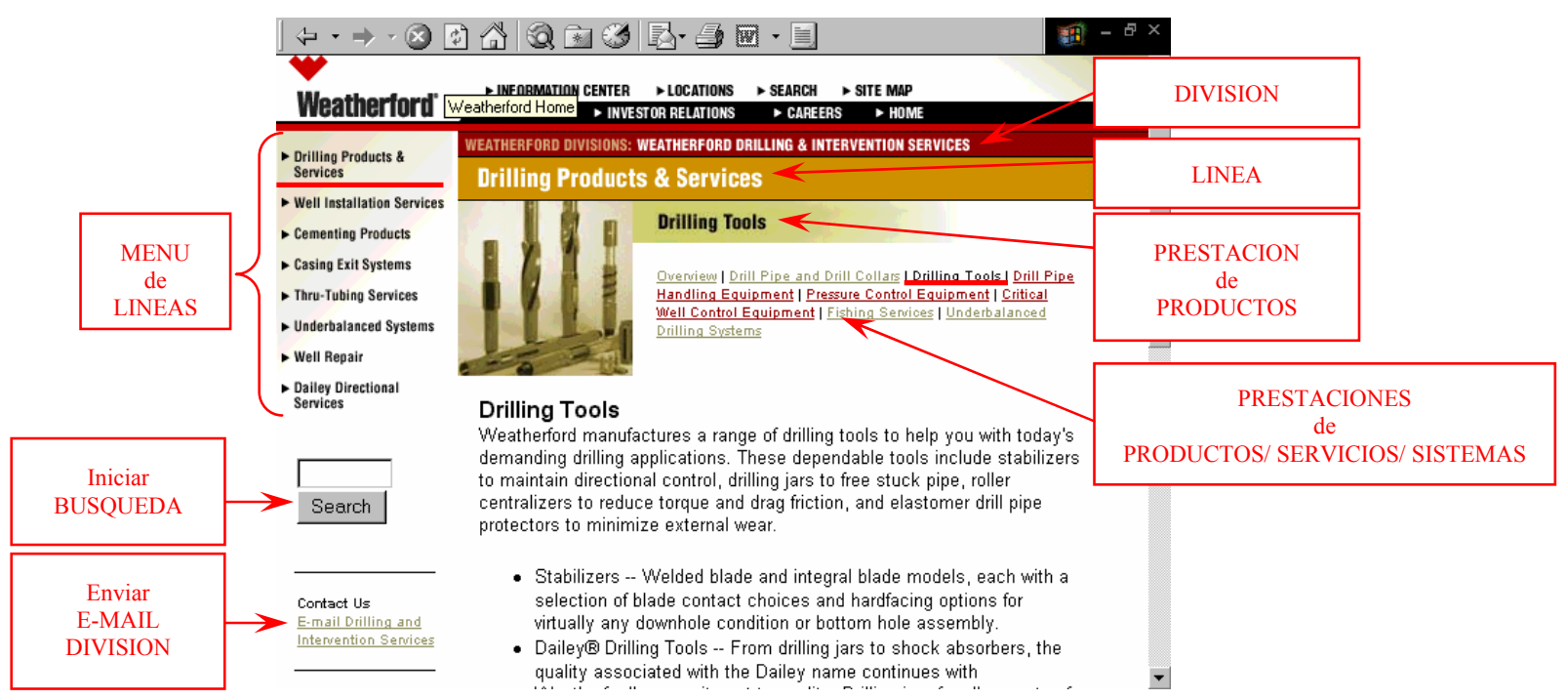

Figura 6.13 (a): Navegando la prestación de productos y seleccionando un producto

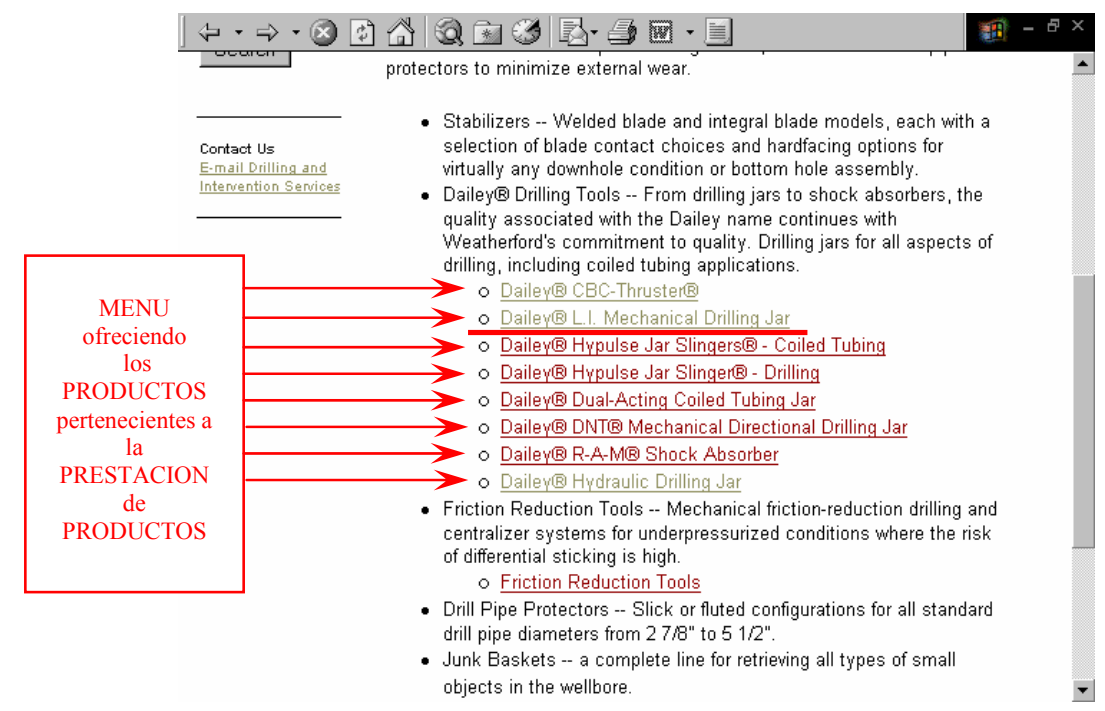

Figura 6.13 (b): Navegando la prestación de productos y seleccionando un producto 


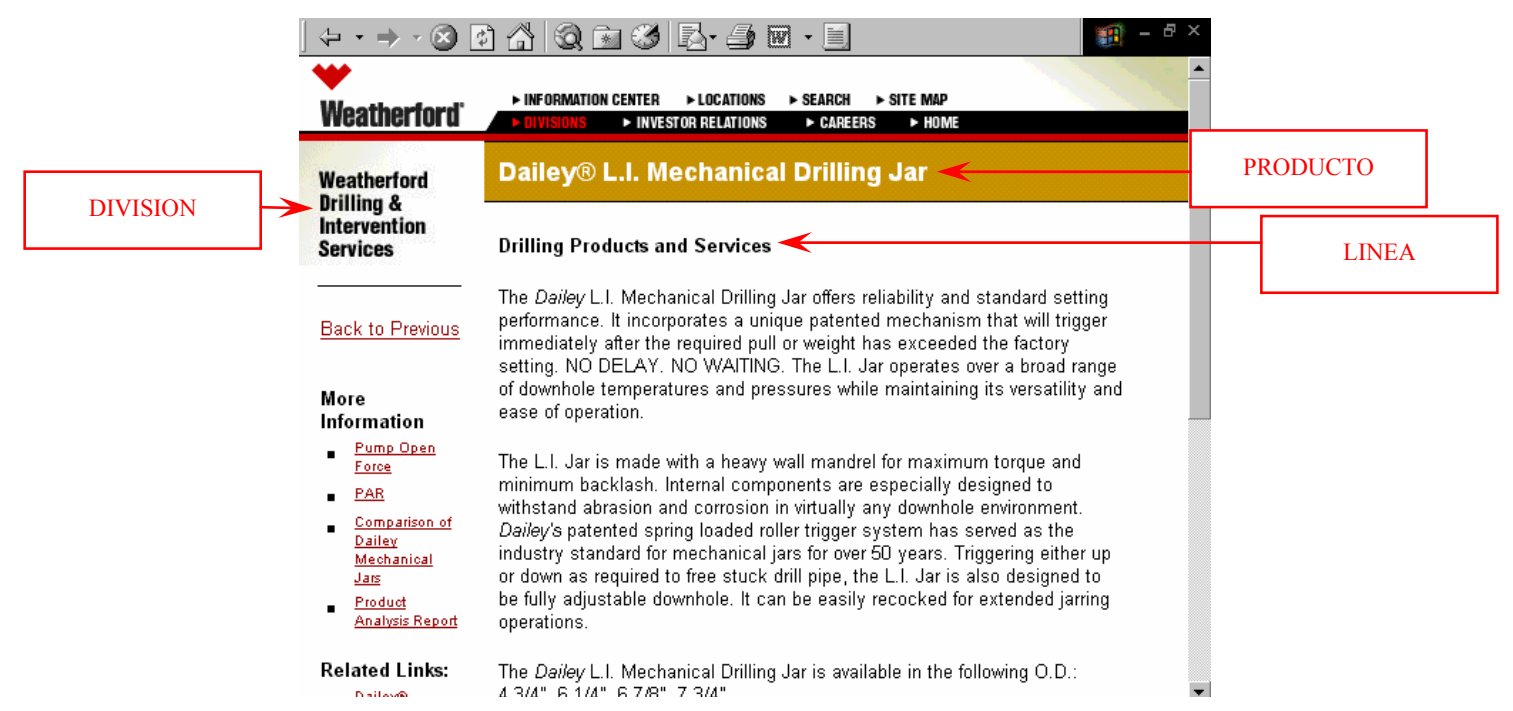

Figura 6.14: Navegando el producto seleccionado

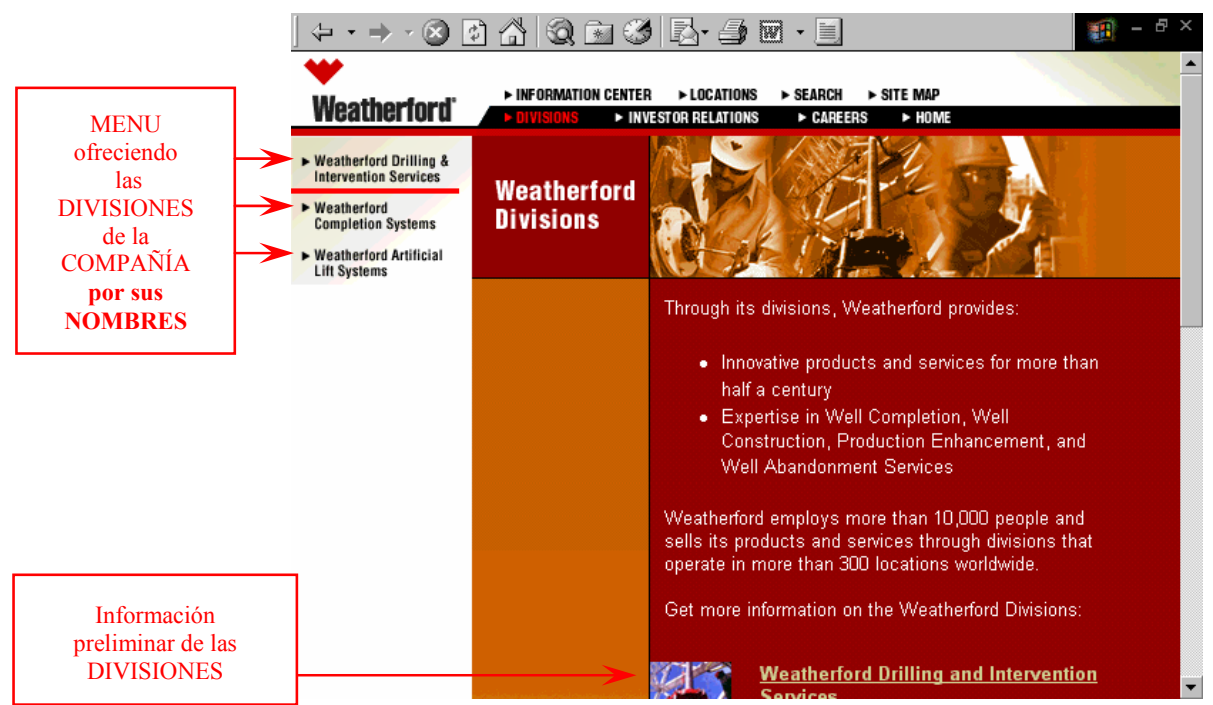

Figura 6.15: Seleccionando una división desde la página Divisiones

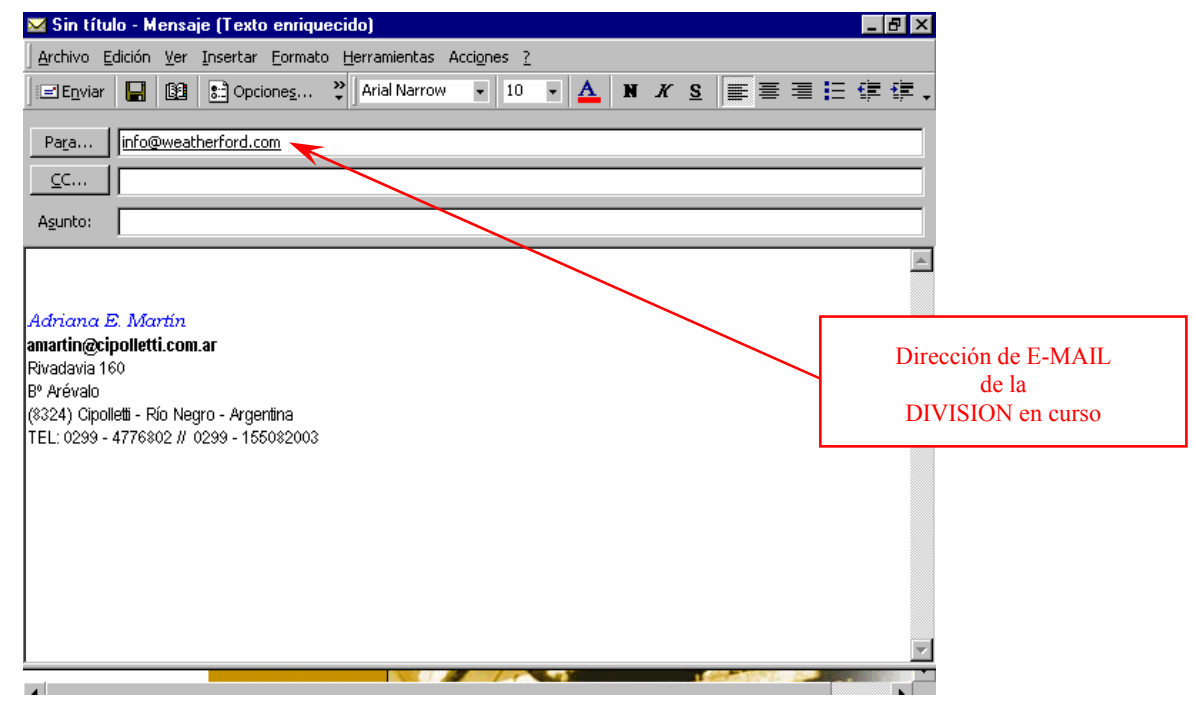

Figura 6.16: Enviando un e-mail a la División en curso 


\section{Caso de uso (5): “Brindando Información Financiera”}

\section{Descripción Caso de uso (5)}

\section{Curso básico de eventos}

A. El caso de uso comienza cuando el usuario selecciona la opción Relaciones de Inversión que ofrece el sistema en su 'home page'. Figura 6.17

B. El sistema retorna la página asociada mostrando título, texto-presentación e imagen del Dpto. Relaciones de Inversor y un menú formado por tópicos informativos. De cada tópico el sistema exhibe título y texto-preliminar. El usuario selecciona el tópico Reporte Anual. Figura 6.18

C. El sistema retorna la página correspondiente a este tópico, mostrando un listado de los reportes de los tres últimos años de la compañía, manteniendo el menú formado por los tópicos informativos del Dpto. de Relaciones de Inversor. De cada reporte el sistema exhibe el año y ofrece un menú formado por 3 documentos en formato PDF que constituyen las secciones que componen el reporte. De cada una de las secciones exhibe título y tamaño en unidades de bytes ( $\mathrm{Kb}$ o $\mathrm{Mb}$ ). El usuario elige una sección de un reporte. Figura 6.19

D. El sistema invoca a la aplicación Adobe Acrobat y retorna el documento correspondiente a la sección elegida. El usuario dispone del mismo para su navegación, impresión y 'download'. El usuario selecciona una de estas operaciones utilizando las opciones de menú de la aplicación citada o de Internet según corresponda, la operación se completa y el caso de uso también se completa. Figura 6.20

\section{Cursos alternativos de Eventos}

Alternativa B,C: Si el usuario lo desea puede enviar un e-mail del Dpto. Relaciones de Inversor. En este caso, el caso de uso invocará la aplicación de correo electrónico que tenga instalada el usuario en su computador, retornando un e-mail con la dirección de correo electrónico del Dpto. Relaciones de Inversor y permitiendo el ingreso del texto del e-mail y su envío. ${ }^{\text {Figura }} 6.21$ El usuario cierra la aplicación de correo y el caso de uso continuará en la etapa $\mathbf{B}$ o $\mathbf{C}$ desde la cual se disparó este evento. Figuras 6.18/6.19

Alternativa B: Si el usuario lo desea puede consultar las últimas noticias publicadas por la Compañía seleccionando el tópico Comunicados de Prensa. Figura 6.18/6.19 En este caso, el caso de uso (2) “Comunicando noticias de la compañía” comenzará, y el caso de uso en curso finalizará. Figura $6 . .9$

\section{Cursos de Eventos de retroceso}

Retroceso D: Si el usuario lo desea, puede seleccionar otra sección del mismo u otro reporte, retrocediendo el caso de uso con la opción atrás de la aplicación de Internet. ${ }^{\text {Figura } 6.20}$ En este caso, el caso de uso cierra la aplicación en curso (Acrobat) y continuará en la etapa C. Figura 6.19 


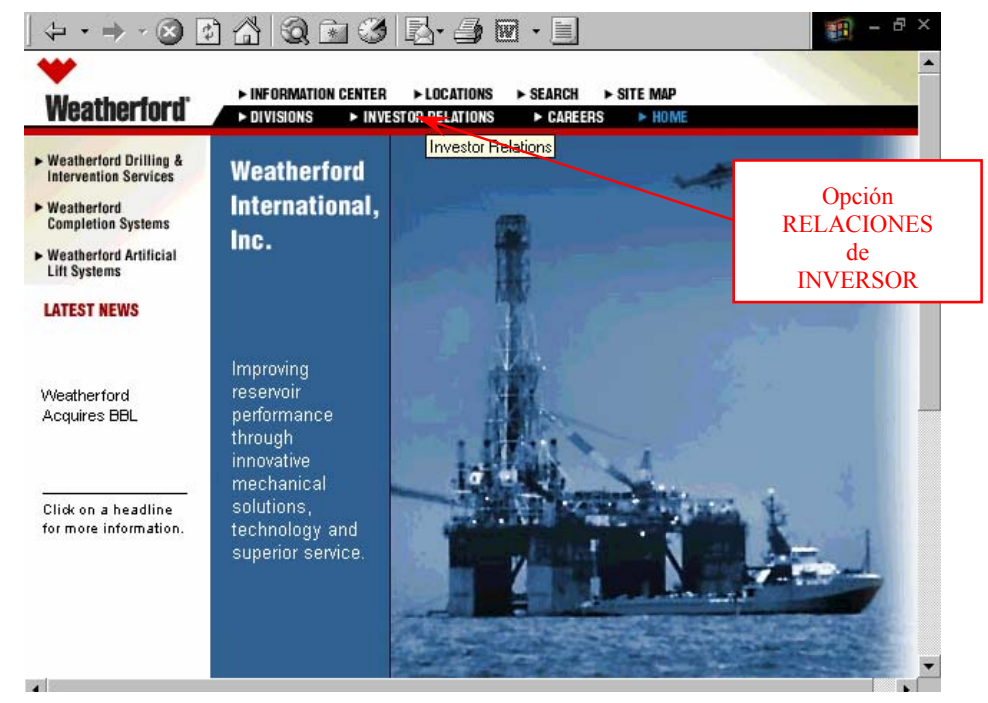

Figura 6.17: Seleccionando la opción Relaciones de Inversor

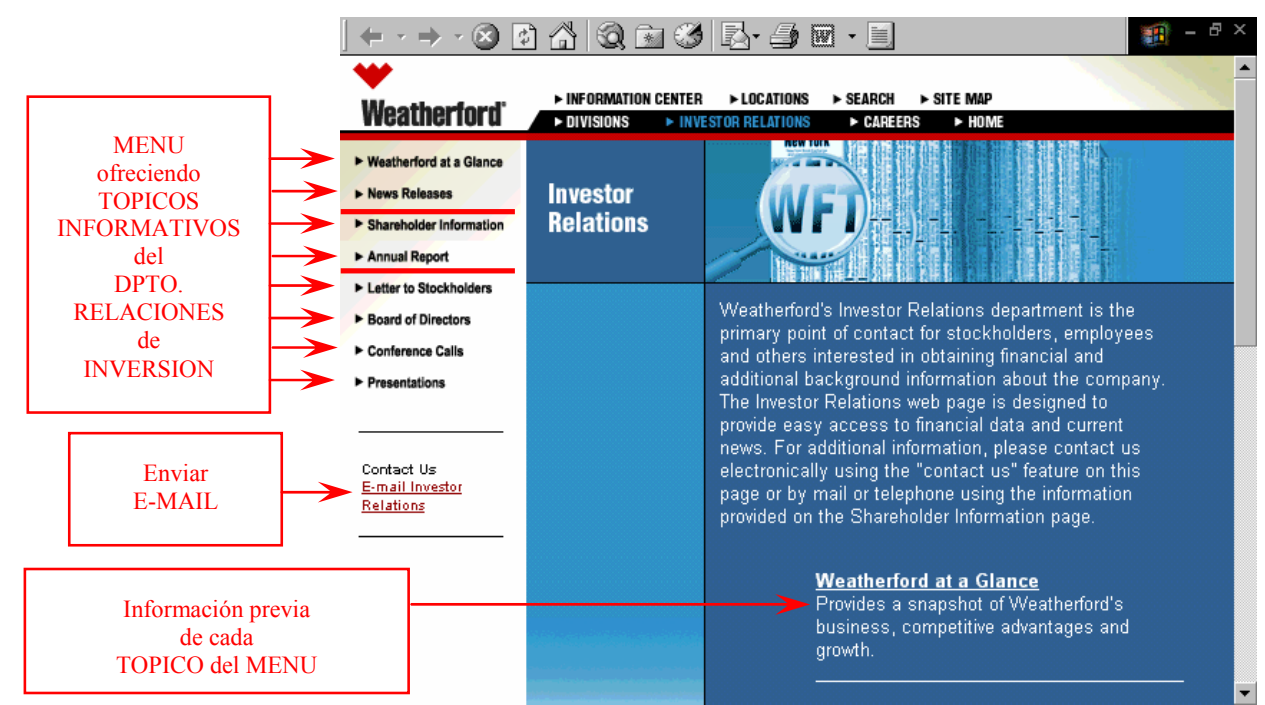

Figura 6.18: Navegando Relaciones de Inversor y seleccionando el tópico Reporte Anual

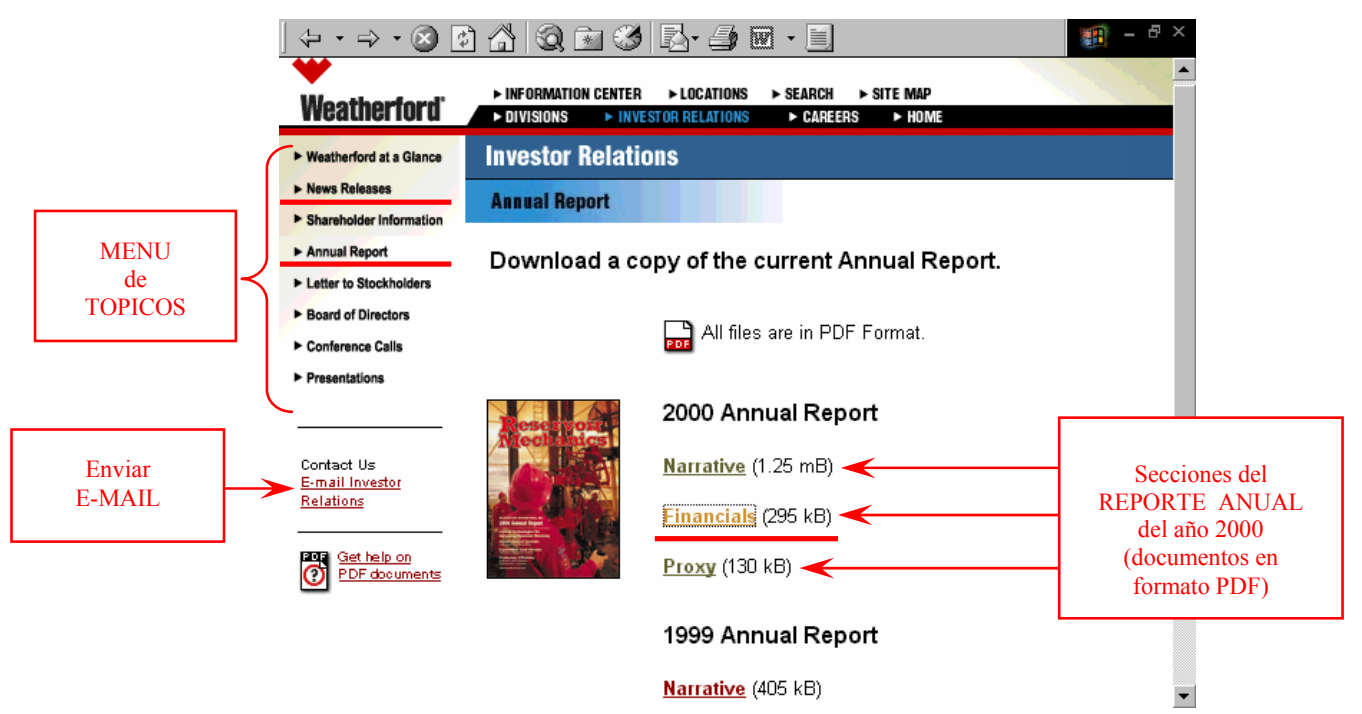

Figura 6.19: Navegando el tópico Reporte Anual y seleccionando una sección de un reporte 


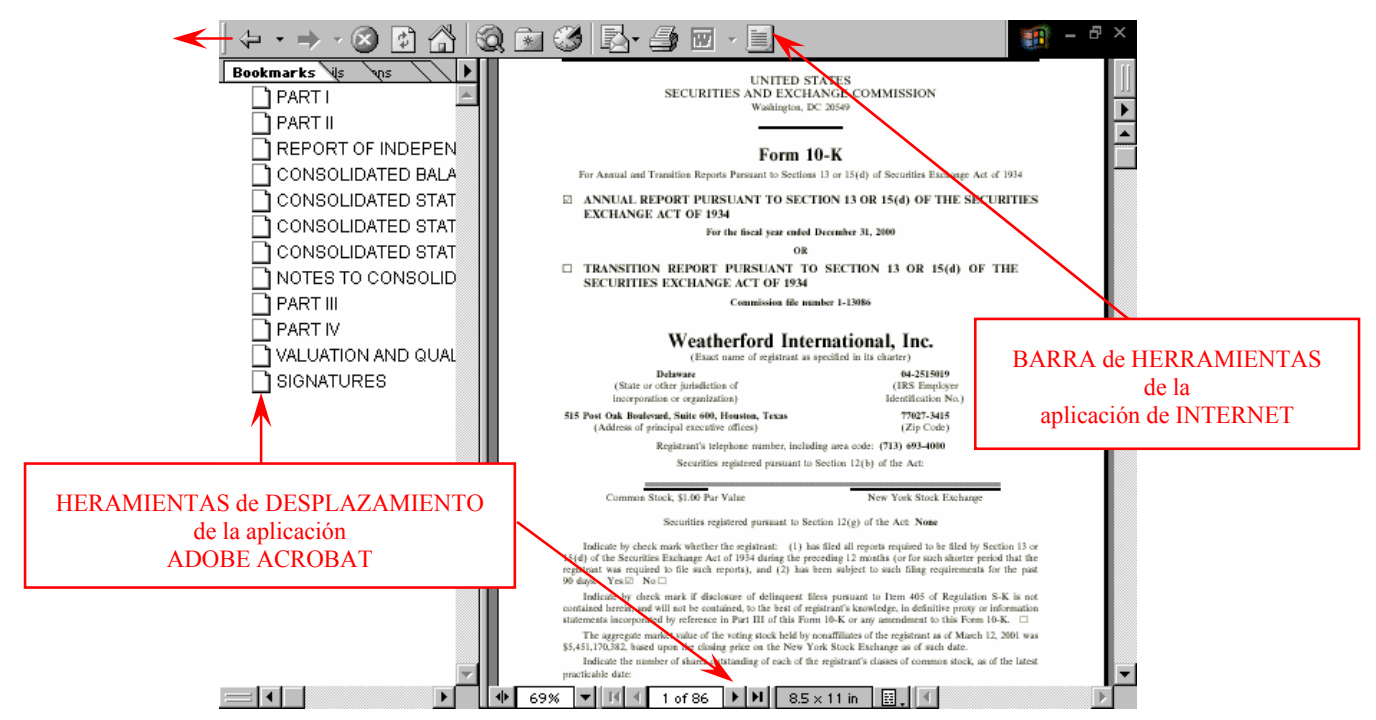

Figura 6.20: Navegando el documento de la sección elegida

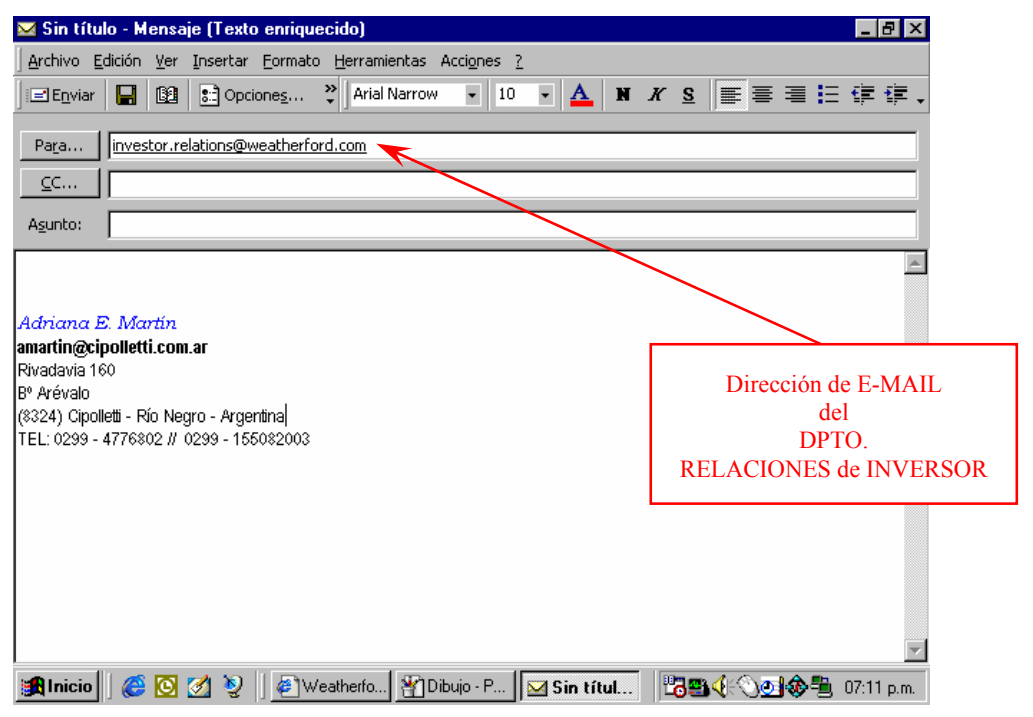

Figura 6.21: Enviando un e-mail al Dpto. Relaciones de Inversor 
Caso de uso (8): “Informando prestaciones Weatherford al pozo petrolífero"

\section{Descripción Caso de uso (8)}

\section{Curso básico de eventos}

A. El caso de uso comienza cuando el usuario selecciona la opción Centro de que ofrece el sistema en su 'home page', mostrando nombre, logotipo e imagen de la compañía. Figura 6.22

B. El sistema retorna la página asociada (del Centro de Información que como su nombre lo indica es un recurso informativo de las actividades de la Compañía y de la industria de servicio al petróleo), mostrando título del recurso, imagen, texto presentación de este recurso de consulta, nombre y logotipo de la Compañía y un menú formado por tópicos informativos. De cada tópico el sistema exhibe título y texto previo. El usuario selecciona el tópico Revista "W" (una publicación de la Compañía para sus clientes compuesta por artículos sobre tecnologías, productos, servicios y sistemas aplicados en el mundo, que el sistema ofrece a los usuarios del sitio). Figura 6.23

C. El sistema retorna la página correspondiente a este tópico, mostrando título del tópico Revista 'W', título del Centro de información, texto presentación, nombre y logotipo de la Compañía y un listado de las revistas publicadas en los tres últimos años de la Compañía, manteniendo el menú formado por los tópicos del Centro de Información. De cada revista el sistema exhibe imagen de la tapa, fecha de publicación y ofrece un menú formado por documentos en formato PDF que componen la publicación: contenido, palabras previas y todos los artículos. De cada uno de estos documentos (secciones de la revista) el sistema exhibe título y tamaño en unidades de bytes $(\mathrm{Kb}$ o $\mathrm{Mb})$. El usuario selecciona una sección o artículo de la revista por su título. Figura 6.24

D. El sistema invoca a la aplicación Adobe Acrobat y retorna el documento correspondiente. El usuario dispone del mismo para su navegación, impresión y 'download'. El usuario selecciona una de estas operaciones utilizando las barras de herramientas y desplazamiento de la aplicación citada, la operación se completa y el caso de uso también se completa. Figura 6.25/6.26

\section{Cursos alternativos de Eventos}

Alternativa B: Si el usuario lo desea puede seleccionar el tópico Catálogo de Productos y Servicios (un inventario de todas las prestaciones de la Compañía, que el sistema ofrece a los usuarios del sitio). En este caso, el caso de uso continuará en la etapa $\mathbf{D}$.

Alternativa B: Si el usuario lo desea puede consultar las últimas noticias publicadas por la Compañía seleccionando el tópico Comunicados de Prensa. ${ }^{\text {Figura 6.23 / } 6.24}$ En este caso, el caso de uso (2) Figura 6.9

“Comunicando noticias de la compañía” comenzará, y el caso de uso en curso finalizará.

\section{Cursos de Eventos de retroceso}

Retroceso D: Si el usuario lo desea, puede seleccionar otro documento de la misma u otra publicación, retrocediendo el caso de uso con la opción atrás de la aplicación de Internet. En este caso, el caso de uso cierra la aplicación en curso (Acrobat) y continuará en la etapa C. Figura 2.2.25 


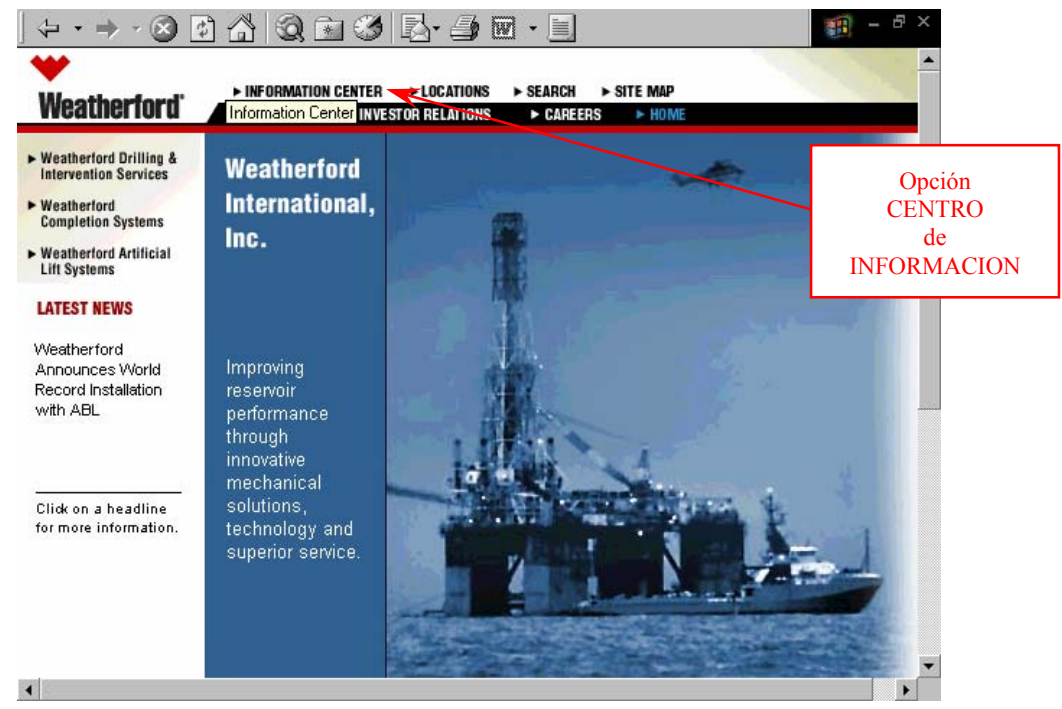

Figura 6.22: Seleccionando la opción Centro de Información

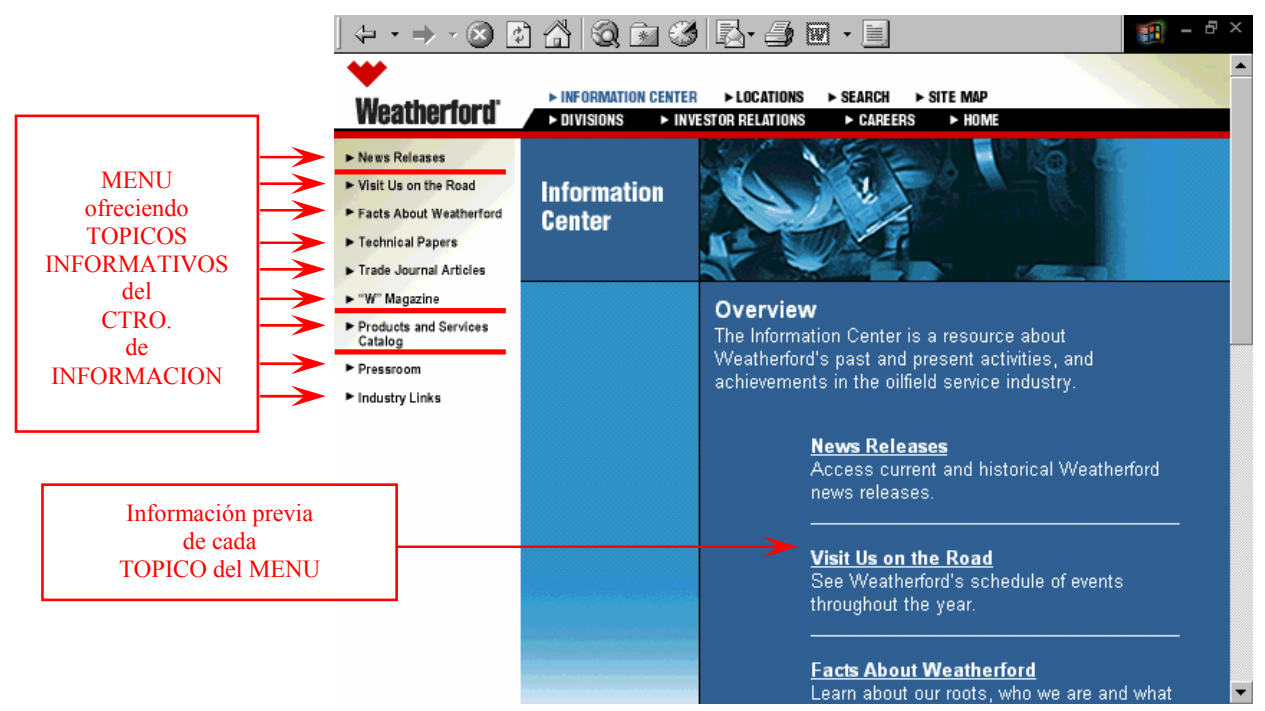

Figura 6.23: Navegando la opción Centro de Información y seleccionando el tópico Revista 'W' // Catálogo de Productos y Servicios

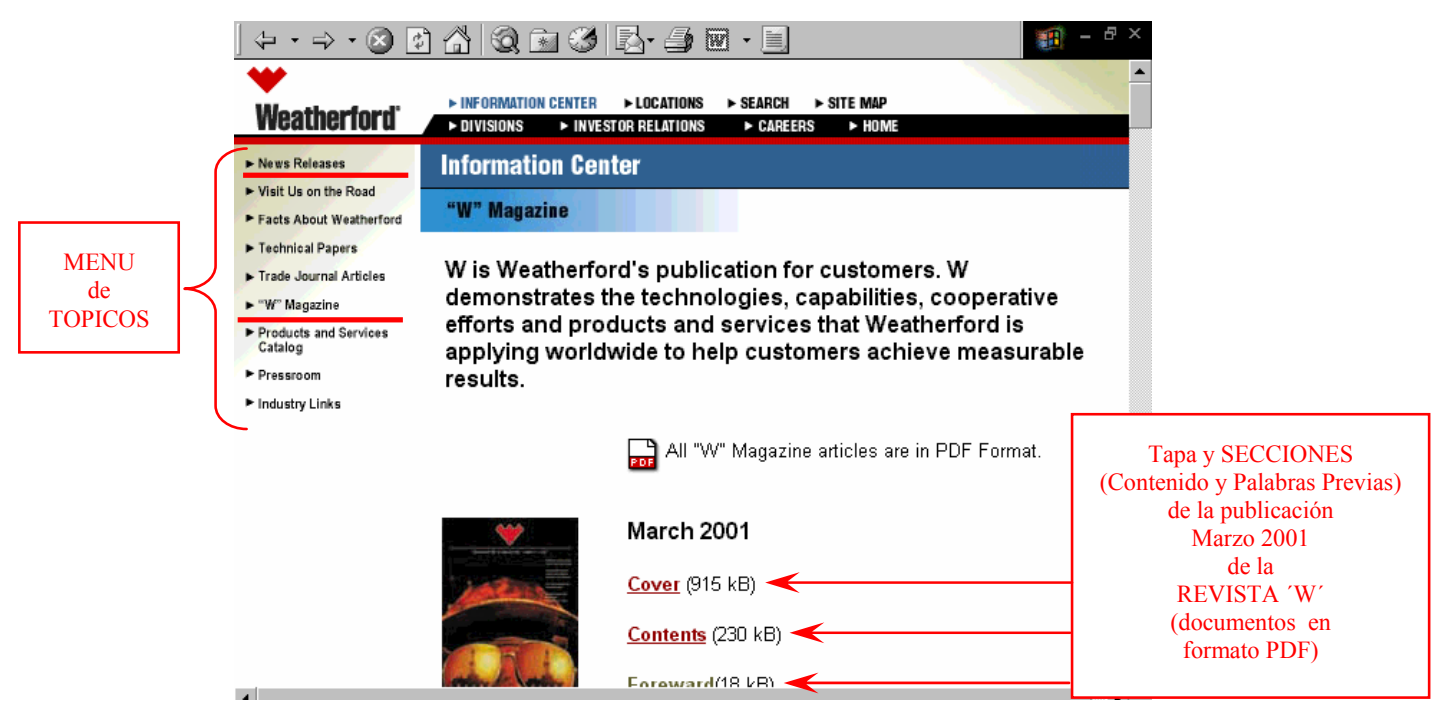

Figura 6.24 (a): Navegando el tópico Revista 'W'

y seleccionando el documento correspondiente a un artículo de una publicación 


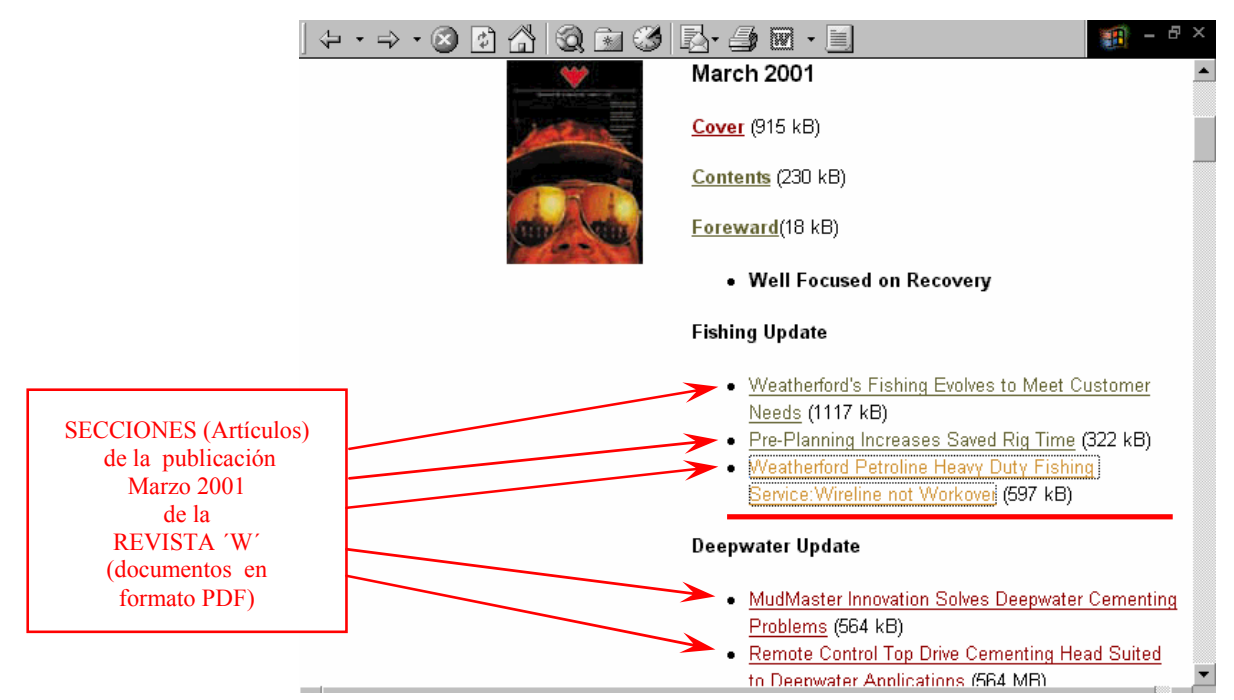

Figura 6.24 (b): Navegando el tópico Revista 'W'

y seleccionando el documento correspondiente a un artículo de una publicación

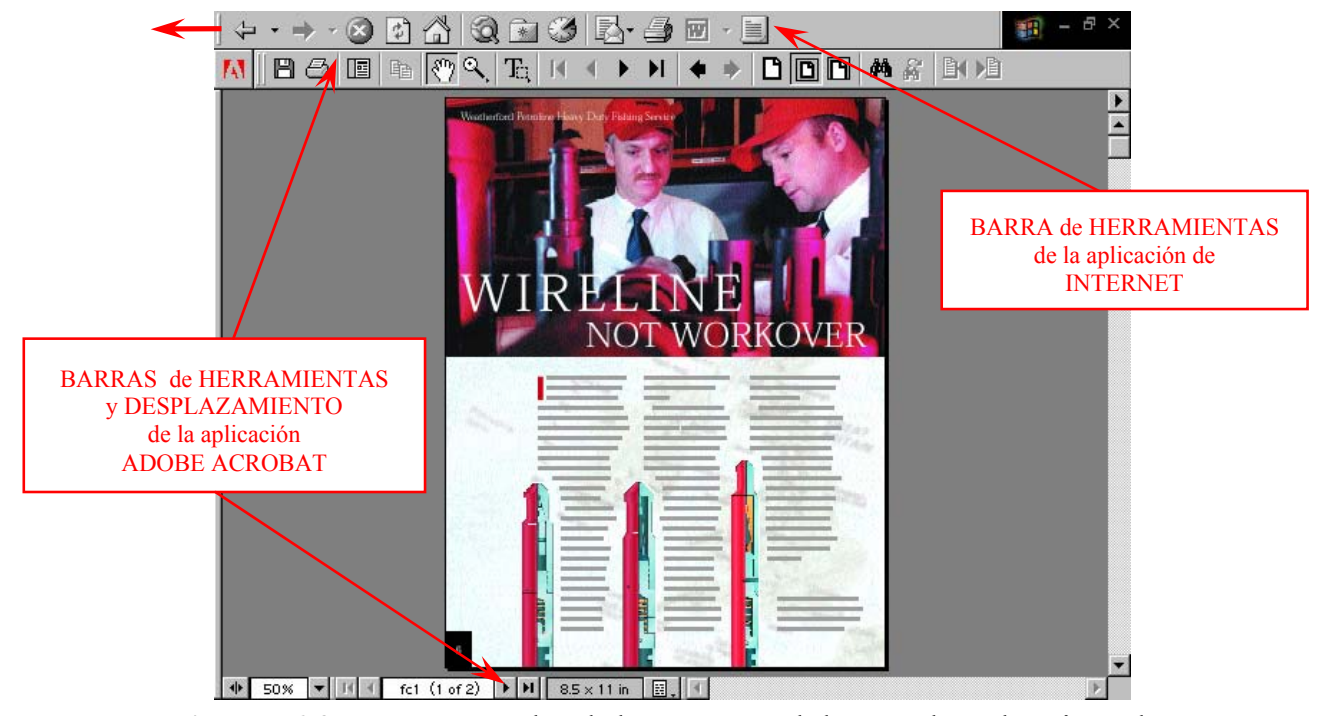

Figura 6.25: Navegando el documento del artículo seleccionado

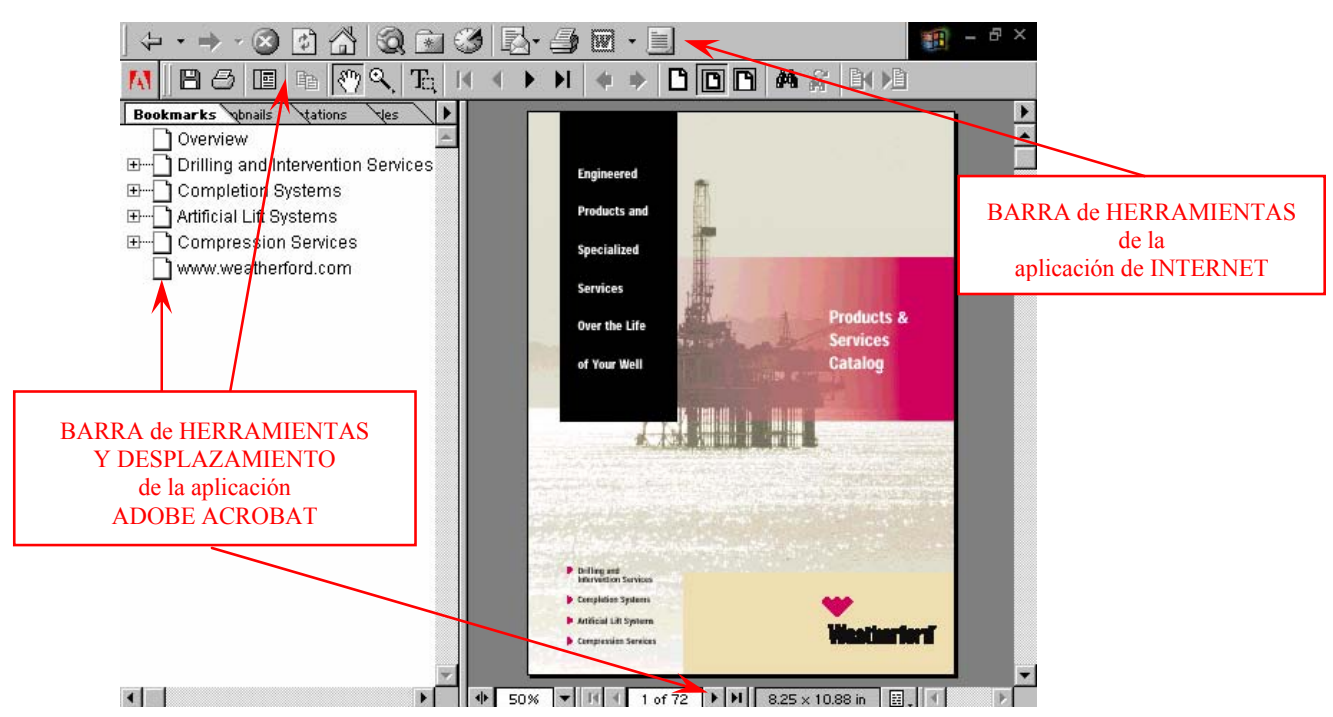

Figura 6.26: Navegando el documento del Catálogo de Productos y Servicios 
Caso de Uso (10): "Posibilitando envío de inscripción en curso de capacitación"

\section{Descripción Caso de Uso (10): Perfil Empleado}

\section{Curso básico de eventos}

F. El caso de uso comienza cuando el usuario Empleado selecciona la opción Capacitación que ofrece el sistema en su 'home page'. Figura 6.27

G. El sistema retorna la página asociada ofreciendo un menú formado por tópicos referidos a la capacitación que brinda el Centro de Capacitación de la Compañía; tres de ellos corresponden a las distintas propuestas de capacitación de las divisiones de la Compañía. El usuario selecciona el tópico Capacitación División X. Figura 6.28

H. El sistema retorna la página asociada a las propuestas de capacitación de la División X elegida. El usuario Empleado selecciona el tópico Formulario de Inscripción 'Online'. Figura 6.29

I. El sistema solicita al usuario Empleado el ingreso de su clave que lo identifica como usuario del servicio de inscripción 'online' del Centro de Capacitación. El usuario Empleado ingresa su clave de identificación. Figura 6.30

J. El sistema valida la clave ingresada y ofrece un formulario de inscripción 'online'. El usuario Empleado ingresa los datos en el formulario y solicita su envío. Figura 6.31

K. El sistema envía el formulario y el caso de uso se completa.

NOTA: Si bien el caso de uso se completa, el usuario Empleado debe esperar la confirmación de su inscripción vía e-mail, ya que su solicitud debe ser aprobada por su/s superior/es.

\section{Cursos alternativos de eventos}

Alternativa E: Si el sistema no identifica al usuario Empleado, emitirá un mensaje de error señalando un punto de contacto al que el usuario Empleado puede comunicarse. En este caso, el caso de uso ofrecerá al usuario Empleado una nueva posibilidad de ingresar su clave de identificación, que de ser esta segunda vez correcta, permitirá que el caso de uso continúe. Si el problema persiste, el caso de uso finalizará.

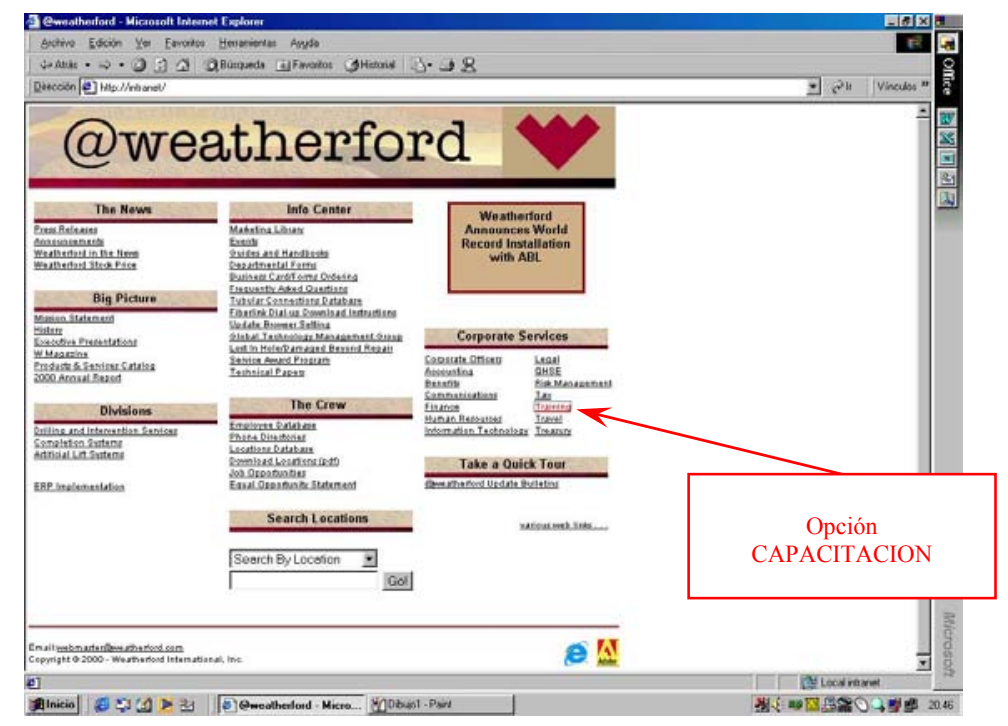

Figura 6.27: Seleccionando la opción Capacitación 


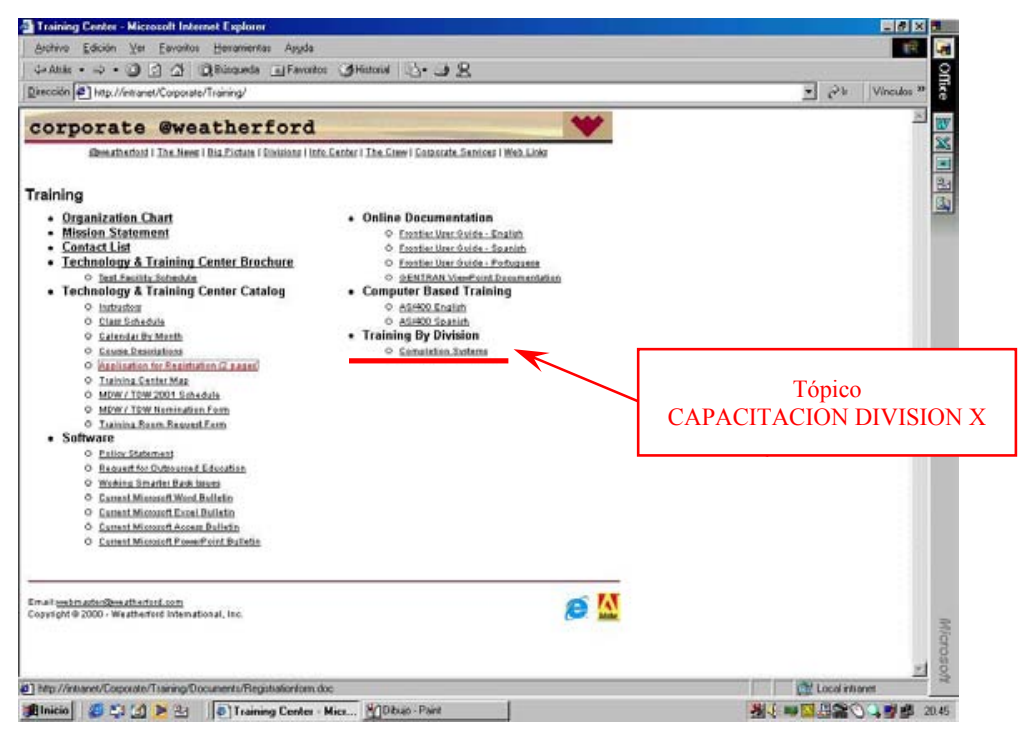

Figura 6.28: Navegando la opción Capacitación

y seleccionando el tópico Capacitación División X

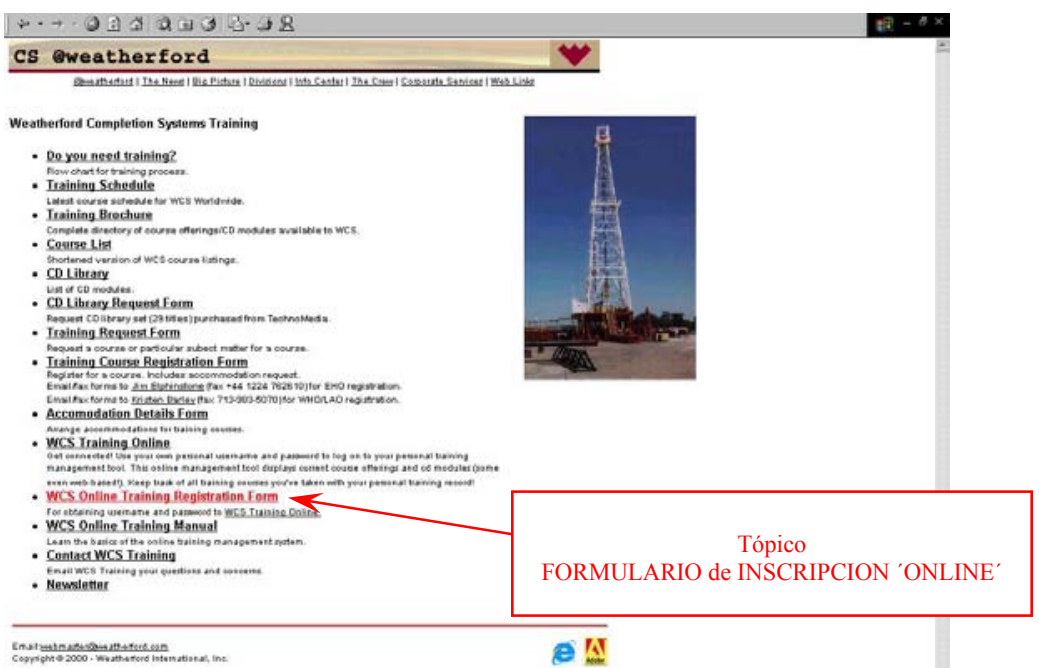

Figura 6.29: Navegando el tópico Capacitación División $X$ y seleccionando el tópico Formulario de Inscripción 'OnLine'

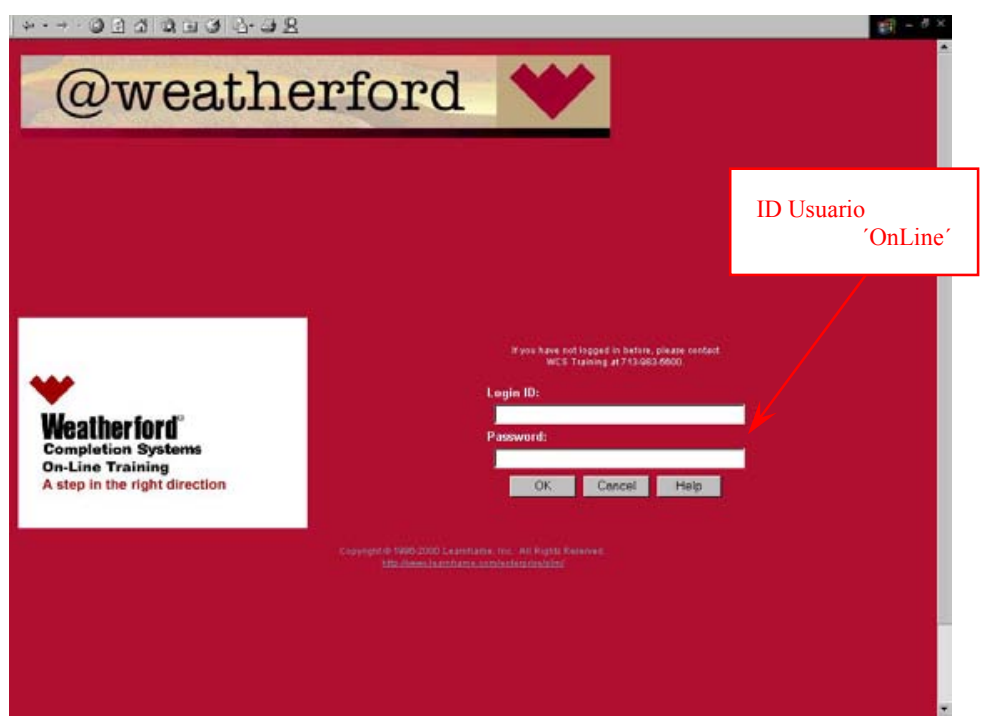

Figura 6.30: Ingresando la clave de identificación para acceder al servicio de inscripción 'online' del Centro de Capacitación 


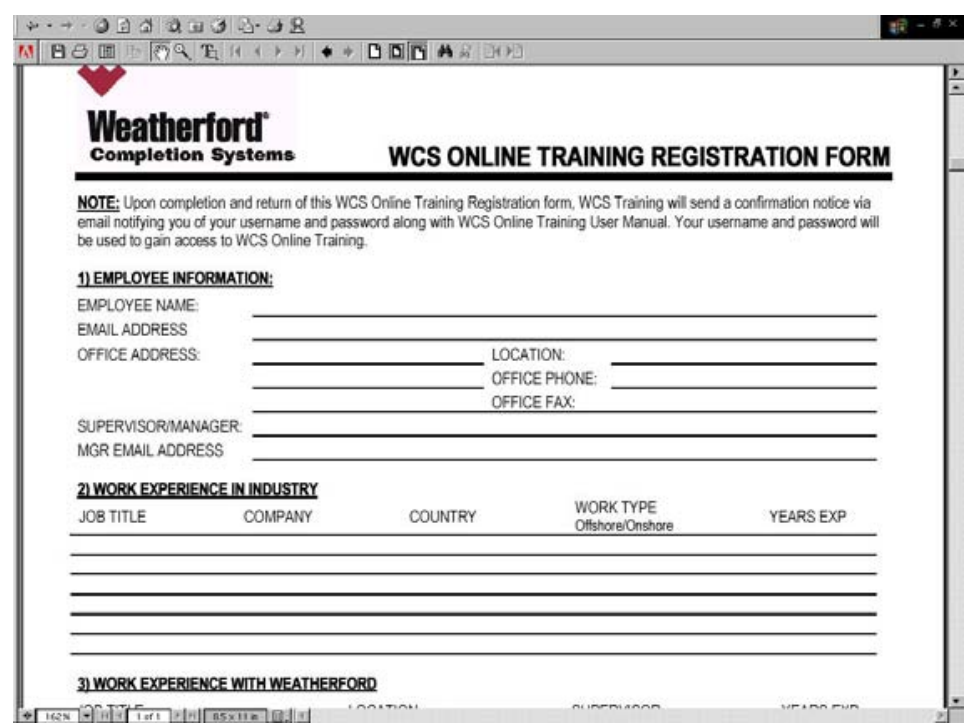

Figura 6.31: Ingresando datos en el formulario y solicitando su envío

\subsubsection{Delineando la especificación objetiva del nuevo sitio con patrones de personalización}

La tarea de formular la especificación objetiva del nuevo sitio, implica llevar adelante la actividad de 'envisioning' Figura 5.2 analizando de manera individual y conjunta, las pautas señaladas en 5.3, 5.4.3 y transcriptas a continuación, a los efectos de delinear una especificación objetiva que describa con claridad una visión coherente de la futura aplicación.

Situados en el contexto del caso real, se inicia la tarea de formular la especificación objetiva manteniendo presente la directiva de reingeniería de personalización:

- Comprensión del sitio http://www.weatherford.com.

- Objetivos estratégicos para el nuevo sitio coincidentes con los fijados por la Compañía para el sitio actual.

- Demandas de los usuarios del sitio, correspondientes a los perfiles favorecidos por la directiva de reingeniería: inversor, cliente actual y empleado.

- 'Benchamarking' con otros sitios, http://www.smith.com y http://www.bakerhughes.com, pertenecientes a compañías consideradas relevantes en el entorno competidor, reconociendo Patrones de Hipermedia, [Rossi99a, 99b, 99d, 00].

A continuación, se explica brevemente la forma que en que han sido consideradas estas pautas a los efectos de obtener lineamientos para la formulación de la correspondiente especificación objetiva ${ }^{\text {Figura }}$ 6.34 .

- Comprensión del sitio http://www.weatherford.com

Para lograr esta comprensión, se recurrió a dar inicio al proceso de ingeniería en reversa hasta alcanzar el modelo externo del caso real. Se considera que la visión externa del sitio proporcionada por el modelo caso de uso de la aplicación Figura 6.4 , brinda información suficiente para alcanzar la comprensión requerida por la actividad de 'envisioning'.

- Objetivos estratégicos para el nuevo sitio coincidentes con los fijados por la Compañía para el sitio actual.

Para lograr esta coincidencia, se mantuvieron presentes durante la confección de los objetivos estratégicos para el nuevo sitio, la directiva de reingeniería originada en la compañía, la cual 
refleja, sin lugar a dudas, los lineamientos básicos de los objetivos estratégicos fijados para el sitio actual. Dentro del marco de estos objetivos existentes, se enuncian los objetivos estratégicos para el proceso de reingeniería de personalización:

"El nuevo sitio debe contribuir a la satisfacción de sus usuarios dando respuesta a sus necesidades. Considerar este objetivo como prioritario en la concreción de los objetivos restantes: contribuir a la presencia de la compañia en el mercado publicitando sus servicios al yacimiento petrolifero; aportar al incremento de su cartera de clientes; generar entusiasmo en sus empleados para que consideren al sitio un recurso válido para la comunicación y la representatividad interna y externa de la Compañia".

Existen criterios a los que se puede recurrir para confeccionar buenas estrategias aplicables en reingeniería, los cuales no se incluyen en este trabajo porque no forman parte del objetivo del mismo (por ejemplo, si nos remitimos a enfoques tradicionales [Davenport93]).

- Demandas de los usuarios del sitio, correspondientes a los perfiles favorecidos por la directiva de reingeniería: inversor, cliente actual y empleado.

Para mejorar la satisfacción de los usuarios, nada mejor que atender a sus demandas. Estas demandas se reconocieron captando, analizando y cuantificando las expectativas de los usuarios Figura 6.32 con respecto al sitio. La tarea se inició entrevistando a usuarios representativos de los perfiles de interés. Las demandas resultantes, además de expresar gustos y preferencias particulares de los usuarios entrevistados, encuentran un punto clave de coincidencia: el deseo del usuario de ser identificado por el sito, facilitando su navegación.

Existen técnicas de marketing, (por ejemplo, para mencionar una reconocida [Johansson93]), y enfoques derivados de la ingeniería de requerimientos, (por ejemplo [Loucopoulos95]), que aportan notablemente al reconocimiento de necesidades y deseos de usuarios y clientes; no se incluyen en este trabajo porque no forman parte del objetivo del mismo.

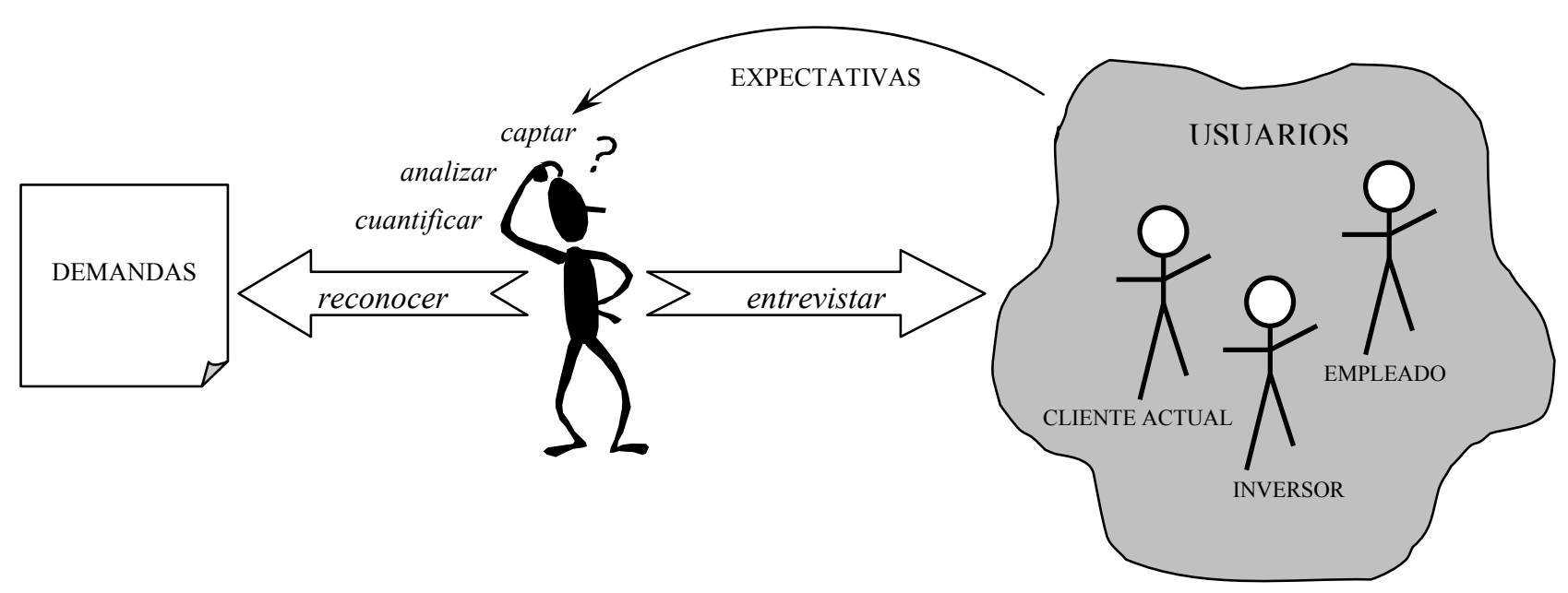

Figura 6.32 : Reconociendo demandas de los usuarios del sitio

- 'Benchamarking' con otros sitios, http://www.smith.com y http://www.bakerhughes.com, pertenecientes a compañías consideradas relevantes en el entorno competidor, reconociendo Patrones de Hipermedia.

La técnica de 'benchamarking' ha ido muy ligada a los procesos de reingeniería. Para el caso real, se tomaron ciertas pautas de esta técnica para analizar e intercambiar conocimiento entre los sitios y reconocer patrones de hipermedia, [Rossi99a, 99b, 99d, 00]. Estos sitios, pertenecen a compañías de servicios al yacimiento petrolífero, consideradas relevantes en el entorno competidor de Weatherford International Inc. 
En el trabajo comparativo, entre las respectivas 'home page' de los sitios de la compañías Weatherford Figura 6.33(a) , Smith Figura 6.33(b) y Baker Hughes Figura 6.33(c) , se observaron las siguientes similitudes:

- 'Home pages' compuestas por agregados de diferentes ítems de información, vínculos, índices, etc. El sitio de Baker Hughes presenta un diseño más atractivo al usuario, ya que hace un uso más oportunista de su 'home page'; este sitio tiene una concepción de diseño con cierta semejanza a la de los sitios de comercio electrónico, p.e. ofrece una opción con las novedades del sitio. Patrón Portal [Rossi00a] - Patrón News [Rossi99b]

- Items de información ofrecidos coincidentes: Relaciones de Inversor, Productos y Servicios, Oportunidades Laborales, Noticias, Búsquedas, Mapa del Sitio, Acerca de la Compañía y acceso a Divisiones.

- Opciones más relevantes de menú en 'home page' uniformes y accesibles desde cualquier página. Además, se observan otros niveles de opciones de menú uniformes y accesibles desde otras páginas de acuerdo al área del sitio que se esté visitando. Patrón Landmark [Rossi99b]

- Menús compuestos por 'anchors' circulantes, p.e. el sitio de Weatherford presenta los títulos de las noticias más recientes de la compañía en la 'home page' y el sitio de Baker Hughes presenta las Divisiones de la compañía con imágenes y texto.

- Personalización inexistente en el diseño de los sitios. 
(a)

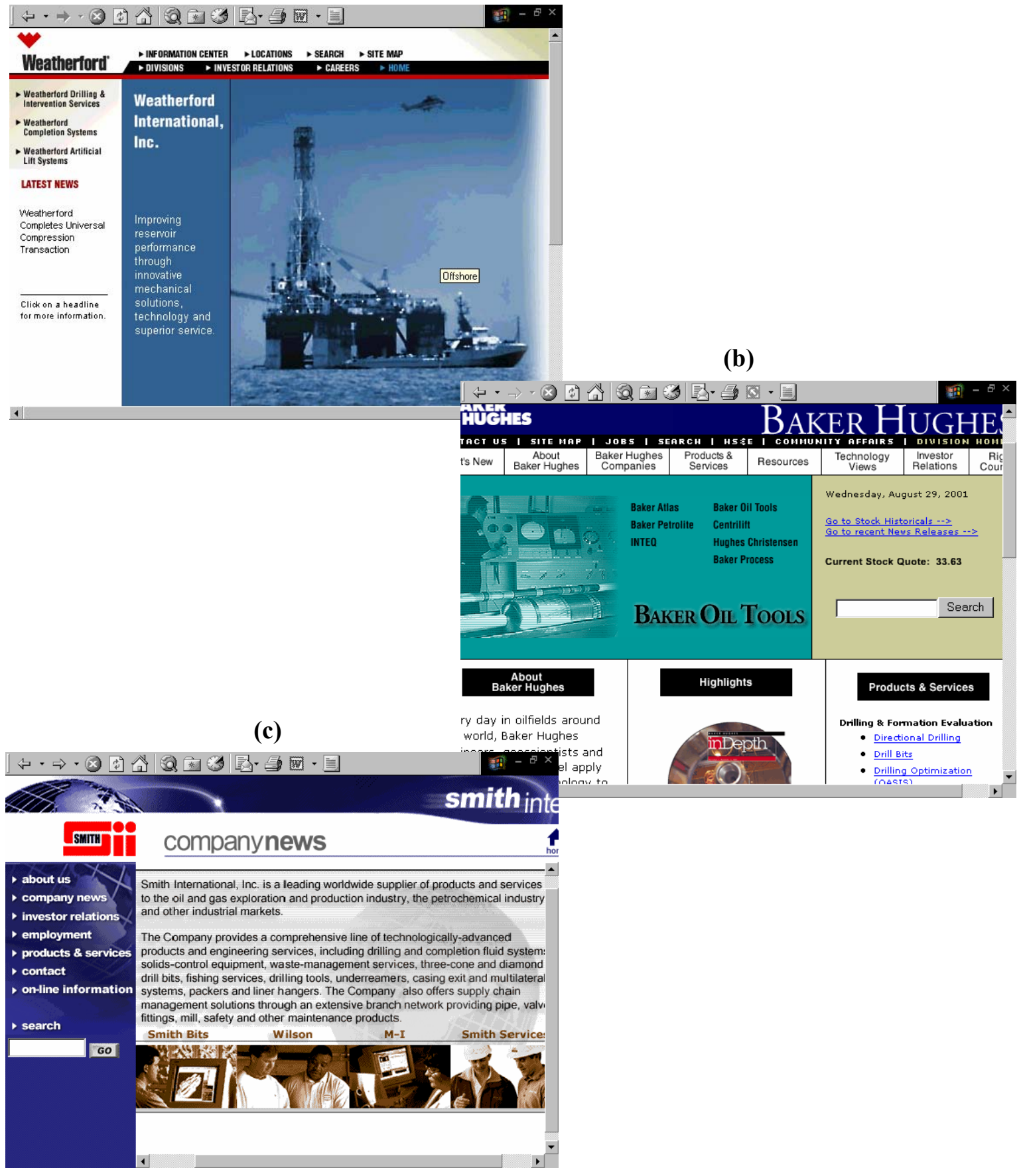

Figura 6.33 : (a) 'Home page' del sitio de Weatherford International; (b) 'Home page' del sitio de Baker Hughes; (c) 'Home page' del sitio de Smith International 


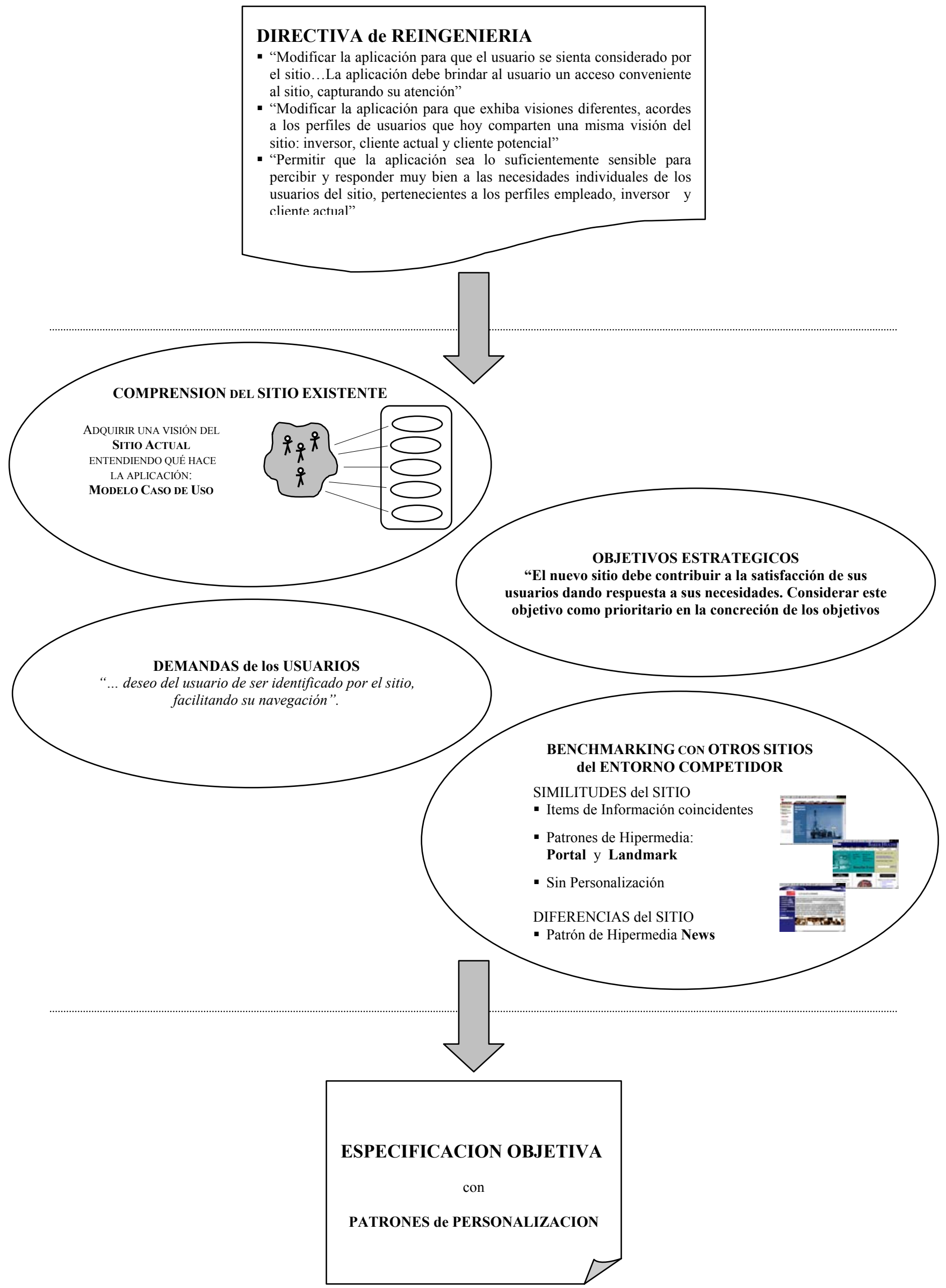

Figura 6.34 : 'Envisionig' el nuevo http://www.weatherford.com personalizado 
Para el caso real, la actividad de 'envisioning' deriva en la siguiente especificación objetiva delineada incorporando patrones de personalización:

- Diseñar una 'home page' del sitio por cada uno de los siguientes perfiles de usuario: inversor, cliente actual y cliente potencial; modificar la aplicación para que exhiba visiones con características diferentes, acordes a cada uno de estos perfiles.

Patrón Portal [Rossi00a] + Patrón Structure Personalization [Rossi01a]

Este será un primer nivel de personalización 'coarse grained' destinada a tratar con grupos de usuarios del sitio, que pertenecen a perfiles identificados en el modelo caso de uso de la aplicación. Recordemos que para el perfil empleado ya existe este grado de personalización, ya que la aplicación provee una 'home page' distinta al identificar un usuario perteneciente a

este grupo.

Patrón Role-Based Personalization [Schwabe02]

- Especializar las visiones ligadas a los perfiles de usuarios: empleado, inversor y cliente actual, para que cada usuario perteneciente a estos perfiles se sienta atendido en sus necesidades individuales:

i El usuario perteneciente al perfil empleado debe recibir atención de la aplicación acorde a su categoría dentro de la compañía.

Patrón Behavior Personalization [Schwabe02]

i El usuario perteneciente al perfil inversor debe tener acceso a cuestiones de inversión más finas sobre su situación particular como inversor de la compañía.

\section{Patrón Content Personalization [Rossi01a]}

i El usuario perteneciente al perfil cliente actual debe tener acceso directo a las páginas de prestaciones de productos/servicios/sistemas que estén ligados no solamente al rubro de la empresa a la que pertenece sino también, de ser posible, a la función que desempeña dentro de dicha empresa.

\section{Patrón Link Personalization [Rossi01a]}

Este será un segundo nivel de personalización 'finer grained' destinada a tratar particularmente con cada uno de los usuarios, pertenecientes a los perfiles de usuarios favorecidos por la directiva de reingeniería.

Patrón Individual-Based Personalization [Schwabe02].

Para aplicar esta personalización a la aplicación web existente reutilizaremos los casos de uso seleccionados en el proceso de ingeniería en reversa, personalizándolos de la siguiente manera:

\begin{tabular}{|c|c|c|c|}
\hline $\begin{array}{c}\text { PERFIL } \\
\text { DE USUARIO }\end{array}$ & $\begin{array}{c}\text { CASOS } \\
\text { DE USO }\end{array}$ & $\begin{array}{c}\text { Grado DE } \\
\text { PERSONALIZACIÓN }\end{array}$ & DESCRIPCIÓN \\
\hline Actiente & $\mathbf{( 2 )}$ & 'coarse grained' & $\begin{array}{c}\text { El Portal ofrece los títulos de las } \\
\text { noticias tecnológicas más recientes } \\
\text { y permite acceder directamente a la } \\
\text { noticia seleccionada. }\end{array}$ \\
(8) & 'coarse grained' & $\begin{array}{c}\text { El Portal ofrece los títulos de los } \\
\text { artículos de la última edición de la } \\
\text { Revista 'W' y permite acceder } \\
\text { directamente al artículo } \\
\text { seleccionado. }\end{array}$ \\
\hline
\end{tabular}




\begin{tabular}{|c|c|c|c|}
\hline $\begin{array}{c}\text { Cliente } \\
\text { Actual } \\
\text { (continuación) }\end{array}$ & (8) & 'fine grained' & 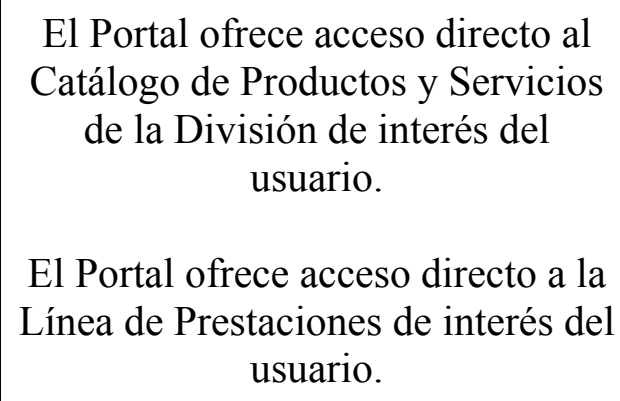 \\
\hline \multirow[t]{3}{*}{ Inversor } & (5) & 'coarse grained' & 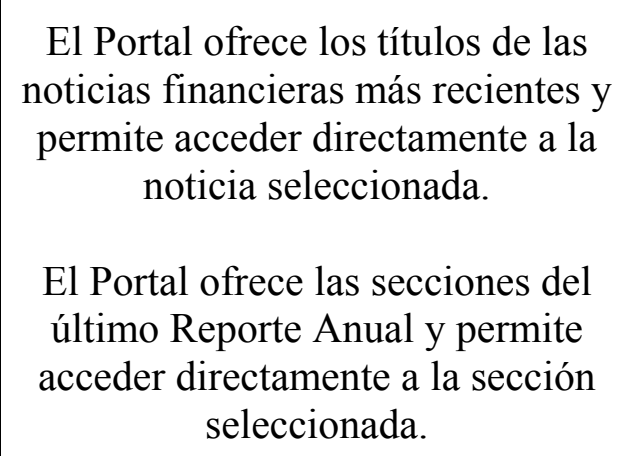 \\
\hline & (5) & 'coarse grained' & $\begin{array}{l}\text { El Portal ofrece la cotización de } \\
\text { apertura del día y de cierre del día } \\
\text { anterior y un vínculo para acceder } \\
\text { directamente a más datos } \\
\text { financieros. }\end{array}$ \\
\hline & (5) & 'fine grained' & $\begin{array}{l}\text { El Portal ofrece acceso directo a las } \\
\text { Inversiones del usuario. }\end{array}$ \\
\hline Empleado & (10) & 'fine grained' & $\begin{array}{l}\text { La opción de Inscripción en Cursos } \\
\text { de Capacitación autoriza } \\
\text { inscripciones de acuerdo a la } \\
\text { categoría del usuario dentro de la } \\
\text { Compañía. }\end{array}$ \\
\hline \multirow[t]{2}{*}{$\begin{array}{c}\text { Cliente } \\
\text { Potencial }\end{array}$} & (8) & 'coarse grained' & $\begin{array}{c}\text { El Portal ofrece acceso directo al } \\
\text { Catálogo de Productos y Servicios } \\
\text { de la Compañía. }\end{array}$ \\
\hline & (4) & 'coarse grained' & $\begin{array}{c}\text { El Portal presenta las tres } \\
\text { Divisiones de la Compañía y } \\
\text { permite acceder directamente a la } \\
\text { División seleccionada. }\end{array}$ \\
\hline
\end{tabular}




\subsubsection{Construyendo el puente UID entre modelos}

Paso 5. Obtener el mapeo de los casos de uso en UIDs[Vilain00]. El UID, (ver UIDs, capítulo3), es una herramienta gráfica que juega un rol fundamental en este procedimiento, ya que además de representar la interacción usuario/sistema, se observará en los puntos sucesivos que se convierte en el pivote que habilita el nexo entre el modelado externo y el modelado interno del sitio.

Este paso consiste en reflejar cada caso de uso seleccionado para el caso real, en un UID, aplicando el método [Vilain00], que se presenta en 5.4.4 de este trabajo.

Caso de Uso (2): “Comunicando noticias de la compañía”

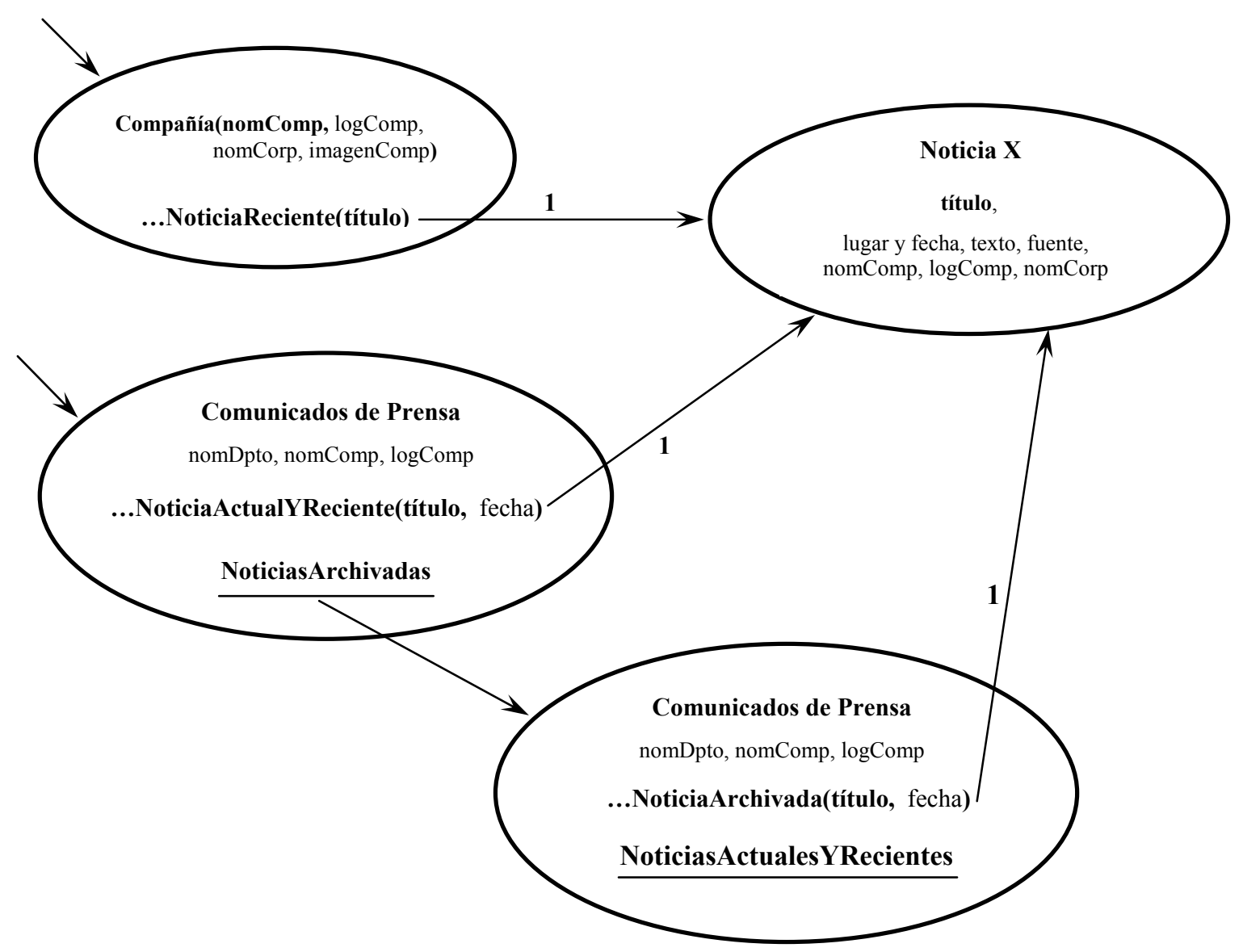

Figura 6.35: UID para el caso de uso "Comunicando noticias de la compañia" 
Caso de Uso (4): "Navegando líneas de productos, servicios y sistemas dada una división"

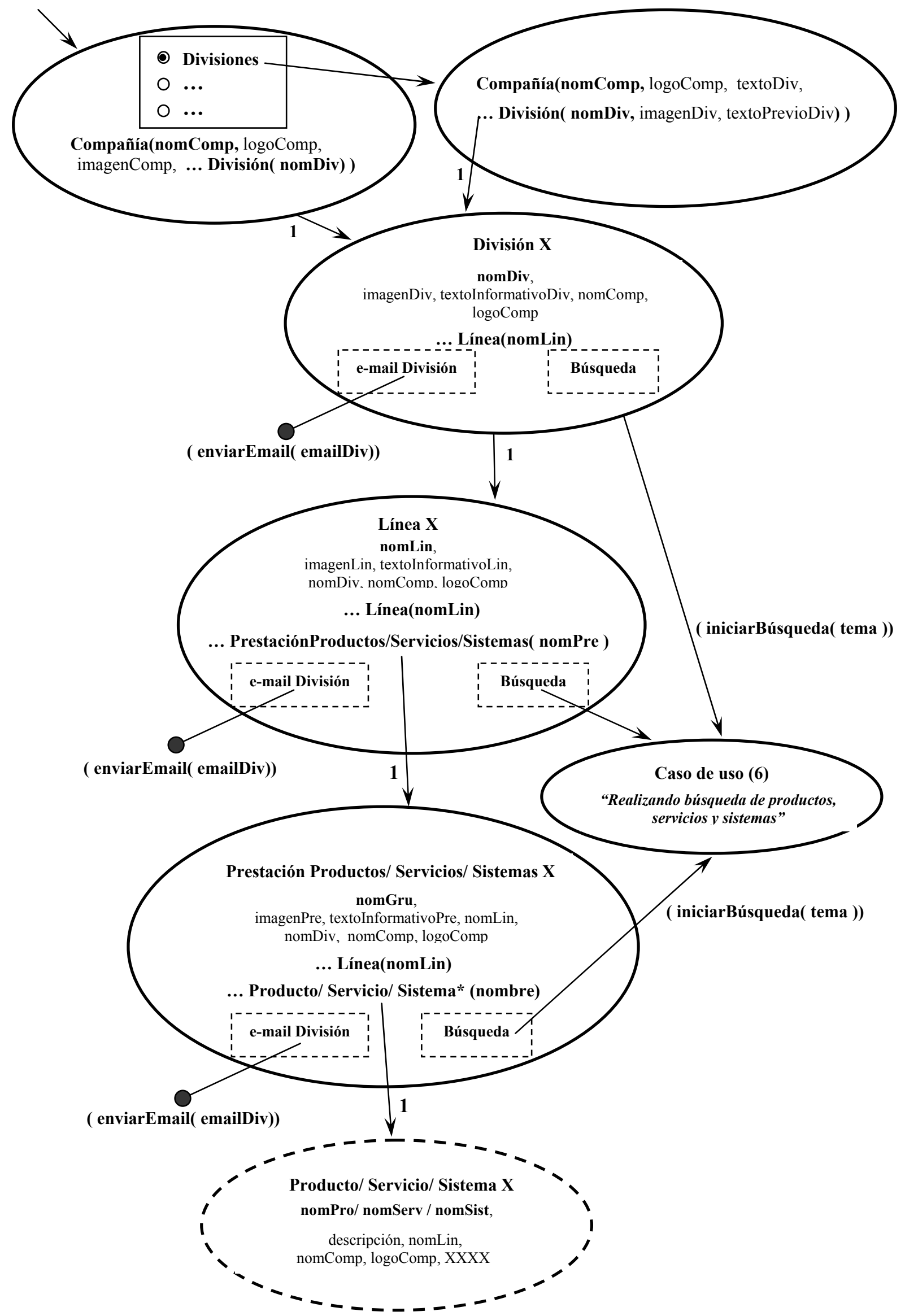

Figura 6.36: UID para el caso de uso "Navegando líneas de prestaciones dada una división" 
Caso de Uso (5): "Brindando Información Financiera"

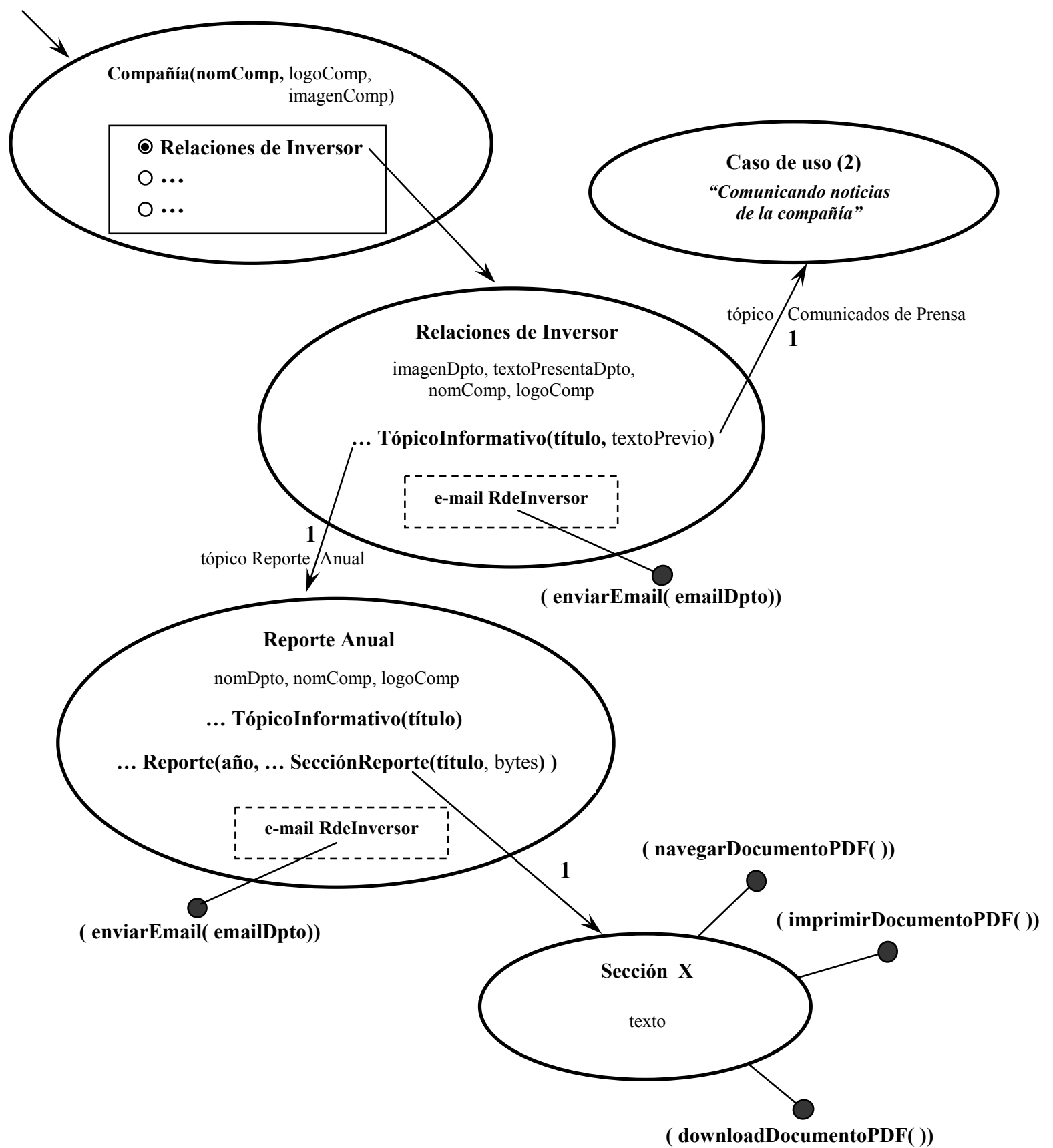

Figura 6.37: UID del caso de uso "Brindando información financiera" 
Caso de Uso (8): “Informando prestaciones al yacimiento petrolifero"

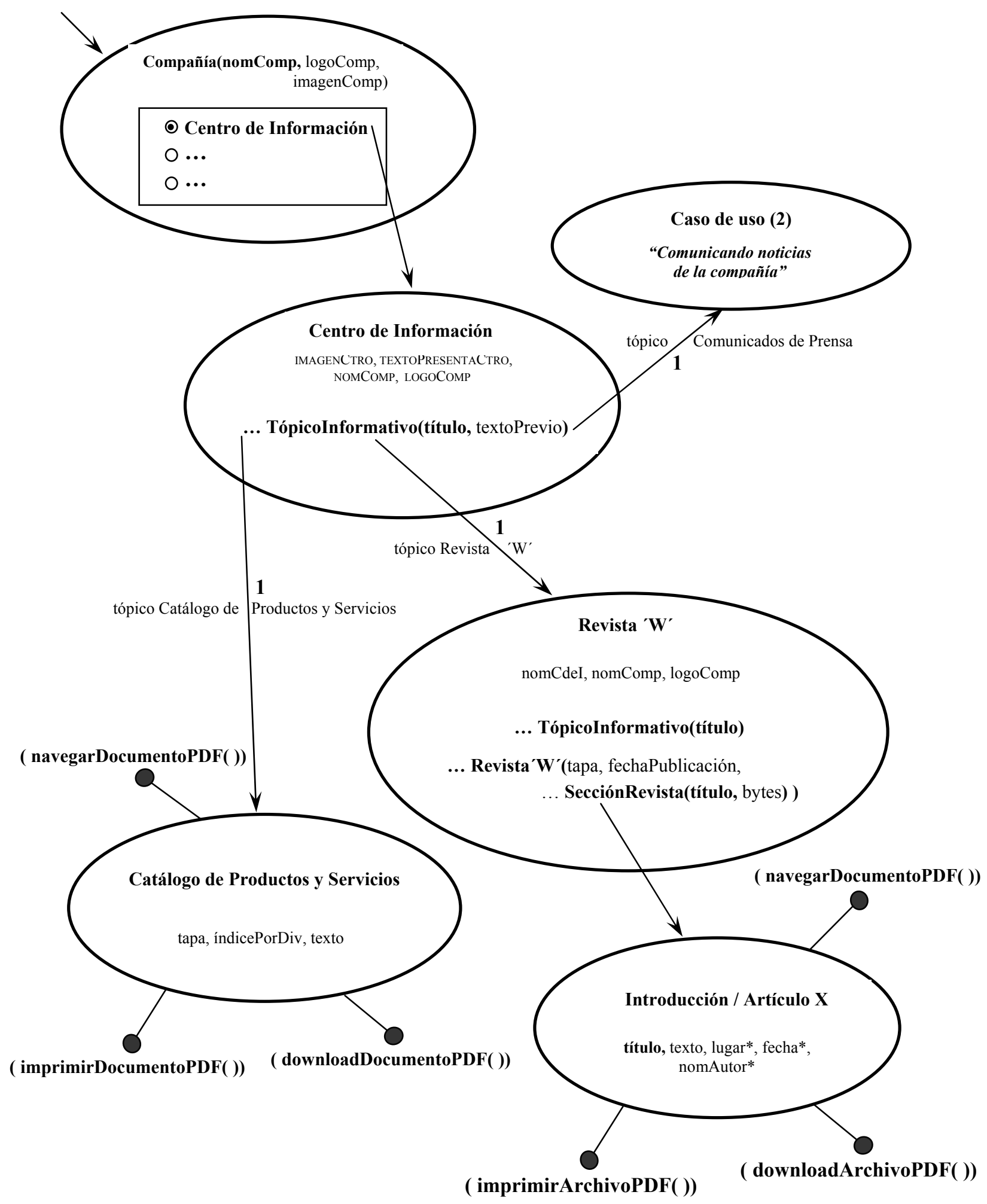

Figura 6.38: UID del caso de uso "Informando prestaciones al yacimiento petrolífero" 
Caso de Uso (10): "Posibilitando envío de inscripción en curso de capacitación"

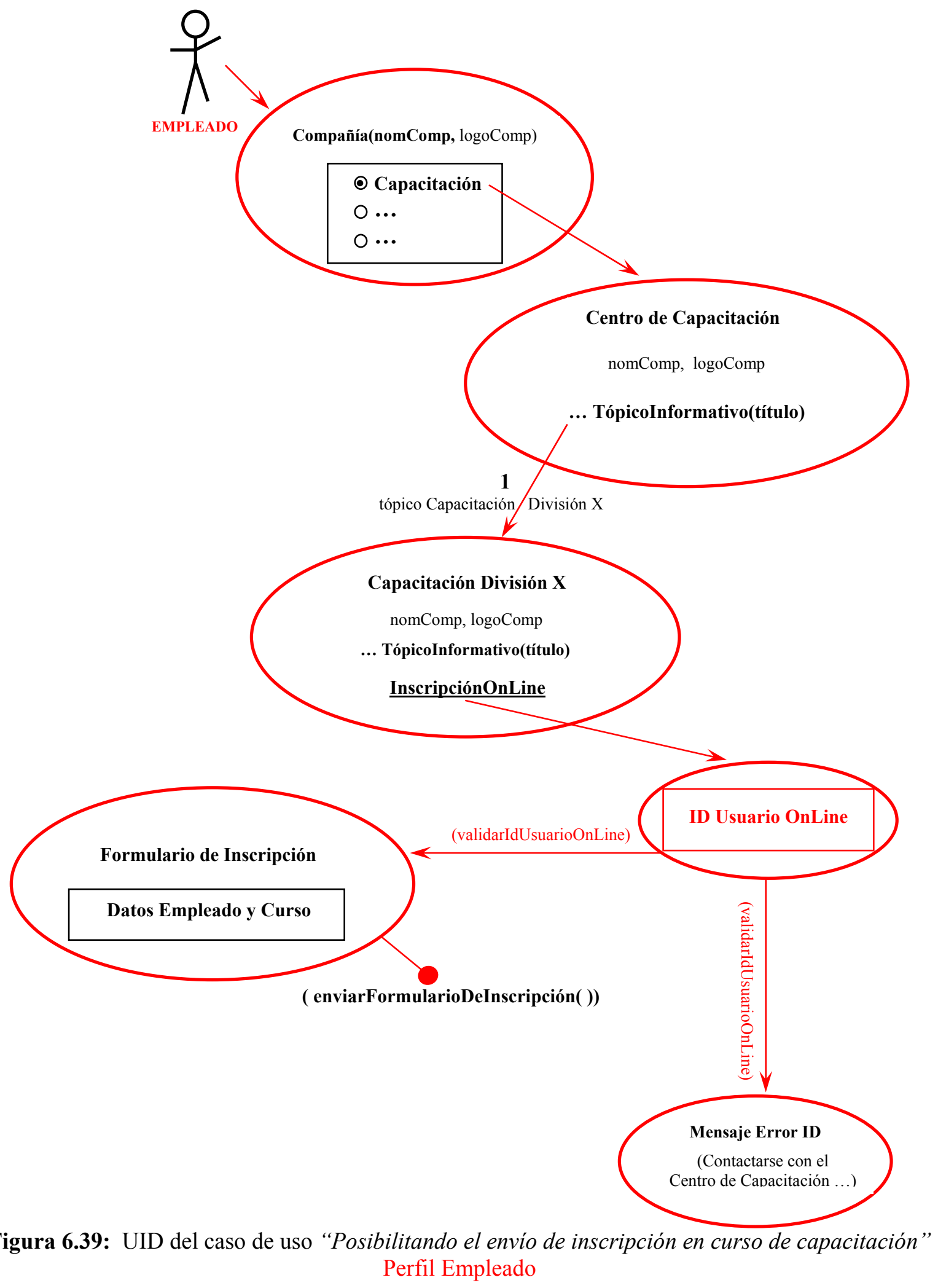

Figura 6.39: UID del caso de uso "Posibilitando el envío de inscripción en curso de capacitación" Perfil Empleado 


\subsubsection{Obteniendo el modelo interno: modelos conceptual y modelos de navegación con patrones de hipermedia}

Paso 6. Definir el Modelo Conceptual OOHDM del sitio existente. Proponemos diseñar el esquema conceptual aplicando a los UIDs el conjunto de reglas que se detallan en [Vilain00] y en [Güell00a].

Utilizando como puente los UID concebidos en el paso anterior, la siguiente actividad define un modelo conceptual para cada caso de uso seleccionado para el caso real. El conjunto de reglas a aplicar [Vilain00] y [Güell00a], se exponen en 5.4.5.1 de este trabajo.

El modelo conceptual de la aplicación Weatherford resultará de componer los respectivos modelos conceptuales obtenidos en este ítem.

Por una cuestión de practicidad, tanto en este proceso de ingeniería en reversa como en el de ingeniería 'forward' trabajaremos con los modelos fraccionados por casos de uso para facilitar sus respectivas manipulaciones.

Caso de Uso (2): “Comunicando noticias de la compañía”

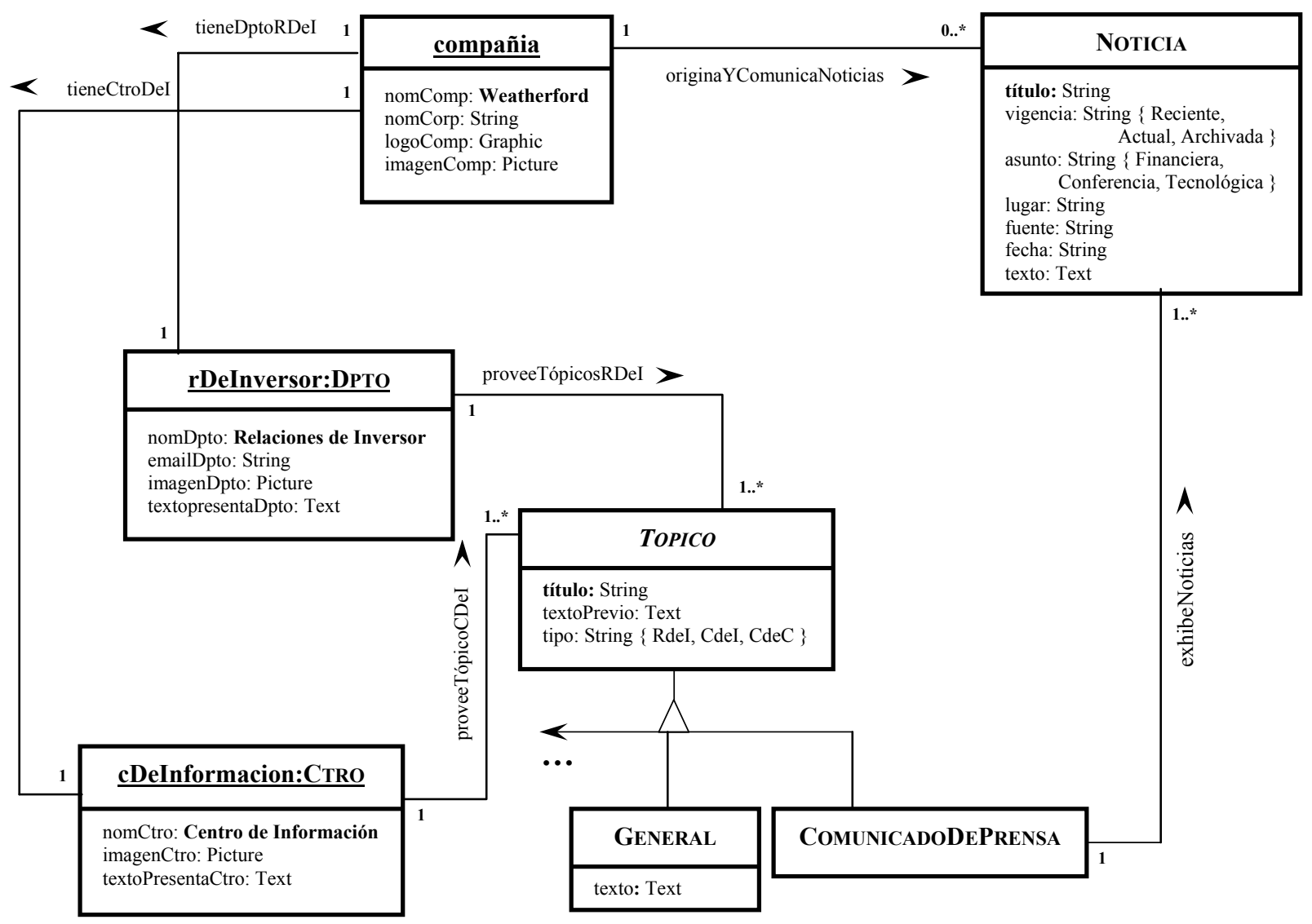

Figura 6.40: Modelo conceptual correspondiente al caso de uso "Comunicando noticias de la compañía" 
Caso de Uso (4): “Navegando líneas de productos, servicios y sistemas dada una división"

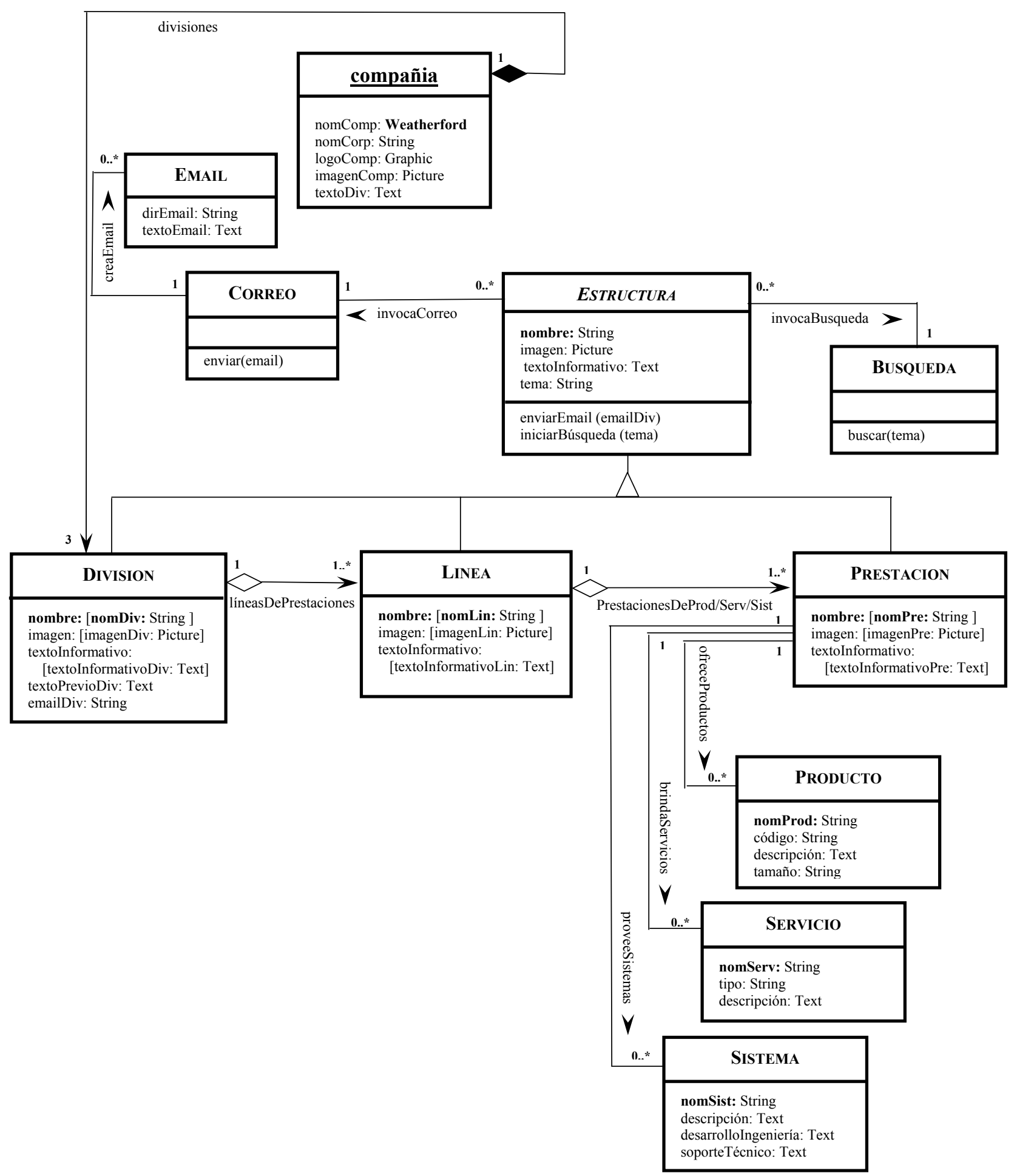

Figura 6.41: Modelo conceptual correspondiente al caso de uso

"Navegando líneas de prestaciones dada una división " 
Caso de Uso (5): "Brindando Información Financiera"

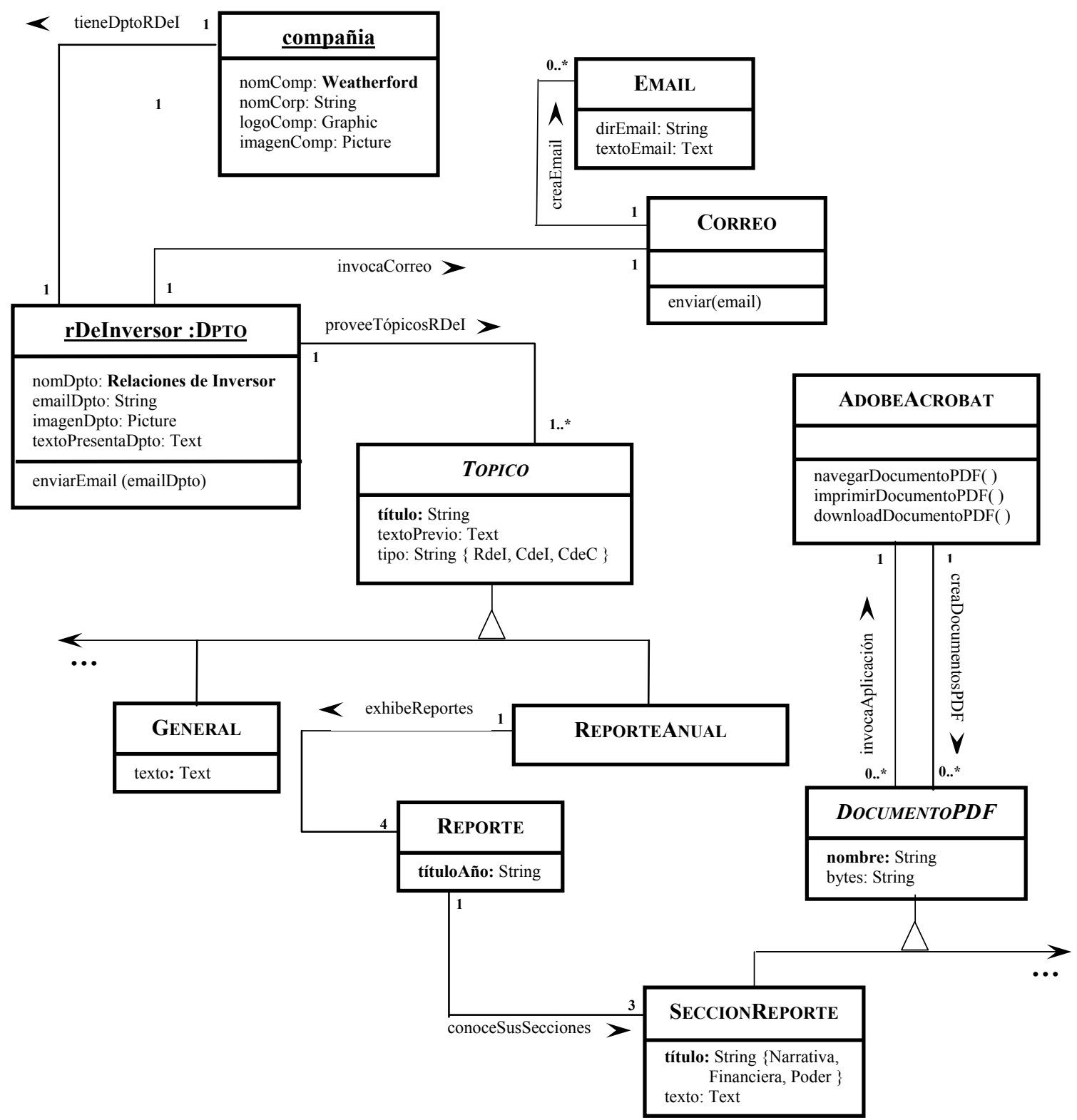

Figura 6.42: Modelo conceptual correspondiente al caso de uso "Brindando información financiera" 
Caso de Uso (8): “Informando prestaciones al yacimiento petrolifero"

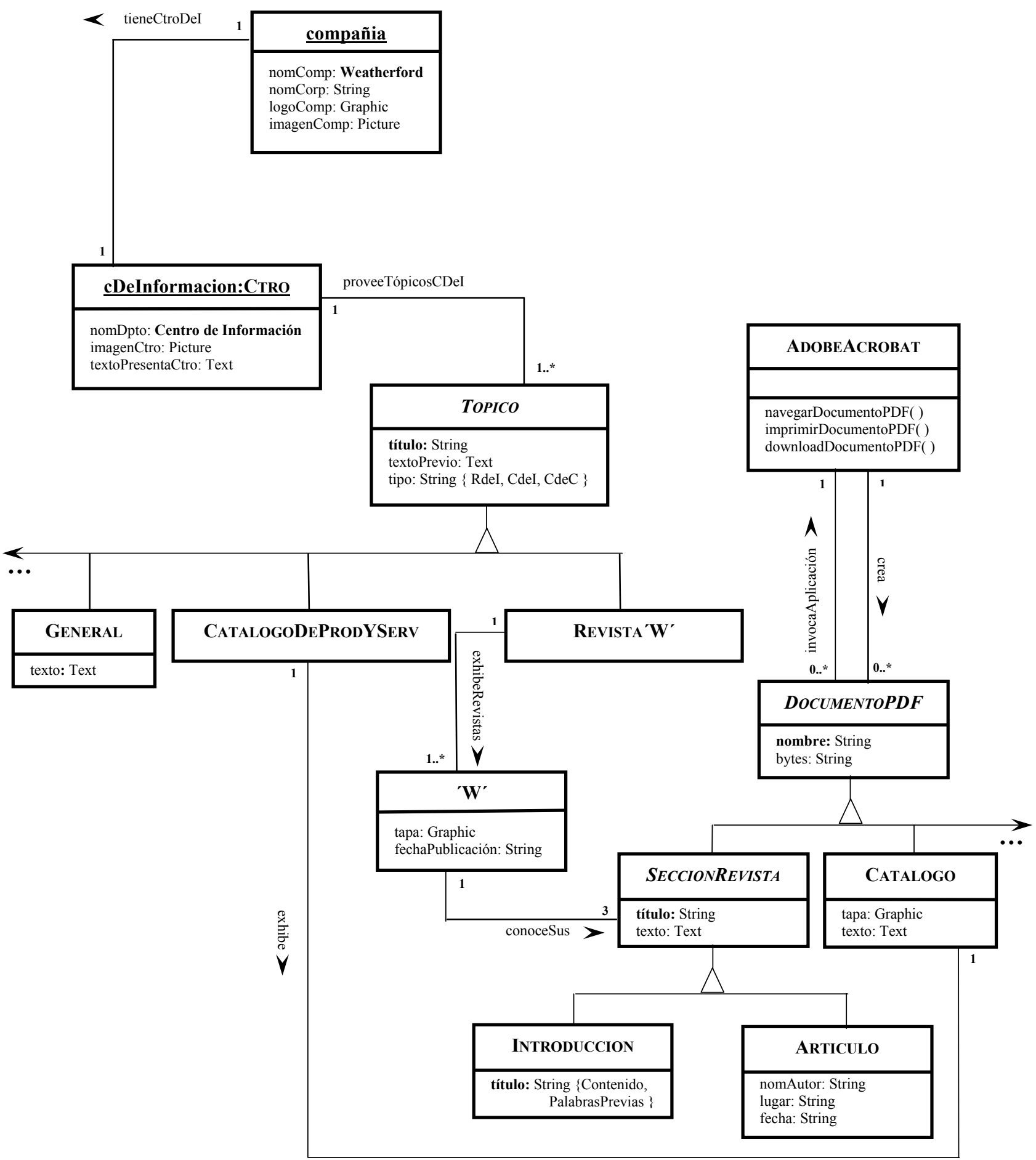

Figura 6.43: Modelo conceptual resultante de aplicar las directivas al UID "Informando prestaciones al vacimiento petrolifero" 
Caso de Uso (10): "Posibilitando envio de inscripción en curso de capacitación"

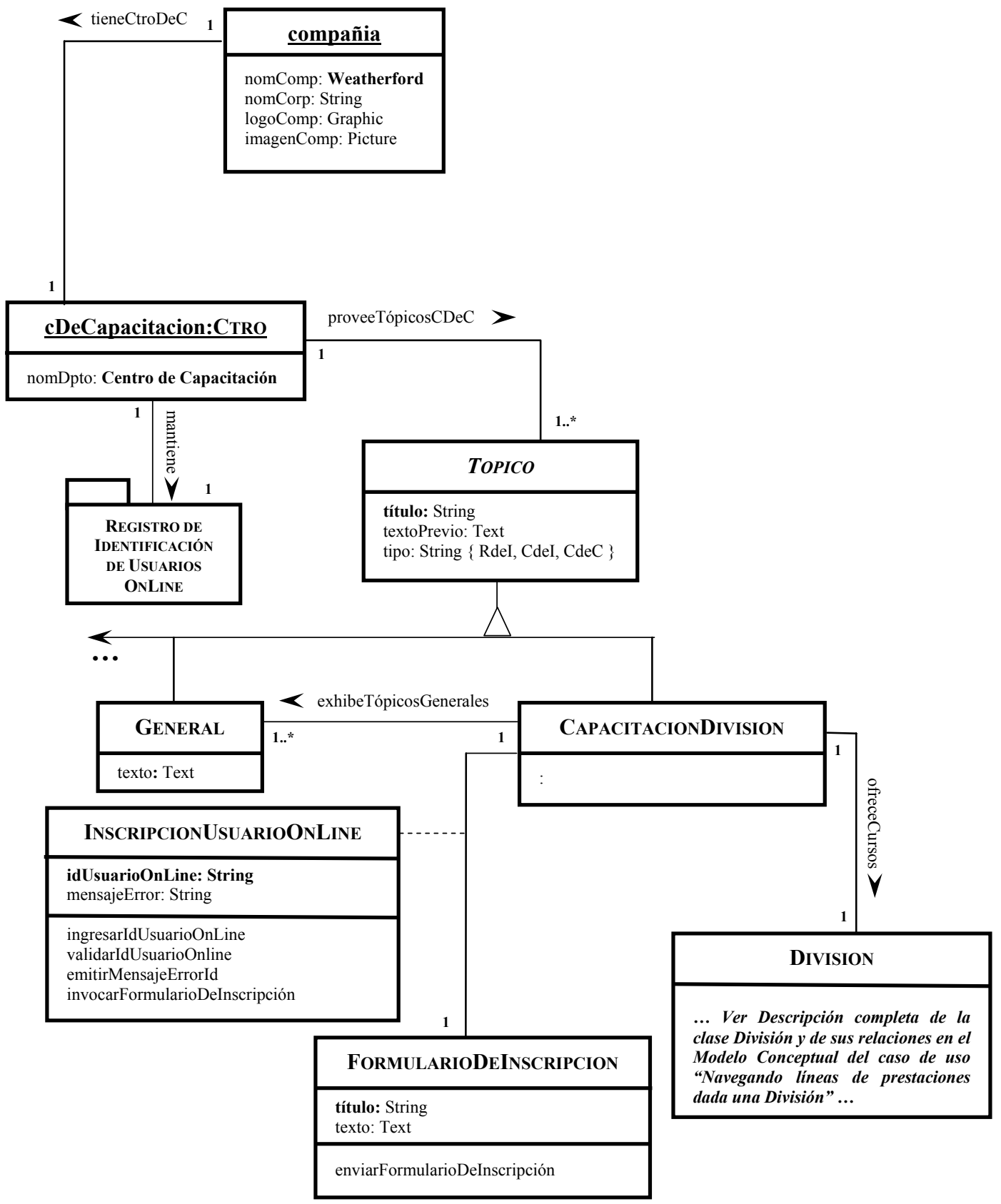

Figura 6.44: Modelo conceptual resultante de aplicar las directivas al UID "Posibilitando envío de inscripción en curso de capacitación" 
Paso 7. Obtener el Modelo de Navegación OOHDM, para completar el modelo objeto del sitio existente. Proponemos utilizar los UIDs y el método que se describe en [Güello0a].

Utilizando como puente los UID concebidos en el paso anterior, la siguiente actividad define un modelo de navegación para cada caso de uso seleccionado para el caso real. El método a aplicar propuesto en [Güell00a], se describe en 5.4.5.2 de este trabajo. En el diseño de los esquemas de contexto de navegación se incorporan patrones de hipermedia [Rossi99a, 99b, 99d, 00], que se citan en el capítulo3 de este trabajo.

Caso de Uso (2): “Comunicando noticias de la compañia”

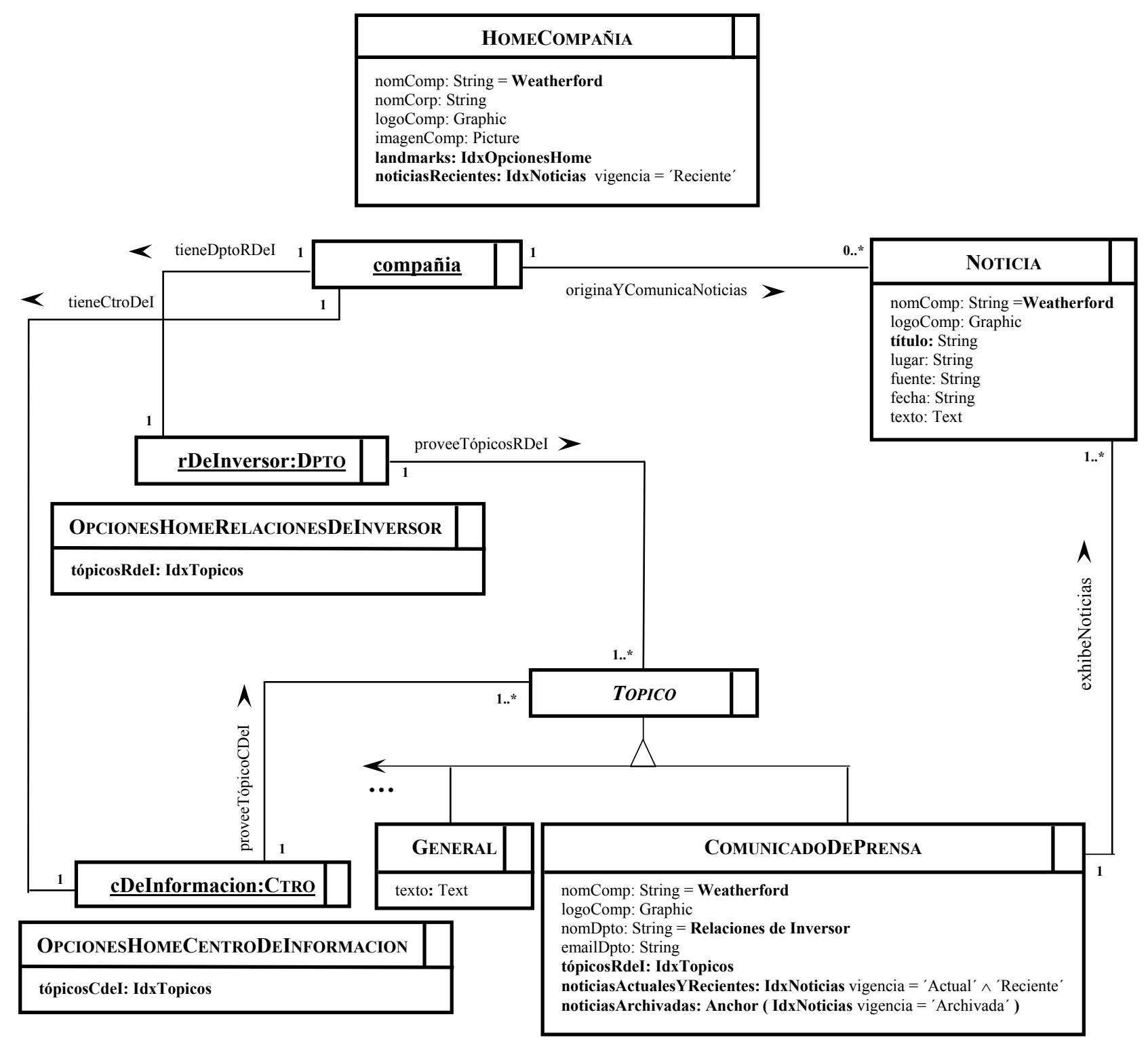

Figura 6.45: Esquema de clases de navegación correspondiente al caso de uso "Comunicando noticias de la compañia" 


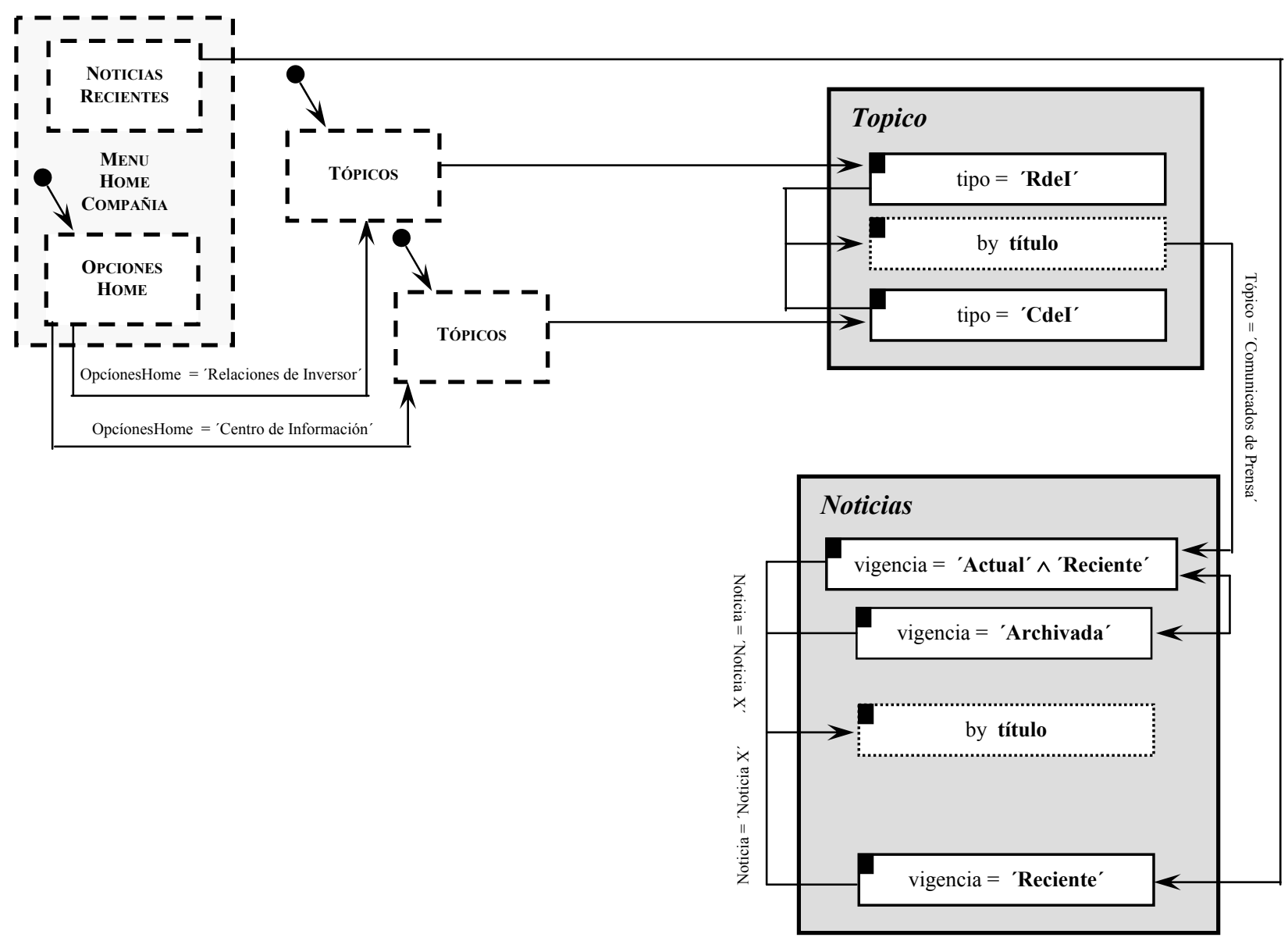

Figura 6.46: Esquema de contexto de navegación correspondiente al caso de uso "Comunicando noticias de la compañía" 
Caso de Uso (4): "Navegando líneas de productos, servicios y sistemas dada una división"

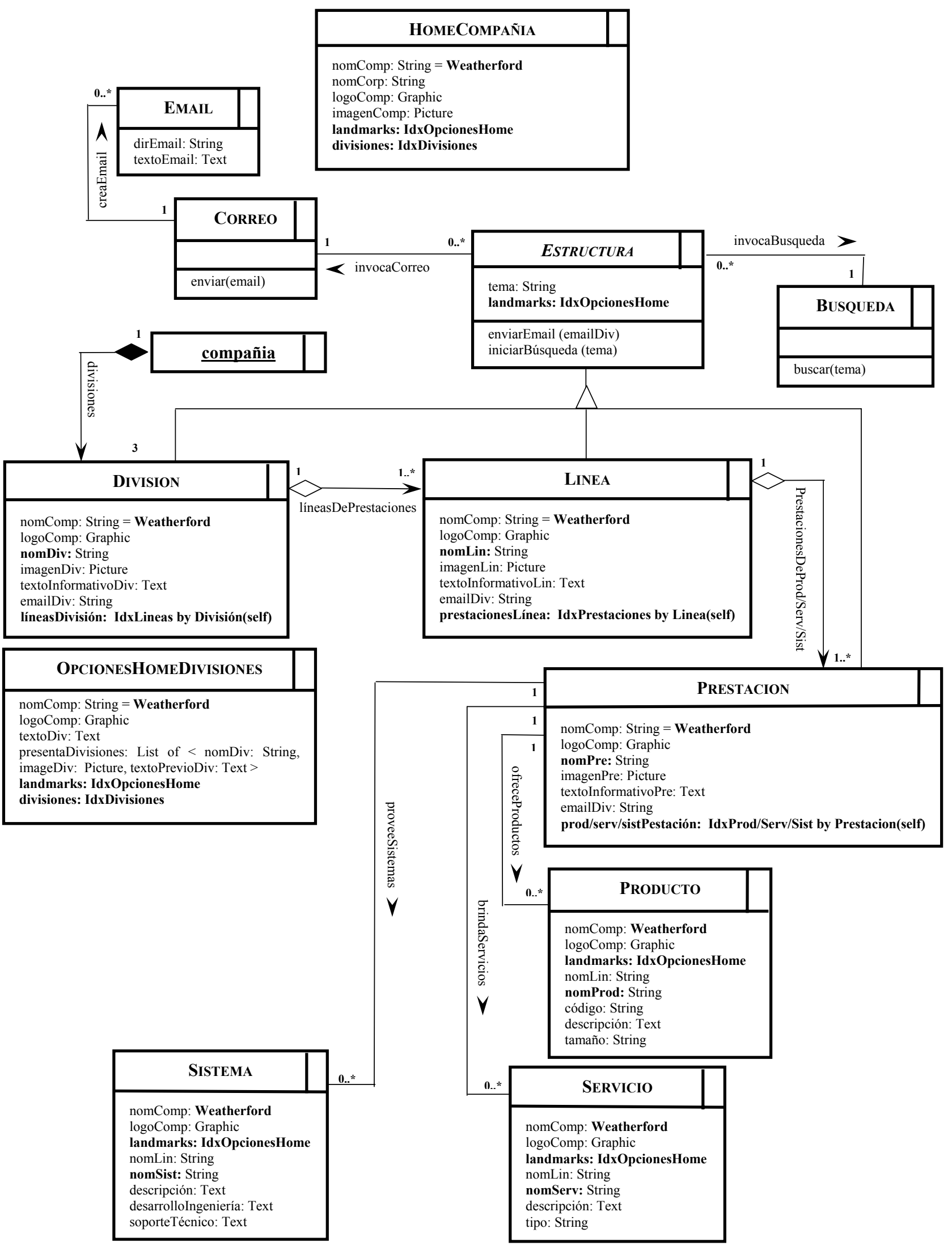

Figura 6.47: Esquema de clases de navegación correspondiente al caso de uso "Navegando líneas de prestaciones dada una división" 


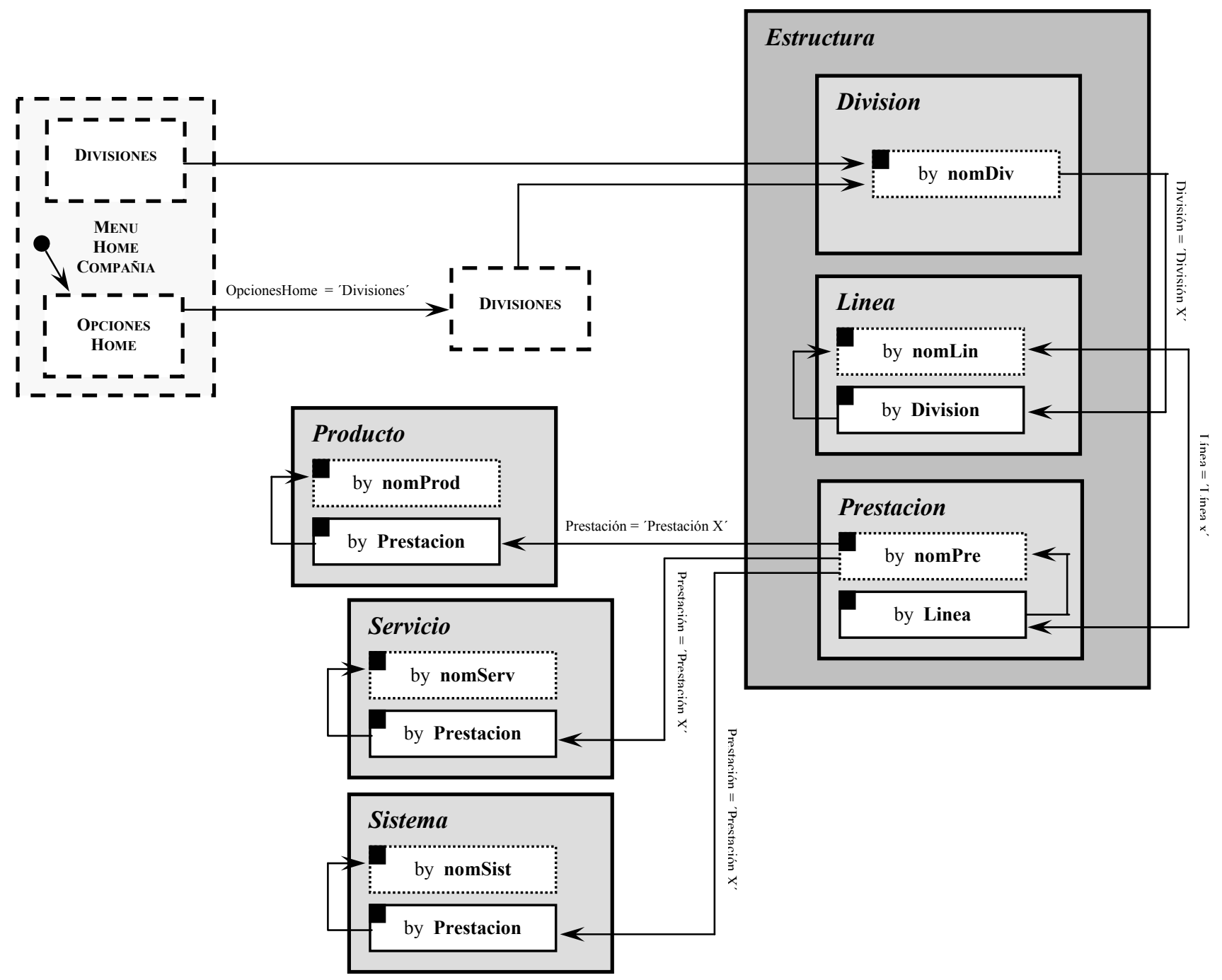

Figura 6.48: Esquema de contexto de navegación correspondiente al caso de uso "Navegando líneas de prestaciones dada un división" 
Caso de Uso (5): “Brindando Información Financiera”

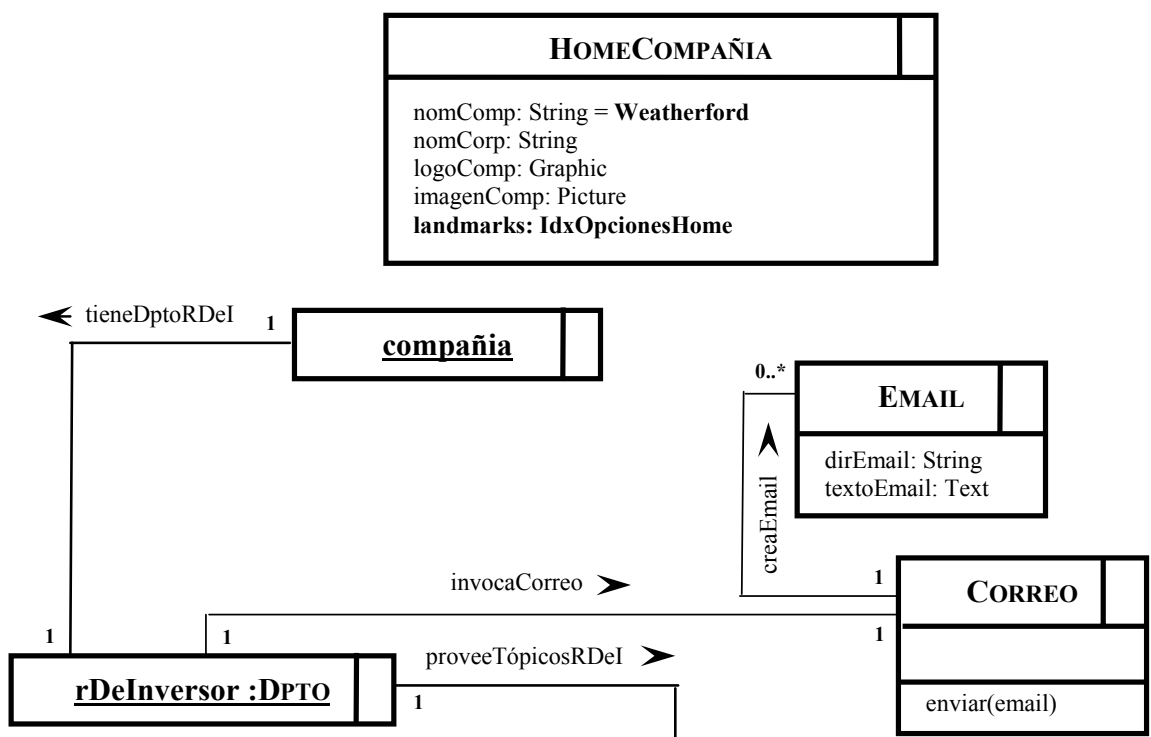

\begin{tabular}{|l|}
\hline \multicolumn{1}{|c|}{ OPCIONESHOMERELACIONESDEINVERSOR } \\
\hline nomComp: String = Weatherford \\
logoComp: Graphic \\
landmarks: IdxOpcionesHome \\
presentaDpto: List of < nomDpto: String = Relaciones de Inversor, \\
imagenDpto: Picture, textoPresentaDpto: Text, emailDpto: String $>$ \\
presentaTópicosRdeI: List of < título: String, textoPrevio: Text $>$ \\
tópicosRdeI: IdxTopicos \\
\hline enviarEmail (emailDpto)
\end{tabular}
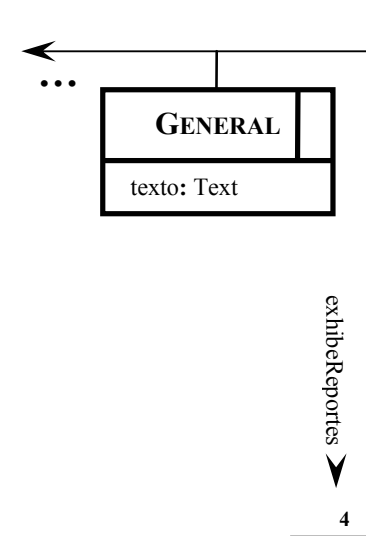

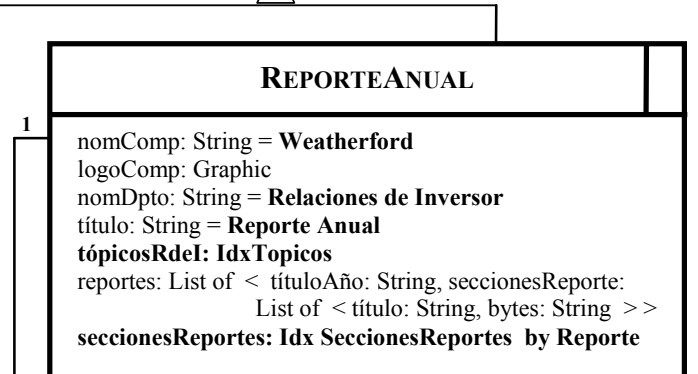

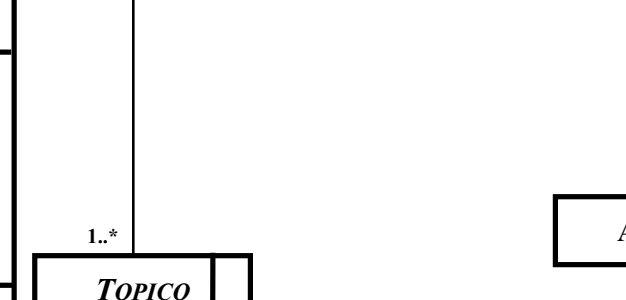

AdobeAcrobat
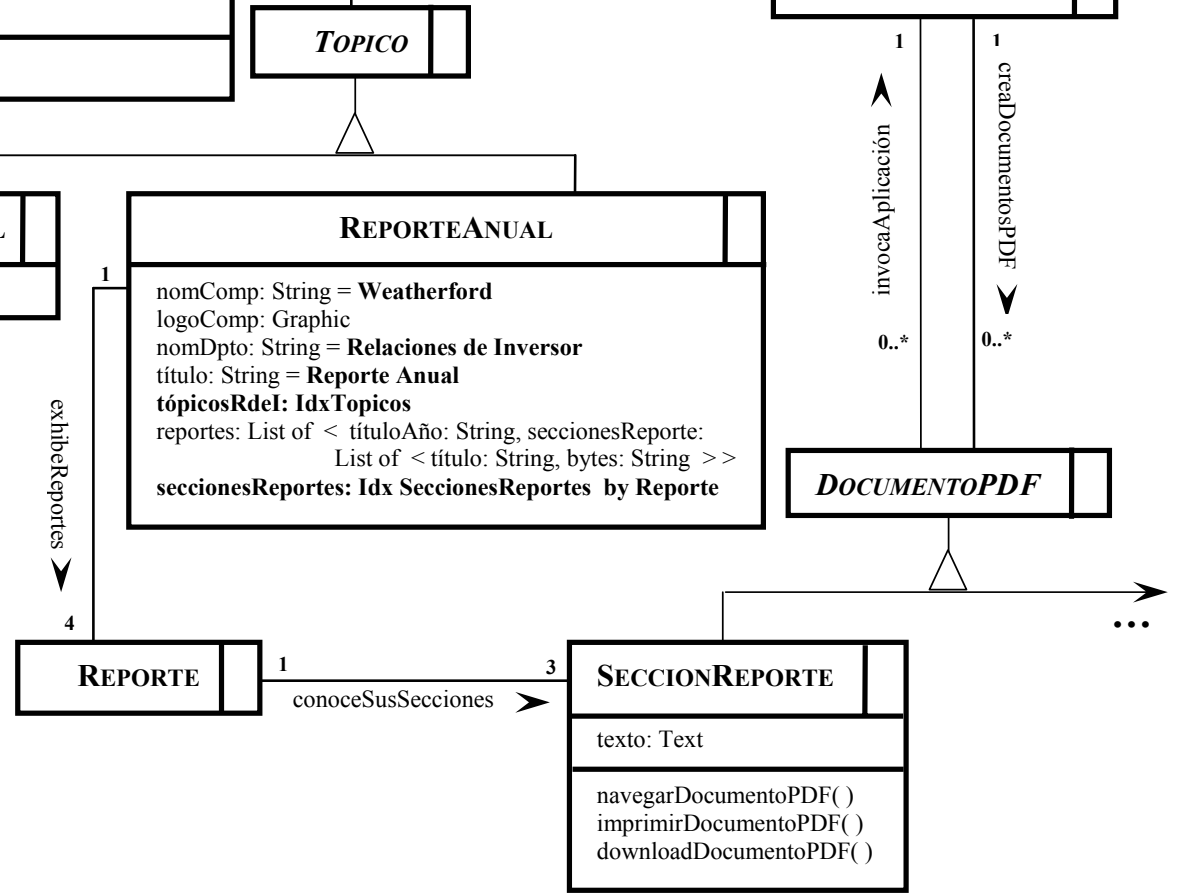

Figura 6.49: Esquema de clases de navegación correspondiente al caso de uso "Brindando información financiera" 


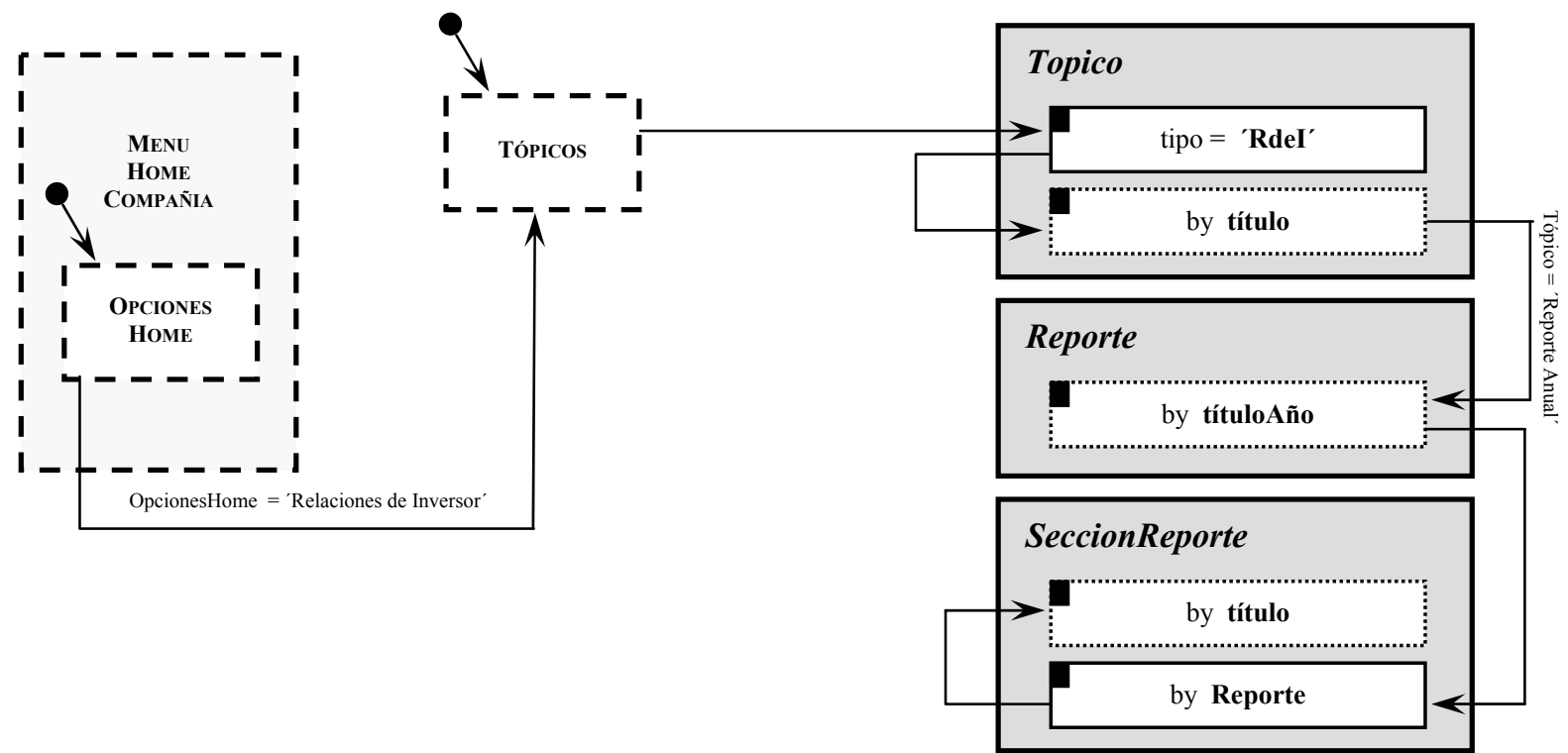

Figura 6.50: Esquema de contexto de navegación correspondiente al caso de uso "Brindando información financiera" 
Caso de Uso (8): "Informando prestaciones al yacimiento petrolífero"

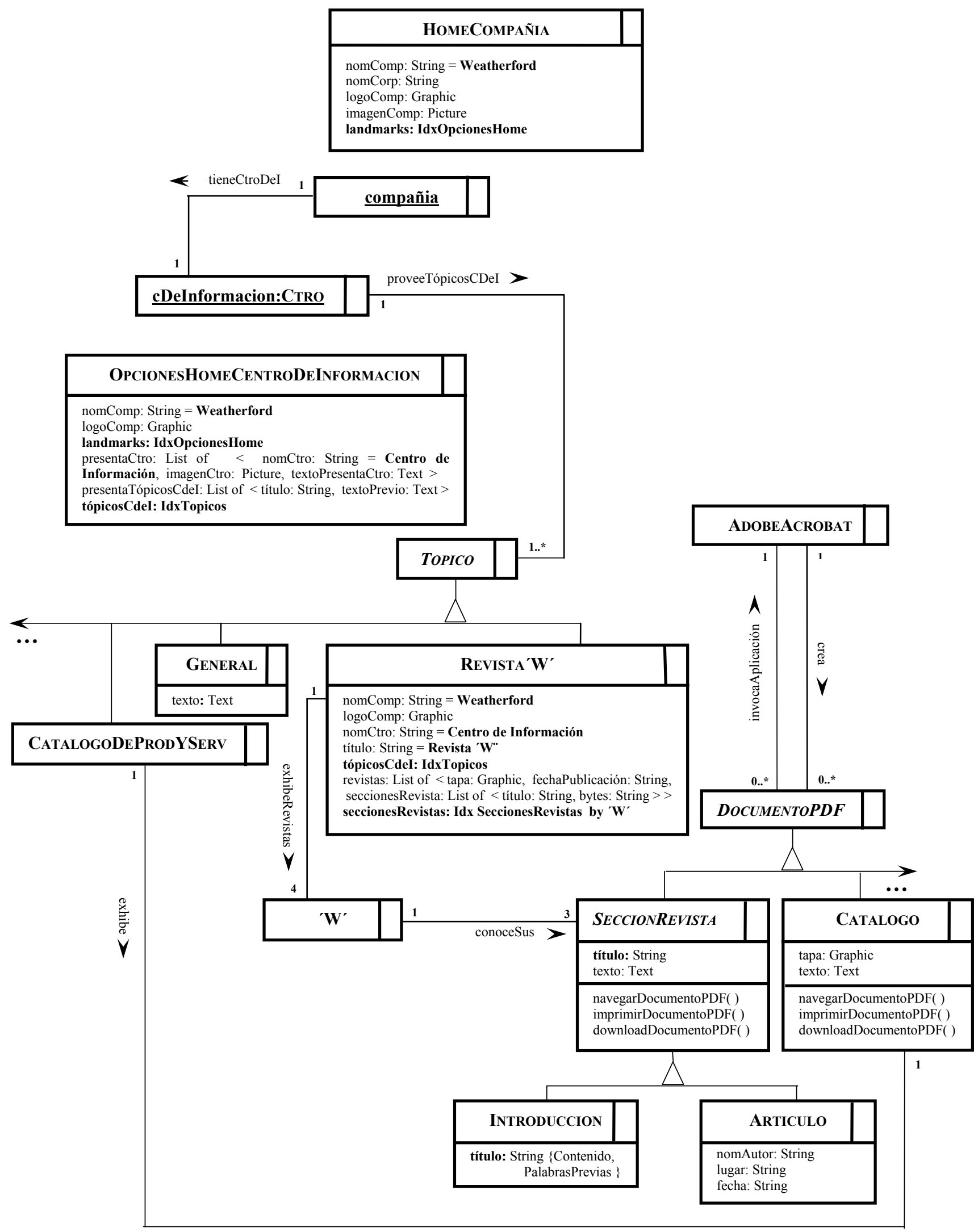

Figura 6.51: Esquema de clases de navegación correspondiente al caso de uso "Informando prestaciones al vacimiento petrolífero" 


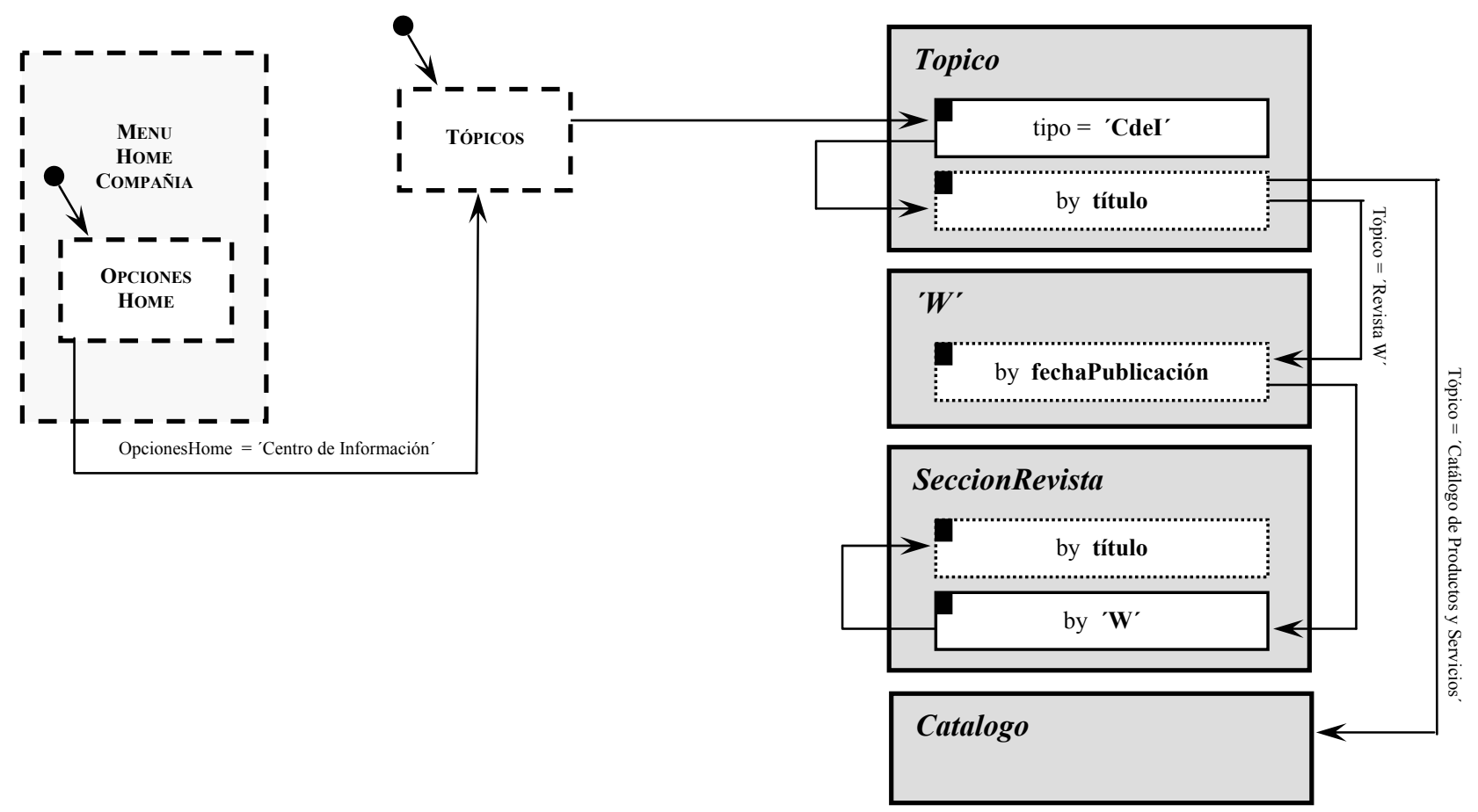

Figura 6.52: Esquema de contexto de navegación correspondiente al caso de uso "Informando prestaciones al yacimiento petrolifero" 
Caso de Uso (10): "Posibilitando envío de inscripción en curso de capacitación"

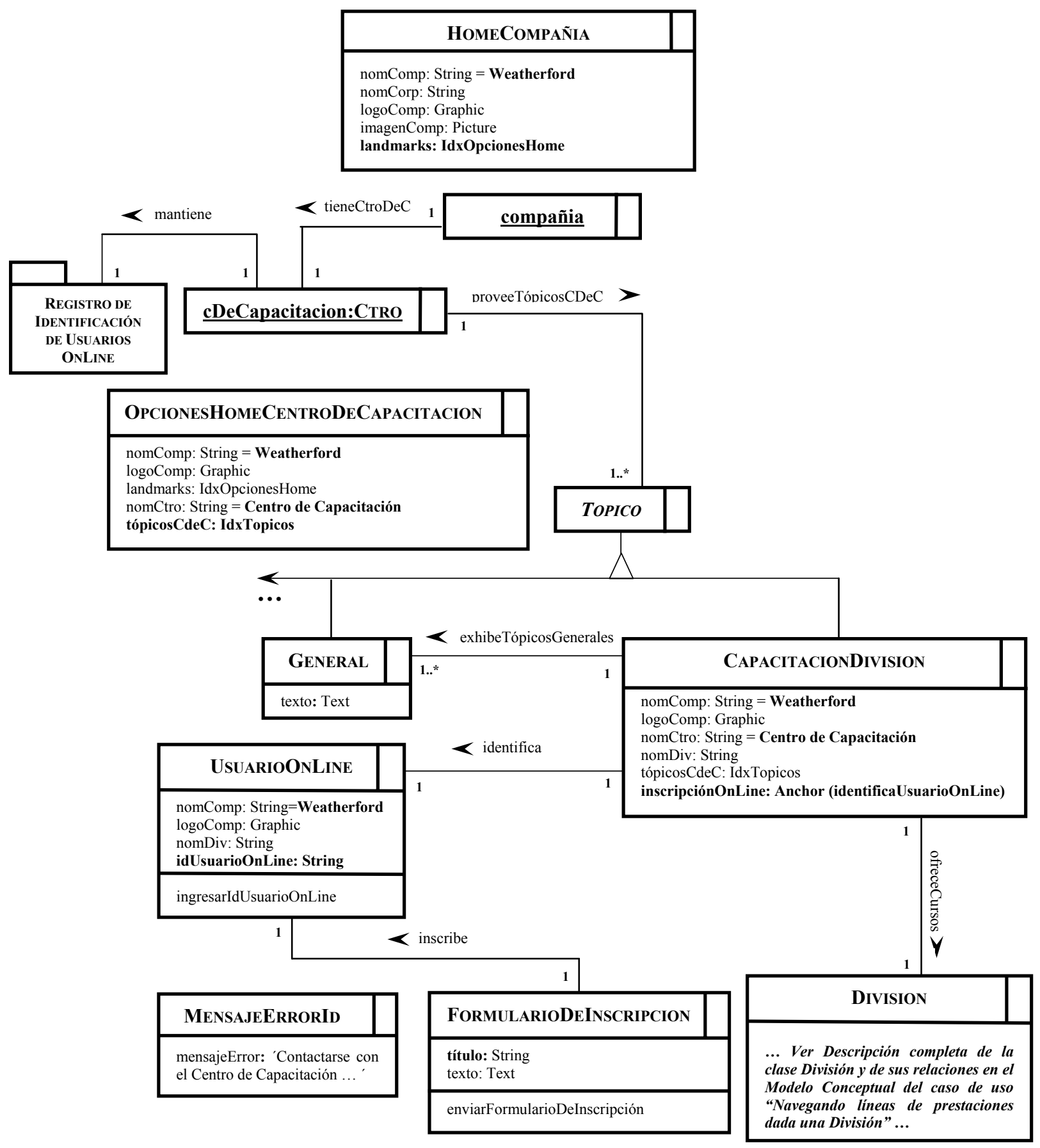

Figura 6.53: Esquema de clases de navegación correspondiente al caso de uso "Posibilitando envío de inscripción en curso de capacitación" 


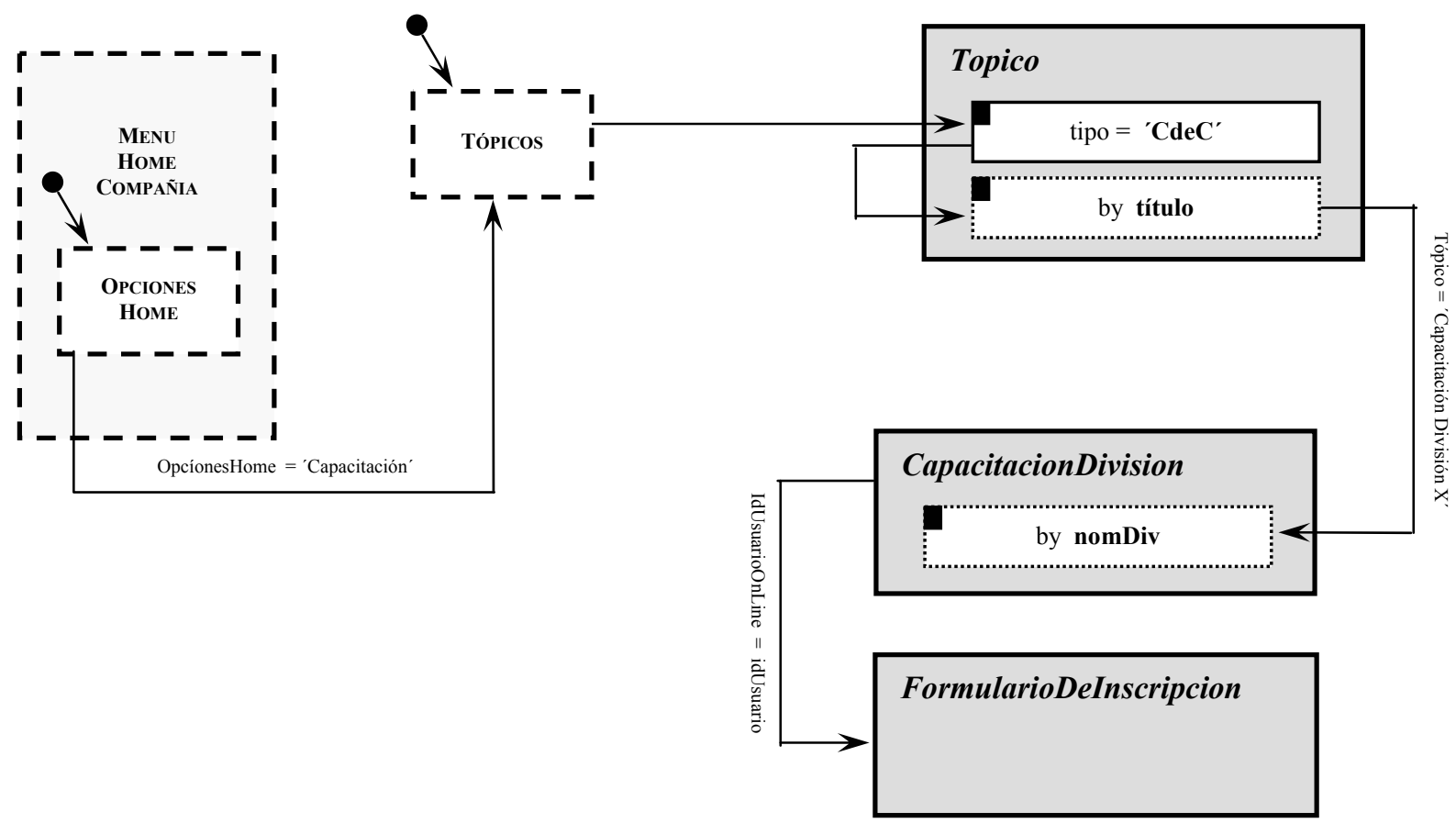

Figura 6.54: Esquema de contexto de navegación correspondiente al caso de uso "Posibilitando envío de inscripción en curso de capacitación" 


\subsection{Haciendo ingeniería 'forward' de personalización}

Una vez consensuada la especificación objetiva con los 'stakeholders' del sitio y el proceso de ingeniería en reversa concluido, el verdadero trabajo de desarrollo del proceso de reingeniería de personalización debe comenzar. En los ítem siguientes se aplica al caso real el procedimiento propuesto en 5.4.1 para la actividad de ingeniería 'forward' de personalización.

\subsubsection{Bosquejando Portales para los perfiles de usuarios}

Paso 1. Producir bosquejos de la/s página/s que reflejeln los cambios deseados en el sitio personalizado. Utilizando una herramienta gráfica a elección, la representación resultante, perseguirá moldear y complementar la especificación objetiva, reforzando no solo el acuerdo entre las partes interesadas en el sitio 'stakeholders del sitio', sino también el punto de partida para la tarea de personalización.

Una imagen habla más que mil palabras... Es por ello que el Paso 1 del procedimiento de ingeniería 'forward' propone la confección de bosquejos que reflejen los cambios deseados en el sitio personalizado.

En este caso, dichos bosquejos plasman los futuros portales y páginas del caso real personalizado. En respuesta a lo prescripto por la especificación objetiva como primer nivel de personalización 'coarse grained' destinada a tratar con grupos de usuarios del sitio:

"Diseñar una 'home page' del sitio por cada uno de los siguientes perfiles de usuario: inversor, cliente actual y cliente potencial ..."

y como segundo nivel de personalización 'finer grained' destinada a tratar individualmente con cada uno los usuarios del sitio pertenecientes a los perfiles de usuarios favorecidos por la directiva de reingeniería:

"Especializar las visiones ligadas a los perfiles de usuarios: empleado, inversor y cliente actual, para que cada usuario perteneciente a estos perfiles se sienta atendido en sus necesidades individuales: ..."

y re-utilizando los casos de uso seleccionados en el proceso de ingeniería en reversa, se proponen para el caso real los siguientes portales y páginas: Portal Usuario Inversor Figura 6.55 , Portal Usuario Cliente Actual Figura 6.56, Portal Usuario Cliente Potencial Figura 6.57, Portal Usuario Empleado Figura 6.27 bis y Página Formulario de Capacitación Usuario Empleado Figura 6.31 bis . 


\section{Portal Usuario Inversor}

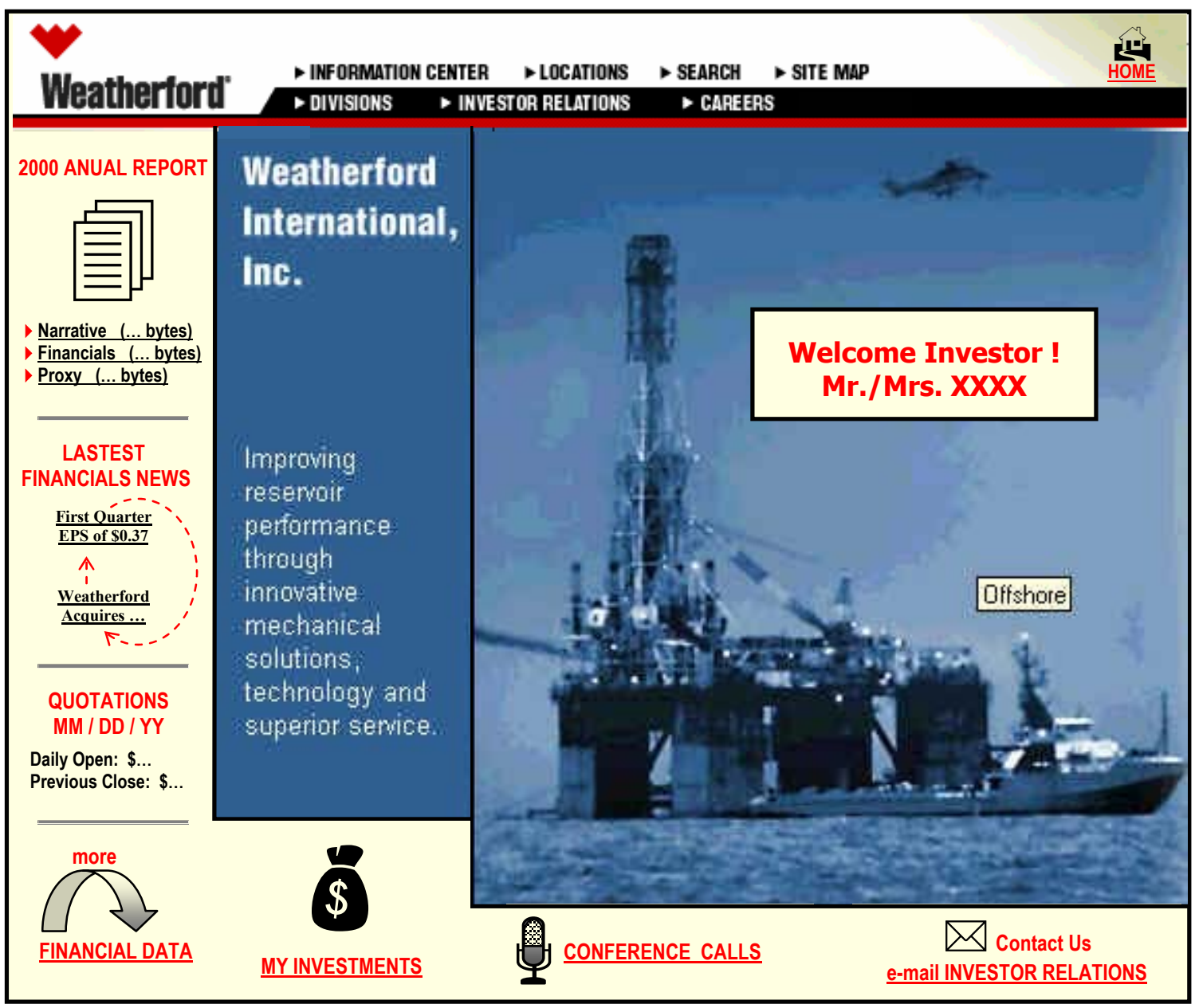

Figura 6.55 : Bosquejo del Portal para el Perfil Inversor 


\section{Portal Usuario Cliente Actual}

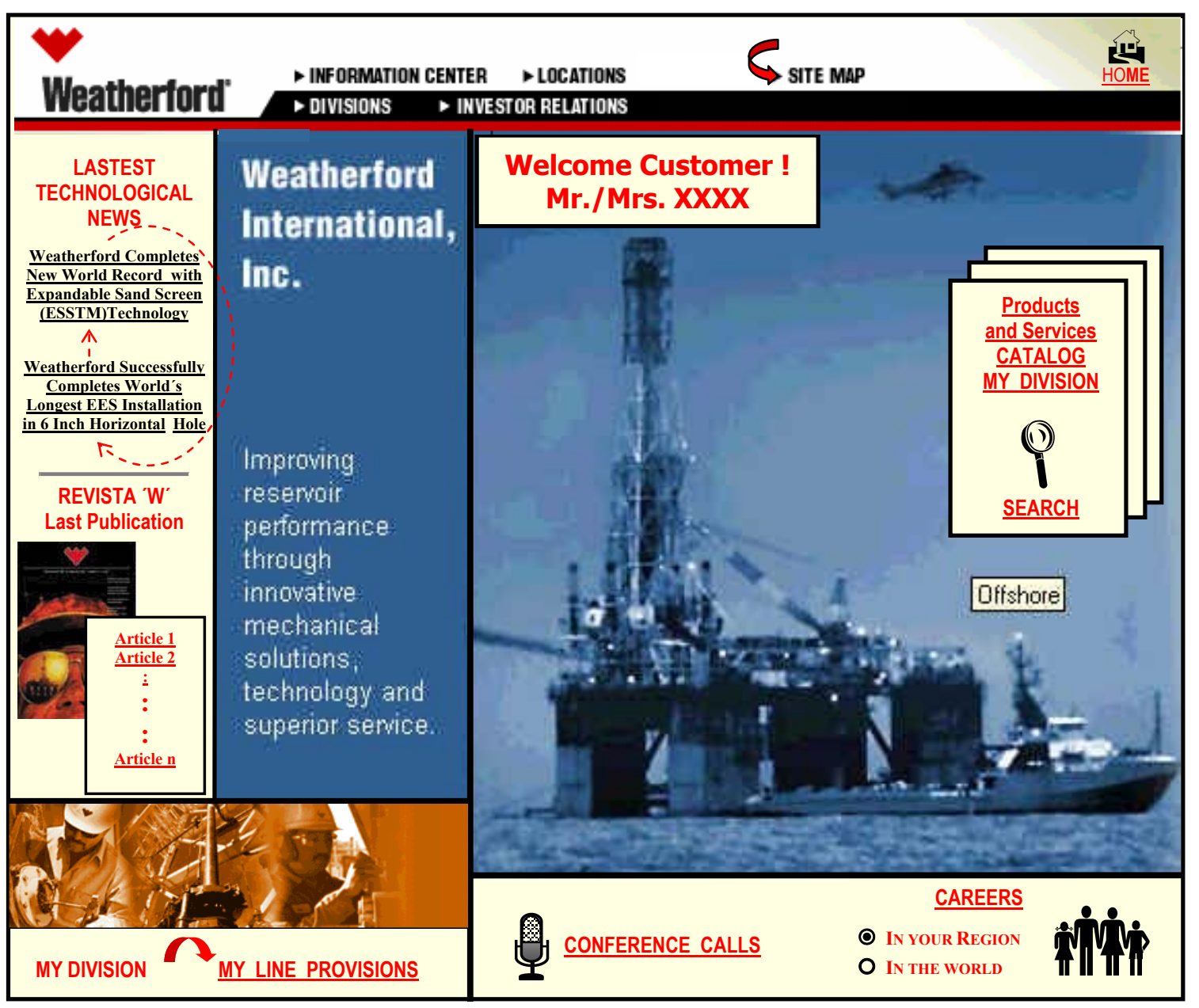

Figura 6.56: Bosquejo del Portal para el Perfil Cliente Actual 
Portal Usuario Cliente Potencial

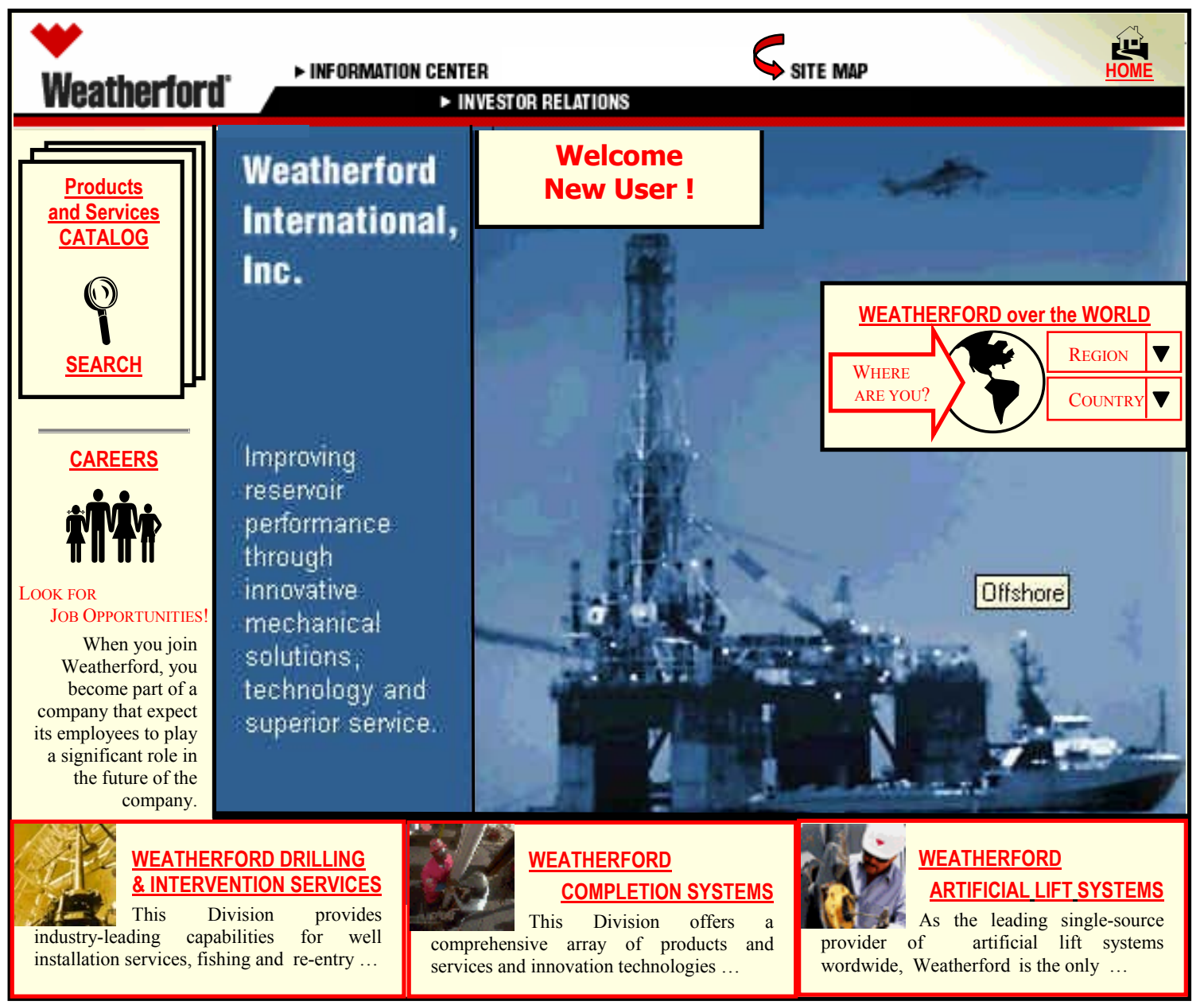

Figura 6.57: Bosquejo del Portal para el Perfil Cliente Potencial 


\section{Portal Usuario Empleado}

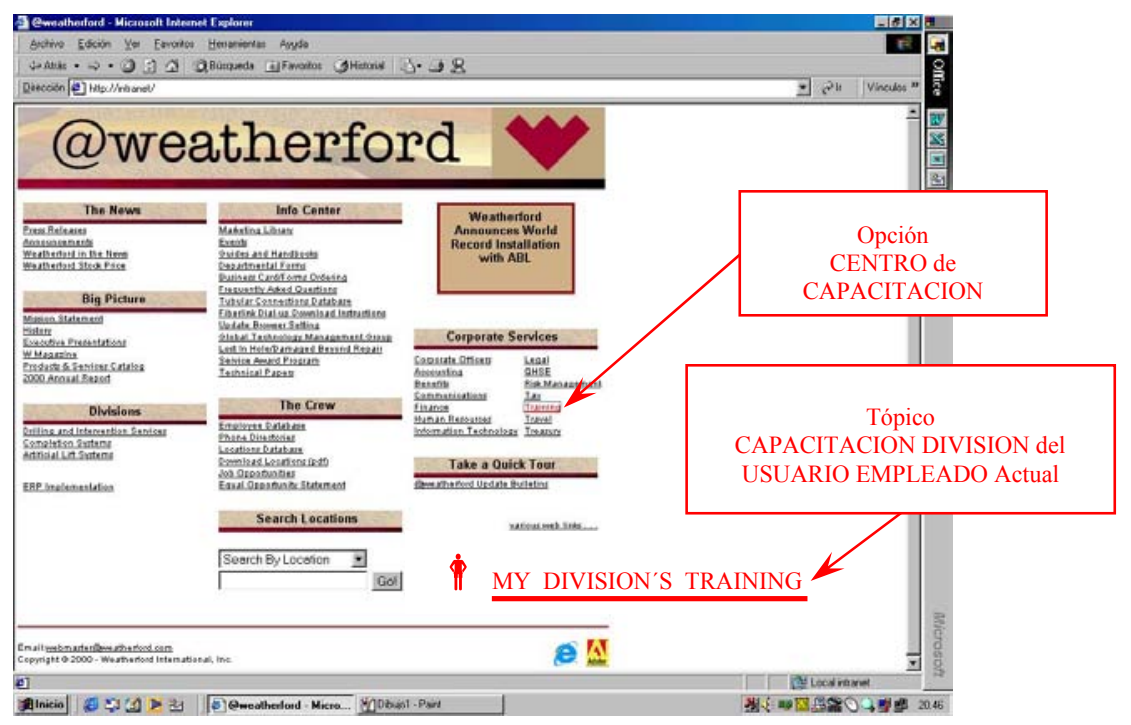

Figura 6.27 bis: Bosquejo de las modificaciones al Portal para el Perfil Empleado

\section{Página Formulario de Capacitación Usuario Empleado}

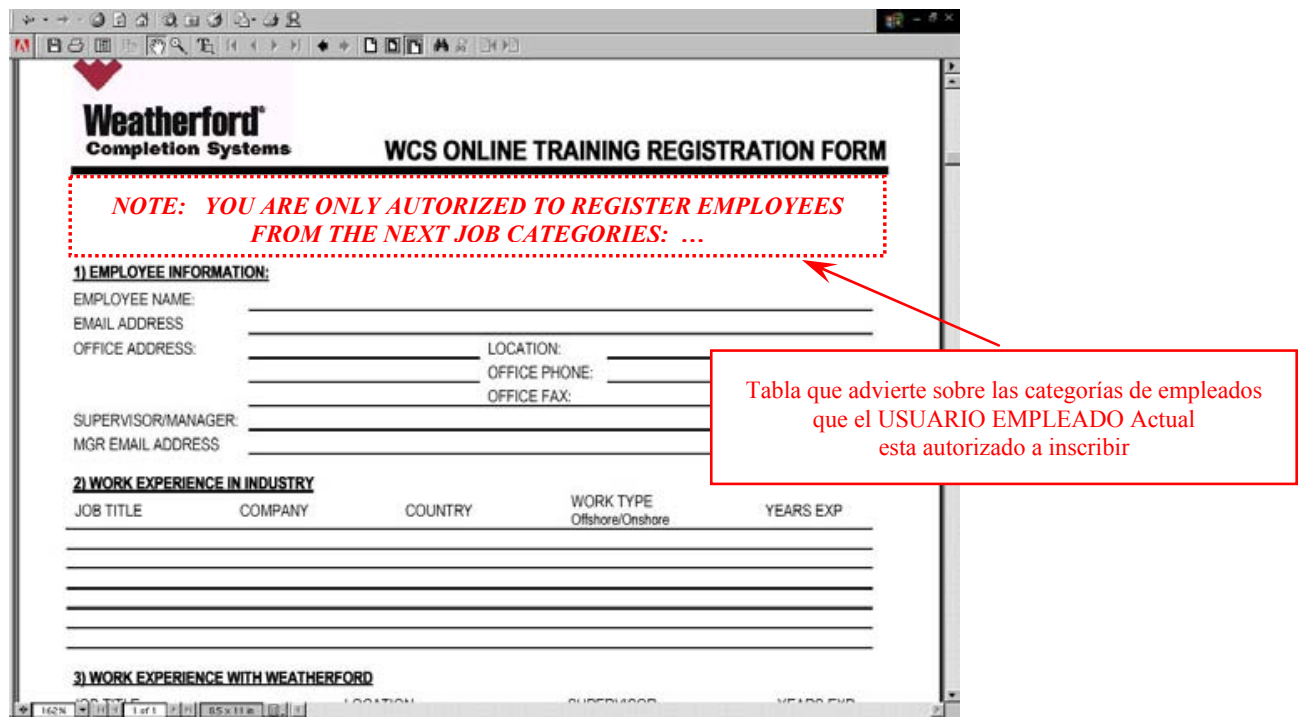

Figura 6.31 bis: Bosquejo de las modificaciones a la página del Formulario de Capacitación para el Perfil Empleado 


\subsubsection{Reflejando la especificación objetiva en un nuevo modelo caso de uso}

Paso 2. Confeccionar una vista externa para el nuevo sitio en un Modelo Caso de Uso Personalizado. Para lograr este propósito, utilizar como material inicial los casos de uso seleccionados en el proceso de ingeniería en reversa y los productos resultantes de la actividad de 'envisioning' (la especificación objetiva) y del proceso de ingeniería en reversa (el modelo del sitio existente, especialmente los casos de uso seleccionados en dicho proceso de ingeniería en reversa).

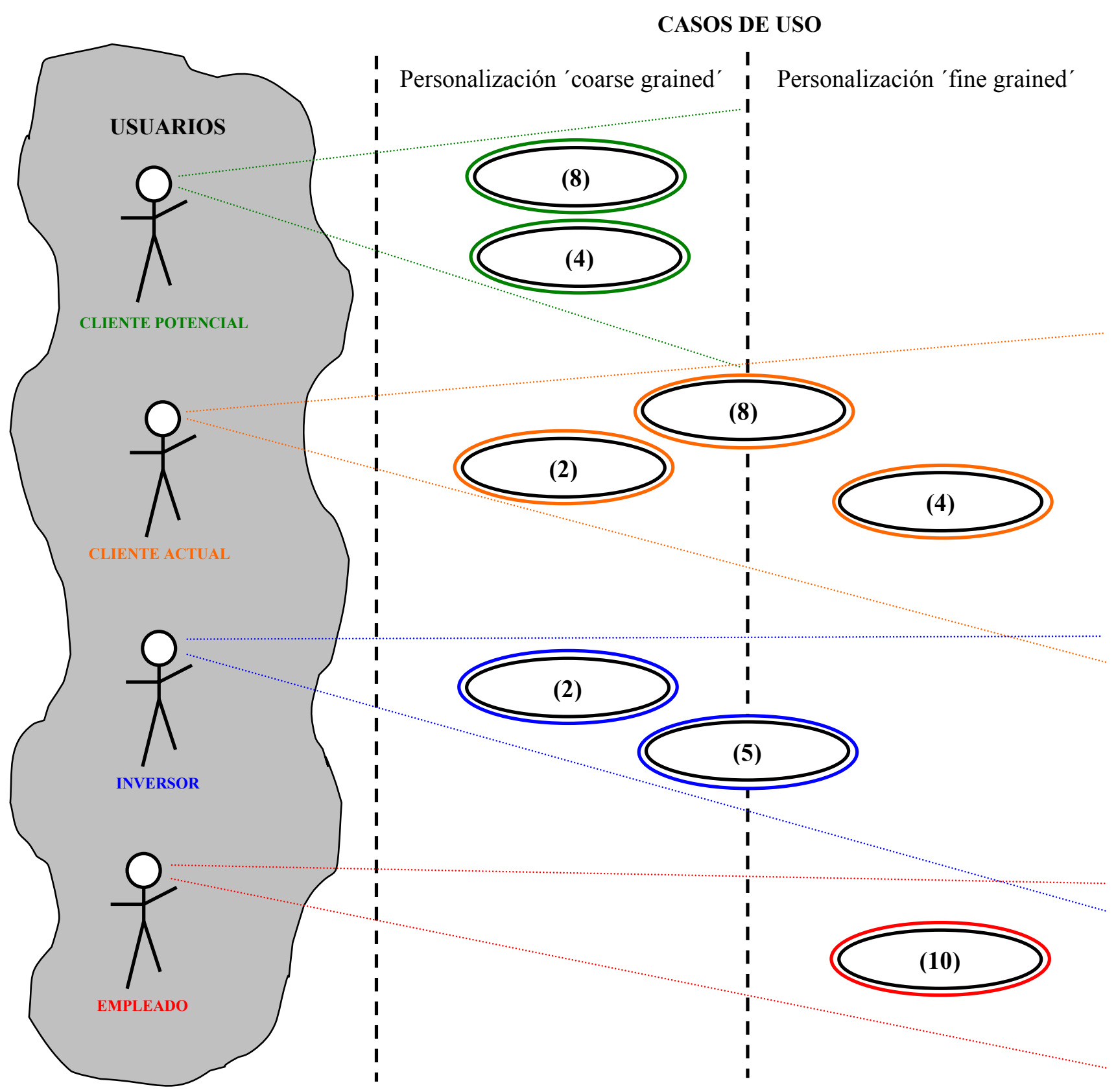

Figura 6.58: Modelo Caso de Uso Personalizado 


\subsubsection{Describiendo los casos de uso personalizados}

Paso 3. Describir los casos de uso personalizados (utilizar para tal fin: las descripciones de los casos de uso seleccionados en el proceso de ingeniería en reversa, el modelo caso de uso personalizado, la especificación objetiva y los bosquejos producidos en el Paso 1).

Para el caso real, de la observación del modelo caso de uso personalizado y los bosquejos de los portales propuestos, surge claramente la necesidad de adaptar cada una de las formas en que se usa la aplicación (casos de uso más prometedores seleccionados en el proceso de ingeniería en reversa) para que describan la interacción de cada usuario (general, perteneciente a un perfil o individual) con la aplicación.

A continuación, se delinean y ligan las respectivas descripciones alternativas a cada uno de los casos de uso seleccionados, personalizando los mismos a los usuarios que los utilizan.

Caso de Uso (2): “Comunicando noticias de la compañía”

\section{Descripción Caso de uso (2): Perfil Inversor}

\section{Curso básico de eventos}

A. El caso de uso comienza cuando el usuario Inversor selecciona una noticia por su título del menú que ofrece el sistema en su 'home page', compuesto por las noticias financieras más recientes de la Compañía. Figura 6.55

(a partir de acá, ídem Caso de uso(2) no personalizado)

\section{Caso de uso (2): Perfill Cliente Actual}

\section{Curso básico de eventos}

A. El caso de uso comienza cuando el usuario Cliente Actual selecciona una noticia por su título del menú que ofrece el sistema en su 'home page', compuesto por las noticias tecnológicas más recientes de la Compañía. Figura 6.56

(a partir de acá, idem Caso de uso(2) no personalizado)

Nota: El usuario General (incluye la totalidad de los usuarios del sitio: Inversor, Cliente Actual, Cliente Potencial y Empleado) también tienen acceso a todas las noticias de la compañía seleccionando el tópico Comunicados de Prensa, incluido en el menú de tópicos que componen las opciones Relaciones de Inversor Figura 6.7 y Centro de Información Figura 6.8 de sus respectivas 'home pages'. Figura 6.55 - Figura 6.56 - Figura 6.57 - Figura 6.2 En este caso, la descripción del caso de uso es ídem a la del Caso de uso(2) no personalizado, disparado desde la Alternativa A. 
Caso de Uso (4): "Navegando líneas de productos, servicios y sistemas dada una división"

\section{Descripción Caso de uso (4): Perfill Cliente Actual}

\section{Curso básico de eventos}

A. El caso de uso comienza cuando el usuario Cliente Actual selecciona una prestación de productos/ servicios/ sistemas por su nombre del menú que sugiere el sistema en su 'home page', de acuerdo con su historial como cliente de la compañía. Figura 6.56

B. El sistema retorna la página asociada a la prestación requerida mostrando nombre-prestación, imagen, texto-descriptivo citando los productos/ servicios/ sistemas pertenecientes a la prestación seleccionada, nombre-línea, nombre-división, e-mail-división y manteniendo el menú formado por las líneas de prestaciones que componen la división y el menú formado por las prestaciones de productos/servicios/ sistemas. En este caso, el usuario Cliente Actual recibe toda la información de la que dispone la aplicación y el caso de uso se completa. Figura 6.13

C. El sistema retorna la página asociada al producto/ servicio/ sistema específico correspondiente a la prestación de productos/ servicios/ sistemas seleccionado en B. mostrando nombre-producto/ servicio/ sistema, descripción, nombre-división, nombre-línea y otra información relevante acorde al producto/ servicio/ sistema consultado.. En este caso, el usuario Cliente Actual recibe toda la información de la que dispone la aplicación y el caso de uso se completa. Figura 6.14

\section{Cursos alternativos de eventos}

Alternativa B: Si el usuario Cliente Actual lo desea puede enviar un e-mail a la división. En este caso, el caso de uso invocará la aplicación de correo electrónico que tenga instalada el usuario en su computador, retornando un e-mail con la dirección de correo electrónico de la división y permitiendo el ingreso del texto del e-mail y su envío. Si el usuario Cliente Actual desea continuar con el caso de uso, cerrará la aplicación de correo y el caso de uso retomará la etapa B. Figura 6.13

Alternativa B: Si el usuario Cliente Actual lo desea puede disparar una búsqueda. Figura 6.13 En este caso, el caso de uso (6) “Realizando búsqueda de productos, servicios y sistemas” comenzará, y el caso de uso en curso finalizará.

Alternativa B: Si el usuario Cliente Actual lo desea puede acceder a otra prestación de productos/ Figura 6.13 servicios/ sistemas desde la prestación actual. En este caso, el caso de uso continuará en la etapa $\mathbf{B}$.

Alternativa B: Algunas prestaciones de productos/ servicios/ sistemas en su texto-descriptivo no solamente citan los productos/ servicios/ sistemas, sino que además los presentan en un menú que permiten acceder a nuevas páginas informativas. En este caso, el usuario Cliente Actual selecciona un producto/ servicio/ sistema por su nombre y el caso de uso continúa en la etapa C. ${ }^{\text {Figura 6.13 }}$

\section{Descripción Caso de Uso (4) Perfil Cliente Potencial}

\section{Curso básico de eventos}

A. El caso de uso comienza cuando el usuario Cliente Potencial selecciona una división del menú informativo que ofrece el sistema en su 'home page', formado por el nombre, imagen y texto previo de cada una de las tres divisiones en que se estructura la compañía. Figura 6.57

(a partir de acá, ídem Caso de uso(4) no personalizado)

Cursos alternativos de eventos

(idem Caso de uso(4) no personalizado, suprimiendo la Alternativa A.)

Nota: El usuario Inversor, Cliente Actual y Empleado, también tienen acceso a navegar las divisiones, líneas y prestaciones, seleccionando la opción Divisiones de sus respectivas 'home pages'. Figura $\mathbf{6 . 5 5}$ - Figura 6.56 Figura6.2 En este caso, la descripción del caso de uso es ídem a la del Caso de uso(4) no personalizado, disparado desde la Alternativa A. 
Caso de Uso (5): "Brindando Información Financiera"

\section{Caso de uso (5): Perfil Inversor}

\section{Curso básico de eventos}

(idem etapas Caso de uso(5) no personalizado, ver Nota correspondiente a este caso de uso)

\section{Cursos alternativos de Eventos}

Alternativa A: Si el usuario Inversor lo desea puede acceder directamente al último Reporte Anual, seleccionando una de las secciones que lo componen, desde el menú que ofrece el sistema en la 'home page'. Figura 6.55 En este caso, el caso de uso continuará en la etapa D.

Alternativa A: Si el usuario Inversor los desea puede leer la cotización del día que ofrece el sistema en la 'home page' (cierre día previo y apertura actual) y seleccionar el vínculo 'más Datos Financieros'. Figura 6.55 En este caso, el caso de uso invocará una página que brinda más detalles sobre las cotizaciones del día y días anteriores. El usuario Inversor consulta la información y el caso de uso se completará.

Alternativa A: Si el usuario Inversor lo desea puede enviar un e-mail al Dpto. Relaciones de Inversor desde la 'home page' seleccionando el vínculo 'e-mail Relaciones de Inversor'. Figura ${ }^{\mathbf{6 . 5 5}}$ En este caso, el caso de uso invocará la aplicación de correo electrónico que tenga instalada el usuario en su computador, retornando un e-mail con la dirección de correo electrónico del Dpto. Relaciones de Inversor y permitiendo el ingreso del texto del e-mail y su envío. Figura 6.21 El caso de uso continuará en la etapa $\mathbf{A}$ desde la cual se disparó este evento.

Alternativa A: Si el usuario Inversor lo desea puede consultar sus inversiones seleccionando el vínculo 'mis Inversiones' que ofrece el sistema en la 'home page'. Figura $\mathbf{6 . 5 5}$ En este caso, el caso de uso solicita el ingreso de la clave de identificación, 'pasword' del usuario Inversor. Si la clave es válida, el sistema retorna una página con detalles de las inversiones del usuario Inversor para su consulta y el caso de uso se completa. Caso contrario, el sistema ofrece al usuario Inversor la posibilidad de ingresar su clave de identificación por segunda y última vez y de persistir una 'password' inválida, el sistema emite mensaje de error acorde y el caso de uso finaliza.

(a partir de acá, idem alternativas Caso de uso(5) no personalizado)

Nota: El usuario General (incluye la totalidad de los usuarios del sitio: Inversor, Cliente Actual, Cliente Potencial y Empleado) también tienen acceso a información financiera, seleccionando la opción correspondiente (Relaciones de Inversor / Finanzas) de sus respectivas 'home pages'. Figura 6.55 - Figura 6.56 - Figura

6.57 - Figura 6.2 En este caso, la descripción del caso de uso es ídem a la del Caso de uso(5) no personalizado. 
Caso de Uso (8): "Informando prestaciones al yacimiento petrolifero"

\section{Descripción Caso de Uso (8): Perfill Cliente Actual}

\section{Curso básico de eventos}

A. El caso de uso comienza cuando el usuario Cliente Actual selecciona un artículo por su título de la última edición de la Revista "W", cuya tapa, fecha de publicación y menú de artículos ofrece el sistema en su 'home page'. Figura $\mathbf{6 . 5 6}$

B. El sistema invoca a la aplicación Adobe Acrobat y retorna el documento correspondiente. El usuario dispone del mismo para su navegación, impresión y 'download'. Figura ${ }^{6.20}$ El usuario Cliente Actual selecciona una de estas operaciones utilizando las barras de herramientas y desplazamiento de la aplicación citada, la operación se completa y el caso de uso también se completa.

\section{Cursos alternativos de Eventos}

Alternativa A: Si el usuario Cliente Actual lo desea puede seleccionar el vínculo a la sección de las prestaciones correspondientes a la División X, del Catálogo de Productos y Servicios que ofrece el sistema en su 'home page' (la División X de mayor interés para el cliente, la determina su historial como cliente de la compañía). Figura 6.56 ${ }^{2}$ En este caso, el caso de uso continuará en la etapa B.

\section{Cursos de Eventos de retroceso}

Retroceso B: Si el usuario Cliente Actual lo desea, puede seleccionar otro documento de la misma publicación, retrocediendo el caso de uso con la opción atrás de la aplicación de Internet. En este caso, el caso de uso cierra la aplicación en curso (Acrobat) y continuará en la etapa A.

\section{Descripción Caso de Uso (8): Perfil Cliente Potencial}

\section{Curso básico de eventos}

A. El caso de uso comienza cuando el usuario Cliente Potencial selecciona el vínculo al Catálogo de Productos y Servicios, que ofrece el sistema en su 'home page'. Figura 6.57

B. El sistema invoca a la aplicación Adobe Acrobat y retorna el documento correspondiente. El usuario Cliente Potencial dispone del mismo para su navegación, impresión y 'download'. Figura 6.20 $\mathrm{El}$ usuario Cliente Potencial selecciona una de estas operaciones utilizando las barras de herramientas y desplazamiento de la aplicación citada, la operación se completa y el caso de uso también se completa.

Nota: El usuario General (incluye la totalidad de los usuarios del sitio: Inversor, Cliente Actual, Cliente Potencial y Empleado) también tienen acceso a los tópicos Revista ' $\mathrm{W}$ ' y Catálogo de Productos y Servicios Figura 6.23 seleccionando la opción Centro de Información de sus respectivas 'home pages'. Figura 6.55 - Figura 6.56 Figura 6.57 - Figura 6.2 En este caso, la descripción del caso de uso es ídem a la del Caso de uso(8) no personalizado. 
Caso de Uso (10): "Posibilitando envio de inscripción en curso de capacitación"

\section{Descripción del Caso de Uso (10): Perfil Empleado por Categoría}

\section{Curso básico de eventos}

A. El caso de uso comienza cuando el usuario Empleado selecciona el vínculo a las propuestas de capacitación de la División del usuario Empleado que ofrece el sistema en su 'home page'. El usuario Empleado selecciona este vínculo. ${ }^{\text {Figura }} 6.27$ bis

B. El sistema retorna la página asociada. El usuario Empleado selecciona el tópico Formulario de Inscripción Online. Figura 6.29

C. El sistema solicita al Empleado el ingreso de su clave que lo identifica como usuario Empleado. El usuario Empleado ingresa su clave. Figura 6.30

D. El sistema valida la clave ingresada y de acuerdo con la categoría del usuario Empleado, ofrece una página mostrando una tabla de categorías de empleados a los cuales el usuario Empleado esta autorizado a inscribir y ofreciendo un formulario de inscripción 'online'. El usuario Empleado ingresa los datos en el formulario y solicita su envío. Figura 6.31 bis

E. El sistema envía el formulario y el caso de uso se completa.

\section{Cursos de eventos de retroceso}

Retroceso D: Si el sistema no identifica al usuario Empleado, emitirá un mensaje de error señalando un punto de contacto al que el usuario Empleado puede comunicarse. En este caso, el caso de uso ofrecerá al usuario Empleado una nueva posibilidad de ingresar su clave, que de ser esta segunda vez correcta, permitirá que el caso de uso continúe. Si el problema persiste, el caso de uso finalizará.

Retroceso D: Si el sistema detecta discordancia entre la categoría del empleado para el cual se solicita inscripción y el usuario Empleado, emitirá un mensaje de error acorde. En este caso el caso de uso continuará en la etapa $\mathbf{D}$ ofreciendo nuevamente el formulario de inscripción 'online'. Si el error persiste, el caso de uso finalizará .

Retroceso E: Si el usuario Empleado lo desea puede realizar otra inscripción, retrocediendo el caso de uso con la opción atrás de la aplicación de Internet. En este caso, el caso de uso continuará en la etapa $\mathbf{E}$ Figura 6.31 bis posibilitando otra inscripción.

Nota: El usuario Empleado, sigue teniendo acceso a la opción Centro de Capacitación que ofrece el sistema en su 'home page' Figura 6.27 bis , la cual brinda tópicos informativos referidos al Centro de Capacitación de la Compañía Figura 6.28bis. En este caso, dicha página no ofrecerá el tópico Capacitación División X, ya que el usuario Empleado tiene acceso directo al mismo a través de un vínculo situado en su 'home page'.

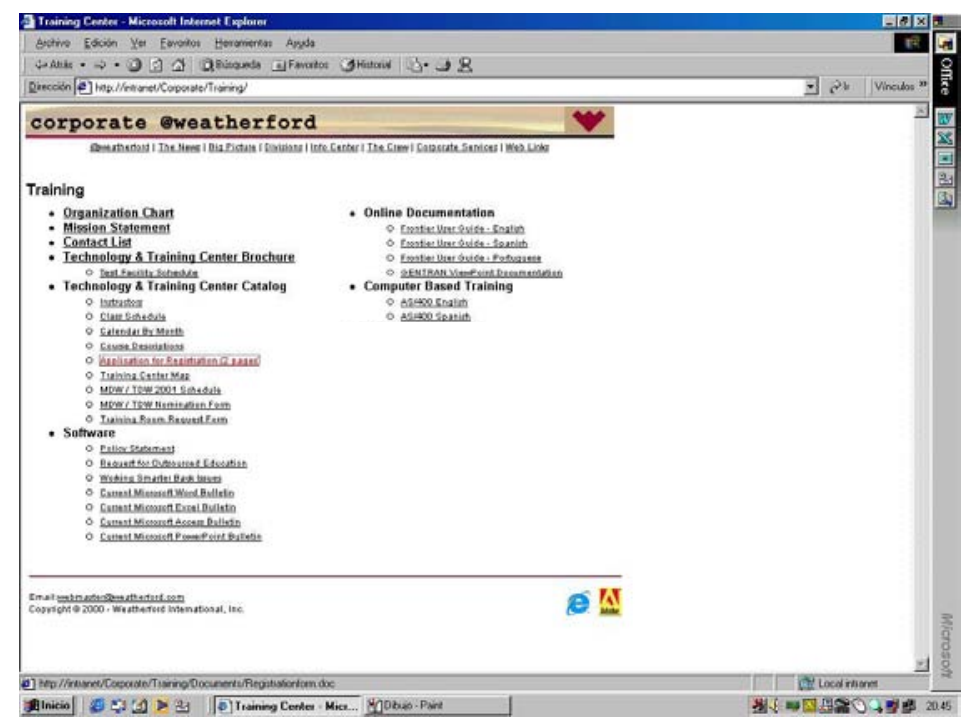

Figura 6.28bis: Navegando la opción Capacitación y sus tópicos informativos 


\subsubsection{Construyendo el puente UID entre modelos personalizados}

Paso 4. Mapear los casos de uso personalizados en UIDs [Vilain00] que reflejen las formas en que los distintos usuarios (generales, pertenecientes a un perfil o individuales) interactúan con el sitio.

A continuación, por cada caso de uso personalizado, se diseña un UID personalizado que lo represente, es decir, un UID que unifique todas las descripciones alternativas ligadas al caso de uso.

Caso de Uso (2): “Comunicando noticias de la compañia”"

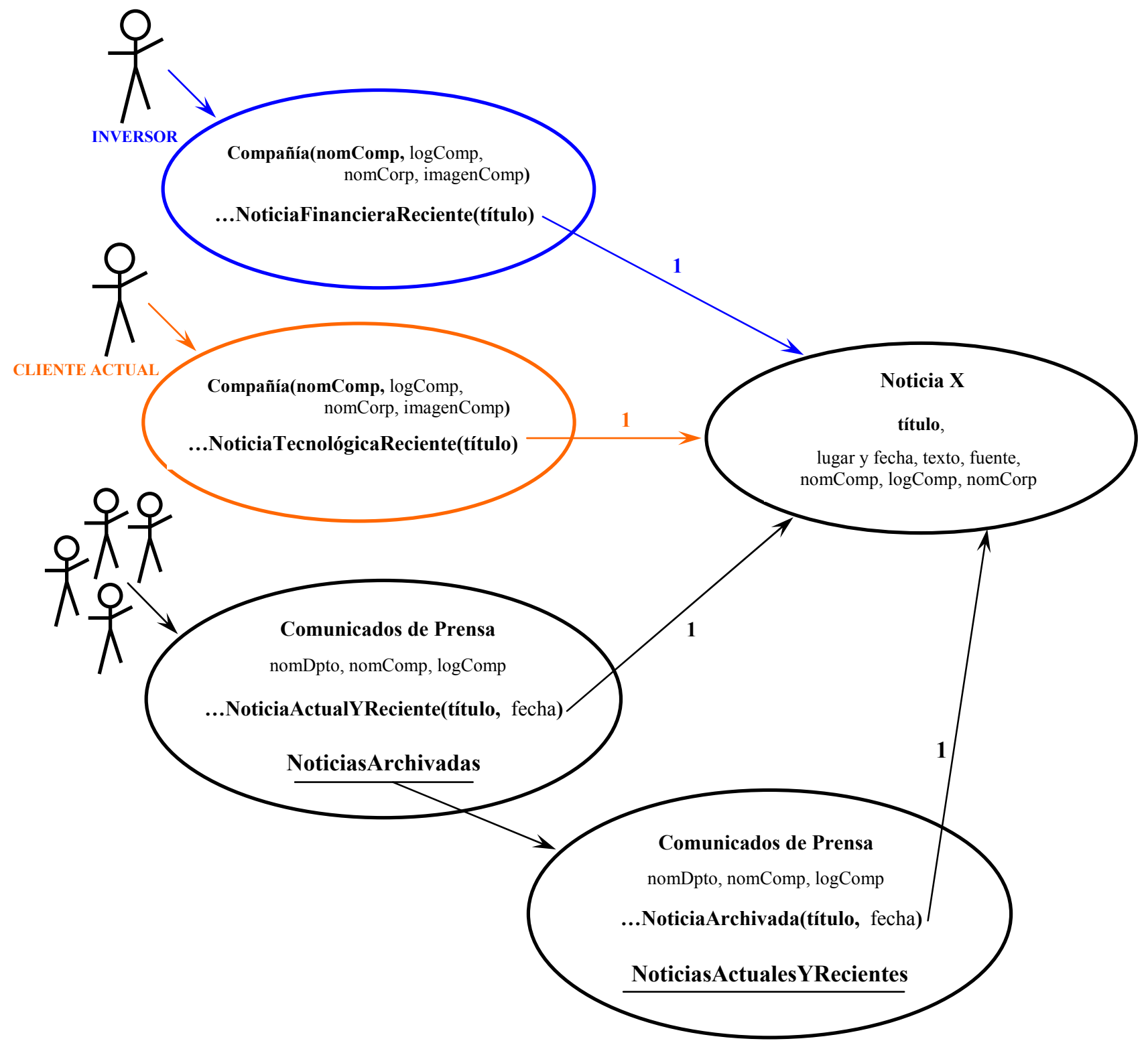

Figura 6.59: UID para el caso de uso "Comunicando noticias de la compañia"

Perfil Inversor, Perfil Cliente Actual y Usuario General 
Caso de Uso (4): "Navegando líneas de productos, servicios y sistemas dada una división"

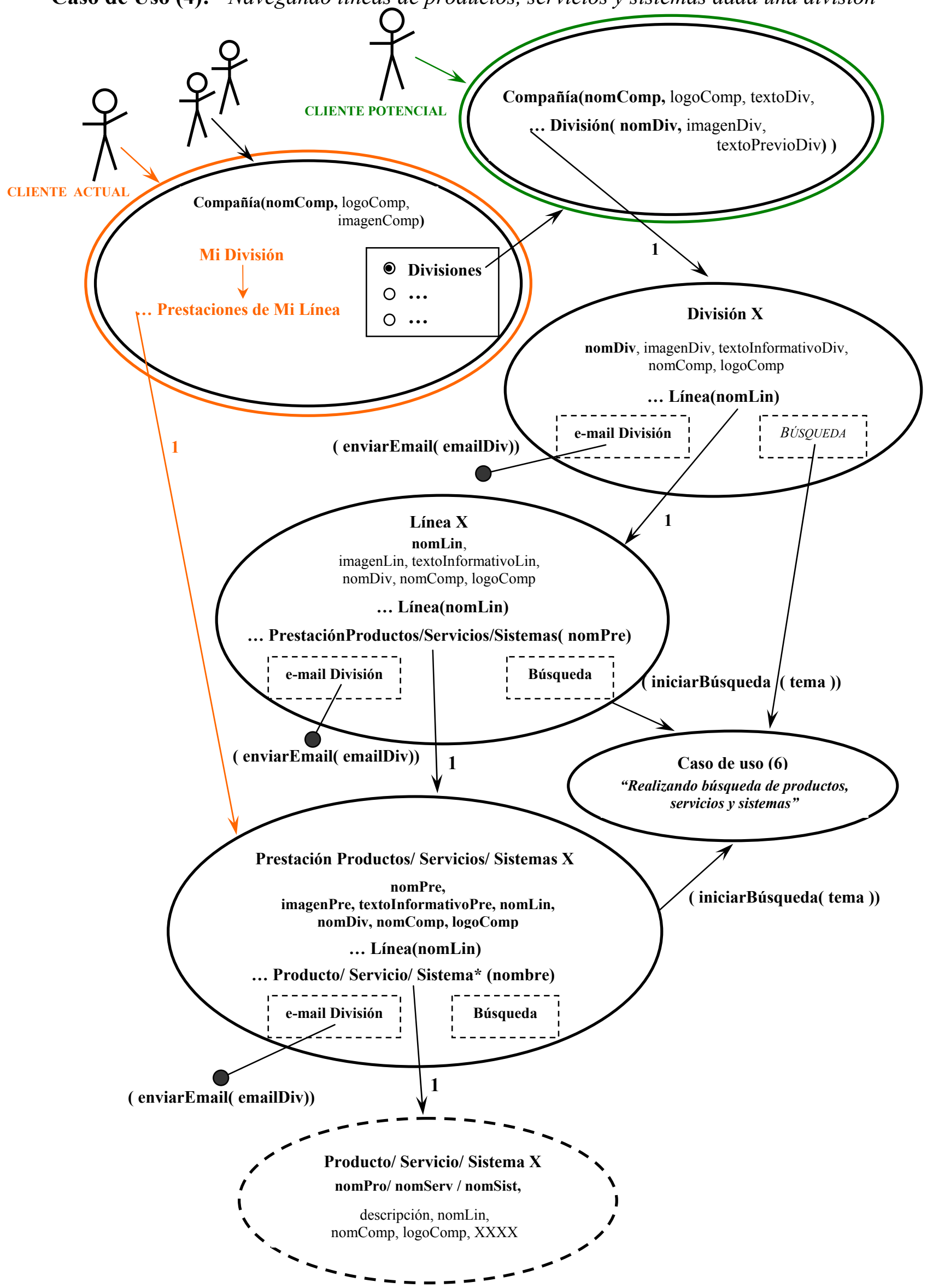

Figura 6.60: UID para el caso de uso "Navegando líneas de prestaciones dada una división"

Perfil Cliente Actual, Perfil Cliente Potencial y Perfiles Inversor / Empleado 


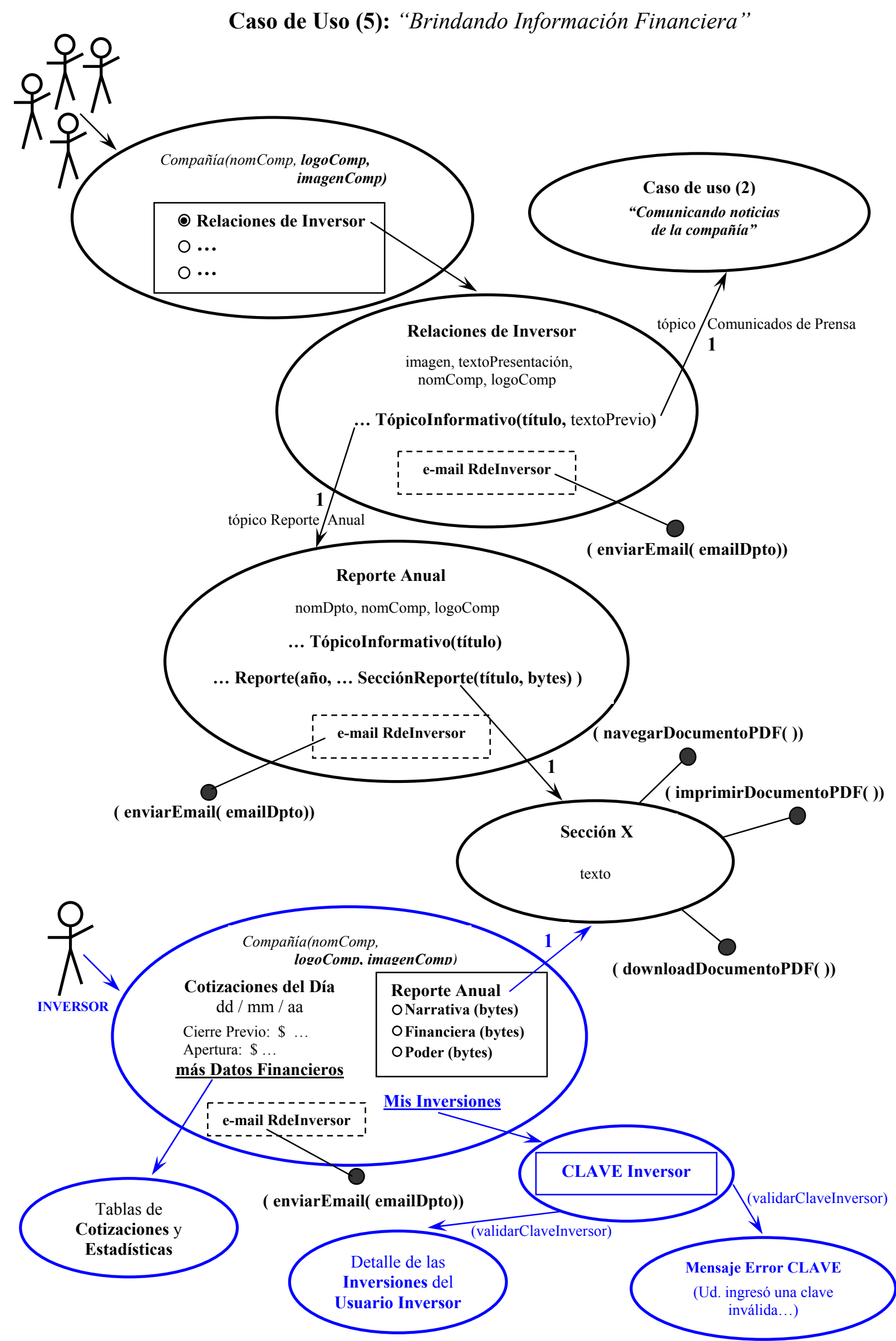

Figura 6.61: UID del caso de uso "Brindando información financiera" Perfil Inversor y Usuario General 
Caso de Uso (8): "Informando prestaciones al yacimiento petrolífero"

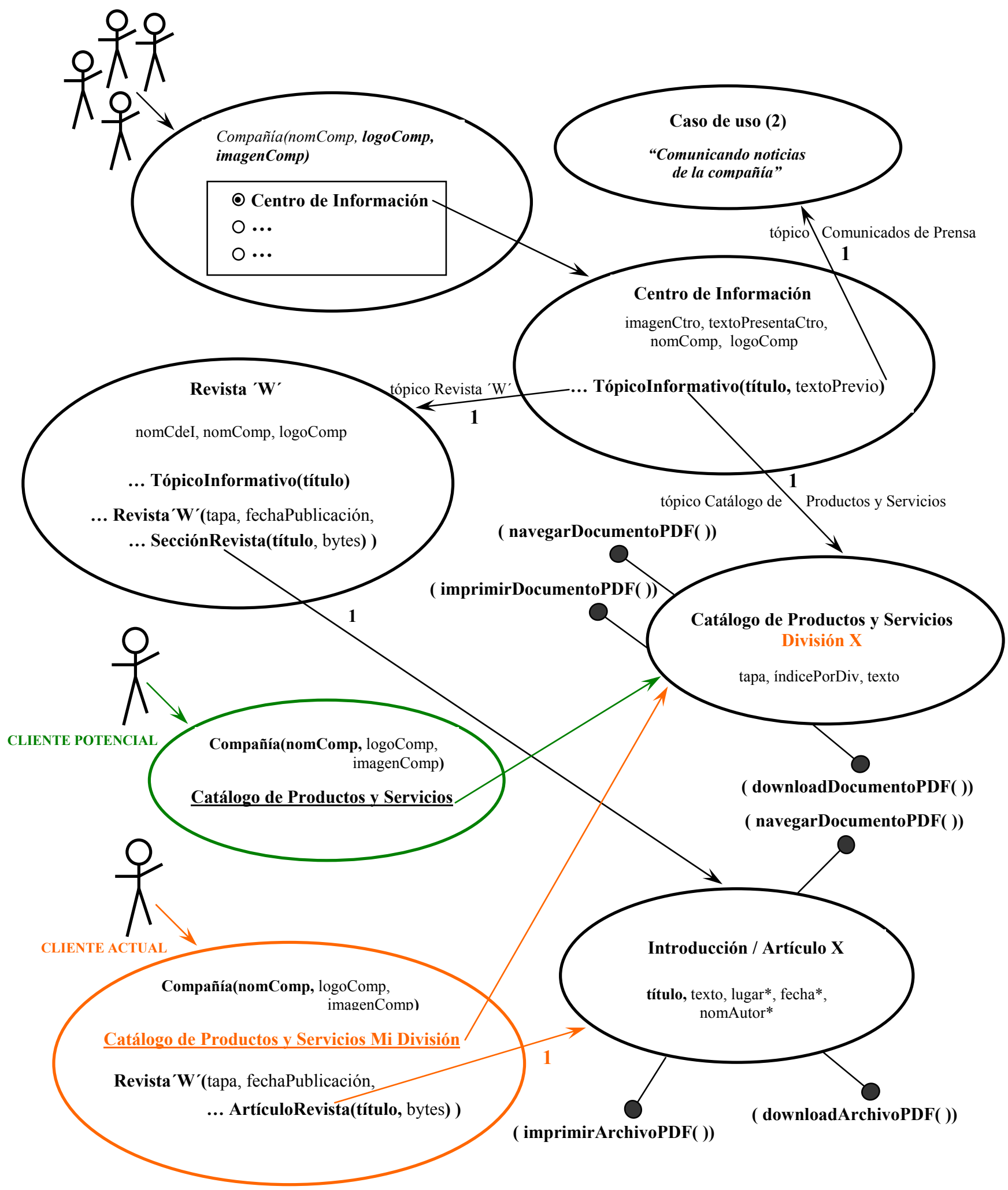

Figura 6.62: UID del caso de uso "Informando prestaciones al yacimiento petrolifero" Perfil Cliente Actual, Perfil Cliente Potencial y Usuario General 
Caso de Uso (10): "Posibilitando envio de inscripción en curso de capacitación"

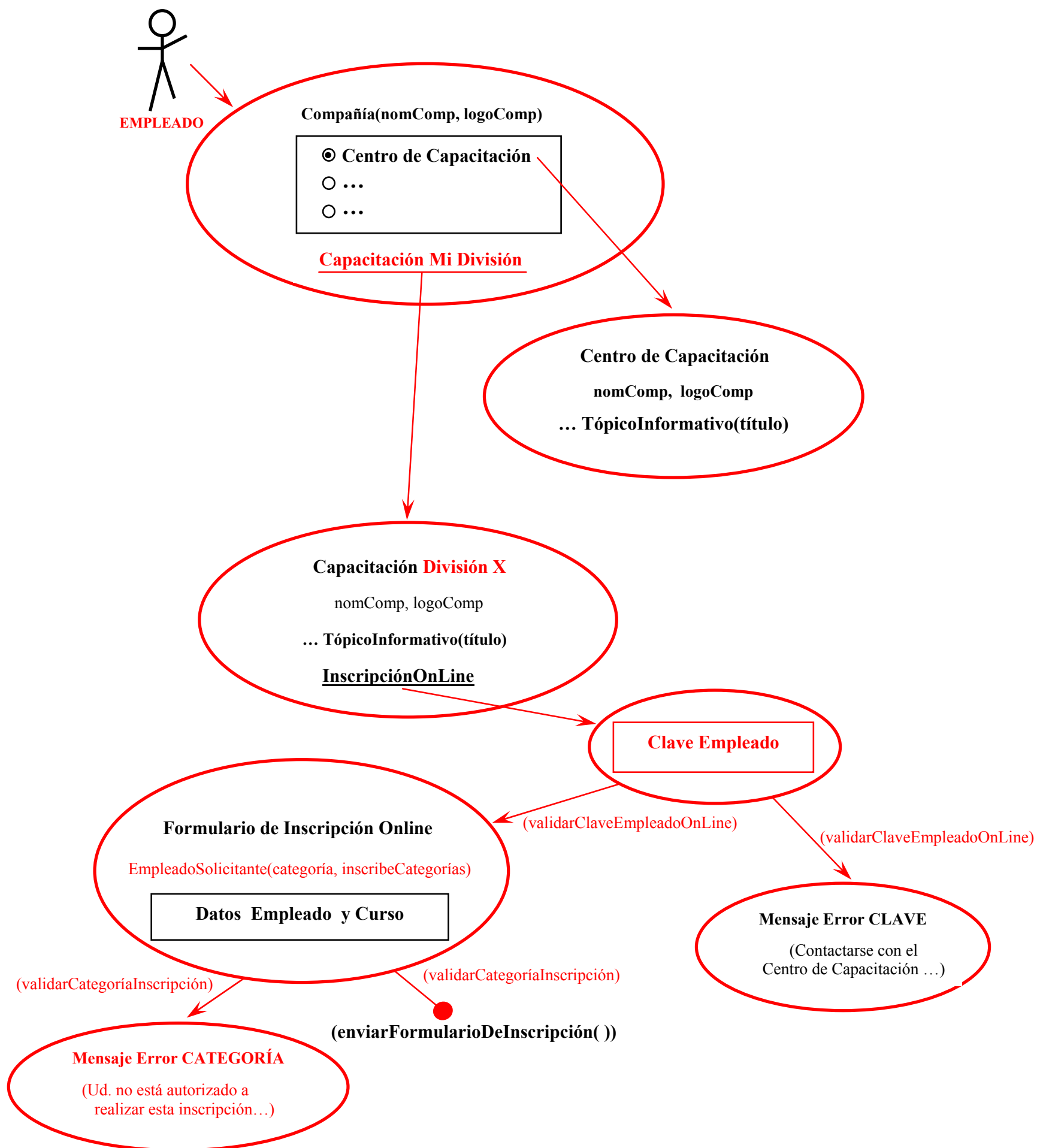

Figura 6.63: UID del caso de uso "Posibilitando el envío de inscripción en curso de capacitación" Perfil Empleado por Categoría 


\subsubsection{Obteniendo el modelo interno personalizado: modelo conceptual y modelo de navegación incorporando patrones de hipermedia y de personalización}

Paso 5. Adaptar el Modelo Conceptual OOHDM existente para que responda a los requerimientos de personalización. Para lograr este ajuste se propone:

- aplicar a los UIDs personalizados el conjunto de reglas que se detallan en 5.4.5.1, sugerido en el Paso 6 del proceso de ingeniería en reversa, [Vilain00] y [Güell00a]. Este ejercicio permite descubrir la necesidad de incluir nuevos objetos o de agregar atributos o comportamiento a objetos existentes.

- considerar e incorporar los conceptos de diseño de aplicaciones web personalizadas con patrones de personalización, [Rossi01c], [Schwabe02] y [Bäumer00], (capitulo3).

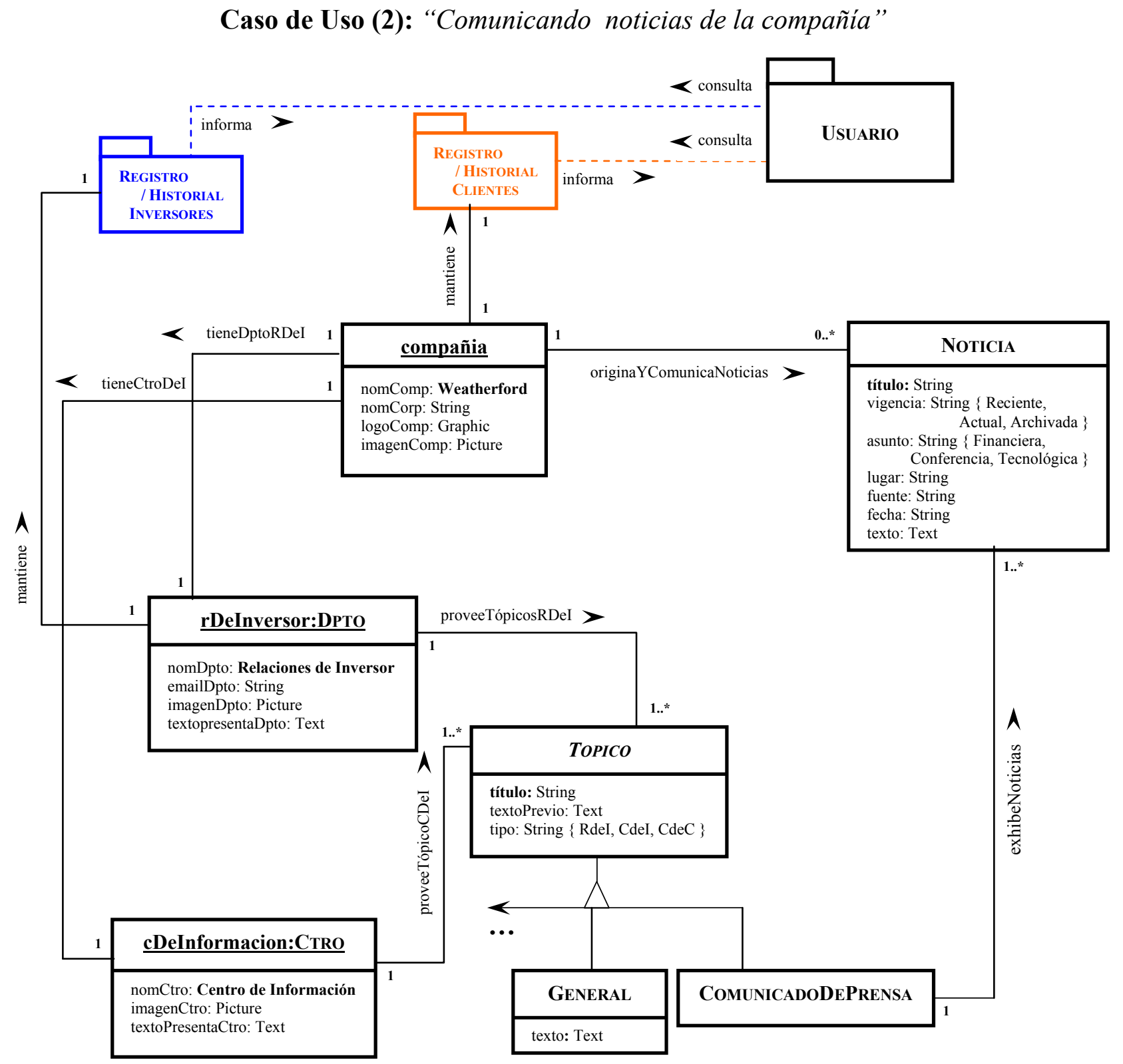


Caso de Uso (4): “Navegando líneas de productos, servicios y sistemas dada una división"

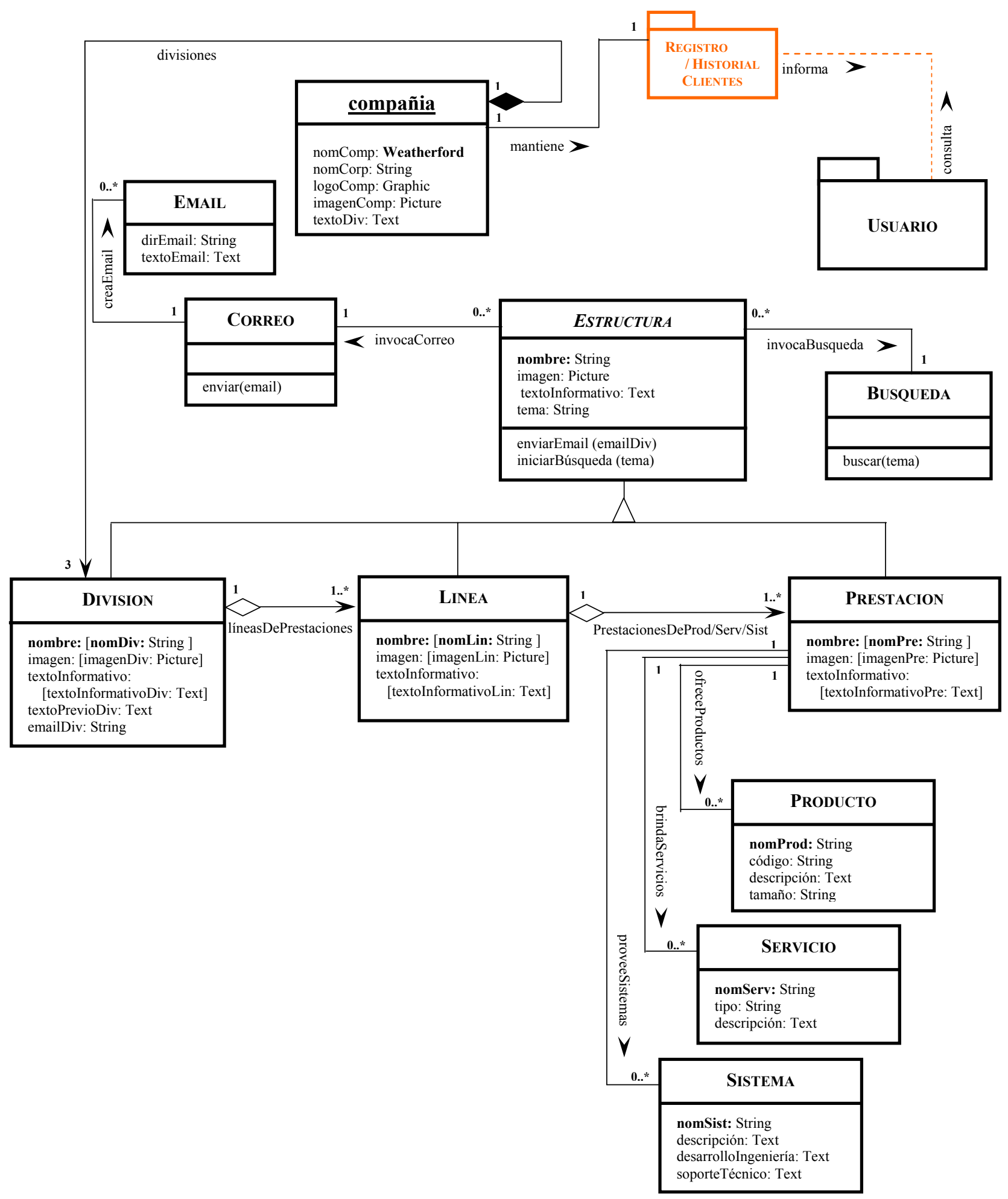

Figura 6.65 : Ajustes al Modelo conceptual resultante de aplicar las directivas al UID personalizado "Navegando líneas de prestaciones dada una división" 
Caso de Uso (5): "Brindando Información Financiera"

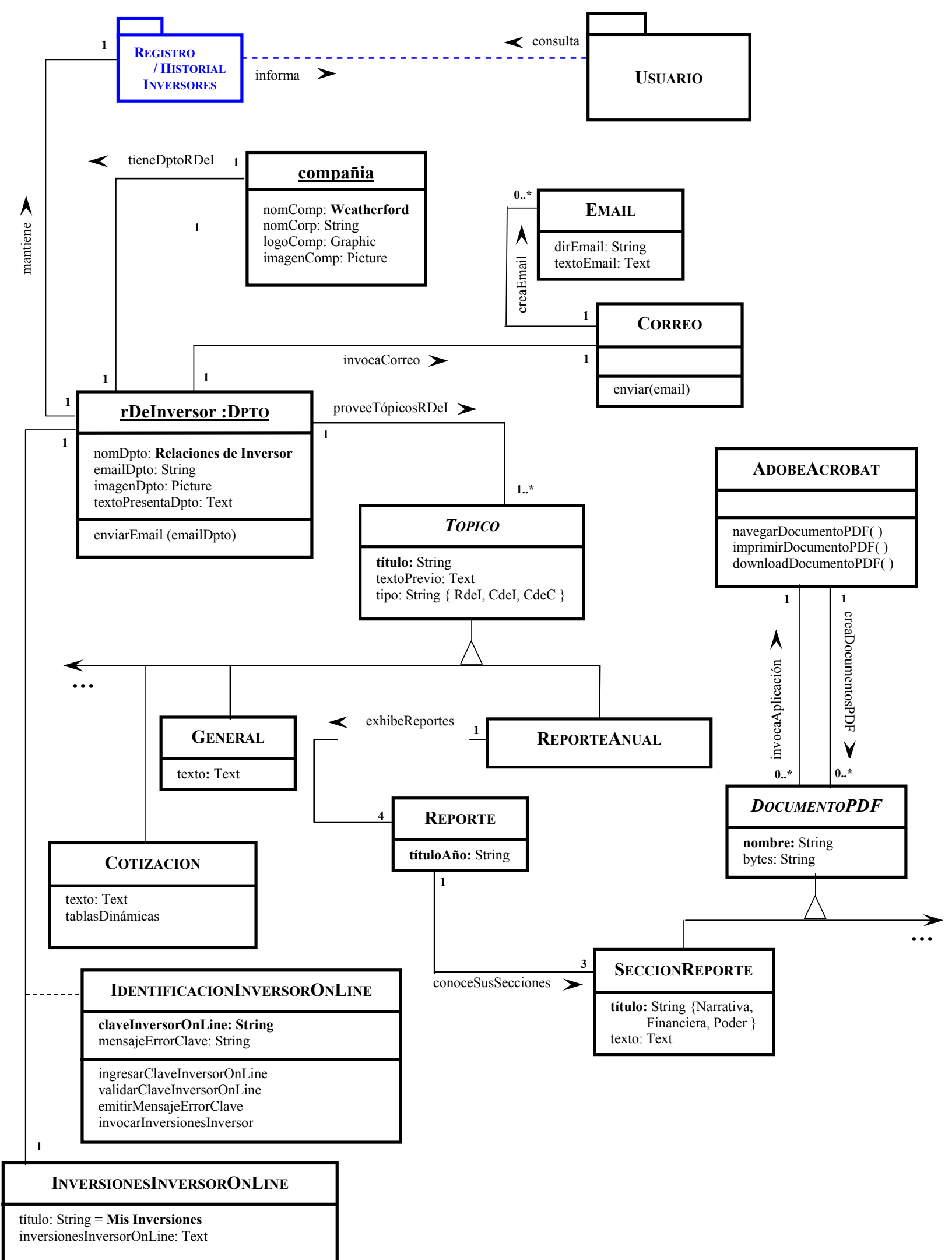

Figura 6.66 : Ajuste al Modelo conceptual resultante de aplicar las directivas al UID personalizado "Brindando información financiera" 
Caso de Uso (8): “Informando prestaciones al yacimiento petrolifero"

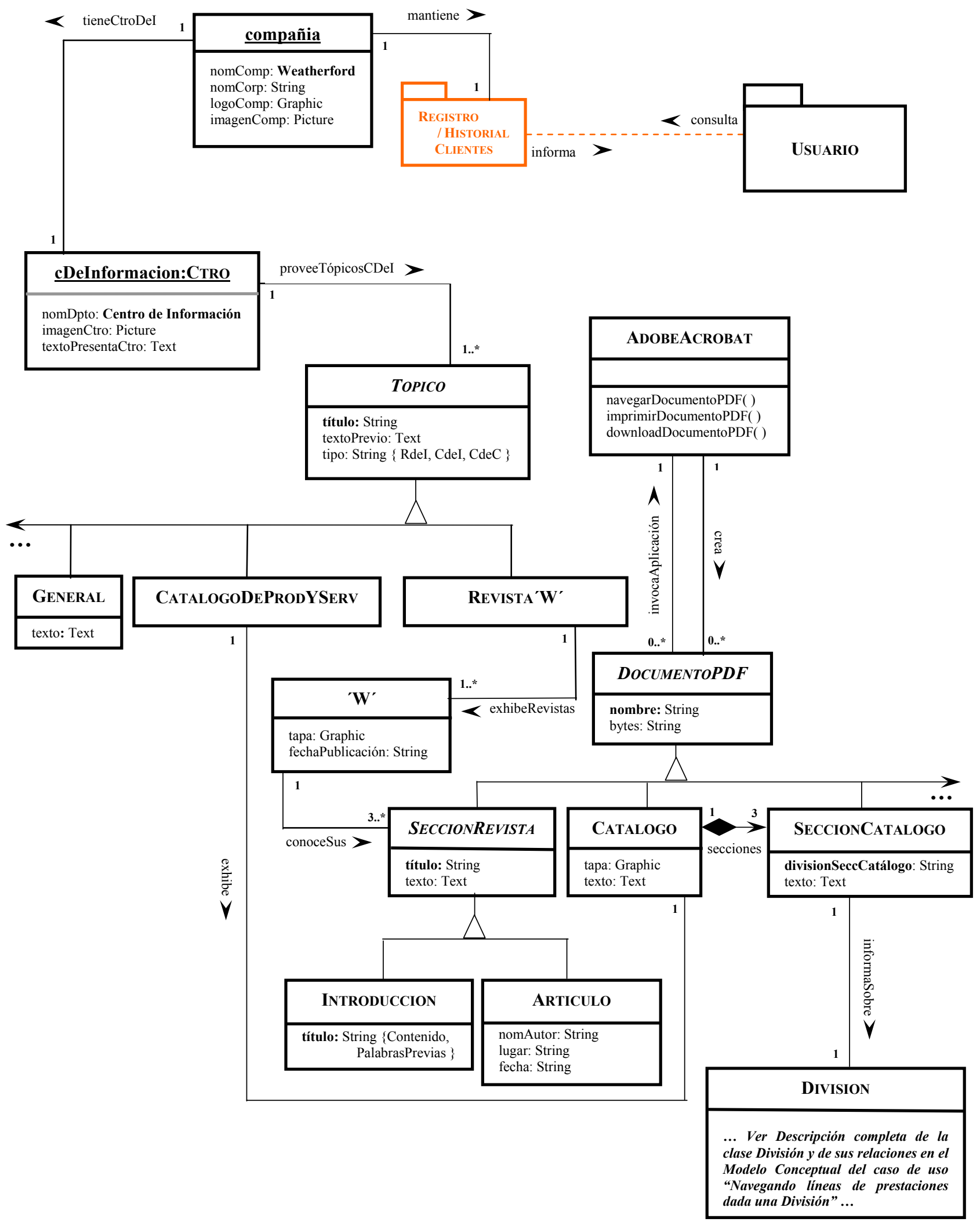

Figura 6.67 : Ajustes al Modelo conceptual resultante de aplicar las directivas al UID personalizado "Informando prestaciones al yacimiento petrolifero" 
Caso de Uso (10): "Posibilitando envío de inscripción en curso de capacitación"

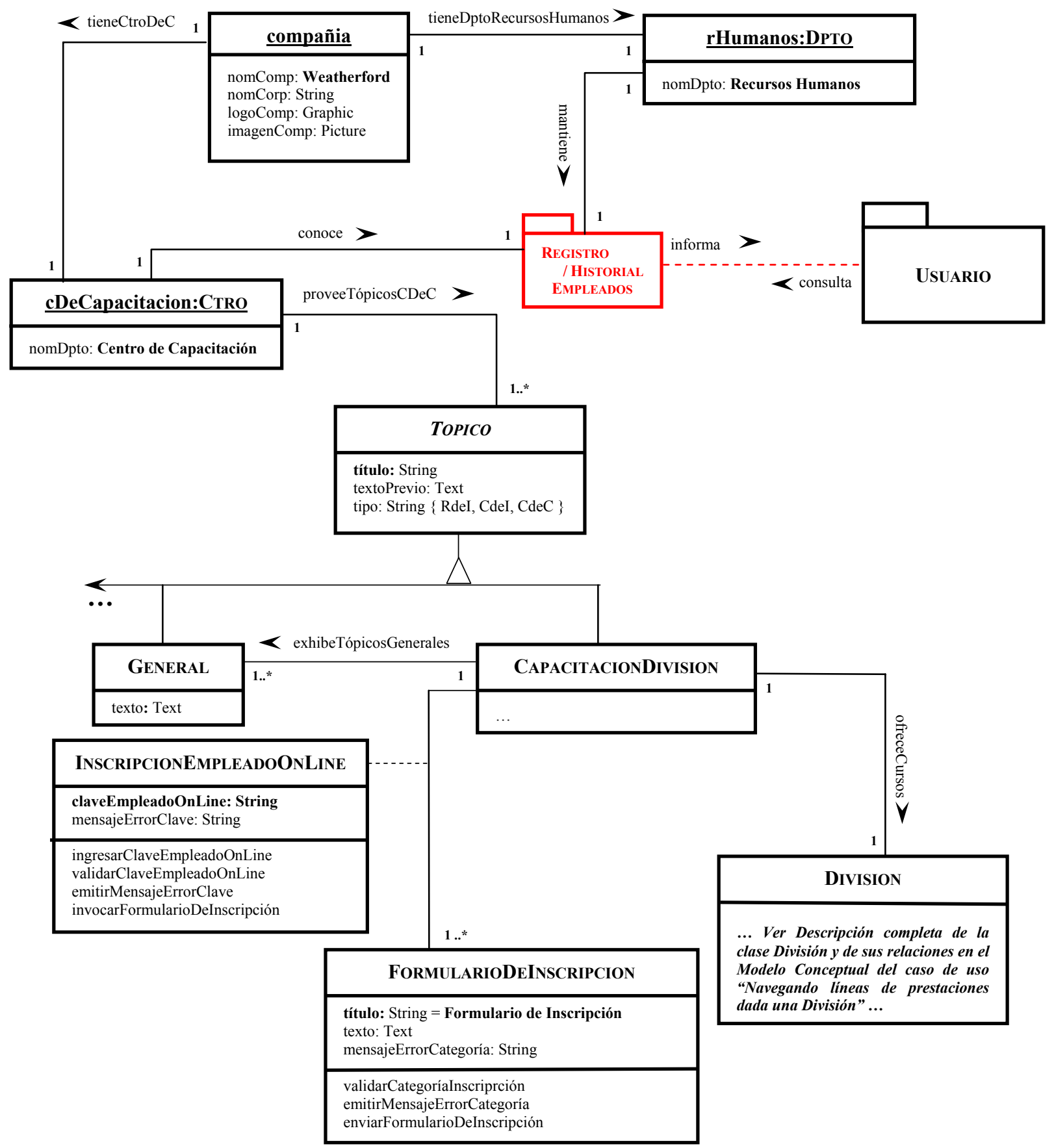

Figura 6.68: Modelo conceptual correspondiente al UID "Posibilitando envío de inscripción en curso de capacitación" Perfil Empleado por Categoría 
Las adaptaciones realizadas sobre los respectivos modelos conceptuales, fundamentalmente se basan en incluir módulos que no solamente manipulan los perfiles de usuarios definidos para la aplicación sino que también desdoblan el usuario propiamente dicho de su registro de información, utilizando conceptos vertidos en [Bäumer00] y [Schwabe02]. Con este objetivo, se incorporan el módulo Usuario y los módulos Registro / Historial.

A continuación se detallan el módulo Usuario y las relaciones de este módulo para con los módulos Registro / Historial:

\section{Módulo Usuario}

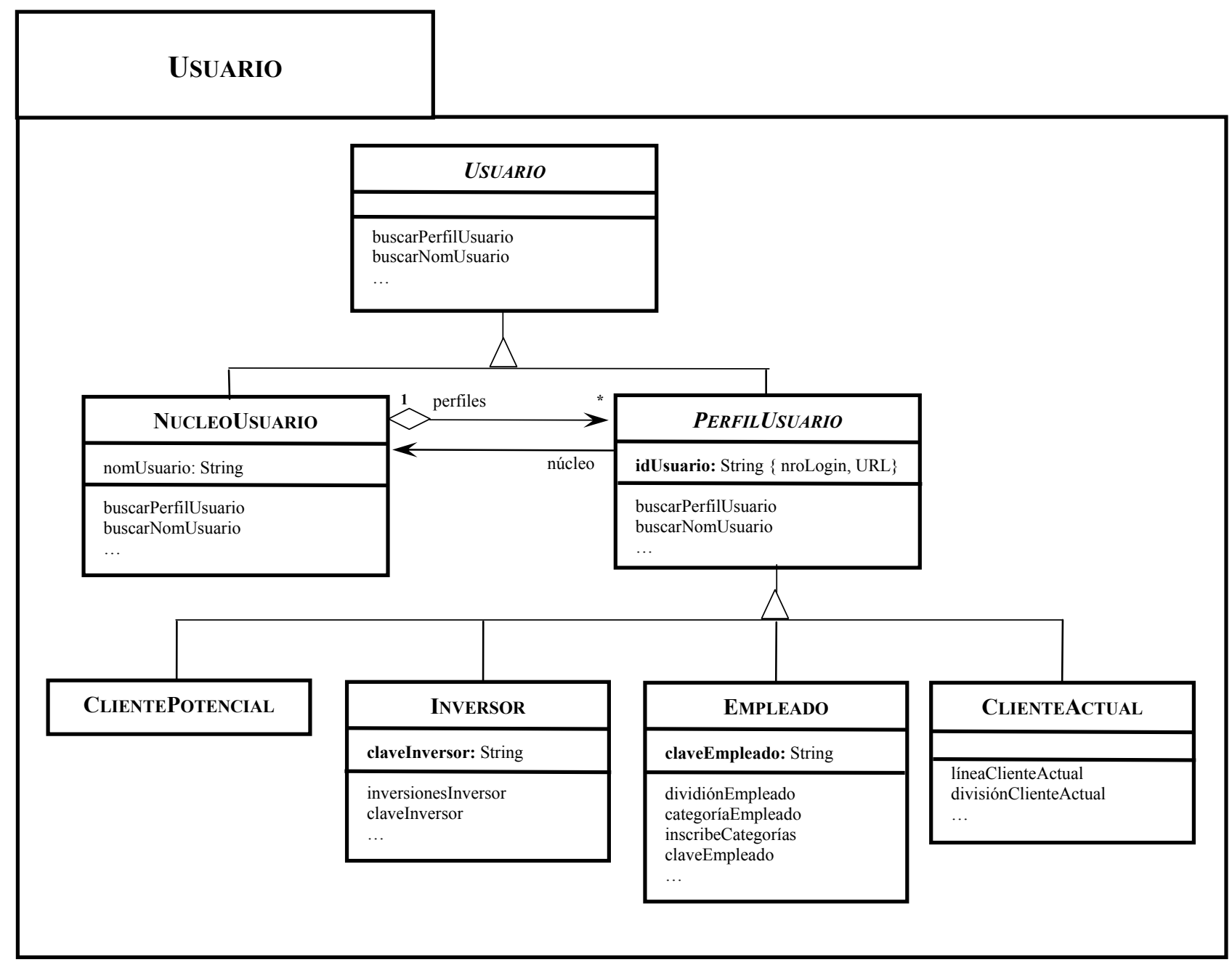

Figura 6.69a : Detalle del módulo Usuario

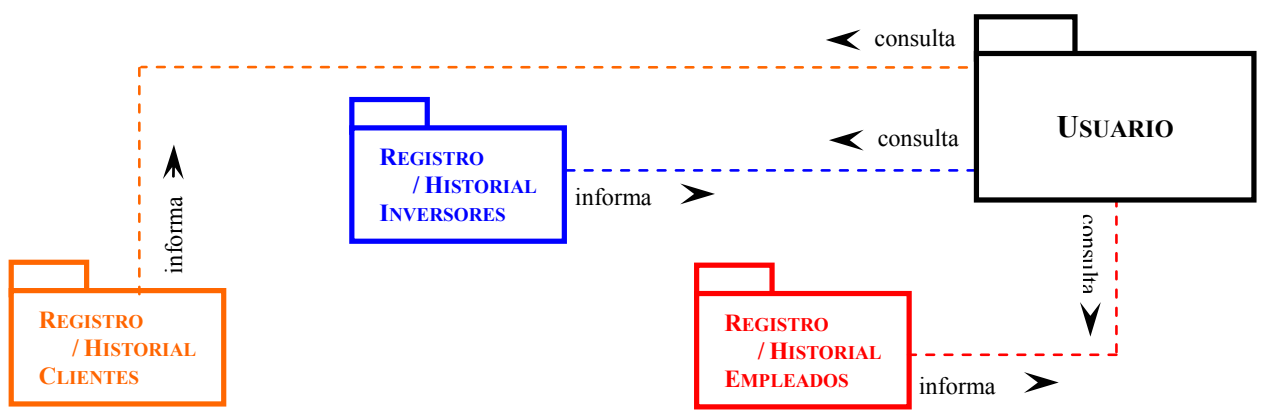

Figura 6.69b : Relaciones del módulo Usuario con los módulos Registro/Historial Empleados, Registro/Historial Inversores y Registro/Historial Clientes

Figura 6.69 : Módulo Usuario 
Paso 6. Rediseñar el Modelo de Navegación OOHDM, para completar el modelo objeto de la aplicación web personalizada. Para lograr este rediseño se propone:

- aplicar a los UIDs personalizados el método que se detalla en 5.4.5.2, sugerido en el Paso 7 del proceso de ingeniería en reversa, [Güello0a] y en [Güello0b]. Este ejercicio permite descubrir la necesidad de incluir nuevos nodos o de agregar atributos a nodos existentes y de incorporar contextos y estructuras de acceso a objetos existentes.

- considerar e incorporar patrones de personalización [Rossi01b] y [Schwabe02].

Tal como lo indica el Paso 6, el objetivo de esta actividad es completar el diseño interno de la aplicación web personalizada proporcionando el nuevo Modelo de Navegación.

La determinación del usuario que está accediendo la aplicación requiere ya sea que él mismo se identifique explícitamente al comienzo $\left(\mathrm{N}^{\circ}\right.$ de Login) o que diferentes puntos se proporcionen (externos a la aplicación) a diferentes clases de usuarios (URLS), [Rossi01b].

En la personalización del Modelo de Navegación no solamente se utilizan los conceptos vertidos en [Rossi01b] y [Schwabe02] sino que también las consignas propuestas en el ítem5.5.4.2 (capítulo5) destinadas a reflejar gráficamente la personalización y sus grados en el Esquema de Contexto de Navegación.

Seguidamente se incorporan los Modelos de Navegación (Diagrama de Clases de Navegación y Diagrama de Contextos de Navegación) correspondientes a cada caso de uso personalizado: 


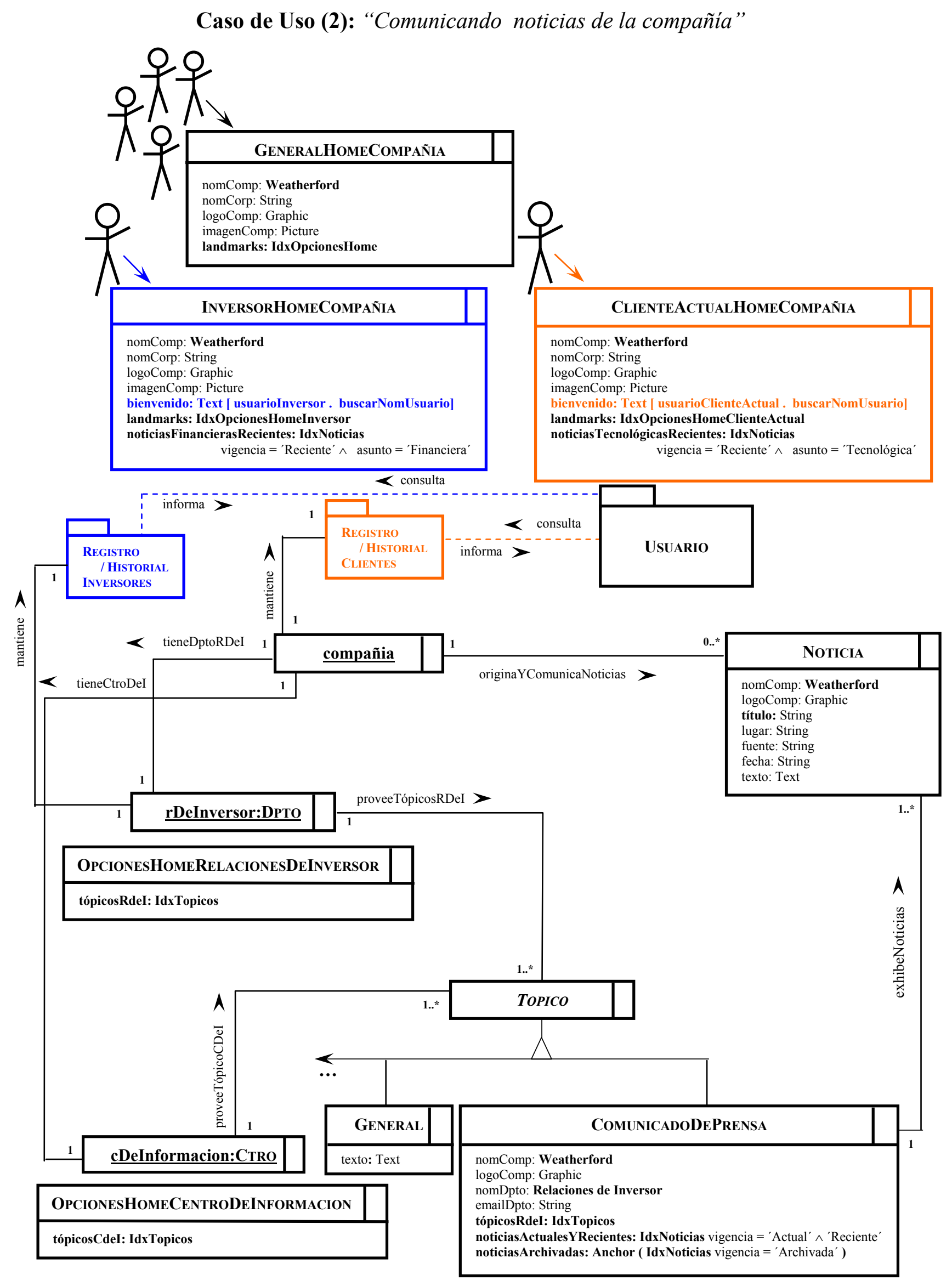

Figura 6.70 : Personalizando el Esquema de clases de navegación correspondiente al caso de uso "Comunicando noticias de la compañía" Perfil Inversor, Perfil Cliente Actual y Usuario General 


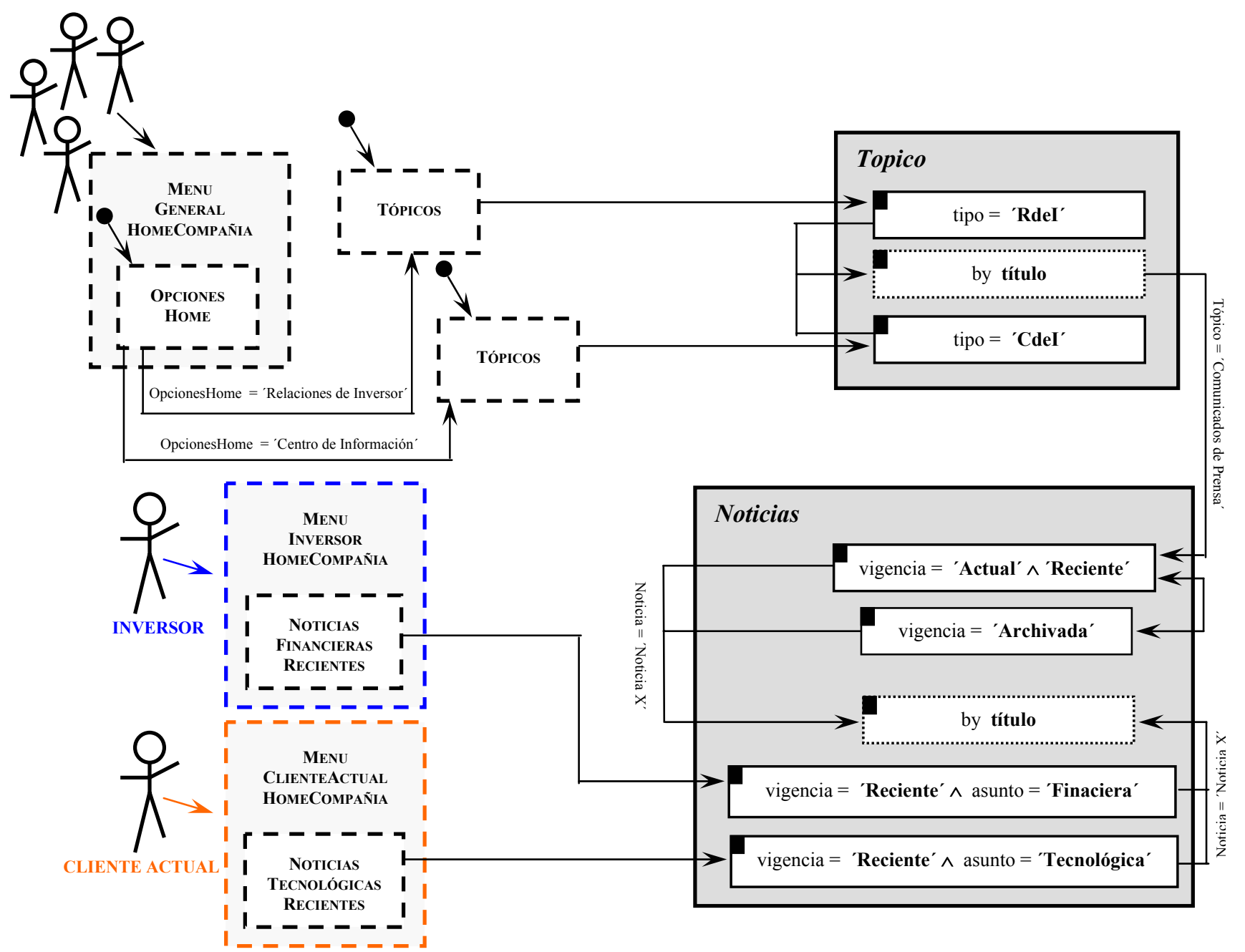

Figura 6.71 : Esquema de contexto de navegación correspondiente al caso de uso "Comunicando noticias de la compañía” Perfil Inversor, Perfil Cliente Actual y Usuario General 
Caso de Uso (4): "Navegando líneas de productos, servicios y sistemas dada una división"
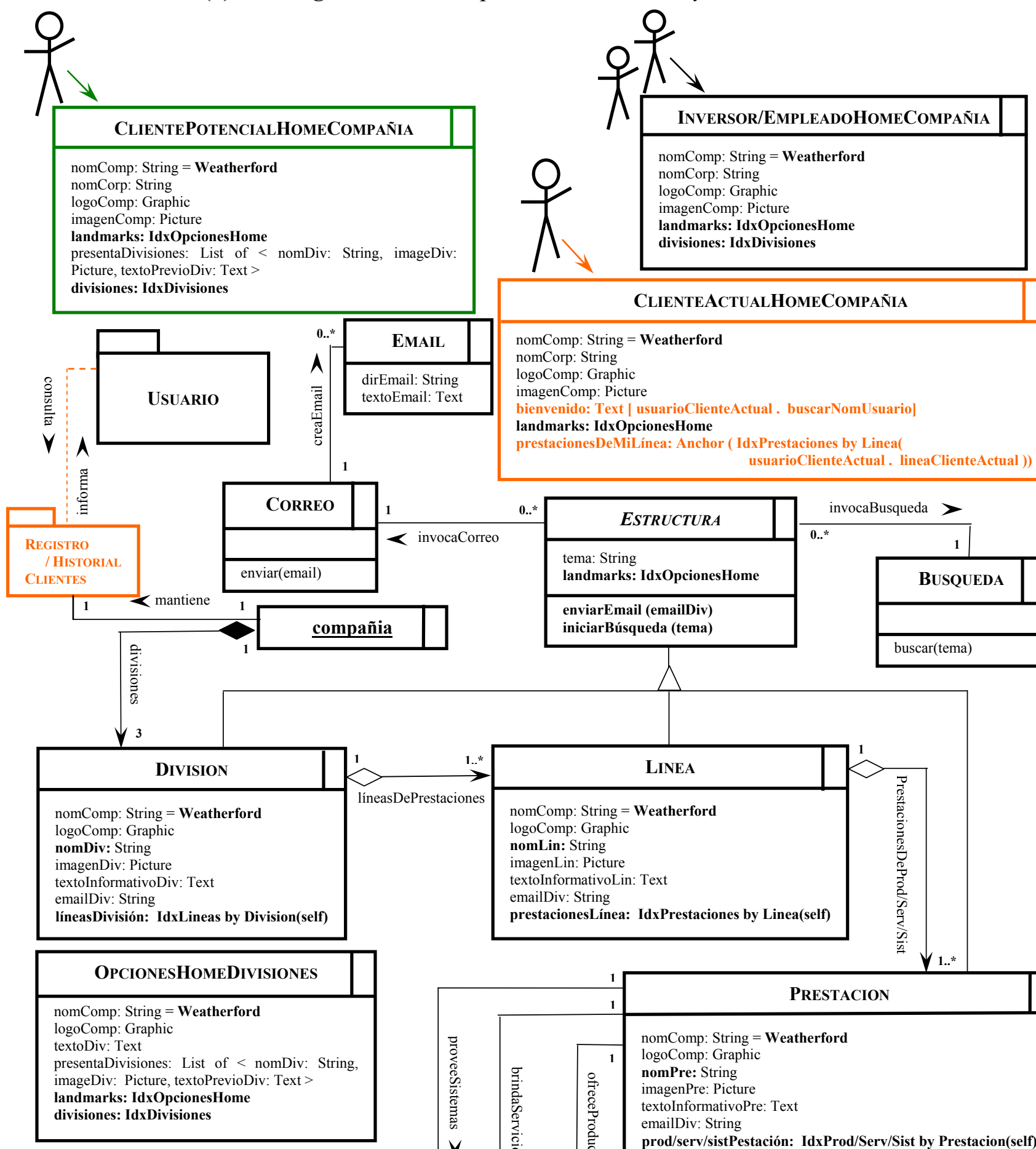

ClienteActualHomeCoMPañIA

nomComp: String $=$ Weatherford

nomCorp: String

logoComp: Graphic

imagenComp: Picture

bienvenido: Text [ usuarioClienteActual . buscarNomUsuario]

landmarks: IdxOpcionesHome

prestacionesDeMiLínea: Anchor (IdxPrestaciones by Linea(

usuarioClienteActual . lineaClienteActual ))

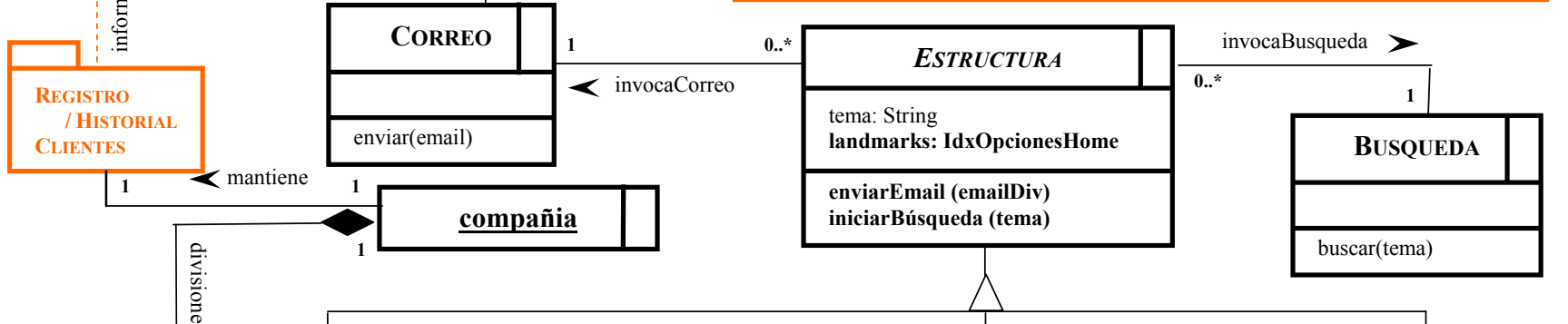

\begin{tabular}{|l|}
\hline \multicolumn{1}{|c|}{ SISTEMA } \\
\hline nomComp: String = Weatherford \\
logoComp: Graphic \\
landmarks: IdxOpcionesHome \\
nomLin: String \\
nomSist: String \\
descripción: Text \\
desarrolloIngeniería: Text \\
soporteTécnico: Text
\end{tabular}

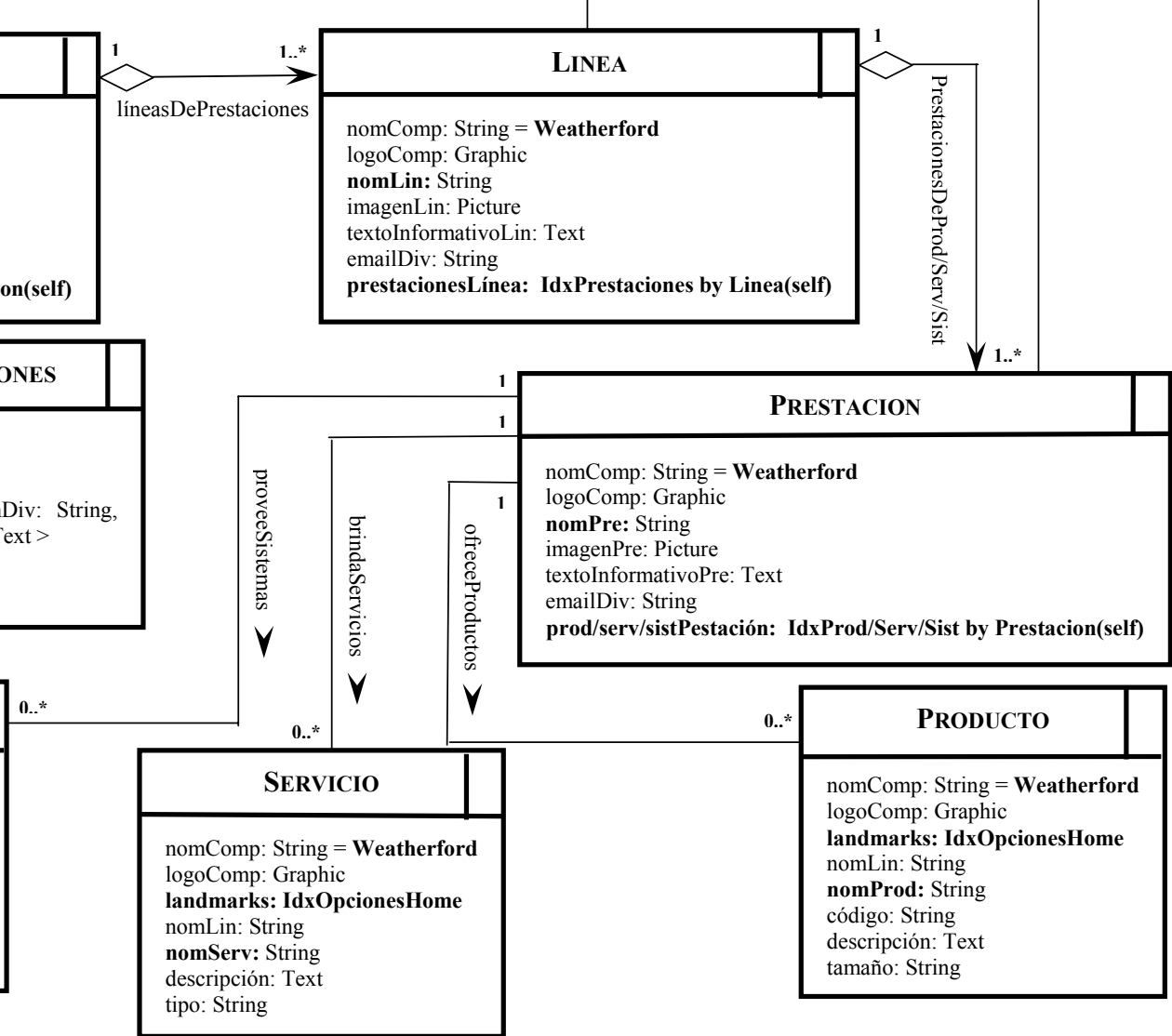

Figura 6.72 : Personalizando el Esquema de clases de navegación correspondiente al caso de uso "Navegando líneas de prestaciones dada una división" Perfil Cliente Actual, Perfil Cliente Potencial y Perfiles Inversor / Empleado 


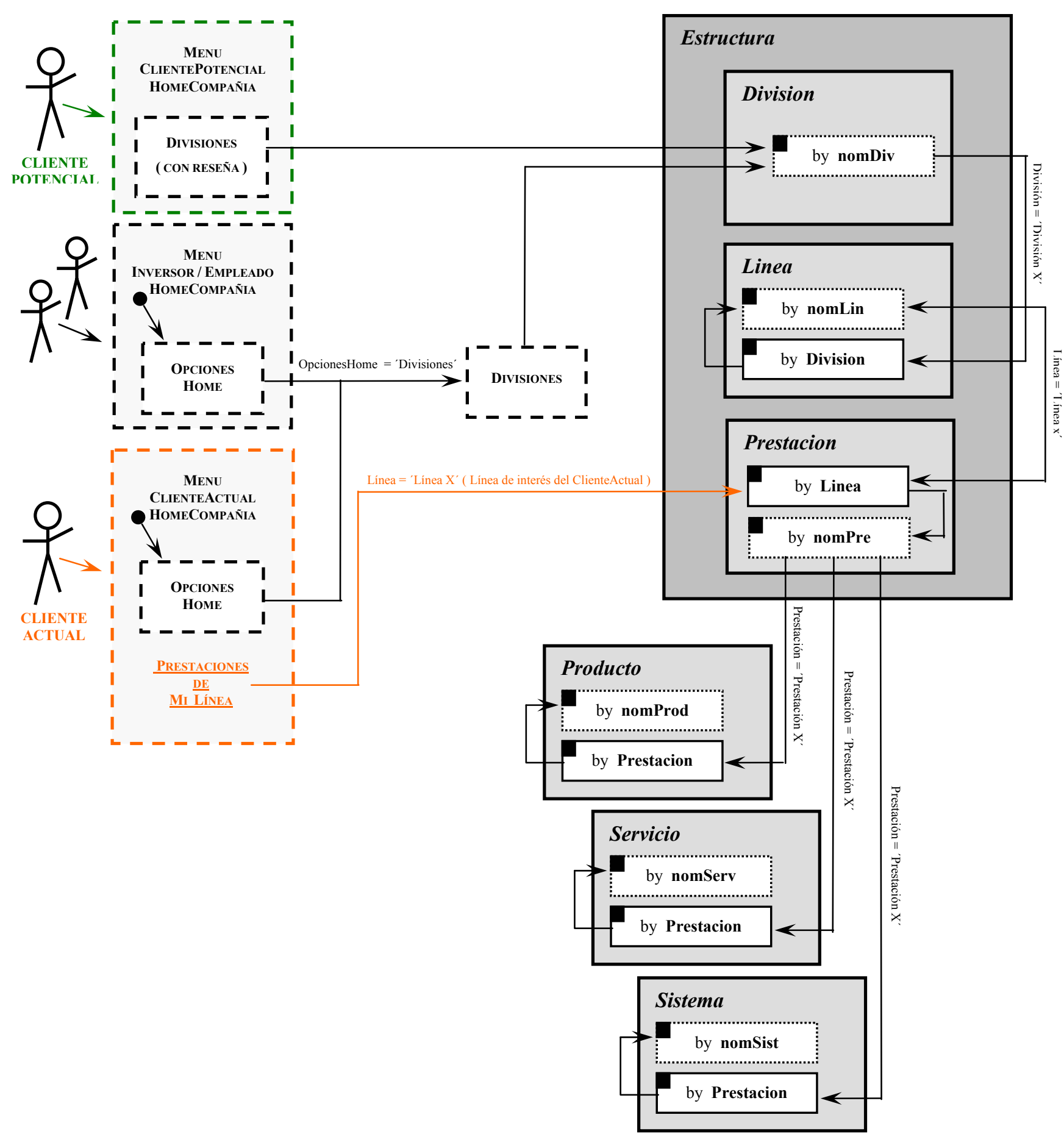

Figura 6.73 : Esquema de contexto de navegación correspondiente al caso de uso "Navegando líneas de prestaciones dada un división" Perfil Cliente Actual, Perfil Cliente Potencial y Perfiles Inversor / Empleado

A continuación se detalla la Carta de Especificación del Contexto Prestaciones By Linea personalizado al usuario Perfil Cliente Acual: 
Context: Prestaciones By Linea

PARAmeters: usuarioClienteActual : ClienteActual, lineaClienteActual : Linea

Elements: p : Prestacion WHERE p eslaPrestacion By lineaClienteActual = usuarioClienteActual . lineaClienteActual

InCONTEXT CLASS: ---

NAVEGATION: by index

ACCESS RESTRICTION：---

PERMission: navegar 
Caso de Uso (5): "Brindando Información Financiera"

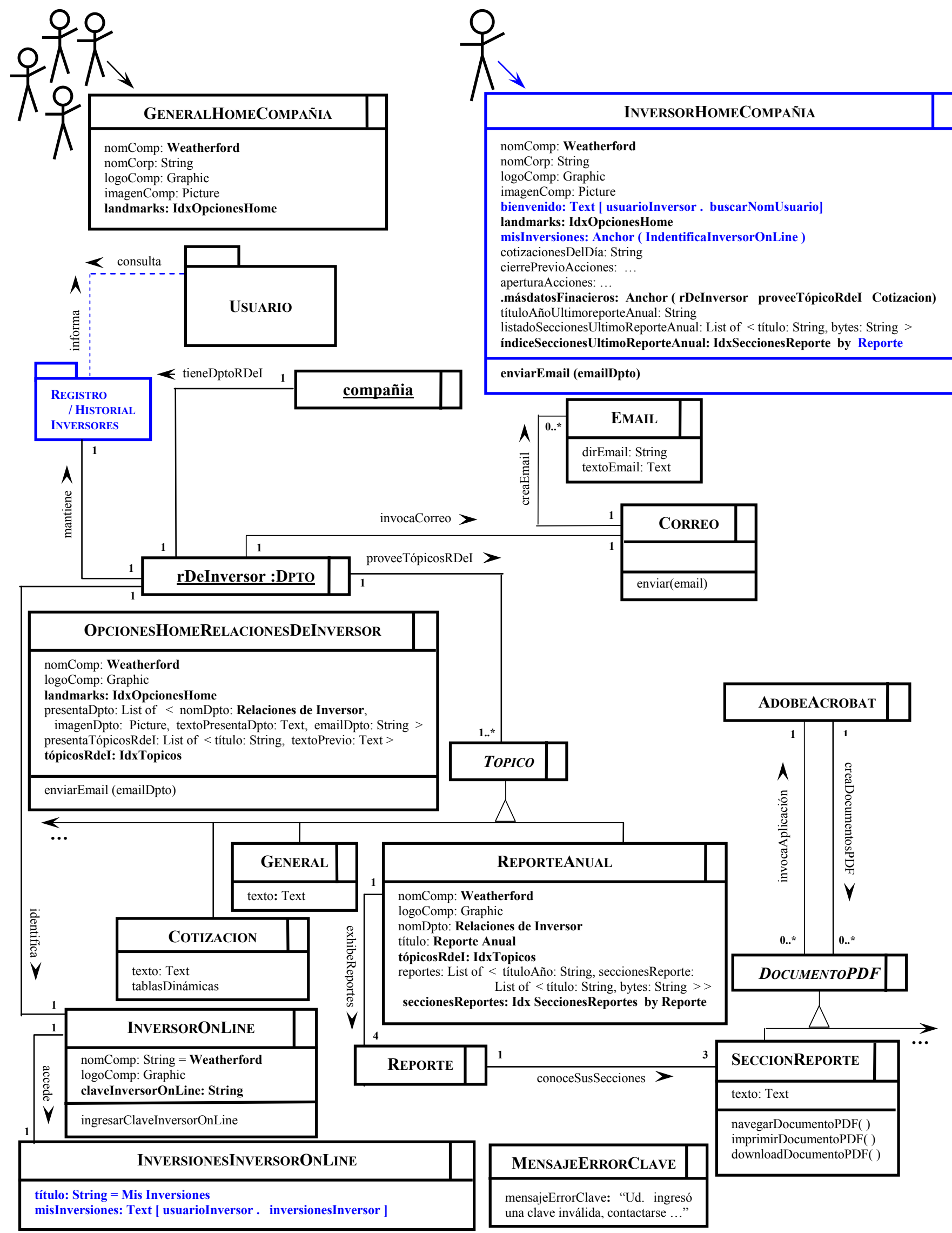

Figura 6.74 : Personalizando el Esquema de clases de navegación correspondiente al caso de uso "Brindando información financiera" Perfil Inversor y Usuario General 
A continuación se especifica el Link IdentificaInversorOnLine personalizado al usuario Perfil Inversor:

LINK IdentificaInversorOnLine, usuarioInversor: Inversor

SourCE InversorHomeCompañia

TARGET InversionesInversorOnLine: II WHERE II permiteAcceso usuarioInvesor AND claveInversorOnLine $=$ usuarioInversor c claveInversor
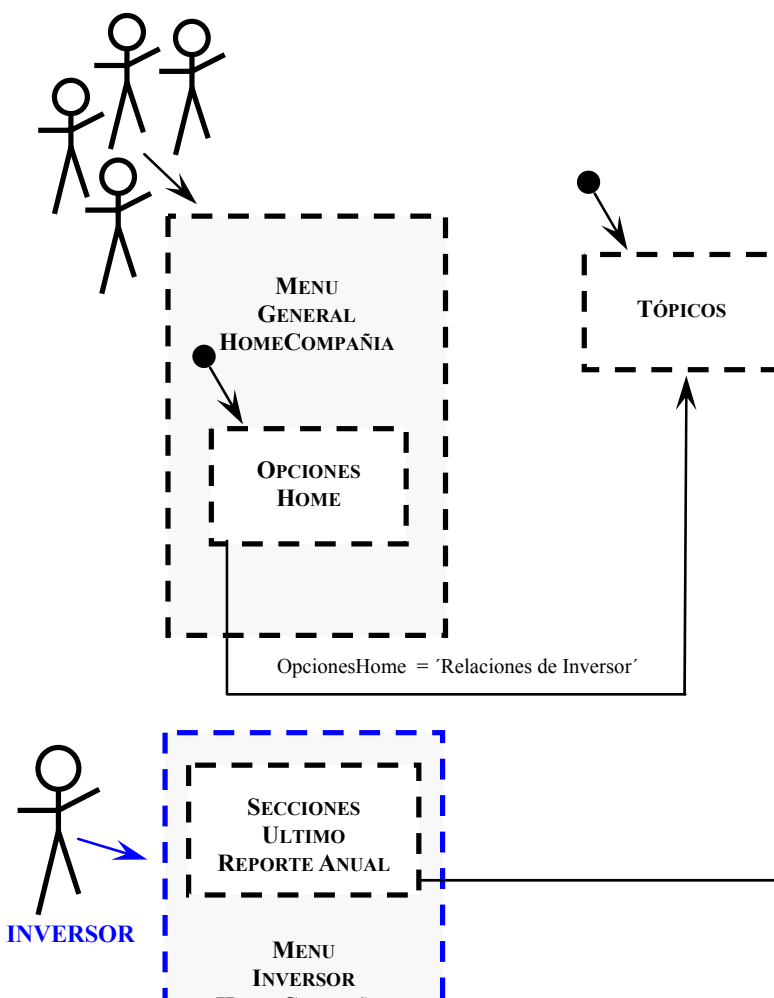

$$
\text { INVERSOR }
$$
HOMECOMPAÑIA

INVERSIONES
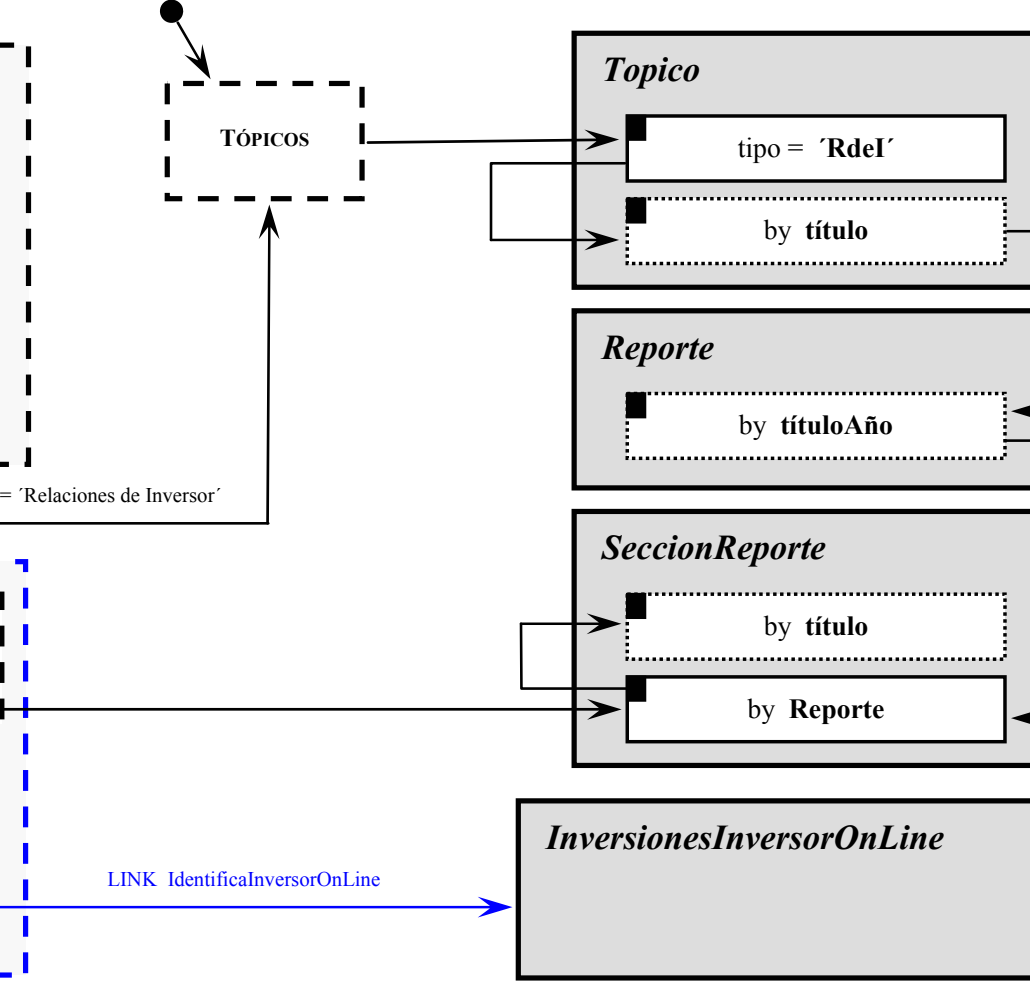

Reporte

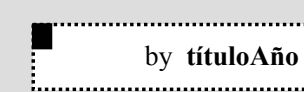

SeccionReporte

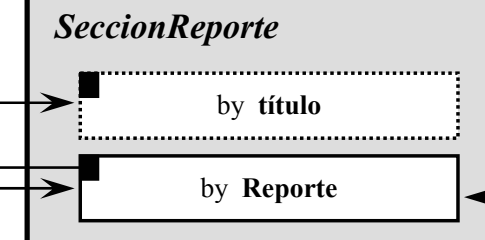

InversionesInversorOnLine

Figura 6.75 : Esquema de contexto de navegación correspondiente al caso de uso "Brindando información financiera" Perfil Inversor y Usuario General 
Caso de Uso (8): "Informando prestaciones al yacimiento petrolifero"
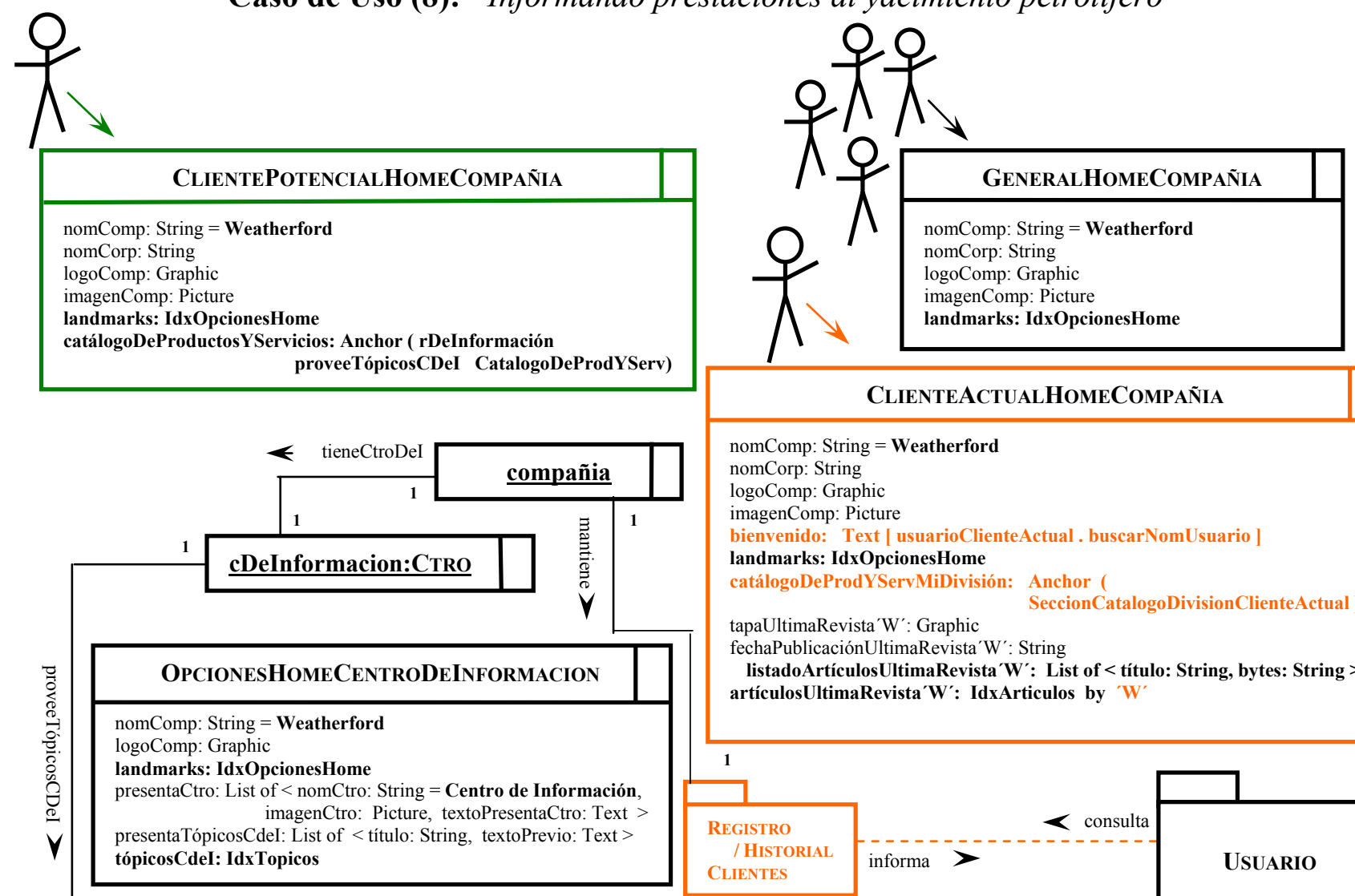

\begin{tabular}{|c|}
\hline CLIENTEACTUALHOMECOMPAÑIA \\
\hline 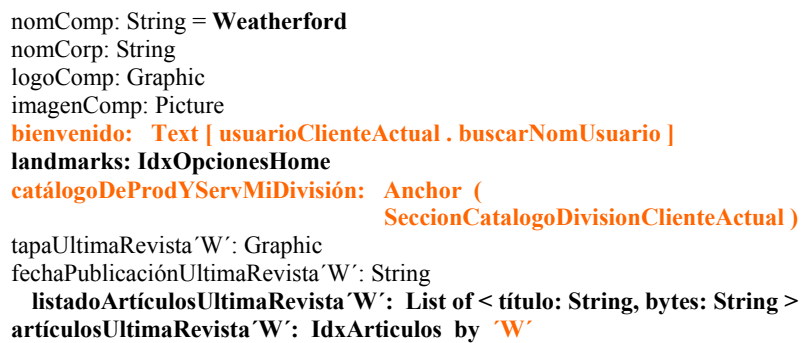 \\
\hline
\end{tabular}

logoComp: Graphic

landmarks: IdxOpcionesHome

presentaTópicosCdeI: List of < título: String, textoPrevio: Text >

tópicosCdeI: IdxTopicos
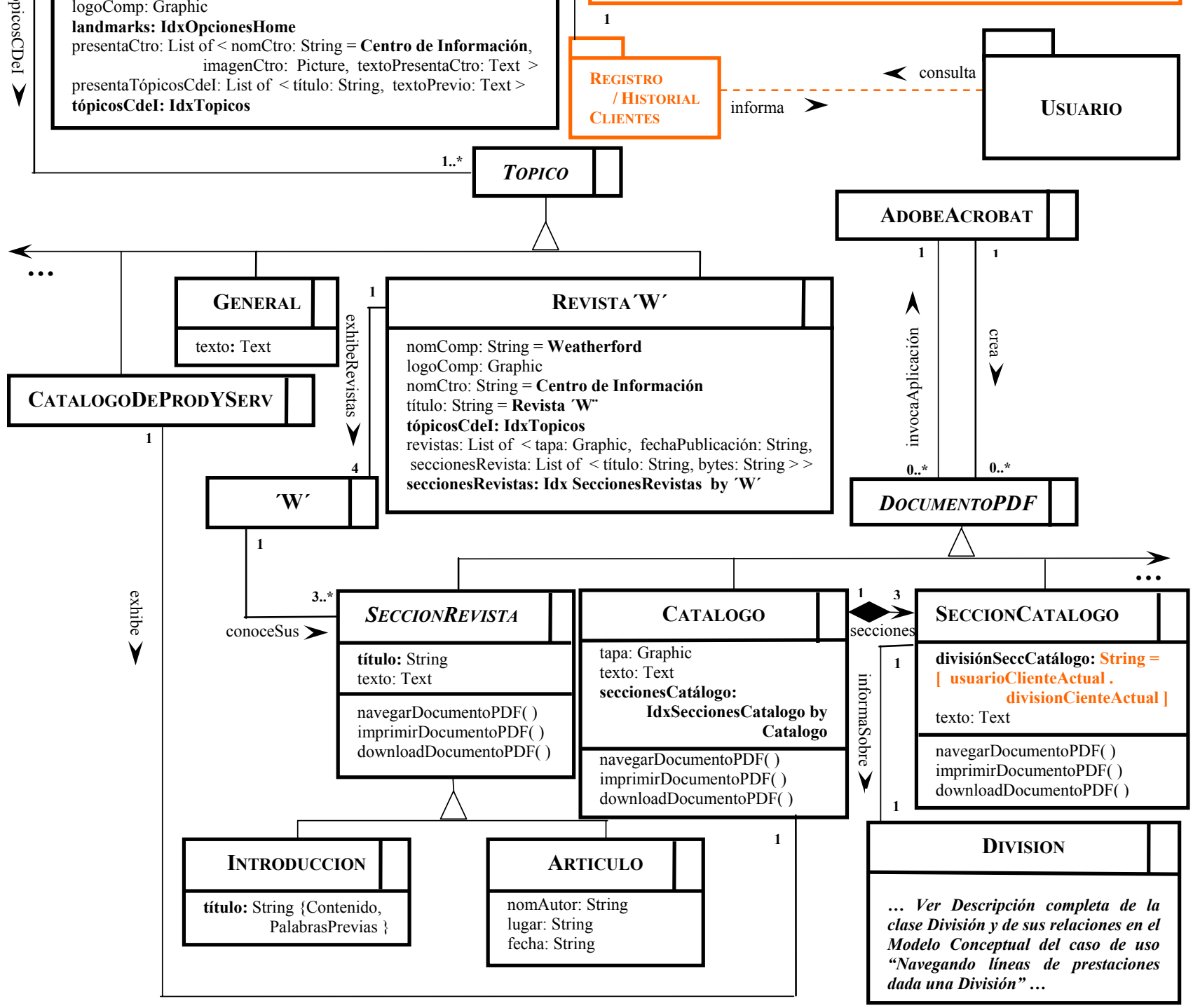

Figura 6.76 : Personalizando el Esquema de clases de navegación correspondiente al caso de uso "Informando prestaciones al yacimiento petrolifero " Perfil Cliente Actual, Perfil Cliente Potencial y Usuario General 
A continuación se especifica el Link SeccionCatalogoDivisionClienteActual personalizado al usuario Perfil ClienteActual:

LINK Seccion CatalogoDivisionClienteActual, usuarioClienteActual: ClienteActual

SourCE ClienteActualHomeCompañia

TARGET SeccionCatalogo: SC WHERE SC informaSobre divisionClienteActual: Division = usuarioClienteActual . divisionClienteActual

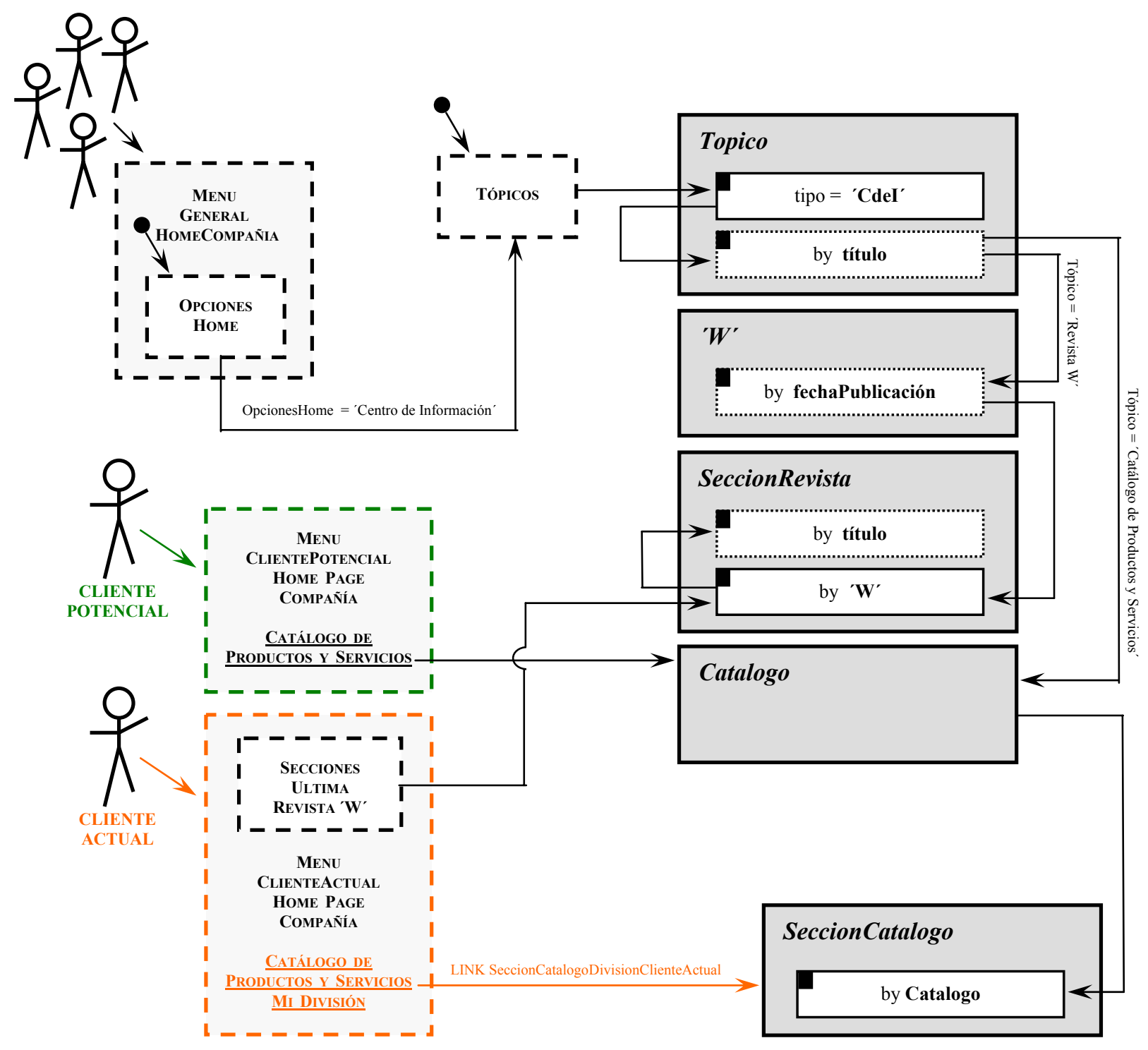

Figura 6.77: Esquema de contexto de navegación correspondiente al caso de uso "Informando prestaciones al yacimiento petrolifero" Perfil Cliente Actual, Perfil Cliente Potencial y Usuario General 
Caso de Uso (10): "Posibilitando envío de inscripción en curso de capacitación"
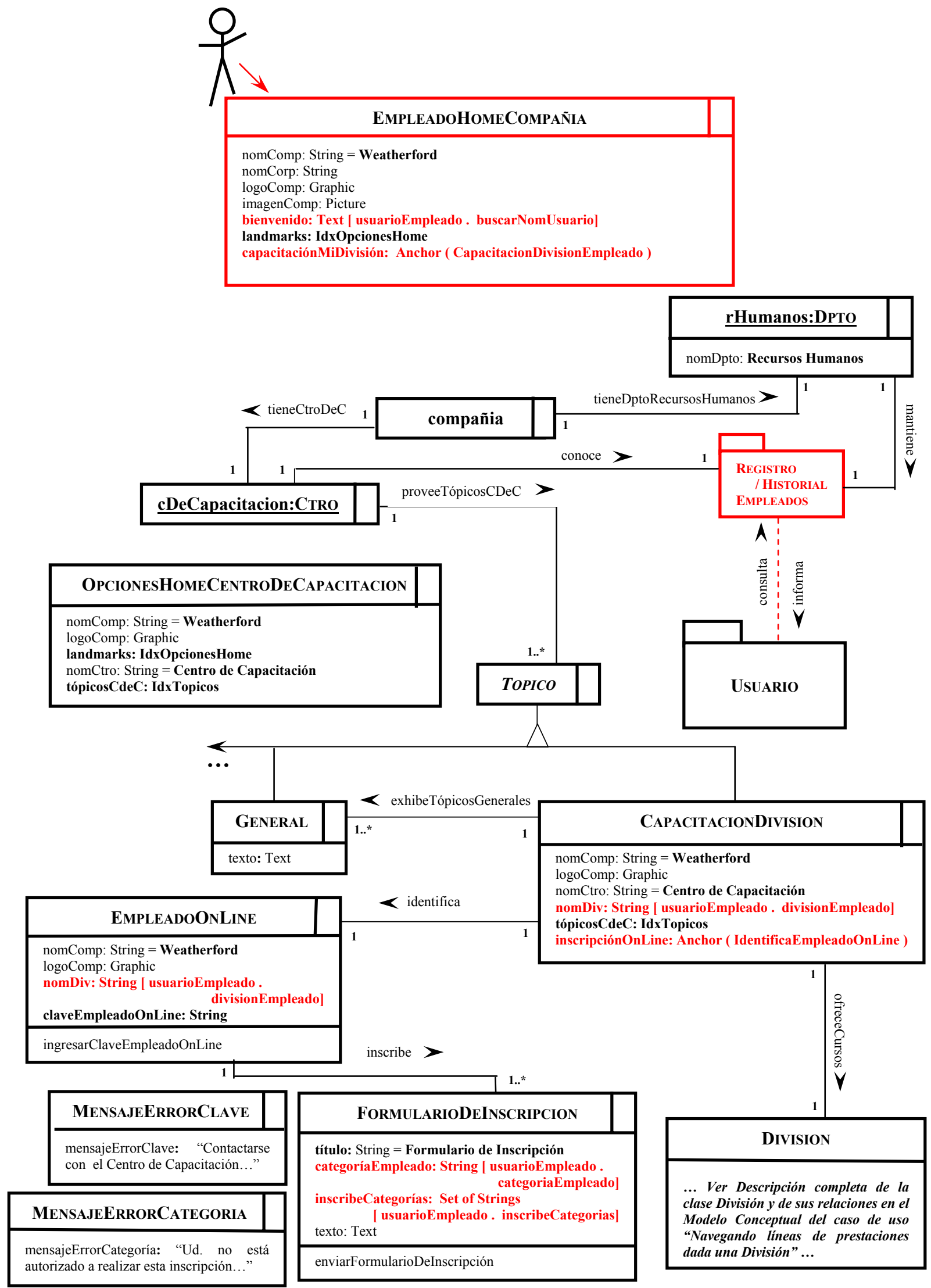

Figura 6.78 : Esquema de clases de navegación correspondiente al caso de uso

"Posibilitando envío de inscripción en curso de capacitación" Perfil Empleado por Categoría 
A continuación se especifican el Link CapacitacionDivisionEmpleado y el Link IdentificaEmpleadoOnLine personalizado al usuario Perfil Empleado:

LINK CapacitacionDivisionEmpleado, usuarioEmpleado: Empleado

SOURCE EmpleadoHomeCompañia

TARGET CapacitacionDivision: CD WHERE CD ofreceCursos divisionEmpleado: Division = usuarioEmpeado . divisionEmpleado

LINK IdentificaEmpleadoOnLine, usuarioEmpleado: Empleado

SOURCE CapacitacionDivision

TARGET FormularioDeInscripcion: FI WHERE FI permiteInscripcion usuarioEmpleado AND claveEmpleadoOnLine $=$ usuarioEmpleado . claveEmpleado
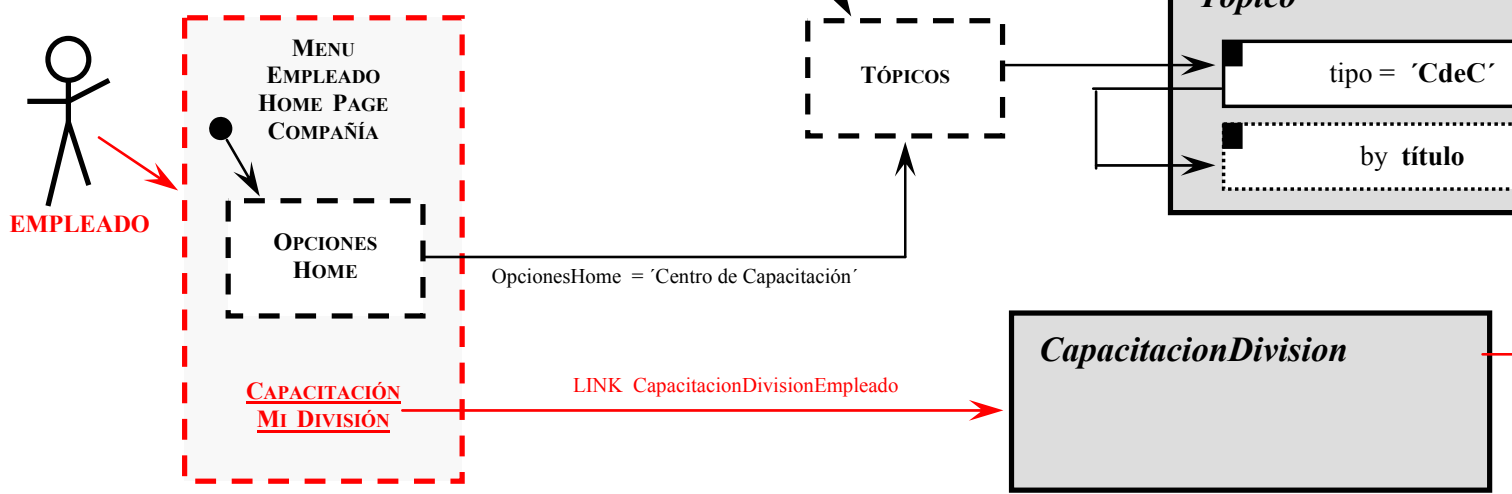

FormularioDeInscripcion

Figura 6.79 : Esquema de contexto de navegación correspondiente al caso de uso "Posibilitando envío de inscripción en curso de capacitación” Perfil Empleado por categoría

En este punto, se alcanzó el nuevo Modelo Objeto Personalizado para el sitio de la corporación Weatherford International Inc. Oil Field Services, completando así la aplicación del proceso de Reingeniería de Personalización propuesto por Nuestro Enfoque a este caso real. Como ya se señaló al finalizar el capítulo5, es además, el punto de partida para lanzar la etapa de implementación de la aplicación web personalizada (que como ya indicamos esta fuera del alcance de este trabajo). 


\section{Capítulo 7}

\section{Trabajos RELACIONADOS}

\subsection{Introducción}

La reingeniería es de por sí un tema relativamente joven. Por su parte, el diseño de aplicaciones Web personalizadas es una problemática muy actual. Ante estas afirmaciones, hablar sobre reingeniería para la personalización de aplicaciones Web existentes, significa incursionar en un terreno más que reciente, casi inédito. Por lo tanto, en lo que resta del capítulo, ítems7.2 y 7.3, se citan por separado trabajos y referencias sobre reingeniería de aplicaciones Web y sobre personalización de aplicaciones Web respectivamente y se discuten las principales diferencias entre estos trabajos y nuestro enfoque.

\subsection{Sobre reingeniería de aplicaciones Web}

Ya se mencionó, capítulo4, que el término reingeniería fue acuñado en 1993 por Michael Hammer y James Champy con el BPR y rápidamente se volvió un tema sumamente popular convirtiéndose con el pasar del tiempo, en un concepto clave y cada vez más vigente.

Desde aquellos inicios, la reingeniería no solamente ha evolucionado notablemente sino que también ha extendido su espectro de aplicación acompañando las necesidades que imponen los avances tecnológicos. Su presencia se vuelve indispensable debido a que todo artefacto que sobrevive requiere en algún punto evolución sustancial y ha sido y sigue siendo trabajo de la reingeniería definir enfoques sistemáticos que permitan alcanzar exitosamente esta evolución.

Al hablar de reingeniería, surge de inmediato un vínculo al enfoque de Ivar Jacobson [Jacobson94]; su libro 'The Object Advantage: Business Process Reengineering with Object Technology', marca un hito al anexar al BPR las ventajas de la tecnología OO, capítulo4.

La reingeniería se ha instalado en otros ámbitos asistiendo a temáticas diversas. Por ejemplo, el libro 'Application (Re)Engineering: Building Web-Based Applications and Dealing with Legacies' de Amjad Umar [Umar97], propone estrategias de (re)ingeniería para aborda la problemática de migrar sistemas 'legacies' a la WWW. Sobre esta línea se sigue trabajando con intensidad y se ha convertido en uno de los tópicos predilectos de las comunidades de investigación.

En los últimos años, los 'workshops' y las conferencias sobre reingeniería y Web han cobrado un auge notable. Por ejemplo, se pueden referenciar los siguientes eventos:

- WCRE - Working Conference on Reverse Engineering - programa 2001 disponible en http://reengineer.org/wcre2001/program2.html

- CSMR - European Conference on Software Maintenance and Reengineering - programa 2002 disponible en http://rgai.inf.u-szeged.hu/CSMR2002/program.html

- WSE - International Workshop on Web Site Evolution - programa 2002 disponible en http://star.itc.it/wse2002/program/

Cuando se trata de facilitar el diseño propiciando el reuso, el rol de los patrones de diseño puede ser protagónico, capítulo3. Por lo tanto, extender la utilización de los patrones al proceso de rediseño es una decisión más que acertada. En esta dirección, se pueden mencionar los 'Object-Oriented 
Reengineering Patterns' (OORP) de Serge Demeyer [Demeyer02]; su trabajo propone un catálogo de patrones aplicables al proceso de reingeniería.

Como ya se señaló al comienzo de este capítulo, hacer reingeniería para personalizar una aplicaciones Web existente, es una problemática sumamente novedosa. A continuación, ítem7.2.1, 7.2.2 se sintetizan dos trabajos de ingeniería en reversa de aplicaciones Web, por haberse descubierto en ellos cierta afinidad con nuestro enfoque.

\subsection{1 'WARE: a Tool for Reverse Engineering of Web Applications'}

Los autores - Giuseppe Di Lucca, A. Fasolino, F. Pace, P. Tramontana, U De Carlini [DiLucca2002], CSMR2002 - presentan una herramienta integrada de ingeniería en reversa que extrae automáticamente información de una aplicación Web, cuya arquitectura comprende los siguientes componentes principales:

(1) 'Interface Layer'

(2) 'Service Layer'

(3) 'Repository'

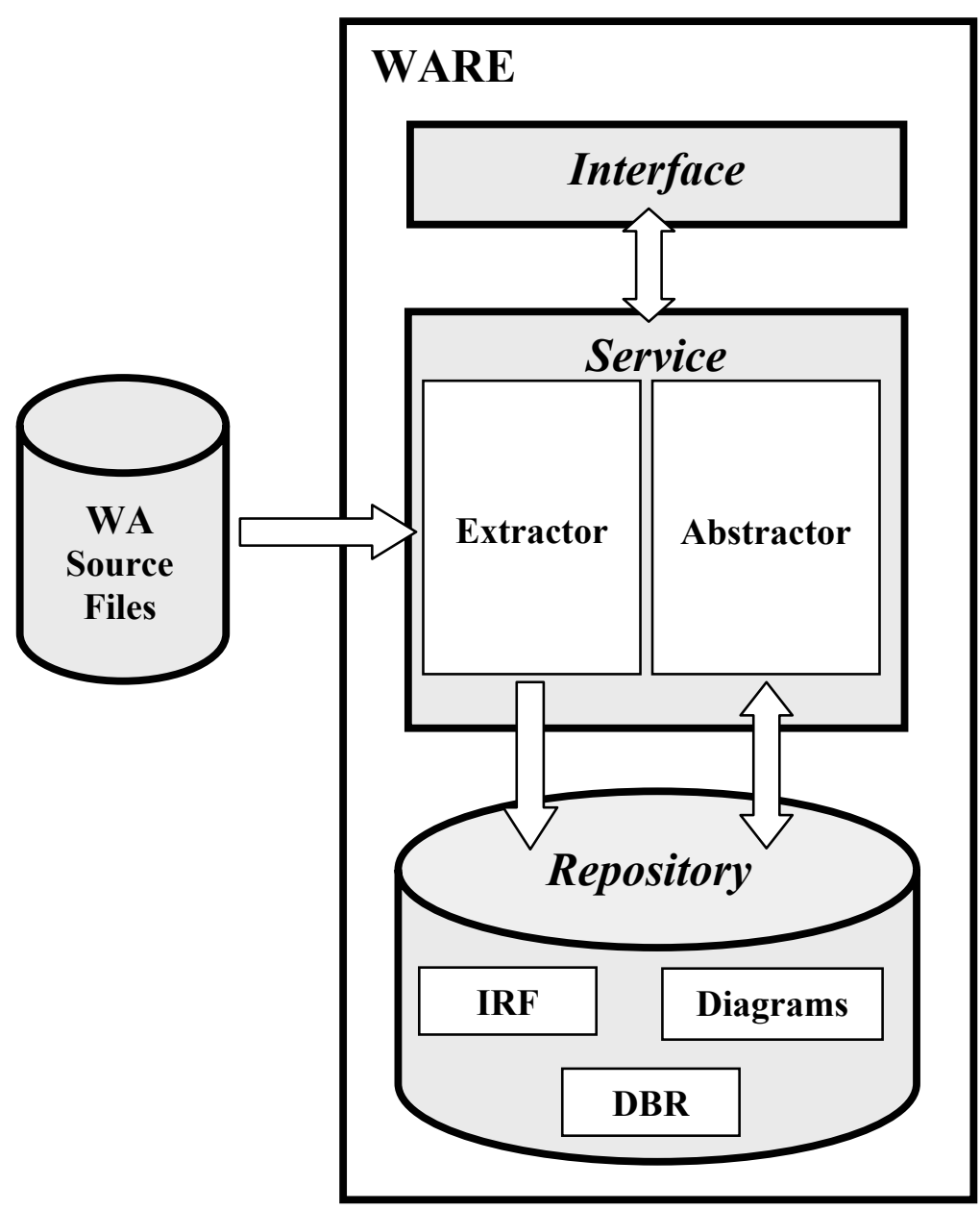

Figura 7.1: La herramienta WARE

El 'Interface Layer' implementa una interfaz de usuario proveyendo el acceso a las funciones ofrecidas por la herramienta, y la visualización de la información y documentación recuperada, ambas en formato textual y gráfico. 
El 'Service Layer' implementa los servicios de la herramienta, e incluye dos componentes principales: el 'Extractor' y el 'Abstractor'. El primero analiza gramaticalmente el código fuente de la aplicación Web y produce un 'Intermediate Representation Form' (IRF), que provee una representación de los ítems de datos extraídos de la aplicación Web. El 'Abstractor' opera sobre el IRF, e implementa varias tareas de abstracción necesarias para soportar la recuperación de los diagramas UML de la aplicación. La información producida por el 'Abstractor' se almacena en una base de datos relacional.

El 'Repository' incluye el IRF, la base de datos relacional y los diagramas recuperados.

La figura7.1 grafica los componentes principales de esta herramienta [DiLucca02].

\subsection{2 'Reverse Engineering to Achieve Maintainable WWW Sites'}

Los autores - Cornelia Boldyreff, R. Kewish [Boldyreff01], WCRE2001 - describen un sistema para analizar sitios Web existentes y extraer diseño y contenido duplicado. En el diseño del sistema se aplican técnicas de Ingeniería en Reversa existentes.

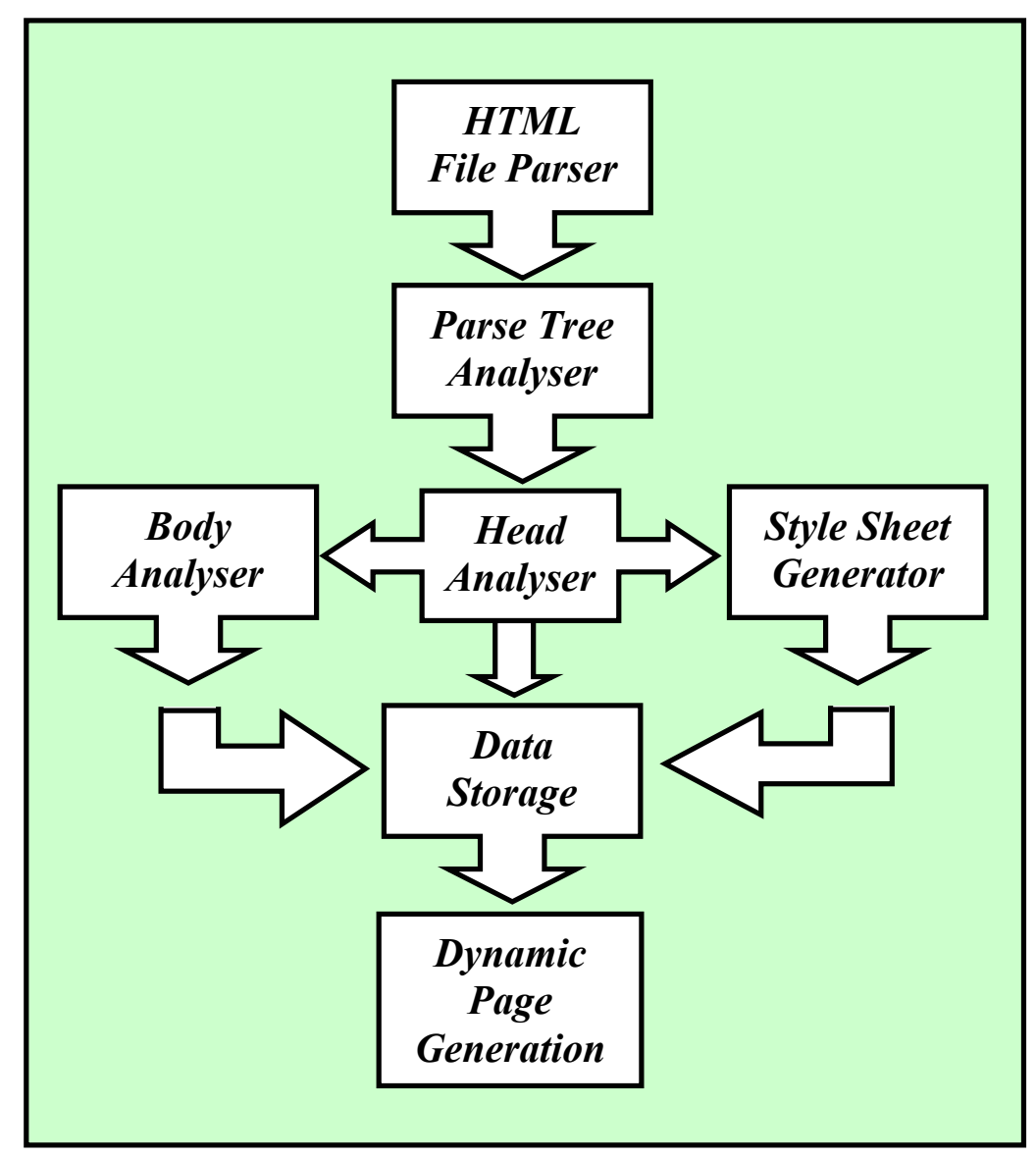

Figura 7.2: La arquitectura del Sistema

Este trabajo demuestra que aplicando el sistema propuesto se puede lograr una reducción significativa en el contenido duplicado de los sitios Web. El sistema logra esto a través de una reestructuración racional de las páginas del sitio Web y sus contenidos. La identificación de modelos y otros contenidos comunes requieren un análisis extenso de las páginas Web existentes. Sin embargo, la racionalización que se obtiene del sitio, en teoría, debería permitir a los encargados de su mantenimiento, entender los contenidos del sitio Web más fácilmente y separar los asuntos de diseño de otros tipos de contenidos de información, durante los mantenimientos subsiguientes del sitio. 
La evidencia empírica de tales beneficios solamente se puede obtener en el largo plazo. En el presente, el sistema desarrollado se ha utilizado en pruebas sobre un número muy reducido de sitios Web. Los resultados alcanzados muestran claramente que las técnicas de la Ingeniería en Reversa convencionales se pueden aplicar para aliviar algunos de los problemas de mantenimiento hallados en los sitios Web existentes y los sistemas de almacenamiento actuales empleados para dichos sitios Web. Ciertamente, este trabajo muestra que existe un ámbito para investigaciones futuras sobre Ingeniería en Reversa de los sitios Web.

La figura 7.2 provee una visión general de la arquitectura de alto nivel del sistema desarrollado [Boldyreff01].

\subsubsection{Nuestro enfoque versus WARE y RI System}

Si bien existe cierta afinidad entre Nuestro Enfoque y estos trabajos, en el sentido de que todos subrayan la importancia de la actividad de ingeniería en reversa como artífice de la obtención del modelo actual, para adquirir la comprensión de la aplicación Web existente y propiciar su mantenimiento y evolución, también existen diferencias entre una y otra propuesta.

La tabla siguiente, ofrece un cuadro comparativo entre trabajos:

\begin{tabular}{|c|c|c|c|}
\hline & NUESTRO ENFOQUE & WARE & RI SYSTEM \\
\hline Objetivo & $\begin{array}{c}\text { Personalizar una } \\
\text { Aplicación Web existente. }\end{array}$ & $\begin{array}{l}\text { Recobrar el modelo de una } \\
\text { Aplicación Web existente. }\end{array}$ & $\begin{array}{l}\text { Analizar un Sitio Web } \\
\text { existente y extraer diseño y } \\
\text { contenido duplicado. }\end{array}$ \\
\hline Descripción & $\begin{array}{l}\text { Proceso de Reingeniería de } \\
\text { Personalización } \\
\text { que permite obtener } \\
\text { el modelo personalizado de } \\
\text { una Aplicación Web } \\
\text { existente - de la cual no se } \\
\text { conoce su modelo actual - }\end{array}$ & $\begin{array}{l}\text { Software de Ingeniería en } \\
\text { Reversa } \\
\text { que soporta la recuperación } \\
\text { del modelo actual de una } \\
\text { Aplicación Web existente. }\end{array}$ & $\begin{array}{c}\text { Sistema que aplica técnicas } \\
\text { de Ingeniería en Reversa } \\
\text { para obtener una } \\
\text { reestructuración racional de } \\
\text { las páginas de un Sitio Web } \\
\text { existente y sus contenidos. }\end{array}$ \\
\hline Entrada & $\begin{array}{l}\text { Requiere interactuar con la } \\
\text { Aplicación Web existente. }\end{array}$ & $\begin{array}{l}\text { Requiere disponer del } \\
\text { código fuente de la } \\
\text { Aplicación Web existente. }\end{array}$ & $\begin{array}{l}\text { Requiere disponer de las } \\
\text { páginas HTML del Sitio } \\
\text { existente. }\end{array}$ \\
\hline
\end{tabular}




\begin{tabular}{|c|c|c|c|}
\hline Características & $\begin{array}{l}\text { Proceso de reingeniería } \\
\text { compuesto de dos } \\
\text { actividades principales: } \\
\text { Ingeniería en Reversa e } \\
\text { Ingeniería 'Forward' de } \\
\text { Personalización. Estas } \\
\text { actividades se describen } \\
\text { paso a paso e incluyen la } \\
\text { utilización de herramientas } \\
\text { específicas al diseño de } \\
\text { Aplicaciones Web, para } \\
\text { obtener un conjunto de } \\
\text { modelos orientados a } \\
\text { objetos basados en el } \\
\text { enfoque OOHDM, de la } \\
\text { aplicación existente y de la } \\
\text { aplicación personalizada. }\end{array}$ & $\begin{array}{c}\text { Herramienta } \\
\text { implementada en C++ } \\
\text { usando Microsoft } \\
\text { Visual C++, cuyos } \\
\text { componentes generan } \\
\text { automáticamente un } \\
\text { 'Repository' que } \\
\text { almacena un IRF, una } \\
\text { base de datos y } \\
\text { diagramas de una } \\
\text { Aplicación Web } \\
\text { existente. }\end{array}$ & $\begin{array}{l}\text { Sistema que analiza un } \\
\text { Sitio Web existente y } \\
\text { extraer diseño y contenido } \\
\text { duplicado. El sistema } \\
\text { cuenta con un 'parser' que } \\
\text { maneja las páginas HTML } \\
\text { del Sitio y almacena una } \\
\text { copia racionalizada de los } \\
\text { datos HTML extraídos. La } \\
\text { racionalización que se } \\
\text { obtiene del sitio, tiene } \\
\text { como objetivo brindar una } \\
\text { comprensión del mismo } \\
\text { facilitando su } \\
\text { mantenimiento posterior. }\end{array}$ \\
\hline Salida & $\begin{array}{l}\text { Modelo de la Aplicación } \\
\text { Web Personalizada. }\end{array}$ & $\begin{array}{l}\text { Modelo de la Aplicación } \\
\text { Web existente. }\end{array}$ & $\begin{array}{l}\text { Sitio Web existente } \\
\text { racionalizado. }\end{array}$ \\
\hline
\end{tabular}

\subsection{Sobre personalización de aplicaciones Web}

La personalización se convierte en una cuestión cada vez más importante y crítica para la Internet y la WWW, como resultado de la creciente sofisticación de los sitios Web, impulsada por la competencia despiadada entre sitios por capturar visitantes. Esta realidad, requiere encontrar enfoques y herramientas que faciliten el diseño de aplicaciones Web personalizadas propiciando el reuso, capítulo3. La rápida evolución de los servicios de Internet interactivos han contribuido no solo a incrementar el número de modernos sitios Web modernos sino que también la funcionalidad de estos sitios, los cuales se tornan cada vez más complejos.

Así, la personalización también se ha convertido en un área rica en trabajo para las comunidades de investigación y la inclusión de trabajos sobre personalización es habitual en los programas de 'workshops', conferencias y proyectos sobre Internet y WWW. Por ejemplo, se pueden referenciar algunos eventos tales como:

- KyotoDL2000 - 2000 Kyoto International Conference on Digital Libraries: Research \& Practice - programa 2000 disponible en http://www.computer.org/caspress/CATALOG/pr01022.htm

- $\mathrm{RPeC}^{\prime} 02$ - Workshop on Recommendation and Personalization in eCommerce - programa 2002 disponible en http://ectrl.itc.it/home/rpec/achedule.html

- UWA - Ubiquitous Web Applications - proyecto disponible en http://www.uwaproject.org

- SSGRR 2002w Computer \& Internet Conference - International Conference Advances in Infrastructure for e-Business, e-Education, e-Science, and e-Medicine on the Internet - programa disponible en http://www.ssgrr.it/en/ssgrr2002w/index.htm

A continuación, ítem7.3.1 y 7.3.2 se sintetizan dos trabajos, que si bien no guardan estrecha relación con nuestro enfoque, desde distintas ópticas, también hacen propuestas para facilitar el abordaje de la problemática de la personalización. 


\subsection{1 'Modelling Customizable Web Applications - A Requirement's Perspective'}

Los autores - Gerti Kappel, W. Retschitzegger y W. Schwinger [Kappe100], KyotoDL2000 sugieren un 'framework' de requerimientos que cubra el espacio de diseño de aplicaciones Web personalizadas. Los requerimientos se clasifican por medio de tres dimensiones ortogonales que deben ser consideradas cuando se modelan aplicaciones Web: 'Levels', 'Aspects' y 'Phases'. Este 'framework' de requerimientos permite estudiar sistemáticamente los métodos de modelado Web indicando sus puntos fuertes y defectos, y provee las bases para considerar la personalización como una nueva dimensión de modelado.

La figura7.3 ilustra las tres dimensiones del modelado [Kappel00].

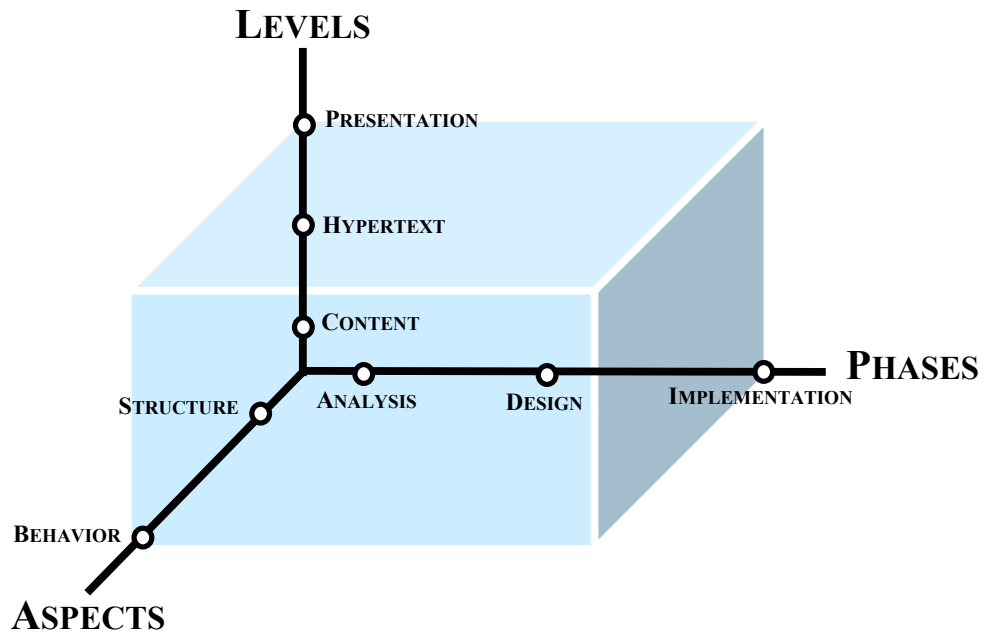

Figura 7.3: Dimensiones de Modelado

En términos de este enfoque, la personalización especializa una aplicación Web llamada 'Core Web Application' hacia circunstancias de consumo particulares denominada 'Context'. El resultado del proceso de personalización representa una aplicación Web personalizada. Los métodos existentes para modelar aplicaciones Web se pueden aplicar para modelar el 'Core Web Application' mientras que para capturar el proceso de personalización se necesitan nuevos conceptos. Consecuentemente, la personalización se puede incorporar como una nueva dimensión de modelado en este 'framework' de requerimientos.

La figura7.4 ilustra el ámbito de la personalización que comprende todas las otras dimensiones de modelado, lo cual significa que la personalización se debe considerar para todos los 'Aspects', 'Levels' y 'Phases' de una aplicación Web [Kappel00].

El espacio de diseño de personalización se puede caracterizar por dos cuestiones principales, figura7.5 [Kappe100]. Primero, las circunstancias de consumo definidas como 'Context', segundo, los posibles cambios al 'Core Web Application' denominados 'Adaption'. Ambos, 'Context' y 'Adaption', pueden ser estáticos, es decir predefinidos o dinámicos, es decir determinados en tiempo de ejecución. 


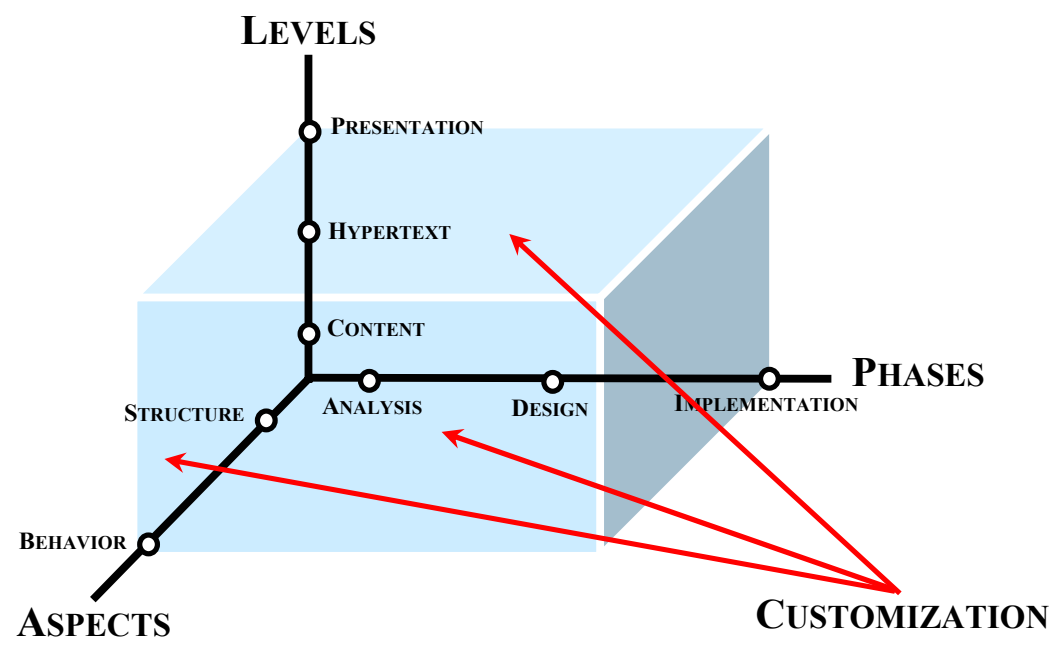

Figura 7.4: Ambito de la Personalización

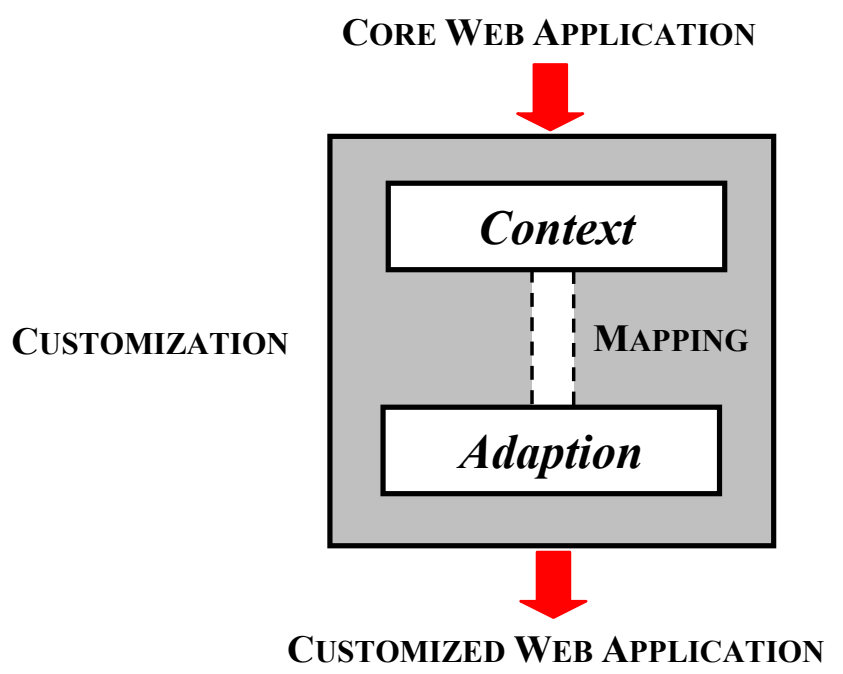

Figura 7.5: Cuestiones de Personalización

La figura7.6 ilustra como esta clasificación influye al grado de personalización de una aplicación Web [Kappel00].

Las aplicaciones Web personalizables que soportan solamente 'Contexts' y/o 'Adaptions' estáticos se denominan normalmente 'Adaptable' mientras que las que también proveen conceptos dinámicos se consideran 'Adaptive'. Juntos, 'Context' y 'Adaptive' determinan la aplicación personalizada actual, así la personalización en realidad traza un mapa entre 'Context' y 'Adaption'.

En este trabajo se discuten luego con detalle estos tres componentes, 'Context', 'Adaption' y 'Mapping', y luego de acuerdo con el 'framework' de requerimientos propuesto, se estudian los enfoques existentes para el desarrollo de aplicaciones Web personalizadas [Kappel00]. 


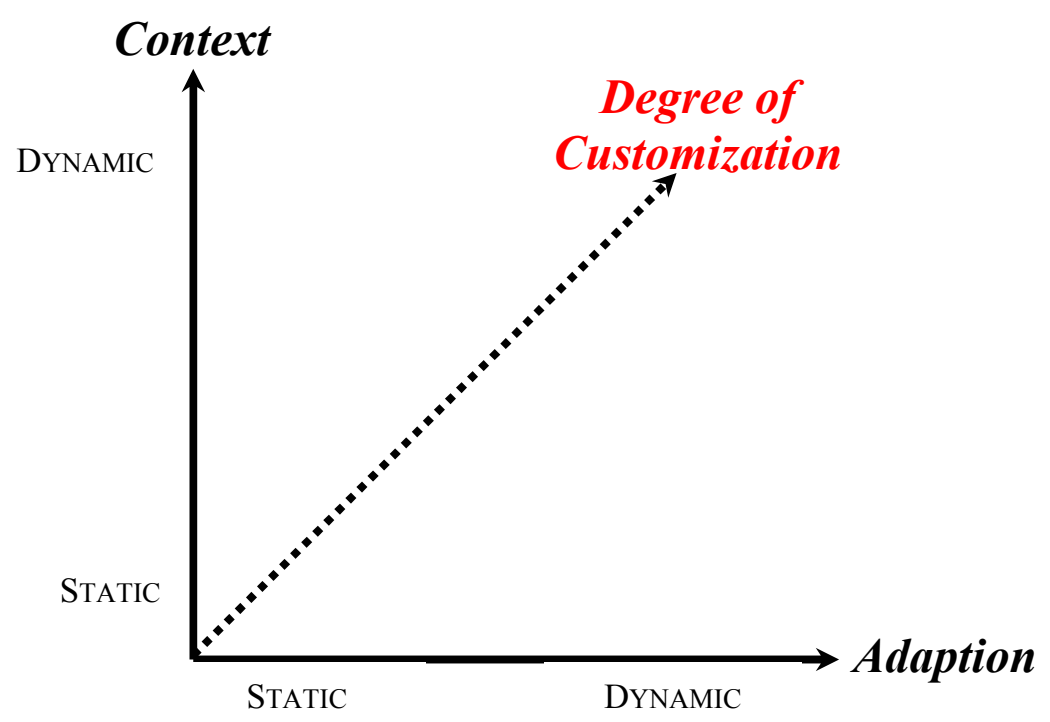

Figura 7.6: Grado de Personalización

\subsection{2 'Improving the Usability of an E-commerce Web Site through Personalization'}

Los autores - Fabio Abbattista, M. Degemmis, O. Licchelli, P. Lops, G. Semeraro y F. Zambetta [Abbattista02], RPeC'02 - presentan el 'Profile Extractor', el componente de personalización basado en técnicas de aprendizaje de máquina, que permite el descubrimiento de las preferencias, necesidades e intereses de los usuarios que acceden a un sitio Web 'e-commerce'. El trabajo propone un proceso de recuperación "inteligente" basado sobre tecnología de 'Chatterbot', técnicas de modelado de usuario, y un mecanismo automático de expansión de consulta que saca ventaja del conocimiento almacenado en los perfiles de usuario para refinar la consulta original asumida por el 'Chatterbot' 'Chat Robot', sistema de software capaz de entablar conversación en forma escrita con un usuario -

El 'Profile Extractor' es un módulo altamente reutilizable que tiene en cuenta la clasificación de los usuarios que acceden a un sitio Web. Utiliza técnicas de aprendizaje supervisadas para inducir un conjunto de reglas que son usadas por un módulo de clasificación, el 'Profile Manager', en el paso de generación de perfil.

El 'Profile Manager' y el 'Profile Rules Extractor' son los módulos principales involucrados en el proceso de generación de perfil; el 'Usage Patterns Extractor', implementa un algoritmo de agrupación y una técnica para la extracción de reglas de asociación. Agrupa sesiones de diálogo para inferir algunos patrones de uso que puedan ser explorados para comprender tendencias útiles a posteriores estudios de mercado y para agrupar usuarios individuales, que compartan los mismos intereses y preferencias, en comunidades de usuarios. El corazón del sistema es 'Weka', una herramienta de aprendizaje de máquina escrita en Java, que se puede bajar de la Web, desarrollada en la Universidad de Waikato (New Zealand). Esta herramienta es apta para algoritmos de aprendizaje supervisados y sin supervisar; en su implementación original, 'Weka' acepta datos en formato ARFF. Para el 'Profile Extractor' se ha desarrollado una nueva versión de 'Weka' que es capaz de representar entrada / salida en formato XML. 
La figura7.7 muestra la arquitectura completa del 'Profile Extractor' [Abbattista02].

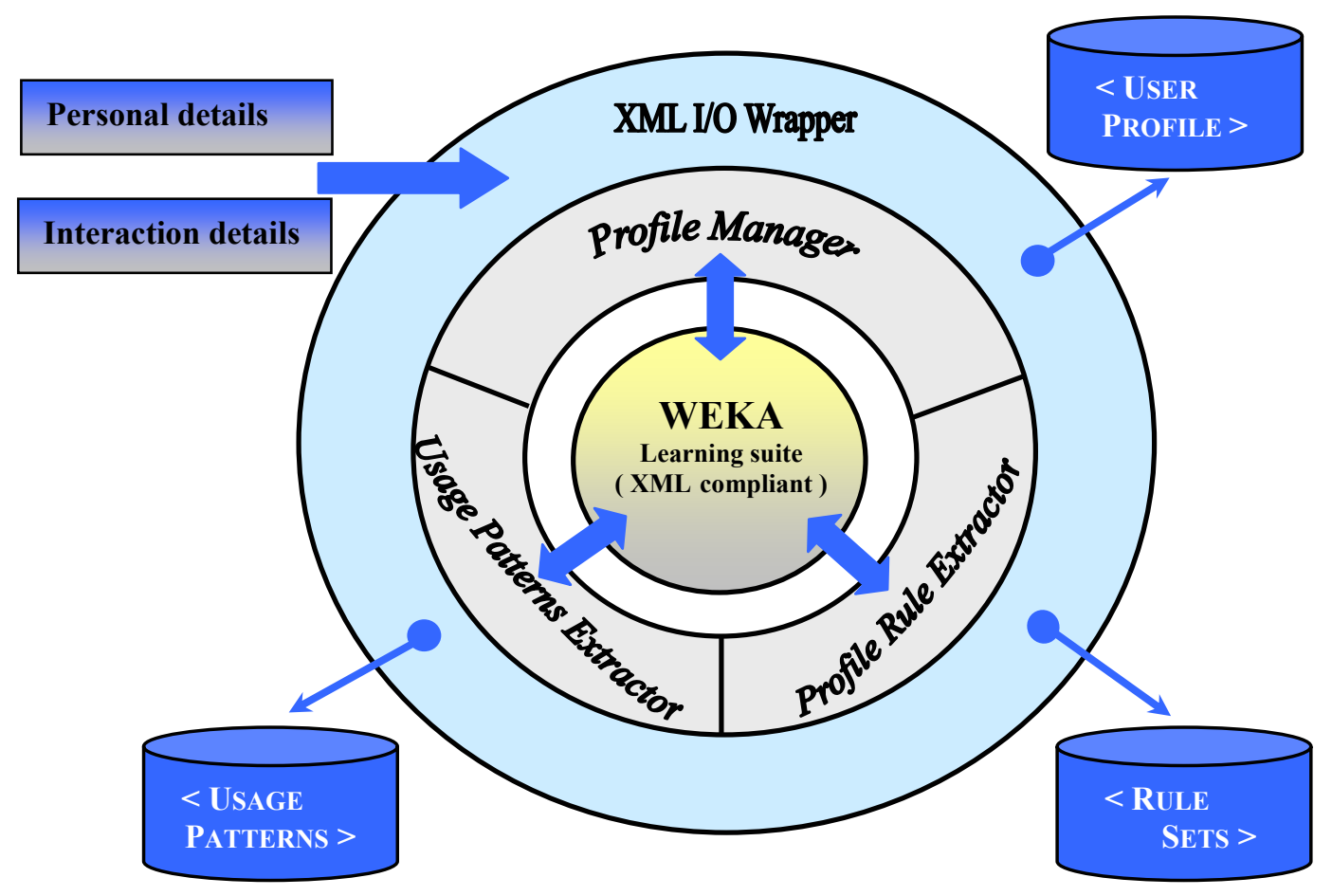

Figura 7.7: La arquitectura del 'Profile Extractor'

\subsubsection{Aportes de Nuestro enfoque, 'Framework' de Requerimientos y 'Profile Extractor'}

Nuestro Enfoque y los trabajos sobre personalización de aplicaciones Web citados, abordan esta temática desde distinto ángulo, proponiendo diferentes aportes para facilitar el desarrollo de buenas aplicaciones Web personalizadas. Cada uno de estos trabajos realiza una contribución diferente con la misma convicción: la necesidad obtener métodos y herramientas eficaces para tratar con esta problemática.

La tabla siguiente, ofrece un cuadro comparativo entre trabajos:

\begin{tabular}{|c|c|c|c|}
\hline & NUESTRO ENFOQUE & $\begin{array}{l}\text { 'FRAMEWORK' DE } \\
\text { REQUERIMIENTOS }\end{array}$ & 'PROFILE EXTRACTOR' \\
\hline Objetivo & $\begin{array}{c}\text { Personalizar una } \\
\text { Aplicación Web existente. }\end{array}$ & $\begin{array}{c}\text { Cubrir el espacio de diseño } \\
\text { de aplicaciones Web } \\
\text { personalizadas. }\end{array}$ & $\begin{array}{c}\text { Descubrir las preferencias, } \\
\text { necesidades e intereses de } \\
\text { los usuarios que acceden a } \\
\text { un Sitio Web } \\
\text { 'e-commerce'. }\end{array}$ \\
\hline
\end{tabular}




\begin{tabular}{|c|c|c|c|}
\hline Descripción & $\begin{array}{l}\text { Proceso de Reingeniería } \\
\text { de Personalización } \\
\text { que permite obtener } \\
\text { el modelo personalizado de } \\
\text { una Aplicación Web } \\
\text { existente - de la cual no se } \\
\text { conoce su modelo actual - }\end{array}$ & $\begin{array}{l}\text { 'Framework' } \\
\text { confeccionado desde la } \\
\text { perspectiva de los } \\
\text { requerimientos que permite } \\
\text { estudiar sistemáticamente } \\
\text { los métodos para el } \\
\text { modelado de Aplicaciones } \\
\text { Web indicando sus puntos } \\
\text { fuertes y defectos, y provee } \\
\text { las bases para considerar la } \\
\text { personalización como una } \\
\text { nueva dimensión de } \\
\text { modelado. }\end{array}$ & $\begin{array}{c}\text { Módulo de alta } \\
\text { reusabilidad que tiene en } \\
\text { cuenta la clasificación de } \\
\text { los usuarios que acceden a } \\
\text { un Sitio Web 'e-commerce' } \\
\text { - cada vez que un usuario } \\
\text { interactúa con el Sitio Web, } \\
\text { el mecanismo de } \\
\text { personalización recolecta } \\
\text { nuevos datos acerca de sus } \\
\text { preferencias, de tal manera } \\
\text { que se le pueda ofrecer a } \\
\text { dicho usuario un servicio } \\
\text { cada vez más satisfactorio - }\end{array}$ \\
\hline Entrada & $\begin{array}{l}\text { Requiere interactuar con la } \\
\text { Aplicación Web existente. }\end{array}$ & $\begin{array}{l}\text { Requiere como punto de } \\
\text { partida una Aplicación } \\
\text { Web, denominada } \\
\text { 'Core Web Application' } \\
\text { y unas circunstancias de } \\
\text { consumo llamadas } \\
\text { 'Context'. }\end{array}$ & $\begin{array}{c}\text { Requiere de la interacción } \\
\text { del usuario con el Sitio } \\
\text { Web. }\end{array}$ \\
\hline Características & $\begin{array}{l}\text { Proceso de reingeniería } \\
\text { compuesto de dos } \\
\text { actividades principales: } \\
\text { Ingeniería en Reversa e } \\
\text { Ingeniería 'Forward' de } \\
\text { Personalización. Estas } \\
\text { actividades se describen } \\
\text { paso a paso e incluyen la } \\
\text { utilización de herramientas } \\
\text { específicas al diseño de } \\
\text { Aplicaciones Web, para } \\
\text { obtener un conjunto de } \\
\text { modelos orientados a } \\
\text { objetos basados en el } \\
\text { enfoque OOHDM, de la } \\
\text { aplicación existente y de la } \\
\text { aplicación personalizada. }\end{array}$ & $\begin{array}{l}\text { Propuesta para el modelado } \\
\text { de Aplicaciones Web } \\
\text { personalizadas, basada en } \\
\text { un 'Framework' que } \\
\text { clasifica los requerimientos } \\
\text { por medio de tres } \\
\text { dimensiones ortogonales: } \\
\text { 'Levels', 'Aspects' y } \\
\text { 'Phases' las cuales deben } \\
\text { ser consideradas por la } \\
\text { personalización. El espacio } \\
\text { de diseño de } \\
\text { personalización se } \\
\text { caracteriza por medio de } \\
\text { dos cuestiones principales: } \\
\text { las circunstancias de } \\
\text { consumo, llamadas } \\
\text { 'Context', y los posibles } \\
\text { cambios al 'Core Web } \\
\text { Application' denominados } \\
\text { 'Adaption'. }\end{array}$ & $\begin{array}{l}\text { Sistema que propone un } \\
\text { proceso de recuperación } \\
\text { “inteligente" basado sobre } \\
\text { tecnología de 'Chatterbot', } \\
\text { técnicas de modelado de } \\
\text { usuario y un mecanismo } \\
\text { automático de expansión de } \\
\text { consulta que saca ventaja } \\
\text { del conocimiento } \\
\text { almacenado en los perfiles } \\
\text { de usuario para refinar la } \\
\text { consulta original asumida } \\
\text { por el 'Chatterbot'. La } \\
\text { arquitectura de este módulo } \\
\text { esta compuesta por cuatro } \\
\text { sub-módulos: 'Profile } \\
\text { Manager', 'Profile Rules } \\
\text { Extractor', 'Usage Patterns } \\
\text { Extractor' y 'Weka'. }\end{array}$ \\
\hline
\end{tabular}




\begin{tabular}{|c|c|c|c|}
\hline \multirow{3}{*}{ Salida } & $\begin{array}{c}\text { Modelo de la Aplicación } \\
\text { Web Personalizada. }\end{array}$ & $\begin{array}{c}\text { Aplicación Web } \\
\text { personalizada. }\end{array}$ & $\begin{array}{c}\text { Generación y } \\
\text { perfeccionamiento de los } \\
\text { perfiles de usuarios que } \\
\text { acceden a un Sitio Web } \\
\text { 'e-commerce'. }\end{array}$ \\
\hline
\end{tabular}

Este cuadro comparativo pone en evidencia que estos trabajos pueden convertirse en complementarios ya que conjuntamente pueden contribuir fuertemente al proceso de diseño / rediseño de aplicaciones Web personalizadas. 


\section{Capítulo 8}

\section{CONCLUSIONES Y TRABAJOS FUTUROS}

\subsection{Conclusiones}

En un período sumamente corto, la Internet y la World Wide Web, han impuesto su presencia sobrepasando cualquier otro progreso tecnológico en la historia. Los sistemas basados en la Web han incrementado y extendido sus ámbitos y usos, generando fuertes y cada vez más crecientes dependencias al mundo cotidiano. Esta evolución vertiginosa, requiere de aplicaciones Web adecuadas a las exigentes demandas de los actuales usuarios de Internet. A tal efecto, la personalización surge y rápidamente se convierte en una cuestión clave, casi vital, al éxito de la nueva generación de aplicaciones. Pero este panorama enfrenta a un serio dilema: ¿qué hacer con todas esas aplicaciones Web existentes, desarrolladas con anterioridad al fenómeno de la personalización?

En esta tesis, se presenta un enfoque de reingeniería aplicable al campo de las aplicaciones web existentes no personalizadas, para propiciar y contribuir a la evolución de las mismas hacia la personalización, cuestión esencial de la Internet (y de la WWW). Este enfoque apuesta fuertemente a la utilización de técnicas de diseño/rediseño antes de reconstruir la aplicación actual, ya que estamos convencidos de que es la única manera de obtener aplicaciones Web exitosas y flexibles, cuyas evoluciones futuras sean factibles.

Como resultado, nuestro enfoque, capítulo5, describe completamente un proceso de reingeniería compuesto por dos actividades básicas: Ingeniería en Reversa e Ingeniería 'Forward' de Personalización; la elección de estas actividades como constitutivas del proceso, se funda en los conceptos de reingeniería de Jacobson [Jacobson94], capítulo4. El método de diseño que subyace, dando solidez a los modelos que se construyen durante estas actividades, es el enfoque OOHDM [Schwabe98a] y [OOHDM00], capítulo3; la elección se basa en que este método goza de una efectividad y robustez probadas en el diseño de aplicaciones Web.

Para llevar a cabo cada una de las actividades señaladas, se proponen paso a paso sus procedimientos respectivos. Los mismos se construyen incorporando y asociando además los aportes de las siguientes herramientas de diseño, capítulo3:

- los patrones de hipermedia [Garrido97], [Rossi99a, 99b, 99d, 00], fundamentalmente los que se aplican al diseño de la navegación;

- el diseño de aplicaciones web personalizadas [Rossi01b, 01c], [Schwabe02] y [Bäumer00];

- los patrones de personalización [Rossi01a, 01b], [Schwabe02] y [Bäumer00];

- el UID [Vilain00].

Con el propósito de contribuir a la claridad de esta tesis, separamos nuestro enfoque (capítulo5) de la aplicación de nuestro enfoque (capítulo6). Mientras que en el capítulo5, solamente se incluyen ejemplos simples para ilustrar y aportar a la comprensión del enfoque, en el capítulo6 se aplica completamente el enfoque a un caso real, una aplicación Web no personalizada perteneciente a una corporación petrolera internacional.

Por último, esta tesis pretende además estimular una discusión en entorno al rediseño de las aplicaciones Web, con la convicción de que este proceso de rediseño debe llevarse a cabo aplicando métodos y herramientas que permitan obtener buenos modelos y aplicaciones flexibles, extendibles y modificables. 


\subsection{Trabajos futuros}

Tal como señalamos en Trabajos Relacionados, capítulo7, hablar de reingeniería para la personalización de aplicaciones Web existentes, es entrar en una temática más que reciente, casi inédita. Es un terreno virgen que plantea toda una fuente de desafíos a las comunidades de investigación.

En esta tesis se propone un enfoque para enfrentar la problemática del rediseño de aplicaciones Web cuando el objetivo es la personalización, pero esto es solamente un comienzo, la punta del ovillo.

En primer lugar, si nos referimos específicamente al proceso propuesto por este enfoque, se pueden citar, tareas pendientes e inmediatas tales como obtener el diseño de la interfaz abstracta personalizada y llevar a cabo la implementación y validación del nuevo modelo personalizado - obviamente esta última tarea estará íntimamente ligada a las restricciones de entorno destinatario -

En segundo lugar, si nos remitimos a las herramientas y esquemas utilizados por este enfoque, se puede observar que, en muchos casos, el modelado de aquellos aspectos propios de la personalización demanda representaciones más expresivas. Por ejemplo, la descripción de casos de uso, el UID y el esquema de contextos de navegación, necesitan incorporar elementos que permitan tratar y reflejar acabadamente las necesidades individuales de cada usuario o grupo de usuarios - roles o perfiles -. En tal sentido, esta tesis hace su aporte proponiendo ciertas consignas y ajustes que minimizan estas carencias, enriqueciendo la expresividad de dichas herramientas y esquemas. Sin embargo, en este camino resta mucho por andar y futuras líneas de trabajo se pueden abrir al buscar nuevos componentes o formas de representación que reflejen eficientemente las distintas facetas de la personalización.

Cuando el objetivo es maximizar el reuso, los patrones de diseño pueden ser excelentes protagonistas. Ya se ha mencionado como estas herramientas ofrecen soluciones que facilitan el diseño e impulsan buenos modelos. Este enfoque de reingeniería de personalización propicia la utilización de patrones de navegación y de personalización para modelar los problemas recurrentes e inherentes al diseño de aplicaciones Web. Fortaleciendo esta filosofía, se puede fijar otra futura línea de trabajo consistente en incorporar patrones de reingeniería al proceso del enfoque propuesto. Sobre esta línea se pueden enfrentar dos actividades, por un lado remitirse al catálogo existente, por ejemplo [Demeyer02], y por el otro descubrir, definir y agregar nuevos patrones específicos al proceso de reingeniería de personalización Figura 8.1. 


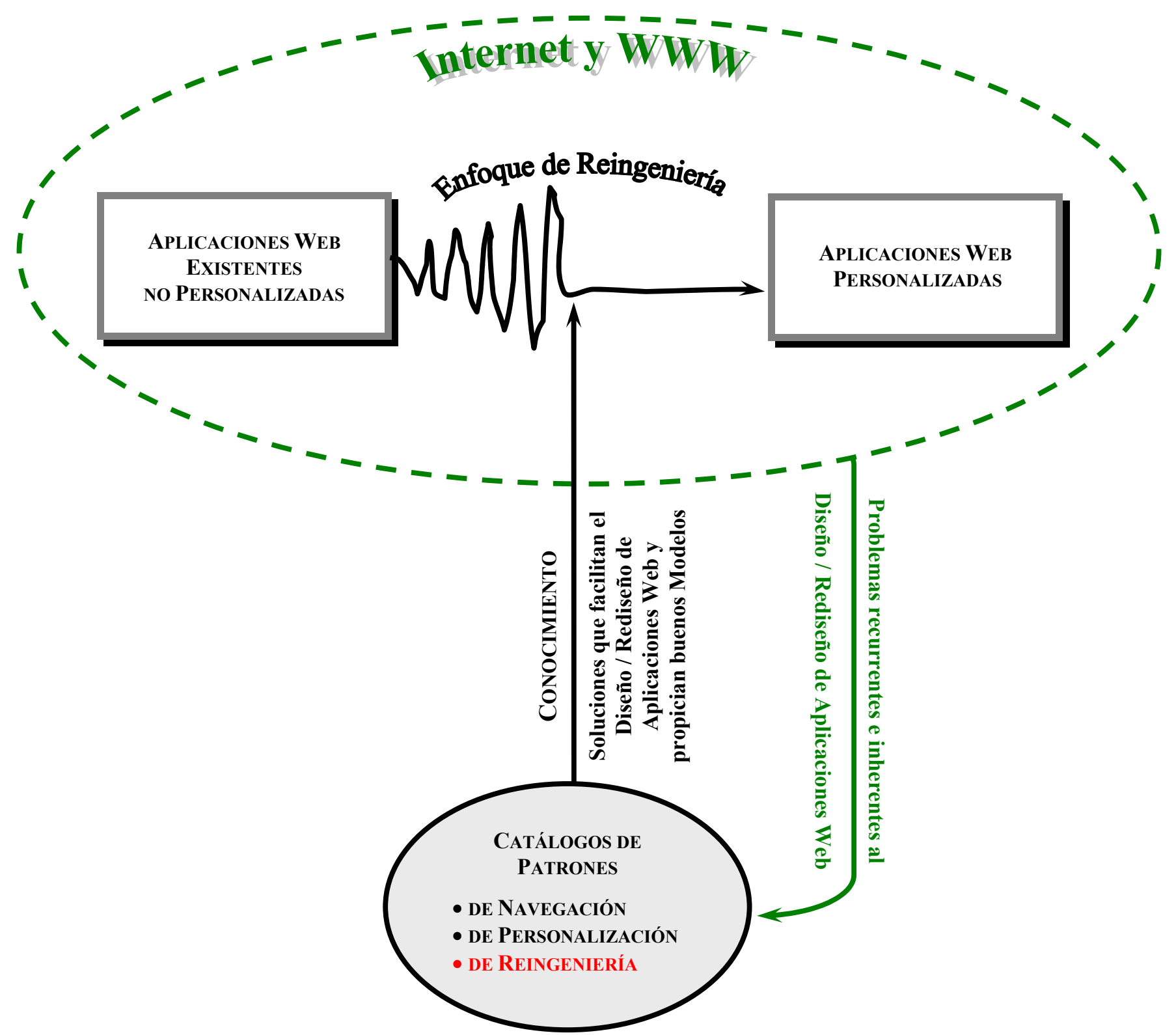

Figura 8.1: Enfoque de Reingeniería de Personalización con Patrones de Diseño 


\section{BIBLIOGRAFÍA Y REFERENCIAS}

[Abbattista02] Fabio Abbattista, M. Degemmis, O. Licchelli, P. Lops, G. Semeraro y F. Zambetta 'Improving the Usability of an E-commerce Web Site'

(available at http://ectrl.itc,it/rpec/RPEC-papers/03-abbattista.pdf)

[Alexander77] Christopher Alexander, S. Ishikawa, M. Jacobson, I. Filsdahl-King, S. Angel

'A pattern language'

Oxford University Press, New York, 1977

[Bäumer00] Dirk Bäumer, D. Riehle, W. Siberski, M. Wulf

'Role Object'

In Pattern Languages of Program Design 4 (Addison-Wesley, 2000)

[BA00] Business Architects Page

'What is Reengineering?'

(available at http://www.businessarch.com/reengineering.htm)

[Boldyreff01] Cornelia Boldyreff, Richard Kewish

'Reverse Engineering to Achieve Maintainable WWW Sites'

(available at http://www.computer.org/proceedings/wcre/1303/1303toc.htm)

[Cockburn01] Alistar Cockburn

'Writing effective use cases'

Editorial Addison-Wesley, 2001

[Davenport93] Thomas Davenport

'Process Innovation: Reengineering Work through Information Technology'

Editorial: Harvard Business School Press, 1993.

[Demeyer02] Serge Demeyer, Stéphane Ducasse, Oscar Nierstrasz

'Object-Oriented Reengineering Patterns' (OORP)

Editorial Morgan Kaufmann \& Dpunkt, 2002

[DiLucca02] Giuseppe Di Lucca, A. Fasolino, F. Pace, P. Tramontana, U. De Carlini

'WARE: a Tool for the Reverse Engineering of WEB Applications'

(available at http://www.computer.org/proceedings/csmr/1438/14380241abs.htm)

[Gamma95] Erich Gamma, R. Helm, R. Jonson, J. Vlissides

'Design Patterns: Elements of Reusable Object-Oriented Software'

Editorial Addison-Wesley, 1995

[Garrido97] Alejandra Garrido, Gustavo Rossi, Daniel Schwabe,

'Pattern System for Hypermedia'

Proceedings of Plop'97, Pattern Language of Program, Allerton, Illinois, 1997 
[Ginige01] Athula Ginige, San Murugesan

'Web Engineering: An Introduction'

In IEEE Internet Multimedia, 2001

[Güell00a] Natacha Güell, Daniel Schwabe, Patricia Vilain

'Modeling Interactions and Navegation in Web Applications'

Proceedings of $2^{\text {nd }}$ International Workshop on World Wide Web and Conceptual Modeling

(WWWCM2000), (Editorial Springer-Verlag, 2000 // Lectures Notes in Computer Science, 2000)

[Güell00b] Natacha Güell, Patricia Vilain, Daniel Schwabe

'Cenários, Use Cases e Diagramas de Interação do Usuario no Projeto da Navegação de Aplicativos Hipermídia'

SBMidia 2000 - VI Simpósio Brasileiro de Multimídia e Sistemas Hipermídia, 2000. 161-179.

[Jacobson94] Ivar Jacobson, M. Ericson, A. Jacobson

'The Object Advantage: Business Process Reengineering with Object Technology'

Editorial Addison-Wesley, 1994-95

[Johansson93] Henry Johansson, P. McHugh, A. Pendlebury, Wheeler

'Business Process Reengineering: Breakpoint Strategies for Market Dominance'

Editorial: John Wiley, 1993

[Kappel00] Gerti Kappel, Werner Retschitzegger, Wieland Schwinger

'Modelling Customizable Web Applications - A Requirement's Perspective'

2000 Kyoto International Conference on Digital Libraries: Research \& Practice

[Kim94] W. Kim

'Advanced Database Systems'

ACM Press, 1994

[Lyardet99] Fernando Lyardet, Gustavo Rossi, Daniel Schwabe,

'Patterns for Adding Search Capabilities to Web Information Systems'

Proceedings of EuroPLoP 99, 1999

[Loucopoulos95] Pericles Loucopoulos, V. Karakostas

'System requirements engineering'

Editorial McGraw-Hill, 1995

[Nielsen95] Jakob Nielsen

'Multimedia and Hypertext: The Internet and Beyong'

Publicado por Morgan Kaufmann, San Francisco, 1995 (originalmente publicado por AP Professional, Boston, MA, paperback)

[OOHDM00] Daniel Schwabe, Patricia Vilain

'The OOHDM notation'

(available at http://sol.info.unlp.unlp.edu.ar/notacaoOOHDM )

[Rossi97] Gustavo Rossi, Daniel Schwabe, Alejandra Garrido

'Design Reuse in Hypermedia Applications Development'

Proceedings of $8^{\text {th }}$ ACM Conference on Hypertext Technology, Southampton, Inglaterra, (Editorial ACM Press, 1997) 
[Rossi99a] Gustavo Rossi, Daniel Schwabe, Fernando Lyardet

'Patterns for Designing Navigable Information Spaces'

In Pattern Languages of Program Design 4 (Addison-Wesley, 1999)

[Rossi99b] Gustavo Rossi, Daniel Schwabe, Fernando Lyardet

'Improving Web Information Systems with Navigational Patterns'

Proceeding of the $8^{\text {th }}$ International Conference on the WWW, Toronto, USA, 1999

[Rossi99c] Gustavo Rossi, Daniel Schwabe, Fernando Lyardet

'Web Applications Models are more than Conceptual Models'

Proceedings of $1^{\text {st }}$ International Workshop on Conceptual Modeling and the WWW, Paris, 1999, (Editorial Springer-Verlag, 1999 // Lectures Notes in Computer Science, 2000)

[Rossi99d] Gustavo Rossi, Daniel Schwabe, Fernando Lyardet

'Designing Hypermedia Applications with Objects and Patterns'

In International Journal of Software Engineering and Knowledge Engineering, Vol. 9, \# 6 (World Scientific publishing Company, 1999)

[Rossi00a] Gustavo Rossi, Daniel Schwabe, Fernando Lyardet

'Abstraction and Reuse Mechanisms in Web Application Models'

Proceedings of $2^{\text {nd }}$ International Workshop on World Wide Web and Conceptual Modeling (WWWCM2000), (Editorial Springer-Verlag, 2000 // Lectures Notes in Computer Science, 2000)

[Rossi00b] Gustavo Rossi, Daniel Schwabe, Fernando Lyardet

'User Interface for Hypermedia Applications'

Proceedings of AVI00, Advance Visual Interfaces, Palermo, Italia, 2000

[Rossi00c] Gustavo Rossi, Daniel Schwabe, Fernando Lyardet

'Patterns for E-Commerce Applications'

Proceedings of EuroPLoP 00, Germany, 2000

[Rossi01a] Gustavo Rossi, D. Schwabe, J. Danculovic, L. Miaton

'Patterns for Personalized Web Applications'

Proceedings of EuroPLoP 01, Germany, 2001

[Rossi01b] Gustavo Rossi, D. Schwabe, R. Guimarães

'Designing Personalized Web Applications'

Proceedings of the $10^{\text {th }}$ International Conference on the WWW (WWW10), Hong Kong, 2001

[Rossi01c] Gustavo Rossi, A. Fortier, J. Cappi, D. Schwabe

'Seamless Personalization of E-Commerce Applications'

Proceedings of $2^{\text {nd }}$ International Workshop on Conceptual Modeling Approaches for e-Business, (Editorial Springer-Verlag, 2001)

[Schwabe98a] Daniel Schwabe, Gustavo Rossi

'An Object-Oriented Approach to Web-Based Application Design'

In Theory and Practice on Object Systems TAPOS (Wiley and Sons, 1998)

[Schwabe98b] Daniel Schwabe, Gustavo Rossi

'Developing Hypermedia Application using OOHDM'

In Workshop on Hypermedia Development, Pittsburgh, USA, 1998 
[Schwabe99] Daniel Schwabe, Rita de Almeida Pontes, Isabela Moura

'OOHDM-Web: An Environment for Implementation of Hypermedia Applications in the $W W W$ ' In ACM SigWeb Newsletter, Vol 8, \# 2, 1999

[Schwabe02] Daniel Schwabe, Gustavo Rossi, Robson Mattos Guimarães

'Cohesive Design of Personalized Web Applications'

In IEEE Internet Computing, 2002

[Umar 97] Amjad Umar

'Application (Re)Engineering: Building Web-Based Applications and Dealing with Legacies'

Editorial Prentice Hall PTR, 1997

[UML97] UML Document Set v1.1 Septiembre 1997

(available al http://www.rational.com/uml/resources/documentation/formats.jsp)

[Vilain00] Patricia Vilain, Daniel Schwabe, Clarisse de Souza

'A Diagrammatic Tool for Representing User Interaction in UML'

To appear in UML 2000, Third International Conference on the Unified Modeling Language, York, UK, 2000

[Vilain02] Patricia Vilain, Daniel Schwabe

'Improving the Web Application Design Process with UIDs'

(available at http://www.dsic.upv.es/ west2001/iwwost02/\#papersub) 